\title{
SEISMIC STRUCTURE BENEATH THE WELLINGTON REGION FROM RECEIVER FUNCTIONS
}

\author{
by \\ Lucy Caroline Hall
}






\section{ABSTRACT}

Seismic velocity structures, interpreted as being associated with the Hikurangi subduction system beneath the lower North Island of New Zealand, are imaged using stacked $\mathrm{P}$ wave receiver functions computed using teleseismic earthquakes.

Receiver functions are a seismological technique that exploits the phenomenon of wave conversion. The upcoming $\mathrm{P}$ wave interacts with seismic velocity impedance contrasts below the receiving station to produce polarized $\mathrm{P}$ to SV converted phases. The time delay between the first arriving P wave and the SV converted phase is interpreted to infer the depth of interfaces and the velocity structure directly below the receiver, allowing estimates to be made of the physical properties of the interface.

Passive seismic data were recorded at eighteen seismic stations deployed across a $\sim 90 \mathrm{~km}$ transect stretching across the breadth of lower North Island of New Zealand, from Kapiti Island, $5 \mathrm{~km}$ off the west coast, to the eastern coast. The transect is oriented normal to the strike of the subducting Pacific Plate, as it dives beneath the overriding Australian Plate. Data were recorded at 10 broadband and 2 short period sensors, deployed as part of the Seismic Array Hikurangi Project (SAHKE 1 deployment), 3 Geonet (New Zealand Geonet Project) permanent short period stations, and 3 temporary stations from part of the 1991-1992 POMS project. Seismic data were recorded between November 2009 and March 2010 on the short period sensors and up to 18 months on the broadband sensor. Data recorded between November 2009 and November 2011 were utilised from the Geonet stations. 
$\mathrm{P}$ wave receiver functions are computed using the multi-taper correlation method using $389>6.0 \mathrm{Mw}$ teleseismic earthquakes recorded at the individual seismic stations. A total of 1082 individual receiver functions from all the stations are stacked for both the individual stations and as a 'super-stack' across the complete transect, using the common conversion point (CCP) method.

The CCP stack shows a distinct, thick low velocity layer (LVL), dipping to the west, from $\sim 18 \mathrm{~km}$ depth in the east to $\sim 30 \mathrm{~km}$ depth in the west. This is above a higher velocity layer, also dipping west, at depths of between $\sim 22 \mathrm{~km}$ and $\sim$ $37 \mathrm{~km}$. The LVL is interpreted as being subducted sediments overlying the higher velocity plate interface. Structures towards the west indicate the presence of possibly imbricated features associated with the overriding plate. Deeper structures, down to a depth of $140 \mathrm{~km}$ are evident, but have less clarity than the shallower features. Some of the deeper layers appear to be dipping towards the west, some to the east. The results of the CCP stack agree well with results from active source methods. 


\section{ACKNOWLEDGEMENTS}

Grateful thanks goes to my supervisor Martha Savage, who has conscientiously supervised, corrected and encouraged me throughout, and generally kept me afloat when in danger of sinking beneath a sea of receiver functions. Thank you so much for allowing me the opportunity to return to SGEES and complete this fascinating piece of research.

Thanks also go to those who have helped me with the many, often and varied issues with coding and data processing; Sapthala Karalliyadda; Rob Holt; Adrian Benson; Carolin Boese.

Thank you also to Tim Stern; Aaron Wech; Anya Seward and Simon Lamb for some very welcome discussions and constructive input during this project.

Thanks must also go to my office mates past and present who have made my time at the computer face bearable, (and even fun at times); Simon; Helen; Sapna and Quang.

And of course thanks to the indubitable Katie Collins, thank you for being a good friend.

Last, but certainly not least, the biggest and most heartfelt thank you goes to my amazing family. To Nick, my husband, who has supported me wholly, financially, emotionally and computationally throughout this long and challenging journey as a mature student. Without your support and encouragement none of this would have been possible; thank you for believing in me. And of course thank you to my fantastic children, Lucy, Tim and Lottie, who have grown up, and nearly completed their own education in the time it 
has taken me to complete mine! I hope it hasn't put you off following your dreams, even when the going gets tough and the challenge seems over whelming.

'It is not the mountain we conquer, but ourselves'. Edmund Hillary 


\section{SOURCE OF DATA}

I acknowledge the following for data used in this study: Seismic array Hikurangi Project (SAHKE); New Zealand GeoNet project and its sponsors EQC, GNS Science and LINZ; data from the Leeds, Tararua (POMS) 1990/1991 project, originally supported by the NERC Grant Number GR3/7699. 


\section{LIST OF CONTENTS}

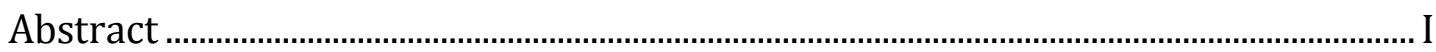

Acknowledgements ................................................................................................ III

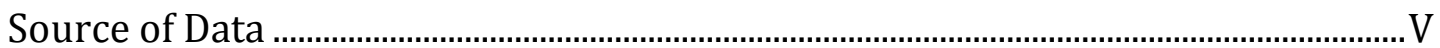

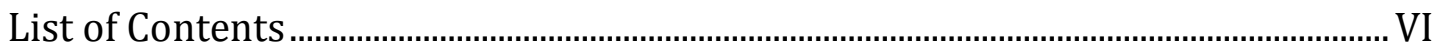

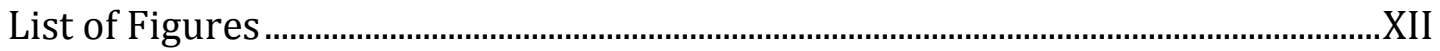

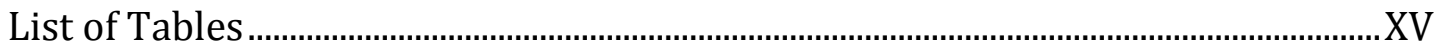

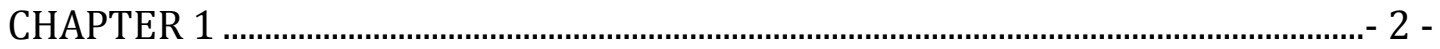

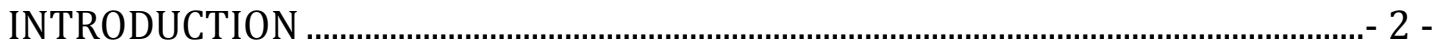

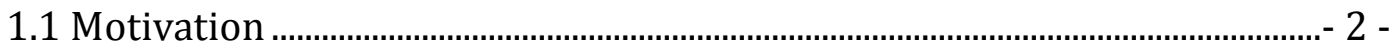

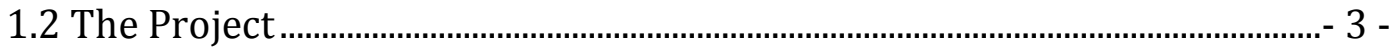

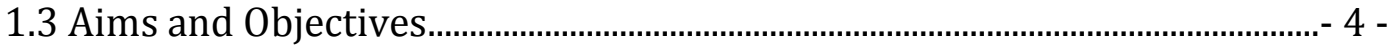

1.3.1 Fundamental questions of subduction seismogenesis. .........................- 4 -

1.4 Study Area

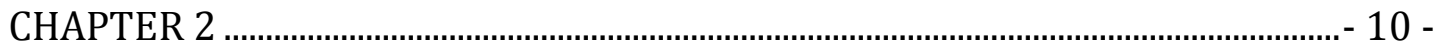

BACKGROUND GEOLOGY.............................................................................................. 10 -

2.1 Tectonic Setting of New Zealand .......................................................................- 10 -

2.2 Structures of the Hikurangi Subduction Zone................................................- 13 -

2.2.1 Geology of the Hikurangi Plateau and the Development of the present day Plate Boundary...................................................................................................... 13 -

2.2.2 Thrust Imbricated Frontal Wedge ...........................................................- 15 -

2.2.3 The Subducting Slab and the Seismogenic Zone.................................... 18 -

2.3 Subduction Zone Coupling..................................................................................- 23 -

2.4 Slow Slip Events and Plate Locking ................................................................- 27 -

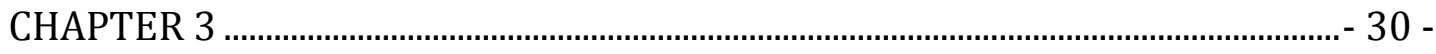

RECEIVER FUNCTION STUDIES............................................................................... 30 - 
3.1 Introduction ................................................................................................................- 30 -

3.2 Development of the Receiver Function Method................................................- 30 -

3.2.1 Cascadia Subduction Zone ..................................................................................- 30 -

3.2.2 The Hikurangi Subduction Zone New Zealand. .........................................- 34 -

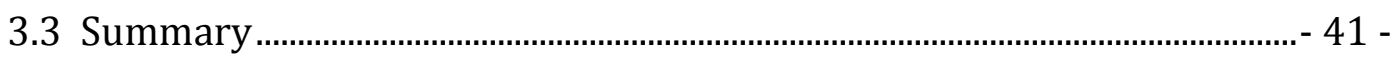

CHAPTER 4. ……........................................................................................................

RECEIVER FUNCTION METHOD...................................................................................... 42 -

4.1 Introduction to Isotropic P Wave Receiver Functions..................................- 42 -

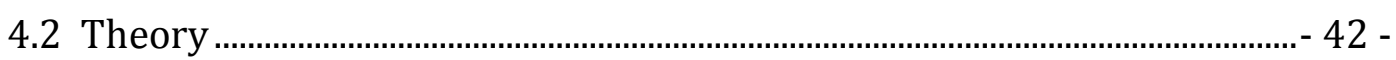

4.3 Wave Conversion ..........................................................................................................- 43 -

4.4 Using Teleseisms ........................................................................................................

4.5 Rotation of the Data................................................................................................. 45 -

4.6 Data Sampling to Create a Single Station Receiver Function Stack ......... 46 -

4.7 Interpretation of Receiver Functions.................................................................- 49 -

4.7.1 Moveout, converted phases and Multiples ………………………………...- 49 -

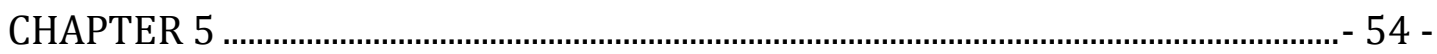

DATA PROCESSING .......................................................................................................... 54 -

5.1 Introduction......................................................................................................... 54

5.2 Event Database .............................................................................................................- 56 -

5.3 Data Pre-processing................................................................................................. 56 -

5.3.1 Raw Data to MiniSEED to SAC.....................................................................- 56 -

5.4 Preparing the Reftek Data. ......................................................................................- 57 -

5.5 Preparing the Earth Data .......................................................................................- 58 -

5.6 Geonet Data............................................................................................................- 59 -

5.7 Second stage of processing ……………………………………………………... 59 -

5.7.1 Filtering, detrending, demeaning, picking the first arrivals, windowing, tapering and sorting.......................................................................... 59 - 
5.8 Final stage of processing: Multiple Taper spectral correlation method- 61

5.8.1 Theory $61-$

5.8.2 Calculating Multiple-Taper Receiver Functions. $63-$

5.8.3 Parameters $66-$

5.9 Common Conversion Point stacking method $69-$

5.91 Theory $69-$

5.9.2 Parameters Used In This Study. $70-$

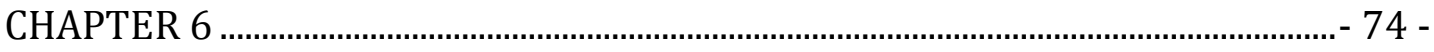

RECEIVER FUNCTION OBSERVATIONS..................................................................... 74 -

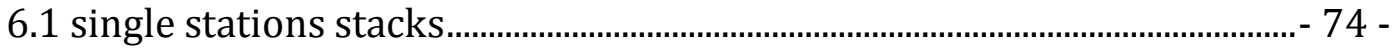

6.2 Receiver Function Plots ........................................................................................ 77

6.2.1 TRWZ

6.2.2 LE4

6.2.3 Т004

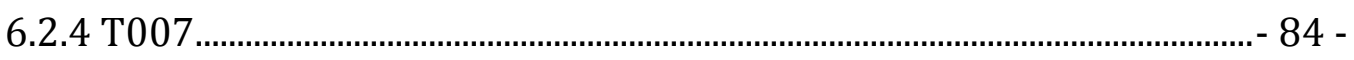

6.2.5 LE3, T010, T014, T016 and MTW............................................................ 86 -

6.2.6 T018

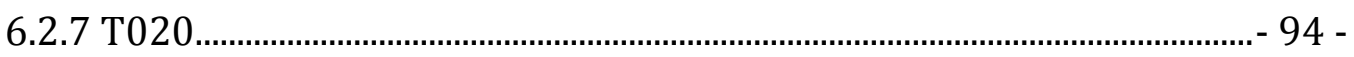

6.2.8 T022 and LTN6........................................................................................ 97 -

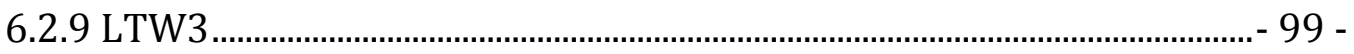

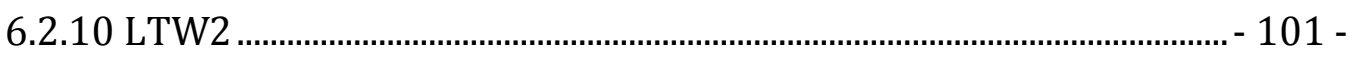

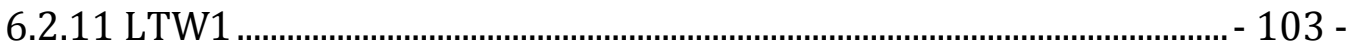

6.2.12 KIW

6.3 Quality Control of Receiver Function Plots................................................ - 105 -

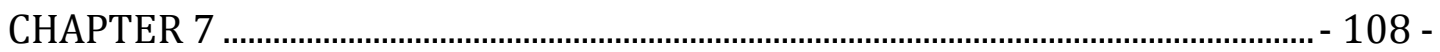

FORWARD MODELING WITH SYNTHETICS ......................................................... 108 -

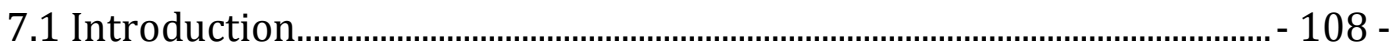


7.1.1 Parameters ............................................................................................................. 108 -

7.1.2 New Zealand Standard Model.......................................................................... - 109 -

7.1.3 KIW (Ewig, 2009) ......................................................................................- 109 -

7.1.4 OC14D20 (Savage, 2007)............................................................................ - 109 -

7.2 Synthetic Plots................................................................................................................ - 111 -

7.2.1 Synthetic Plot for New Zealand Standard Model................................... - 111 -

7.2.2 Synthetic Plot for Velocity Model KIW with 30 degree Dip............. - 112 -

7.2.3 Synthetic Plot for Velocity Model KIW with 5 degree Dip................ - 113 -

7.2.4 Synthetic Plot for Velocity Model OC14D20........................................... - 114 -

7.3 Interpretation....................................................................................................... - 115 -

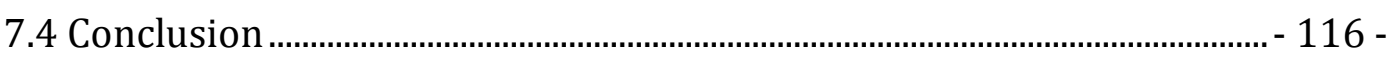

CHAPTER 8 .................................................................................................................... -118 -

COMMON CONVERSION POINT STACKS........................................................................ - 118 -

8.1 Introduction ............................................................................................................ - 118 -

8.2 Discussion of CCP stack made using NZST velocity MODEL ..................... - 121 -

8.3 Comparison of CCP stacks created using KIW (Ewig, 2009) model and

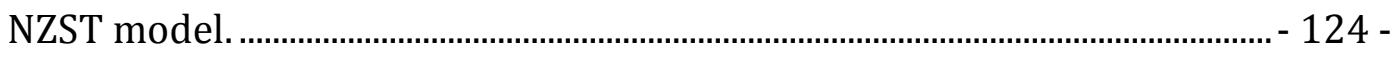

8.3.1 Comparison of KIW (Ewig ,2009) with OC14D20 (Savage, 2007) model; and the effects of $\mathrm{Vp} /$ Vs ratios............................................................ - 125 -

8.4 CCP stacks made using velocity model OC14D20...................................... - 127 -

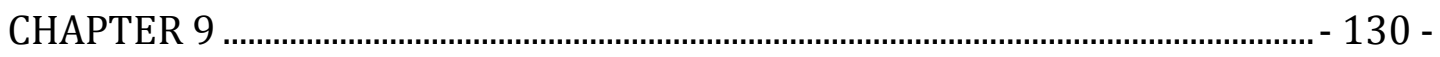

INTERPRETATION and DISCUSSION ………………………………………………... - 130 -

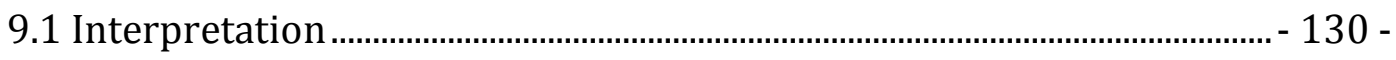

9.1.1 OC14D20 (Savage, 2007) 1Hz velocity model CCP stack.................. - 130 -

9.1.2 Upper-crustal Low velocity layer ............................................................. - 130 -

9.1.3 Low Velocity Layer Above the Subducting Oceanic Crust................. 131 -

9.1.4. The subducting oceanic crust................................................................... - 133 -

9.1.5 The Gutenberg discontinuity. structures beneath the moho.......... - 133 - 
9.2 Comparison with active source results from the SAHKE project. ......... - 134 -

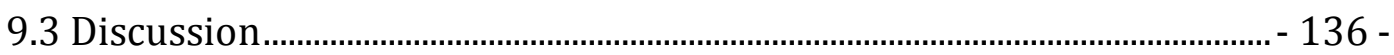

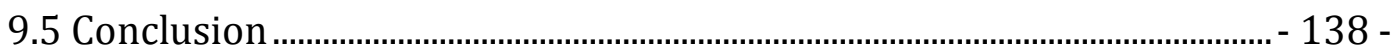

9.6 Opportunities for Further work.................................................................. - 139 -

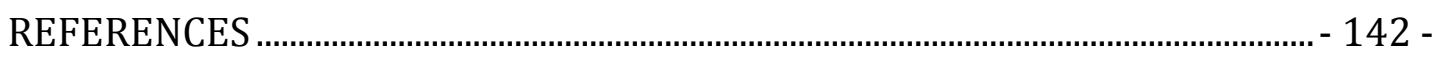

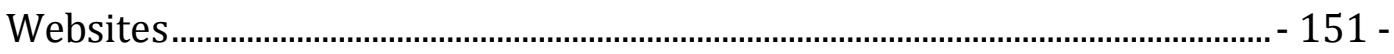

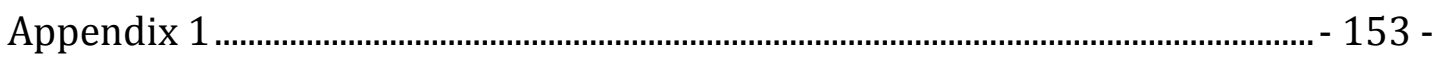

A.1 How to change the raw Reftek data to miniseed and select and cut your earthquake events................................................................................................ - 153 -

A1.1 create the event database

A1.2 Select raw data ...................................................................................... 153 -

A1.3 pre-Processing reftek data .................................................................... - 153 -

A1.4 Changing reftek to mini-seed ................................................................. - 154 -

A1.5 selecting and cutting the earthquake events........................................ - 154 -

A1.6 P wave picking using SAC ……........................................................... 155 -

A1.7 Create receiver functions......................................................................... 155 -

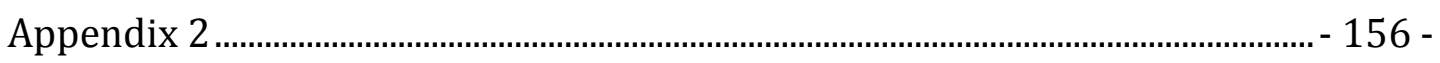

A2 TECHNICAL INFORMATION REGARDING TKEQCUT ................................. - 156 -

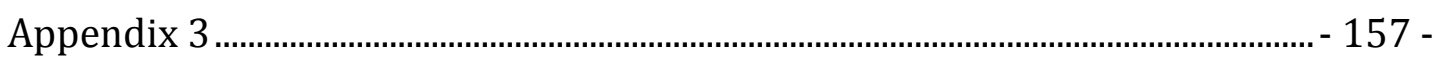

A3 BASH SCRIPTS .............................................................................................. 157 -

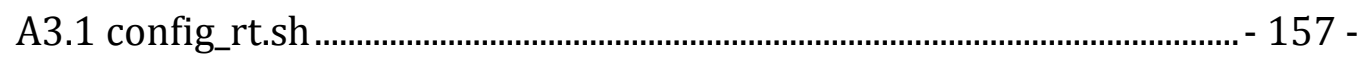

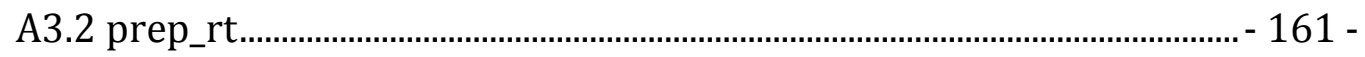

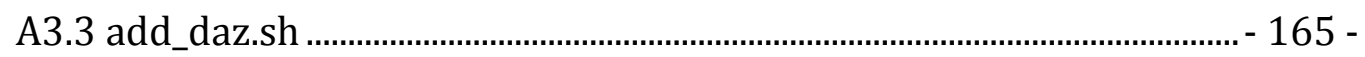

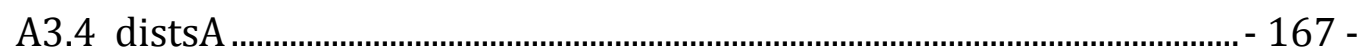

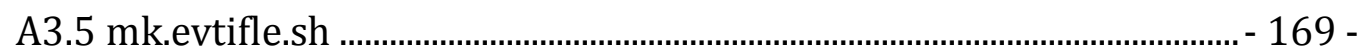

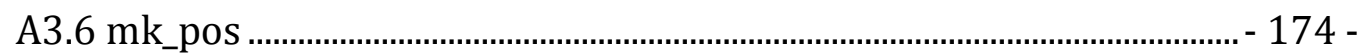

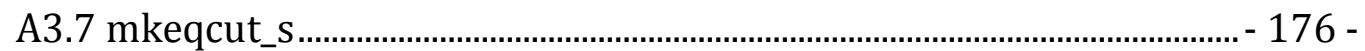

A3.8 convert_raw.sh ........................................................................................... 188 - 
A3.9 add_hdr_modi.sh - 190 -

Appendix 4 . - 197 -

A4.1 Python script to cut earthquake events from Earthdata stations. - 197 Appendix 5 $201-$

A5.1 event-database.csv -201 - 


\section{LIST OF FIGURES}

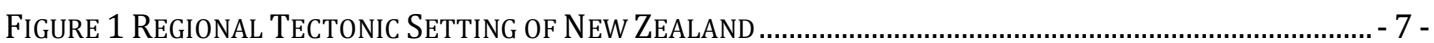

Figure 2 Transect Station Locations and Names across lower North Island, NEW Zealand......... - 8 -

Figure 3 GPS Velocities Relative to the Pacific Plate. (Wallace et Al., 2009)............................... - 12 -

Figure 4 The siX major Regions of the HikURANGi Plateau. (Wood And Davy, 1994)....................... - 14 -

Figure 5 Sedimentary Units of the HikURANGi Plateau. (AFTER DaVy ET AL., 2008).......................... - 15 -

Figure 6 The Imbricate Wedge SeISMic Lines From (A) SOUthern (B) CENTRAL AND (C) NORTHERN SECTIONS OF THE OFFSHORE HIKURANGI MARGIN. (WALLACE ET AL., 2009)...................................... - 17 -

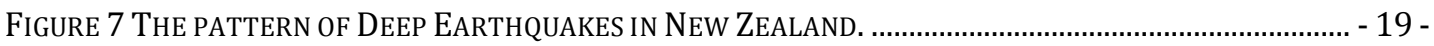

FIGURE 8 EARTHQUAKE TYPES AT VARIOUS DEPTHS. (STEIN AND WYSESSION ,2003).................................. - 20 -

FIGURE 9 A CROSS SECTION OF EARTHQUAKE HYPOCENTRES IN THE WELLINGTON REGION. (ANDERSON AND WEBB, 1994).

-21 -

FIGURE 10 SEISMICITY CROSS-SECTIONS ACROSS THE SOUTHERN NORTH ISLAND, TO THE NORTHERN SOUTH

ISLAND. (FURLONG AND KAMP, 2009)........................................................................................... - 22

FiguRE 11 InTERSEISMIC COUPLING COEFFICIENT AT THE PLATE INTERFACE. (EBERHART-PHILLIPS AND

REYNERS, 2012) ........................................................................................................... - 25 -

FiguRe 12 ImAGe of HikURANGi Plate INTERFACE USING LOCAL-EARTHQUAKE TOMOGRAPHY. (EBERHART-

PHILLIPS AND REYNERS, 2012) .................................................................................................... - 26 -

FIGURE 13 EXAMPLE OF EARLY RECEIVER FUNCTION. (LANGSTON, 1977)................................................. - 31 -

FIGURE 14 BACK AZIMUTH RECEIVER FUNCTION SWEEPS FOR FOUR STATIONS (GNW, COR, DBO, HUMO).

(NIKULIN ET AL., 2009)

-32 -

FIGURE 15 A BACK AZIMUTH SWEEP OF RECEIVER FUNCTIONS COMPUTED FROM SYNTHETIC SEISMOGRAMS.

(NIKULIN ET AL, 2009). $-33-$

FIGURE 16 OVERVIEW OF PROPOSED FINDING IN REFERENCE TO REGIONAL TECTONIC SETTING. (NIKULIN ET AL., 2009) -33 -

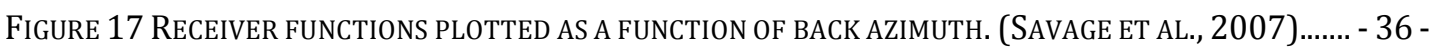
FIGURE 18 SCHEMATIC OF BEST FIT VELOCITY AND DEPTH MODEL FOR TARARUA ARRAY SUMMARISING FINDING FROM SAVAGE ET AL (2007). (FIGURE FROM EWIG, 2009). ............................................................ - 37 -

FIGURE 19 IMAGE OF THE HIKURANGI SUBDUCTION ZONE USING TELESEISMIC RECEIVER FUNCTIONS.

(BANNISTER ET AL., 2007). $-38-$

FIGURE 20 CCP STACK AT 1 Hz USING VELOCITY MODEL TARA ( EWIG, 2009)............................................ - 40 -

FIGURE 21 WAVE CONVERSION OF P WAVE INCIDENT ON SEISMIC VELOCITY BOUNDARY.................................. - 44 -

FigURE 23 ILLUSTRATING RAYPATHS FOR ONE INCOMING P WAVE PHASES AND FOUR OF IT'S MULTIPLES, PPPS

ETC $-47-$

FIGURE 24 RAY PATHS OF PS CONVERTED MODE AND ITS PPMP MULTIPLE. $-48-$

FIGURE 25 SCHEMATIC ILLUSTRATING RAY PATHS AND INCIDENT ANGLE ASSOCIATED WITH EPICENTRAL

DISTANCES $(\theta 1)$ AND $(\Theta 2)$.................................................................................................... - 50 -

FIGURE 26 A) AND B). SCHEMATIC ASSOCIATING INCIDENCE ANGLE WITH EPICENTRAL DISTANCE. ................. - 51 XII 
FIGURE 27 JOB FLOW CHART FOR RECEIVER FUNCTION DATA PREPARATION.

FigURE 28 ThrEe COMPONENT (Z, N, E), HOUR LONG SEISMOGRAMS FROM THE MARCH 11, 2011 JAPAN EARTHQUAKE MW 9.0; RECORDED AT STATION T020..................................................................... - 60 -

FigURE 29 PRolAtE EIGEN TAPERS USED FOR MULTI-TAPER CORRELATION. (SALMON. 2008)..................... - 64 -

FIGURE 30 FIVE INDIVIDUAL UNSTACKED RADIAL RECEIVER FUNCTIONS FROM STATION KIW...................... - 68 -

Figure 31 The SAME FIVE TRACES FROM KIW AS ILLUSTRATEd IN FIgURE 30. STACKEd USING PARK AND

LEVIN'S (2000) MULTIPLE TAPER CORRELATION METHOD WITH COHERENCE WEIGHTING.................. - 68 -

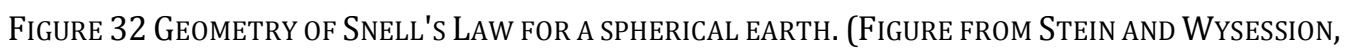
2003). $-70-$

FigURE 33 STATION LOCATIONS AND GEOLOGY OF THE NoRTH ISLAND NEW ZEALAND................................ - 74 -

FIGURE 34 TELESEISMIC EVENTS USED FOR RECEIVER FUNCTION ANALYSIS................................................. - 75 -

FIGURE 35 TRWZ RECEIVER FUNCTION STACK...............................................................................

FIGURE 36 LE4 RECEIVER FUNCTION STACK. …................................................................................. - 79 -

FIGURE 37 T004 RECEIVER FUNCTION STACK.................................................................................... - 81 -

FIGURE 38 T007 RECEIVER FUNCTION STACK................................................................................... 83 -

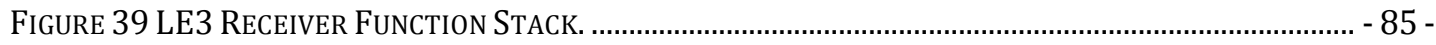

FIGURE 40 T010 RECEIVER FUNCTION STACK.................................................................................... 87 -

FIGURE 41 T014 RECEIVER FUNCTION STACK........................................................................................... - 88 -

FigURE 42 T016 RECEIVER FUnCTION STACK......................................................................................... - 89 -

FIGURE 43 RECEIVER FUNCTION STACK.........................................................................................

FIGURE 44 T018 RECEIVER FUNCTION STACK............................................................................................. - 91 -

FIGURE 45 T020 RECEIVER FUnCTION STACK......................................................................................... - 93 -

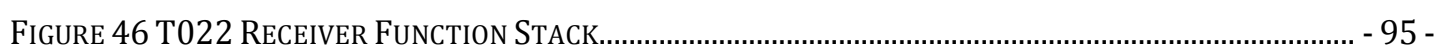

FIGURE 47 LTN6 RECEIVER FUNCTION STACK....................................................................................... - 96 -

FIGURE 48 LTW3 RECEIVER FunCTION STACK.................................................................................. - 98 -

FIGURE 49 LTW2 RECEIVER FUNCTION STACK................................................................................ 100 -

FIGURE 50 LTW1 RECEIVER FUNCTION STACK........................................................................................ 102 -

FIGURE 51 KIW (1Hz) RECEIVER FunCTION STACK......................................................................... 104 -

FIGURE 52 SYNTHETIC RECEIVER FUnCTION FOR NZSM................................................................. 111 -

Figure 53 SYNTHETIC RECEIVER FunCtion FOR VELOCITY MODEL KIW (EWIG, 2009) WITH 30 DEGREE DIP...112 -

FiguRE 54 SYNTHETIC RECEIVER FUnCTION FOR VELOCITY MODEL KIW (EWIG 2009) WITH 5 DEGREE DIP......113 -

FIGURE 55 SYNTHETIC VELOCITY MODEL FOR VELOCITY MODEL OC14D20 ............................................ 114 -

FIGURE 56 SHOWING PIERCING POINTS FOR ALL RECEIVER FUNCTIONS. ................................................... 119 -

FIGURE 57 CCP STACK USING NZST 1Hz. VP/VS = 1.77 SHOWING RAY PATHS AND STATION LOCATIONS. - 121

FIGURE 58 NZST 1Hz RECEIVER FUnCTION STACKED BY RAY PARAMETER. .............................................- 122 -

FIGURE 59 NZST 1Hz RECEIVER FunCTIONS STACKED ACCORDING TO BACK AZIMUTH.............................- 123 -

FIGURE 60 CCP STACK USING KIW VELOCITY MODEL. 1HZ STACK. VP/VS 1.75....................................... 124 - 
Figure 61 ReCEIVER FunCtions STACKED USING RAY PARAMETERS. RECEIVER FunCTIONS FOR ALL STATIONS STACKED USING KIW VELOCITY MODEL AT 1HZ.............................................................................. 126 -

FIGURE 62 CCP STACK USING OC14D20 VELOCITY MODEL...................................................................... 127 -

Figure 63 RECEIVER FunCtions STACKED USING OC14D20 AT 1Hz. RECEIVER FunCTIONS FOR ALL STATIONS STACKED USING OC14D20 VELOCITY MODEL AT 1 Hz. FOR DEPTHS UP TO 95 KM............................ 128 -

FIGURE 64 BEST AND FINAL CCP STACK. INTERPRETED USING OC14D20 AT 1Hz WITH A VP/Vs =1.77. . - 129

Figure 65 Schematics of VElocity models SAVAGE (2007) AND EWIG (2009). (Figure From EWig,

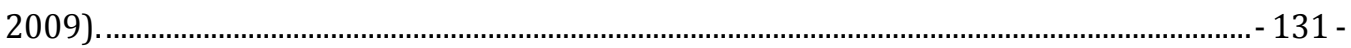

FIGURE 66 FIGURE FROM (UNPUBLISHED) SAHKE PRELIMINARY RESULTS USING CONTROLLED SOURCE SEISMIC DATA. (HENRYS ET AL., 2012). $-136-$ 


\section{LIST OF TABLES}

TAble 1 Station Names And Locations (SEe Figure 2) ................................................... - 9 -

TABLE 2. STATION NAMES AND INSTRUMENTATION............................................................ - 55 -

TABLE 3 ReCEIVER Function EVEnTS (DATES AND NUMBER) PER STATION........................ - 76 -

TABLE 4. PARAMETERS OF VELOCITY MODELS..................................................................... - 110 - 
- 1 - 


\section{CHAPTER 1}

\section{INTRODUCTION}

\subsection{Motivation}

The broad motivation for this investigation is the requirement for further understanding of the nature of subduction interfaces and their seismogenic potential. Specifically, this investigation focuses on the Hikurangi subduction system (Figure 1). The subducting Pacific plate represents a large potential seismic hazard as it plunges beneath the Wellington region situated at the southern end of the North Island of New Zealand.

This project seeks to investigate both physical and structural factors that may be affecting subduction zone seismogenesis beneath the Wellington region. This is achieved by using deconvolved $\mathrm{P}$ to $\mathrm{S}$ converted phases, taken from recorded earthquake data, to compute receiver functions; and from these to make common conversion point (CCP) depth model showing the velocity structure of the down-going slab and associated structures.

Subduction zones have the potential to produce large, destructive earthquakes. Recent global examples are the Mw 9.2 Sumatra earthquake that caused the Boxing Day Tsunami of 2004, and the March 11, 2011 Mw 9.0 off the east coast of Honshu, Japan.

Studies have been made to correlate measurable parameters such as the age and rate of subduction of the plate, thermal structure, recurrence time (e.g. McCaffrey, 1997) and the presence of a sediment layer at the plate interface (Uchida et al., 2009) with the occurrence of megathrust events. But the 2004 Sumatra earthquake raised questions regarding the control of physical properties on the occurrence of megathrust events (Wallace et al., 2009), revealing the need for further studies. 
There have been ten $\mathrm{Mw}<7.2$, plate interface seismic events documented since 1840 in the Wellington region (Barker et al., 2009). The only earthquake known that was larger, estimated Mw 7.9 to 8.2 (Rodgers and Little, 2006) was the 1855 Wairarapa earthquake that ruptured the strike slip Wairarapa Fault and, potentially, also involved part of the plate interface adjacent to the intersection of the Wairarapa Fault with the subducting plate interface (Rodgers and Little, 2006).

However the absence of large, $\mathrm{Mw}>8.0$ megathrust earthquakes involving a rupture of a major portion of the plate interface may be because the physical and geological properties of the subduction plate interface do not allow ruptures of this magnitude to take place (Wallace et al., 2009) or because the recurrence intervals are longer than the $\sim 170$ years of documented record. The occurrence of strong interplate coupling beneath the Wellington region, a result of along strike variation of a variety of physical and tectonic controls, is suggested by several studies (e.g. Reyners, 1998; Barnes et al., 1998; Wallace et al., 2004). Wallace (2004) concludes that the southern portion of the margin may be capable of producing great subduction thrust events as large as $\mathrm{Mw} \sim 8.2-8.7$.

New Zealand represents a good opportunity for a land-based study across a wide cross section of fore-arc basin, parallel with the dip of the subducting plate. The opportunity to use both passive (this study) and active source seismology in tandem allows the use of different, but complementary seismic techniques providing excellent constraints on the resulting models.

\subsection{THE PROJECT}

The major part of the data used in this project was collected as part of the Seismic Array Hikurangi Experiment (SAHKE) (Seward et al., 2010). SAHKE is an international collaboration between New Zealand, the USA and Japan, all countries that are affected by the proximity of large populations to the hazard of large destructive earthquakes. Additional instrumentational support was received from International Research Institutions Seismology (IRIS) and Australian National Research Facility in the Earth Sciences 
(ANSIR). Seismic data were also used in the analysis from two other sources, the Geonet permanent network, (www.geonet.org.nz) and the 1991-1992 Tararua Array seismic experiment (Stuart et al., 1995) in the region (see Figure 2 for seismic station locations).

\subsection{Aims AND OBJECTIVES}

The SAHKE project aim is to understand the potential of large-magnitude seismogenic behaviour of the Pacific plate as it subducts under New Zealand's North Island (Okaya, 2010).

The aim of this thesis is to use seismic data from teleseismic earthquakes, recorded on broadband stations across a $\sim 100 \mathrm{~km}$ transect (Figure 1) normal to the strike of the descending plate, to compute a series of receiver function stacks, using the multiple taper correlation (MTC) method of Park and Levin (2000). The receiver function stacks will provide a depth model below each individual station. The individual stacks are then stacked to make a 'super-stack,' using the common conversion point (CCP) method, to create a depth model imaging the velocity structures across the body of the transect.

The wider objective of this thesis is to add to the body of knowledge regarding subduction zone seismogenesis. The focus is to contribute to the SAHKE project initiative with the analysis and interpretation of passive data. This is achieved by the computation, analysis and interpretation of the receiver functions and the CCP stacked image.

\subsubsection{FUNDAMENTAL QUESTIONS OF SUBDUCTION SEISMOGENESIS.}

The following four guiding questions are documented as scientific objectives in the SAHKE proposal documentation (Okaya, 2010) and are also adopted as guides to the analysis and interpretation of results in this study. 
What controls the occurrence and breadth of interseismic coupling? Along strike changes documented by previous studies (e.g. Reyners, 1998; Barnes et al., 1998; Nicol and Beavan, 2003; Wallace et al., 2004; Wallace et al., 2009; Reyners et al., 2011) indicate that the southern section of the Hikurangi margin is strongly coupled. Observations of this segment also indicate a shallow slab dip, (Eberhart-Phillips and Reyners, 1997) giving a large region where fore-arc continental crust is directly above the descending plate (Barnes et al., 1998); a buoyant subducting crust (Cloos,1993; Barnes et al., 1989); and a strong overlying plate (Barnes et al., 1998). It is not known what properties have influence over the amount of interseismic coupling and build up of stress.

What controls the occurrence and breadth of slow slip events? Slow slip events are a relatively recently investigated phenomenon in this area. It is thought that slow slip occurs on the deeper portions of the seismogenic zone in the segment of the plate interface subducting beneath the study area and on shallower sections further to the north (Wallace and Beavan, 2010; Wallace et al., 2010). Slow slip events are thought to be linked to a stable frictional system, possibly associated with the presence of fluids (Wallace and Beavan, 2010). Imaging the downdip interface structures may provide evidence for this.

Can the presence or absence of fluids affect coupling on the plate interface? The presence and distribution of fluid is likely to have an effect on frictional regimes. High pore pressures are likely to be associated with clusters of seismicity and may be linked with the presence of impermeable rock (Reyners and Eberhart-Phillips, 2009). Fluids may also be associated with low velocity layers (Eberhart-Phillips and Reyners, 1999; Bannister et al., 2007) which are surmised to cause a weak zone with low rigidity and possibly low seismicity. 
How does the presence of other structural and physical property factors affect plate interface coupling? Large scale regional and tectonic factors may control the seismogenic potential of the plate interface. These factors include subduction accretion and the geometry of the accretionary wedge, and how this changes along strike; the thickness of the sediment layer on the Hikurangi Plateau; and the change in relative rate of convergence and angle of the Australian and Pacific plates.

During the course of the investigation of this thesis, there have been some interesting, unexpected results relating to structures that lie at mantle depths of between 50 and $100 \mathrm{~km}$, below structures interpreted as the converging plates. The discovery of these structures has led to some additional questions, and widened the scope of the project to allow discussion and interpretation of these deeper layers. A previous study (Wilson et al., 2004) imaged upper mantle structures beneath the northern tip of the South Island of New Zealand using $\mathrm{P}$ to $\mathrm{S}$ converted modes (receiver functions) and common conversion point (CCP) stacking; techniques analogous to those used in this study. The deep structures imaged in this study, at the southern end of the North Island of New Zealand, are deeper than the $<60 \mathrm{~km}$ Wilson et al., (2004) observed.

\subsection{STUDY AREA}

The study area is situated in the Wellington region situated in the southern North Island of New Zealand (Figure 1). The transect line (Figure 1) stretches across the island in an approximately north-west to south-east direction. The transect consists of seventeen stations (Figure 2); Table 1 lists their names and exact geographic locations and elevations. Table 2, (in Chapter 5), gives technical details of the seismometers employed to record the data used in the analysis. 


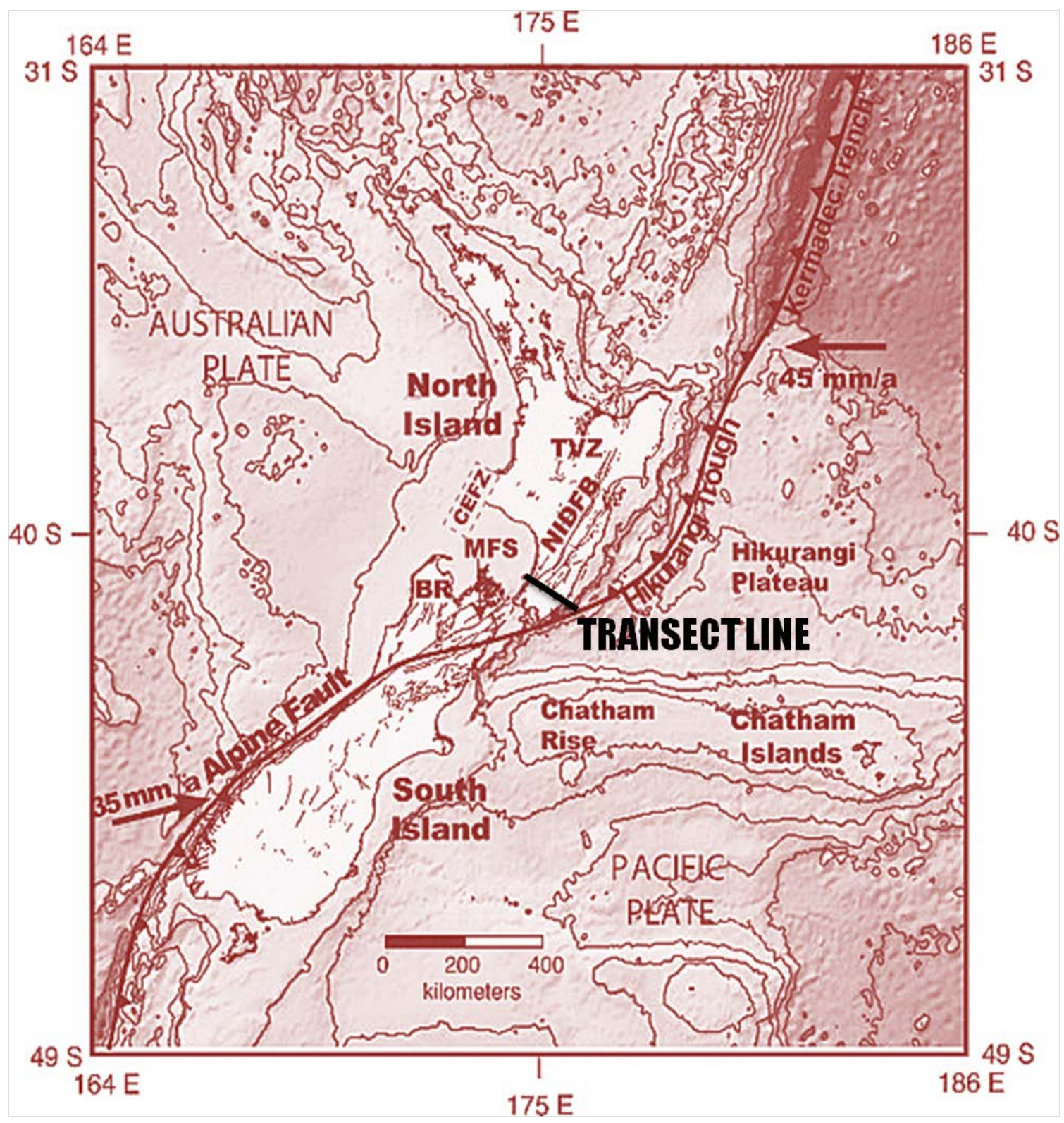

Figure 1 Regional Tectonic Setting of New Zealand

Showing the transect line for this study in bold black. NIDFB, North Island Dextral Fault Belt; TVZ, Taupo Volcanic Zone; MFS, Marlborough Fault System; BR Buller region, and CEFZ Cape Egmont Fault Zone. Arrows show Pacific/Australia relative motion in the New Zealand region [e.g., DeMets et al., 1990, 1994. After Wallace et al (2004). 


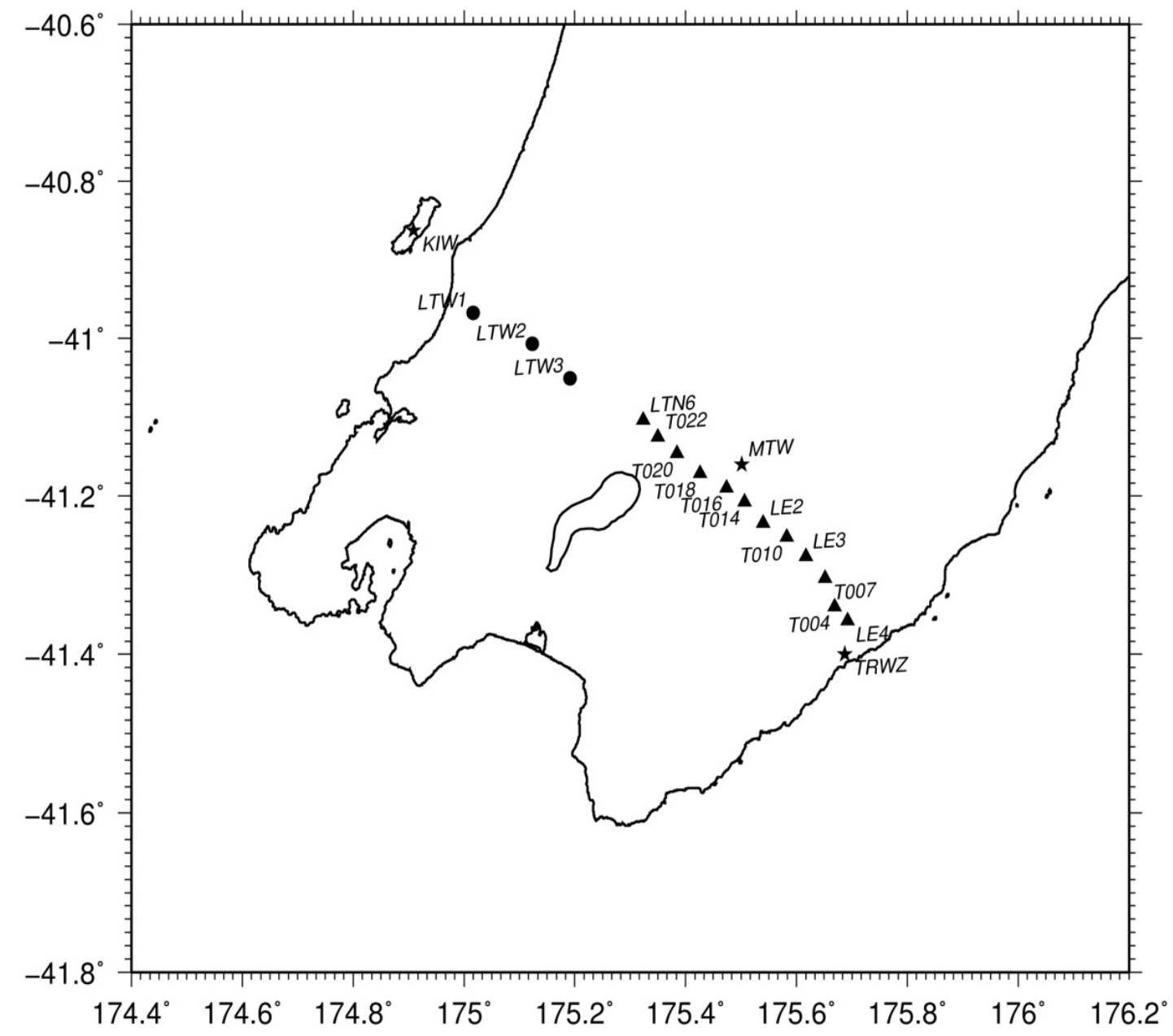

Figure 2 Transect Station Locations and Names across lower North Island, New Zealand.

Stars are stations TRWZ, MTW and KIW which are Geonet permanent stations. Circles are stations LTW1, LTW2 and LTW3 from the 1991-'92 Tararua Broadband Array, POMS experiment. Triangles are stations LE4, T004, T007, LE3, T010, LE2, T014, T016, T018, T020, T022, and LTN6, all deployed as part of the SAHKE 1 project. 
Table 1 Station Names and Locations (See Figure 2)

\begin{tabular}{|l|l|l|l|}
\hline $\begin{array}{l}\text { STATION } \\
\text { NAME }\end{array}$ & LATITUDE & LONGITUDE & $\begin{array}{l}\text { ELEVATION } \\
(\mathrm{m})\end{array}$ \\
\hline TRWZ & -41.3997 & 175.6877 & 379 \\
\hline LE4 & -41.3579 & 175.6919 & 197 \\
\hline T004 & -41.2603 & 175.6684 & 43 \\
\hline T007 & -41.3041 & 175.6513 & 48 \\
\hline LE3 & -41.2763 & 175.6170 & 300 \\
\hline T010 & -41.2520 & 175.5825 & 111 \\
\hline LE2 & -41.2340 & 175.5396 & 91 \\
\hline T014 & -41.2075 & 175.5063 & 145 \\
\hline T016 & -41.1893 & 175.4737 & 39 \\
\hline T018 & -41.1715 & 175.4257 & 56 \\
\hline MTW & -41.1596 & 175.5014 & 311 \\
\hline T020 & -41.1461 & 175.3850 & 23 \\
\hline T022 & -41.1251 & 175.3497 & 31 \\
\hline LTN6 & -41.1033 & 175.3238 & 103 \\
\hline LTW3 & -41.0504 & 175.1910 & 210 \\
\hline LTW2 & -41.0067 & 175.1229 & 210 \\
\hline LTW1 & -40.9674 & 175.0170 & 200 \\
\hline KIW & -40.8626 & 174.9096 & 381 \\
\hline & & & \\
\hline
\end{tabular}




\section{CHAPTER 2}

\section{BACKGROUND GEOLOGY}

\subsection{TECTONIC SETTING OF NEW ZEALAND}

New Zealand is a tectonically active continent, with the two main (North and South) Islands sitting astride the convergent boundaries of the Australian and Pacific plates (Figure 1). Offshore to the east of the North Island lies the Hikurangi trough and plateau (Figure 1). The Hikurangi trough is the morphological expression of the plate boundary, where the Pacific plate subducts obliquely beneath the overriding Australian plate (Figure 1 and Figure $3)$.

To the south of the termination of the Hikurangi trough the subduction zone becomes an oblique transform boundary (De Mets et al., 1994) cutting westwards across the South Island as the Marlborough fault system (EberhartPhillips and Reyners, 1997). The obliquely transpressive Alpine Fault traces the plate margin southwards. Offshore to the west of the South Island the boundary between the two adjacent plates once again becomes a subduction zone, but with the Australian plate now subducting beneath the Pacific plate at the Puysegur margin (Walcott, 1998), (Figure 1).

As the Pacific plate subducts beneath the Australian plate the oblique subduction is expressed as a combination of margin-normal and marginparallel motions. The rate of convergence varies along New Zealand's plate boundaries from about 50-60 $\mathrm{mm}$ per year in the northeast, at around latitude $38^{\circ} \mathrm{S}$, to $\sim 20 \mathrm{~mm}$ per year in southwest, at latitude $42^{\circ}$ south (Wallace et al., 2004) (Figure 3). The rate of subduction beneath the Wellington region is estimated at $\sim 42 \mathrm{~mm}$ per year (Wallace et al., 2010) 
with greater obliquity, but smaller velocities, due to tectonic rotation evident at this point (Wallace et al., 2004). The relative plate motion vector is around 40 - 70 degrees to the trend of the strike of the plate margin (De Mets et al., $1990,1994)$, or $42-48 \mathrm{~mm}$ per year trending at $50^{\circ}$ to the margin according to Nicol et al., (2007). Decrease in the convergence rates to the south of latitude $\sim 40^{\circ}$ is met with an increase in shortening of the upper plate, as shown by GPS campaign data (Wallace, 2004).

More than $80 \%$ of margin normal plate convergence is accommodated by motion on the subduction thrust (Wallace et al, 2009). The remaining margin normal motion and much of the margin parallel movement is accommodated by upper crustal deformation and block rotations (Wallace et al, 2009). Strain partitioning from the relative plate motions (Figure 3 ) is taken up by a combination of differing styles of upper crustal deformation. Crustal shortening, to the south of the North Island is accommodated by reverse and strike slip (or oblique) faulting (Nicol and Beavan, 2003). Beanland et al., (1998) determined that a large proportion of margin-normal shortening between the axial ranges (the Tararua and Ruahine ranges) and the eastern margin of the fore-arc basin was accommodated on the major faults that run along the range fronts. Relative plate motions are accommodated not only by faulting but also by a wide zone of deformation on either side of the faults (Cole and Lewis, 1981). Much of the margin parallel component of the plate motions is taken up with clockwise tectonic block rotation of $0.5^{\circ}-3.8^{\circ}$ per million years (Wallace et al., 2004). Some of the margin parallel component is also taken up by strike-slip faulting (Beanland, 1995; Beanland, 1998; Nicol and Wallace, 2007). This division of geological strain from the relative plate motions depends not only upon the angle of obliquity, but on the strength of the overriding plate and the amount of interplate coupling (Barnes et al., 1998). Crustal extension resulting from the rotation is accommodated by normal faulting and crustal thinning in the Taupo Volcanic Zone (Barnes and De Lepinay, 1997; Barnes et al., 1998; Nicol and Wallace, 2007). The rates of deformation have remained almost constant during the last 1.5 Myr (Nicol and Wallace, 2007).

Plate reconstructions suggest $\sim 800 \mathrm{~km}$ of relative plate motion since $43 \mathrm{Ma}$ (Lamb, 2011), with palaeomagnetic studies showing $80-90^{\circ}$ of clockwise rotation of the Hikurangi plateau and associated structures over the last 20 
My (Lamb, 2011). Palaeomagnetic (Lamb, 2011) and campaign GPS (Wallace, 2004) studies show that rotation of the Pacific plate relative to the Australian plate is still occurring in the present day.

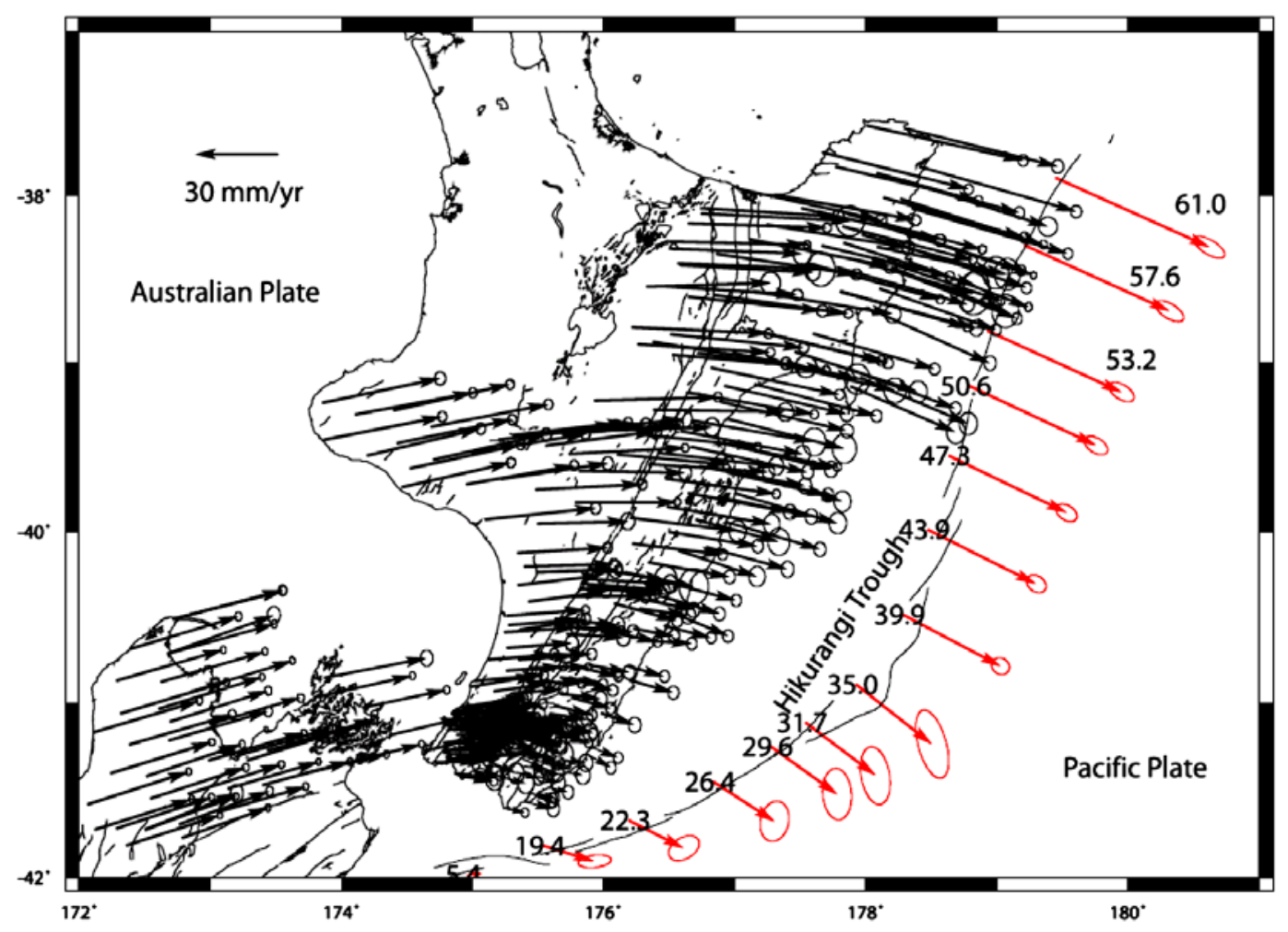

Figure 3 GPS Velocities relative to the Pacific Plate Black arrows are GPS velocities relative to the Pacific plate. Red vectors show the estimated long term convergence rate at the trench. (Figure from Wallace et al., 2009). 


\subsection{STRUCTURES OF THE HIKURANGI SUBDUCTION ZONE}

The focus of this thesis is the structure and seismogenic potential below the Wellington region at the southern end of the North Island of New Zealand (Figure 1 and Figure 4). To aid interpretation of the geological structures below the region an understanding of their genesis before subduction is helpful. The offshore region of the Hikurangi Plateau (Figure 1), and its associated geological structures, are relevant to this study because it may be concluded that the structures subducting into the Hikurangi trough at the present day have a similar geological history to the 'pre-subduction' structures of the Hikurangi Plateau, therefore they may be expected to have related lithology.

\subsubsection{Geology of the HikURANGi Plateau and the DeVELopment of tHe PRESENT DAY PLATE BOUNDARY}

The Hikurangi plateau (Figure 1 and Figure 4) is a $350000 \mathrm{~km}^{2}$ igneous province formed ca. 122 Ma during the early Cretaceous as part of the enormous, $3600000 \mathrm{~km}^{2}$, Ontong Java Plateau, the largest ocean plateau on earth (Neal et al., 1997). The Ontong Java Plateau had an abnormally thickened oceanic crust, not unlike that of normal Pacific crust, but thicker and more buoyant. Estimated thicknesses of the present day Hikurangi Plateau range from 35-42 km (Reyners et al., 2011) using a seismic tomography model, to $12-15 \mathrm{~km}$ thick (Davy et al., 2008) using seismic reflection data. The Hikurangi Plateau rifted from the Ontong Java Plateau around $120 \mathrm{Ma}$, drifting south as a result of seafloor spreading at the Osbourn Trough (Taylor, 2006; Davy et al., 2008). At around 100 Ma, during the mid-Cretaceous, the southern edge of the thick and buoyant Hikurangi Plateau 'choked' the subducting margin of Gondwana, along what is now the north Chatham rise (Davy et al., 2008; Reyners et al., 2011). This led to the margin no longer being one of active subduction, as evidenced with seismic reflection and gravity modelling (Davy et al., 2008). Davy et al (2008) also reveal the overall lithology as faulted volcanic basement with an overlay of Mesozoic-Cretaceous sediment. 
The present plate boundary did not develop through New Zealand until between $20 \mathrm{Ma}$ and $30 \mathrm{Ma}$; with the Hikurangi subduction zone developing $\sim 25 \mathrm{Ma}$ (Furlong and Kamp, 2009). The position of the subduction zone has rotated clockwise from north-west reaching its current position around $5 \mathrm{Ma}$ (Furlong and Kamp, 2009).

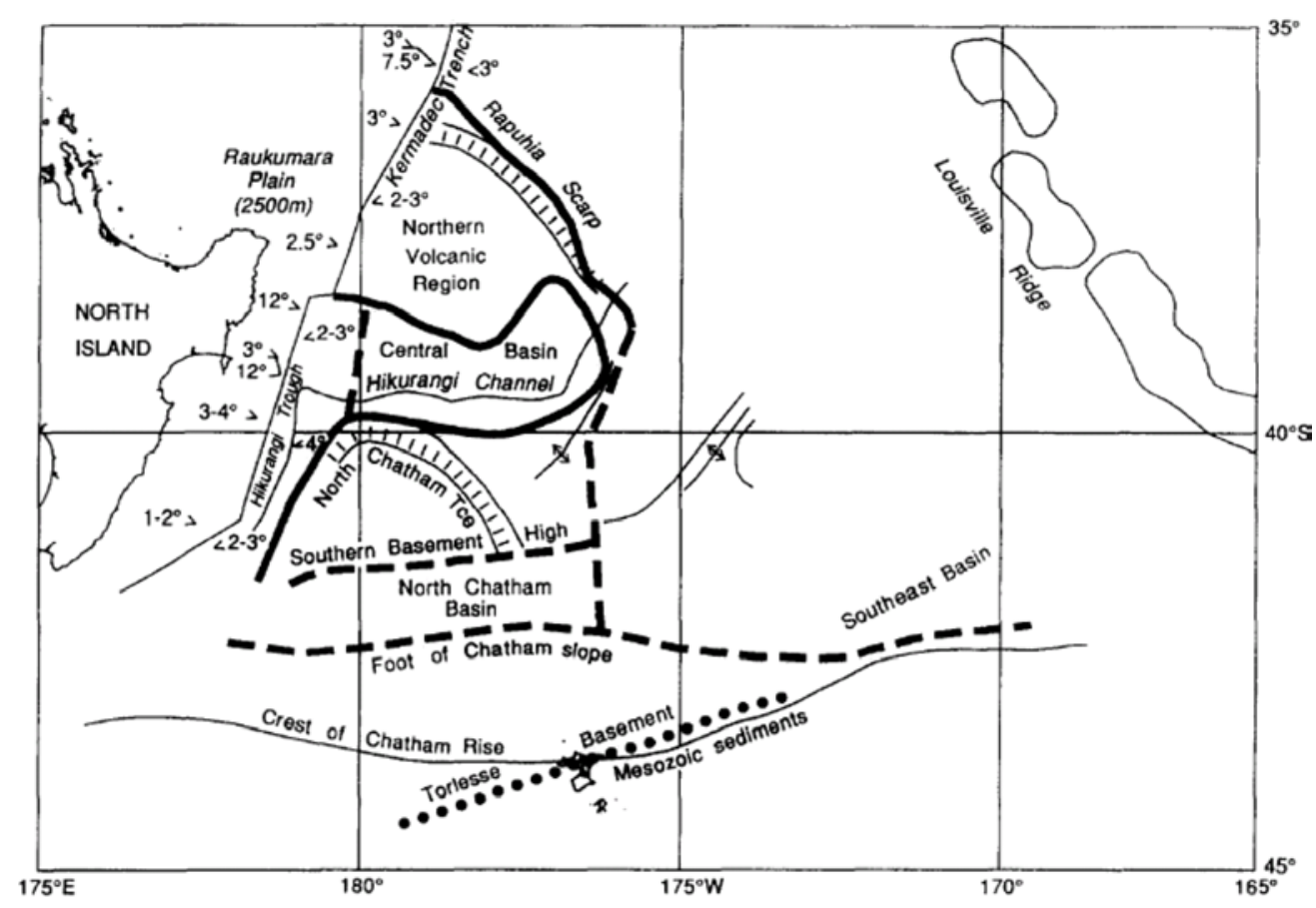

Figure 4 The six major regions of the Hikurangi Plateau The different gradients of the accretionary prism and the down going slab are indicated to the left and right of the line annotated 'Hikurangi Trough, Kermadec Trench'. (Figure from Wood and Davy, 1994).

The area named the Southern Basement High (Figure 4) by Wood and Davy (1994) is covered by a greater than $1 \mathrm{~km}$ thick layer of sediment (Figure 5), interpreted to be deposits from the Cenozoic to the present day (Davy et al., 2008). Below the low velocity Cenezoic sediments (CEN in Figure 5) are faster Oligocene and Mesozoic sedimentary layers (Seg Y and MES in Figure 5); beneath these lies a layer of volcaniclastic sediments with basaltic interlayers (VB in Figure 5). Underlying this is a 500-2000m thick layer of high amplitude reflectors of Hikurangi Basement (HKB in Figure 5). The top third of this basement unit is interpreted as limestone and chert interbeds. 
The bottom two thirds is a strongly normally faulted layer of volcaniclastic sediment. The uppermost layers are cut with channels and turbidite deposits. The thick basaltic basement layer (B in Figure 5) is underlying the sedimentary deposits, indicated by strong high velocity reflectors (Davy et al., 2008), (Figure 5).

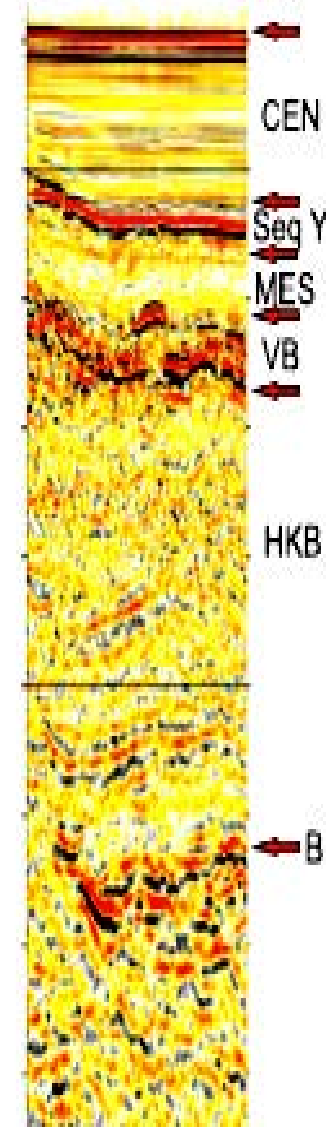

\begin{tabular}{|l|l|l|}
\hline Unit description & $\begin{array}{l}\text { Interval } \\
\text { velocity }\end{array}$ & Age range \\
\hline $\begin{array}{l}\text { Cenozoic sediment-nano fossils } \\
\text { chalks }\end{array}$ & $\begin{array}{l}1500-1600 \\
\mathrm{~m} / \mathrm{s}\end{array}$ & $32-0 \mathrm{Ma}$ \\
$\begin{array}{l}\text { With interbeds of tephras and } \\
\text { clays }\end{array}$ & \\
\hline $\begin{array}{l}\text { E.Oligocene-L.Creatceous } \\
\text { chalks/mudstone }\end{array}$ & $\begin{array}{l}2300-3300 \\
\mathrm{~m} / \mathrm{s}\end{array}$ & $70-32$ \\
\hline $\begin{array}{l}\text { Transparent laminar Mesozoic } \\
\text { sediments }\end{array}$ & $\begin{array}{l}2300-2600 \\
\mathrm{~m} / \mathrm{s}\end{array}$ & $100-70 \mathrm{Ma}$ \\
\hline $\begin{array}{l}\text { Volcaniclastic sediment with } \\
\text { basalt interbeds }\end{array}$ & $\begin{array}{l}\text { Not } \\
\text { resolved }\end{array}$ & $100-90 \mathrm{Ma}$ \\
\hline $\begin{array}{l}\text { Cretaceous volcaniclastic } \\
\text { sediment and/or } \\
\text { Limestone chert. Possibly } \\
\text { sandstone/mudstone }\end{array}$ & $2400-$ \\
$\begin{array}{l}\text { In upper 0.2-0.3 s. Laminated } \\
\text { horizons with widespead } \\
\text { normal faulting. }\end{array}$ & $3500 \mathrm{~m} / \mathrm{s}$ & $125-120(100 ?)$ \\
\hline $\begin{array}{l}\text { Basaltic basement. } \\
\text { Ma }\end{array}$ & & \\
\hline & & \\
\hline
\end{tabular}

Figure 5 Sedimentary Units of the Hikurangi Plateau. (Figure after Davy et al., 2008)

\subsubsection{THRUST IMBRICATED FRONTAL WEDGE}

The thrust imbricated frontal wedge stretches up to $150 \mathrm{~km}$ from the Hikurangi Trough onshore to the axial ranges (Lewis and Pettinga, 1993; Barnes et al, 2010). The Mesozoic Torlesse terrane axial ranges have acted as a backstop against which the thrust shortening of the overlying plate has occurred (Barnes et al., 2010). The eastern section of the transect line (Figure 1) of seismometers used in this thesis, stations TRWZ to T022 
(Figure 2), are located on the continental portion of the imbricated frontal wedge of the overlying Australian plate. The region offshore from the lower North Island of New Zealand exhibits a basin and ridge morphology (Barnes et al., 2010). The lithological units lie over a weak decollment (or detachment zone) (Figure 6A), which is the interface between the deforming overlying sediments of the Australian Plate and the stronger, undeformed subducting sediments of the Hikurangi Plateau section of the descending Pacific plate (Figure 6). This decollment is also the plate interface; it is marked as a red dotted line on Figure 6.

Figure 6, from Wallace et al., (2009), illustrates the changing nature of the imbricate frontal wedge from north to south; Figure $6 \mathrm{~A}$ is closest to the study area, offshore Wairarapa. The wedge reaches a maximum of $150 \mathrm{~km}$ wide (offshore from Hawkes Bay) narrowing both north of Hawkes Bay and south towards the Cook Strait (Wallace et al., 2008). The wedge taper angle in the southern segment is $4-6^{\circ}$, as oppose to the central (Hawkes Bay) and northern (Raukumara) segments where the wedge taper angle is larger, at 6$10^{\circ}$ (Wallace et al., 2010). Wood and Davy (1994) (Figure 4) estimate the wedge taper angle (they refer to it as the gradient of the accretionary prism) at shallower angles of $1^{\circ}-2^{\circ}$ in the south to $3^{\circ}-4^{\circ}$ off Hawke Bay. The variations in the structure of the wedge occurring along its length reflect variations in the obliquity and rate of plate convergence, sediment supply to the Hikurangi trough, and the smoothness of the subducting Pacific plate (Barker et al., 2009).

The offshore accretionary wedge is developing to the west of the Hikurangi Trough, due to thick trench fill sediments combined with oblique convergence, and, typically, the presence of a smooth subducting plate and weak coupling of upper and lower plates (Barnes and DeLepinay, 1997). At around latitude $41^{\circ} \mathrm{S}$ about $75 \%$ of the total $4 \mathrm{~km}$ depth of sediment on the subducting Pacific plate is frontally accreted (Barnes and De Lepinay, 1997) Accretion is the process where accumulation of sediments, from any cause, is greater than that of loss from erosion. At around latitude $41^{\circ} \mathrm{S}$ the plates are obliquely converging at around $50^{\circ}$ at a relatively slow, $27 \mathrm{~mm}$ a year. Barnes and De Lepinay (1997) conclude that over $30 \mathrm{~km}$ of distance orthogonal to 
the main boundary there is a total of $6 \mathrm{~km}$ of horizontal shortening accommodated. A minimum of $80 \%$ of this shortening has occurred over about the last half a million years, giving an overall rate of shortening around $12 \pm 3 \mathrm{~mm}$ a year. When the total amount of shortening at right angles to the boundary is calculated this shortening of the accretionary wedge accounts for about $33-55 \%$ of the whole amount, indicating that some of the convergence is taken up by slip on the plate interface (Barnes and De Lepinay, 1997).
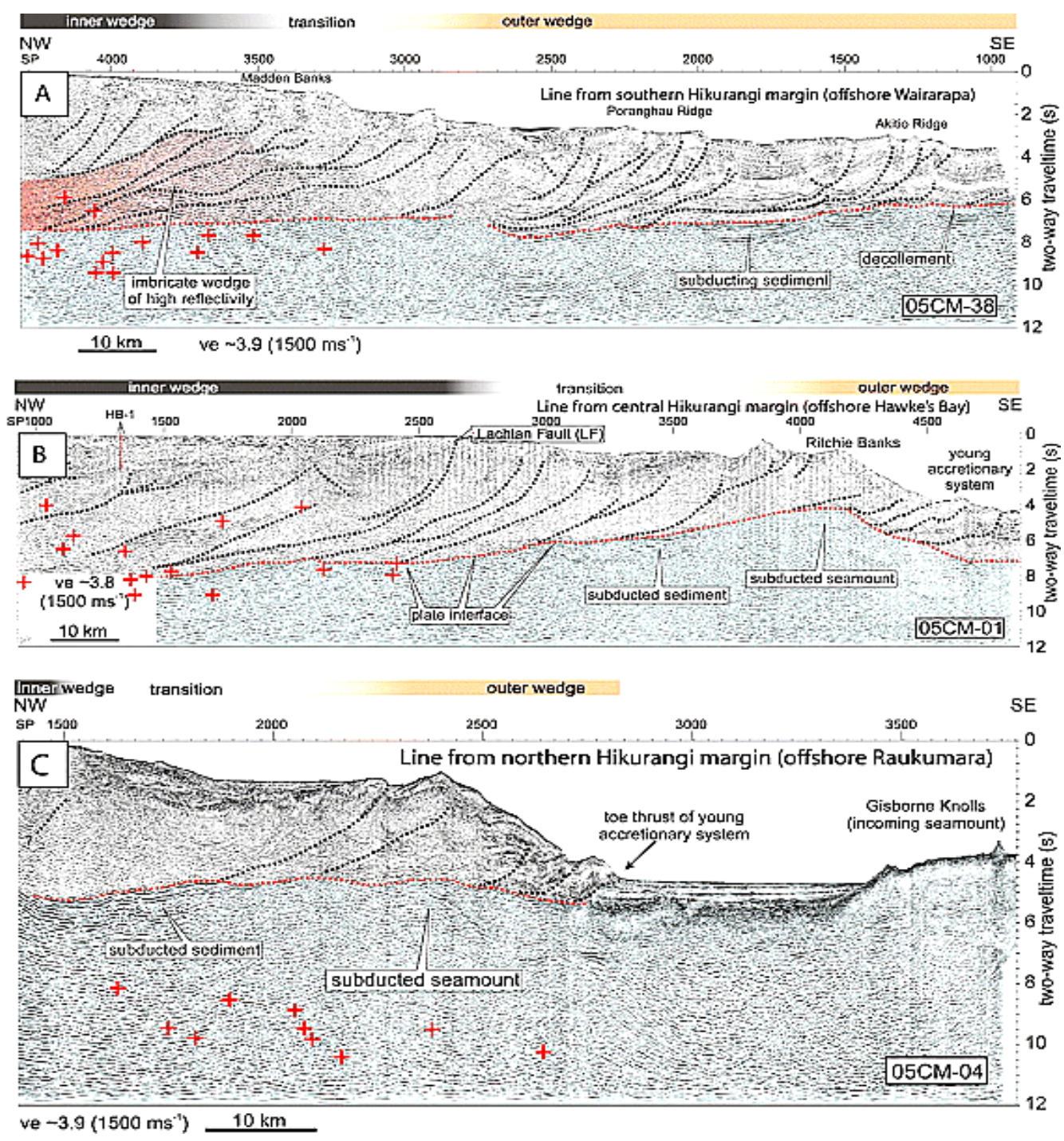

Figure 6 The Imbricate Wedge Seismic lines from (A) southern (B) central and (C) northern sections of the offshore Hikurangi margin. Adapted from Barker et al., (2009). Dotted red line is decollment/plate interface with the subducting material below in blue. Red shading indicates high reflectivity. Red crosses are relocated earthquakes. Interpretation of inner to outer wedge by Barker (2009). There is evidence of splay faulting with unfaulted sediments subducting below the decollment. (Figure from Wallace et al., 2009). 


\subsubsection{THE SUBdUCTING SLAB AND THE SEISMOGENIC ZoNE}

In New Zealand the strike of the subducting slab runs north-east to southwest, a strike of $\sim \mathrm{N} 40^{\circ} \mathrm{E}$ (Ansell and Bannister 1996).This strike is fairly constant along the length of the North Island, but with variations in dip along the length of the strike. Generally the dip is shallower and constant beneath the southern North Island, becoming steeper to the north (Eberhart-Phillips et al., 2008). Beneath the west of the central North Island, the dipping plate extends to about $300 \mathrm{~km}$ depth. To the east of the region, beneath Hawkes Bay the plate interface is around $15 \mathrm{~km}$ depth, dipping at $10^{\circ}$ north-west (Eberhart-Phillips et al., 2008). The Wadati-Benioff* zone is a zone of deep earthquakes hypocentres that, when mapped, (Figure 7), provides a primary source of information regarding the dip and maximum depth of the subducting plate (Stein and Wysession, 2003). 


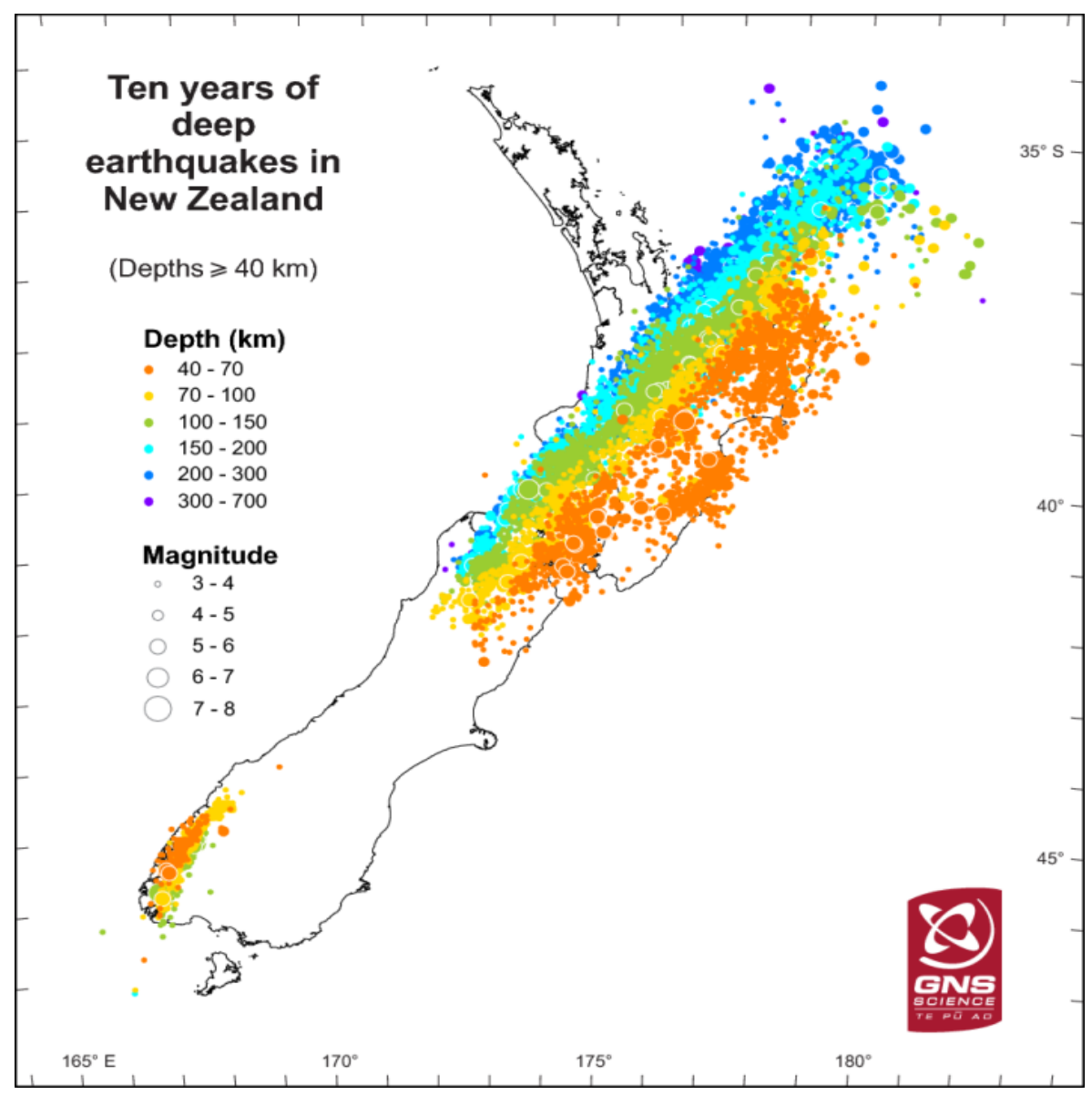

Figure 7 The pattern of Deep Earthquakes in New Zealand. Ten Years of data. Indicating the Wadati-Benioff zone from above. (Figure from http://www.geonet.org.nz/earthquake)

The seismogenic zone of a plate interface (or a fault) is the area where earthquakes nucleate (Wallace et al., 2010 b). Seismogenic zones of the down-going slab may be identified and segregated into distinct areas (Kearey and Vine, 2003), (Figure 8). Beanland (1995) states that, at the Hikurangi subduction zone, the maximum depth of the seismogenic zone associated with the subducting slab changes along strike, from $300 \mathrm{~km}$ in the north, to $200 \mathrm{~km}$ in the Wellington region and $100 \mathrm{~km}$ below Marlborough.

*(Named after Kiyoo Wadati (1902-1995) who discovered the existence of deep seismicity beneath Japan, and Hugo Benioff (1899-1968) who correlated the global patterns of deep earthquakes with surface morphology, indicates the location of the subducting oceanic crust at a convergent margin (Stein and Wysession, 2003). 


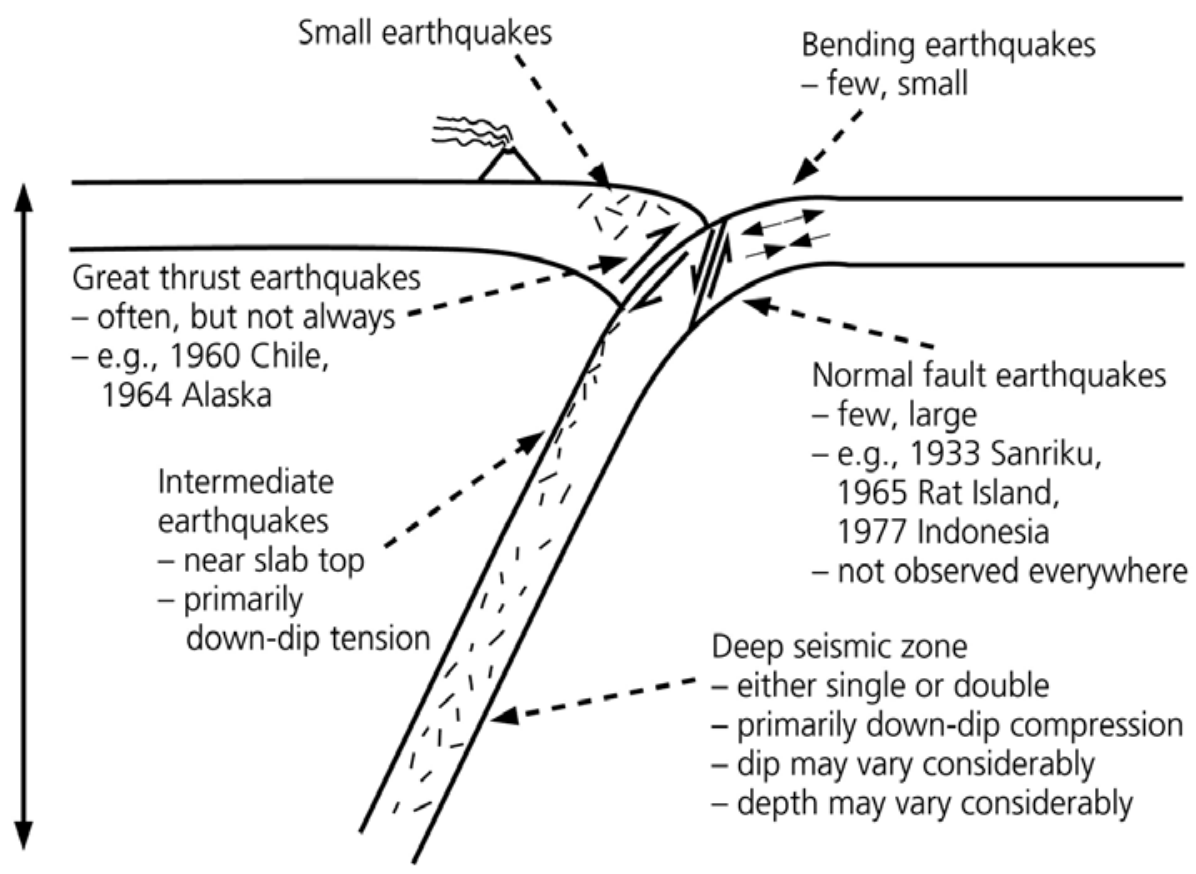

Figure 8 Indicating earthquake types at various depths. (Not specific to the Hikurangi subduction zone) (Figure from Stein and Wysession ,2003).

Shallow earthquakes occuring within the plate, up to a depth of $\sim 25 \mathrm{~km}$, occur as a result of the bending of the lithosphere as it begins it journey downwards. Focal mechanisms for earthqukes down to $\sim 25 \mathrm{~km}$ indicate extensional normal faulting in the upper plate, and thrusting in the lower plate, at a depth of 40-50 km, resuting from downward flexure (Stein and Wysession, 2003).

Earthquakes on the plate interface (interplate), result from the frictional tension between the overriding and subducting plates. These subduction thrust earthquakes are potentially the largest that can occur (see Chapter 1, 1.1). The largest earthquake ever recorded was a subduction thrust, the $\mathrm{Mw}$ 9.5 Chilean earthquake (1960), with $21 \mathrm{~km}$ of slip over $800 \mathrm{~km}$ along strike and $200 \mathrm{~km}$ downdip. Earthquakes of this type release the stress that has built up as a result of the plates locking, their focal mechanisms indicating slip towards the trench (Stein and Wysession, 2003).

Earthquakes that occur within the Wadati-Benioff zone at intermediate depths, greater than the thickness of the lithoshere at the surface, are not assumed to be generated by stick-slip thrusting on the surface of the 
descending plate (Kearey and Vine, 2003). This is because the asthenosphere that is surrounding the descending plate is probably too weak. Earthquakes at these depths are usually within the body of the descending plate, and occur as a result of internal deformation. (Kearey and Vine, 2003). At these depths lithostatic pressure becomes too high for brittle fracture or frictional slip (e.g. Frohlich, 1994 and Kirby, 1995, as cited by Yamasaki and Seno, 2003).

Anderson and Webb (1994) utilised records from the upgraded New Zealand national seismograph network (NZNSN) to locate both shallow and deep earthquake hypocentres. In the Wellington region earthquakes located in the Wadatti-Benioff zone show the dipping structure of the slab, with a gap beneath the Wairarapa Basin (Figure 9).

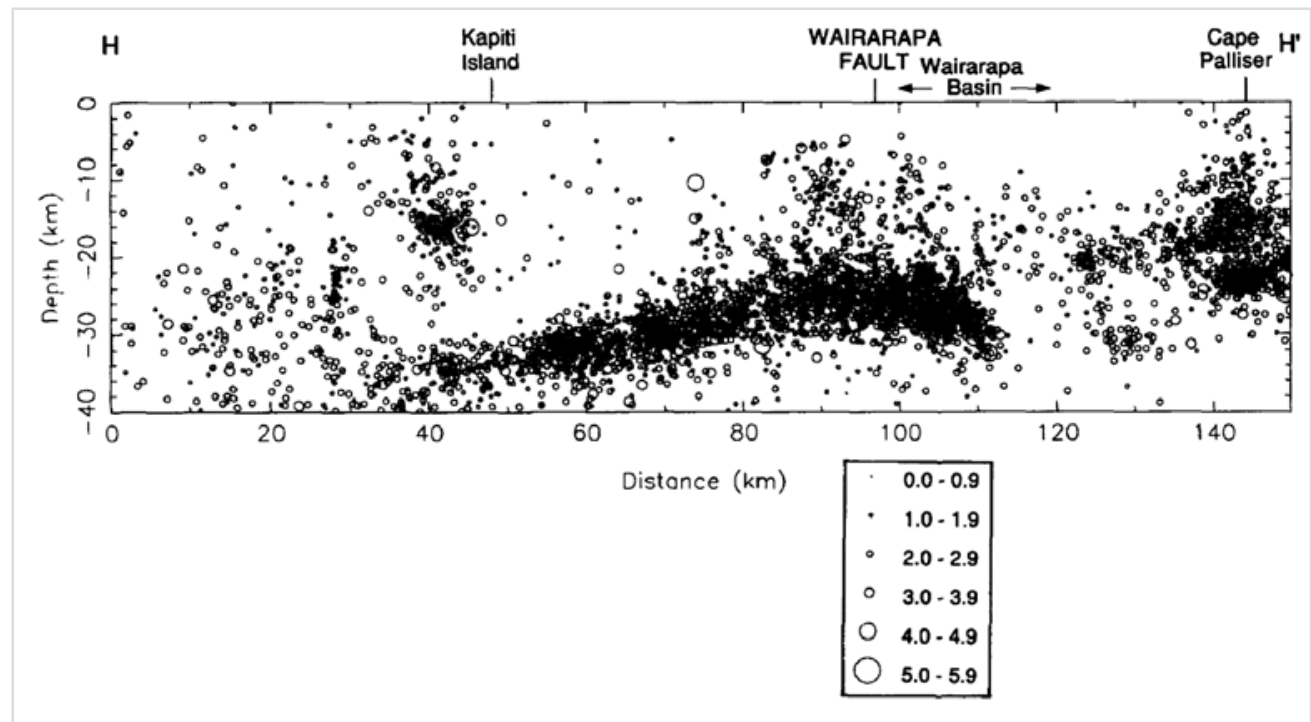

Figure 9 A cross section of earthquake hypocentres in the Wellington region. Events shallower than $40 \mathrm{~km}$ recorded by the NZNSN 01.01/1990 to 28/02/1993. Showing the upper part of the Benioff zone and earthquakes in the overlying Australian plate. (Figure from Anderson and Webb, 1994).

Reyners et al., (1997) used the focal mechanisms of low angle thrust events, at depths shallower than $25 \mathrm{~km}$, occuring on, or just above the upper plane of the dipping seismogenic zone in the southern North Island of New Zealand to estimate the location of the plate interface The low angle thrust events are concentrated in two areas which may indicate the location of the updip and downdip edges of a locked region (Reyners et al., 1997). Further 
observations made it possible to better define the plate interface model and produce a 3D pattern (Furlong and Kamp, 2009) (Figure 10). The patterns of seismicity show a well defined Wadati-Benioff zone that dips sub-parallel to the strike of the trench (see Map Figure 10). The southern edge of the slab appears to be abruptly curtailed across the northern tip of the South Island by what is interpeted as a de-laminated portion of the overriding Australian plate (Figure 10 C) (Furlong and Kamp, 2009).
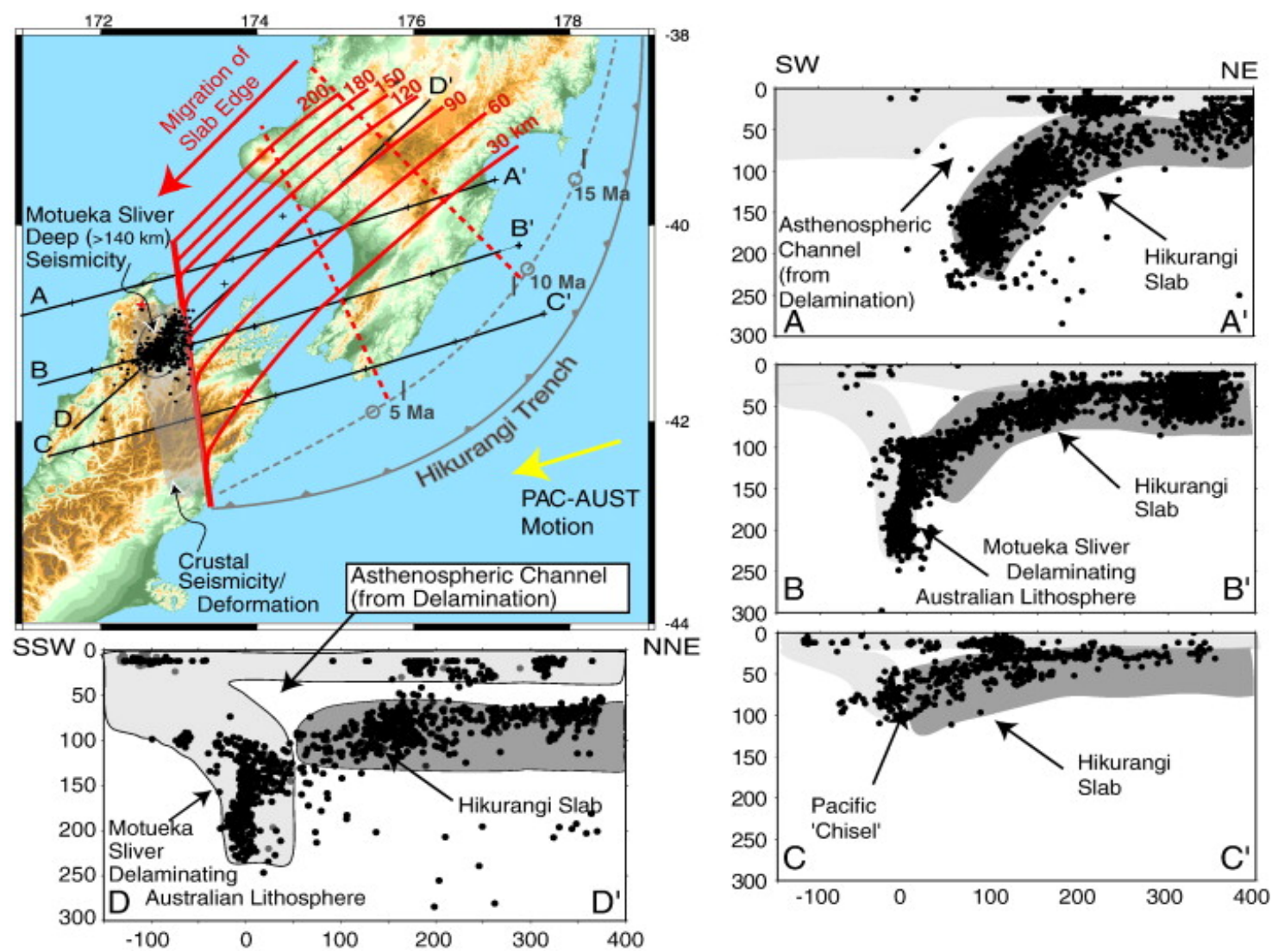

Figure 10 Seismicity cross-sections across the southern North Island, to the northern South Island. The map (top left) shows the locations of the cross sections (black lines) A-A'; B-B';C-C', orientated in the plate motion direction. D-D' is parallel to the $90 \mathrm{~km}$ depth contour of the Wadati-Beniof zone. The solid red lines are the depth contours of the Wadati-Beniof zone. Seismicity is from GNS Science, 2004. (Figure from Furlong and Kamp, 2009).

Double seismic zones have been observed at depths of 50-200 km in several subduction zones, a result of earthquake occurrence on both the plate interface and within the body of the descending plate. This phenomenon was discovered at the Hikurangi margin beneath the northern tip of the South Island of New Zealand and the Wellington region, at the southern end of the North Island (Eberhart-Phillips and Reyners, 1997). Other global examples of a double Wadati-Benioff zone are the Japan subduction zone (Hasegawa et 
al.,1978), the Eastern Aleutians (Yamasaki and Teno, 2003) and Cape Mendocino (Yamasaki and Teno, 2003) on the Cascadia subduction zone, and northern Chile (Yamasaki and Teno, 2003). Yamasaki and Seno (2003) propose that earthquakes occurring at depths of 50-200 km, within the descending slab, may be a result of dehydration embrittlement of metamorphosed oceanic crust and mantle. This process may occur because fluids released by dehydration of anhydrous minerals causes both mechanical instabilities and brittle deformation as they are released. The dehydration of serpentinized mantle may be responsible for the lower plane of the double zone; whilst the upper plane may be as a result of dehydration embrittlement of the subducting ocean crust.

\subsection{SUBDUCTION ZONE COUPLING}

The term coupling is used to describe the frictional behaviour of fault zone (Wallace, 2008). Interseismic coupling is purely a kinematic quantity (Wallace et al., 2009), represented by the coefficient:

$$
\phi_{i c}=1-\left(\frac{V_{c}}{V}\right)
$$

\section{Equation 1}

(Wallace et al., 2009). $V$ is the long term averaged slip rate on the fault (an average taken over many earthquake cycles) and $V_{c}$ is the short term creep rate. If $\phi_{i c}=1$ (equation 1 ) the fault is fully coupled with no movement in the interseismic period. While as if $\phi_{i c}=0$ it indicates that there is creep at the full long term slip rate (Wallace et al., 2009).

Coupling along the Hikurangi margin is dependent on a variety of factors (Eberhart-Philips and Reyners, 2012) such as: the thickness and density of the descending plate, (which affects buoyancy) (Eberhart-Phillips and Reyners, 1997); the dip of the descending plate (the amount of dip is probably a function of buoyancy) (Davey, 1986); geological irregularities on the surface of the descending plate such as subducting seamounts (Cloos, 1993); and the presence (or absence) of fluids or sediments at the plate interface (Morgan and Karig, 1995). All of these factors contribute to the 
balance between strain accumulation in the upper plate and the amount of slip on the plate interface (Nicol and Bevan, 2003). There is evidence of subducted seamounts east of the Raukamara Peninsula (Henrys 2006) causing substantial irregularity on the surface of the subducting plate. These are probably surrounded by fluid rich, low rigidity, sediments, which may correlate with the observed 'slow' ruptures in this region (Henrys 2006). Wallace (2010) identifies the coupling coefficient for the southern segment (Wairarapa) as being 1 for the shallower portions, and 0 for the deeper areas. Moving northwards to the central (Hawkes Bay) and northern (Raukumara) the coupling coefficient is 0 for all areas beneath the onshore landmass.

GPS and seismological data indicate that there is a southward increase in interseismic coupling along the strike of the seismogenic zone (Reyners, 1998. Wallace et al., 2004). It is surmised that the largest subduction thrust earthquakes could occur in the southern portion, but there is also the possibility that they could also be generated from the central and northern parts of the plate interface (Wallace et al., 2008).

Evidence for the hypothesis that there is a strong correlation with plate coupling and velocity structure near the plate interface is further provided by a detailed $3 \mathrm{~d}$ velocity model created using local-earthquake tomography by Eberhart-Phillips and Reyners, (2012). In the region of strongest coupling the plate interface has the highest $V p / V s$, at greater than 1.85 , and the sharpest velocity gradient (Eberhart-Phillips and Reyners, 2012) (Figure 12). This finding indicates that strong coupling is related to the inability of fluid to cross the plate interface. In the region of the interface where there is evidence of slow slip the $V p / V s$ is still high but the gradient where the $\mathrm{Vp} / \mathrm{Vs}$ changes from high to low is less sharp (Eberhart-Phillips and Reyners, 2012) (Figure 12); this indicates that in the slow slip regions there may be movement of fluid across the plate interface.

The area of strongest plate coupling, to the greatest depth, is identified as being below the centre of the overlying Rakaia terrane (Adams et al., 2009, cited by Eberhart-Phillips and Reyners, 2012) (Figure 11); this area correlates very closely to the transect used in this study, and so is very 
relevant to the analysis and interpretation of these results. Of all the depth sections examined by Eberhart-Phillips and Reyners, (2012) it is the Wairarapa and Wellington region that has the sharpest gradient in Vp/Vs across the plate interface, and the most concentrated seismicity in the top of the subducted slab. The large gradient occurs because there is observed low $\mathrm{Vp} / \mathrm{Vs}$ in the overlying plate and high $\mathrm{Vp} / \mathrm{Vs},>1.85$, within the slab (Figure 12). The low Vp/Vs of the Rakaia terrane is identified as being consistent with that of schist. Eberhart-Phillips and Reyners, (2012) conclude that the region of lowest $\mathrm{Vp} / \mathrm{Vs}$ is restricted to the Rakaia terrane, and that this area has likely undergone the most metamorphism compared to the other observed terranes in the overlying plate.

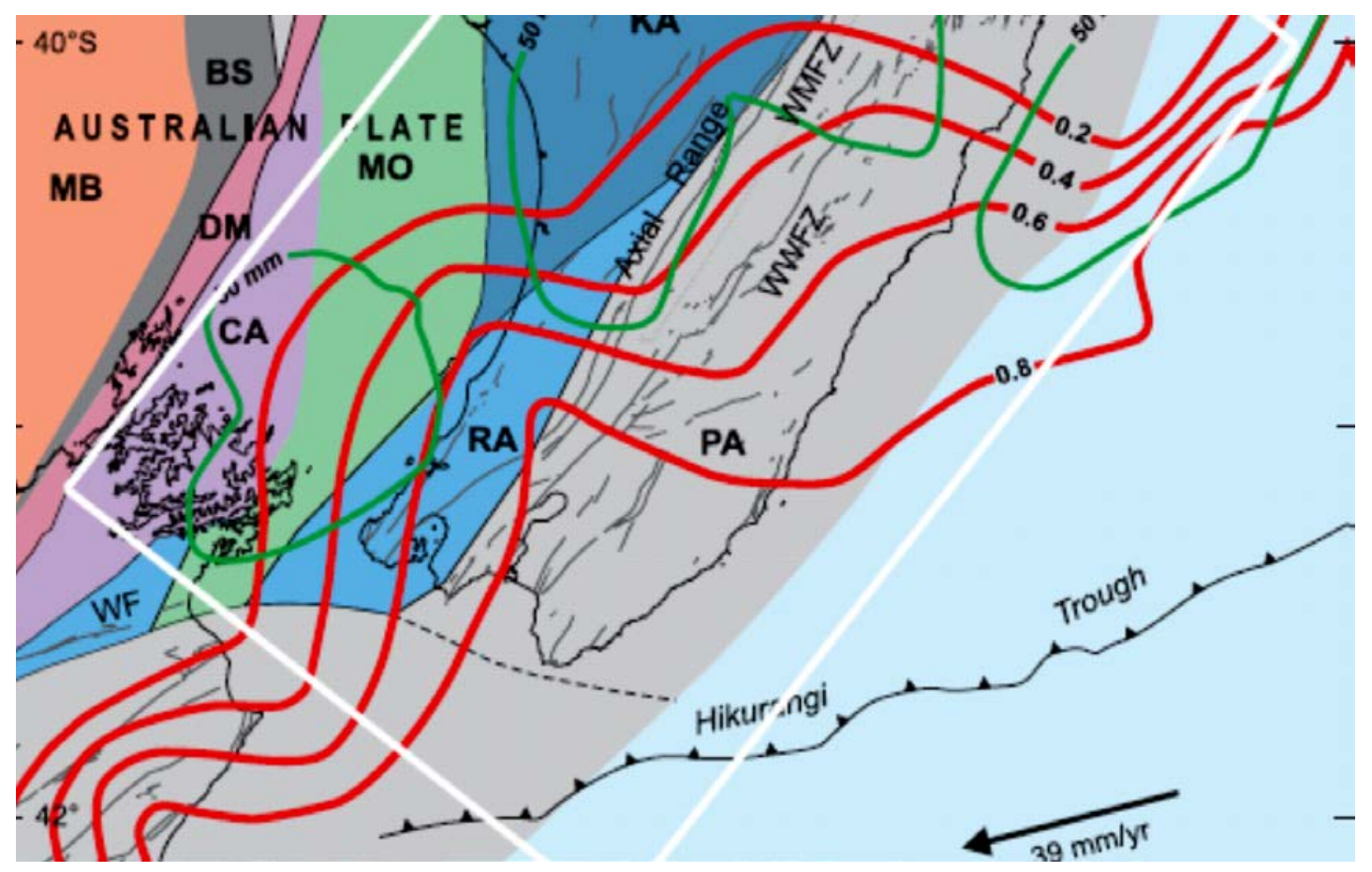

Figure 11 Interseismic coupling coefficient at the plate interface (Wallace et al 2012) in red contours; and regions where the total slip in slow slip events at the Plate Interface has exceeded 50mm since 2002 in green contours (Wallace and Beavan 2010). Terranes in the overlying plate are PA-Pahau; RA-Rakaia; MO-Morrinsville; CA-Caples; DM-Dun Mountain; BS-Brook Street; MB-Median Batholith. Thin black lines are faults mapped at the surface. Major faults zones named are WWFZ, Wairarapa-Waewaepa Fault Zone and WMFZ, Wellington-Mohaka Fault Zone. The black arrow shows the velocity of the Pacific Plate relative to the Australian Plate (DeMets et al. 2010). (Figure from Eberhart-Phillips and Reyners, 2012). 

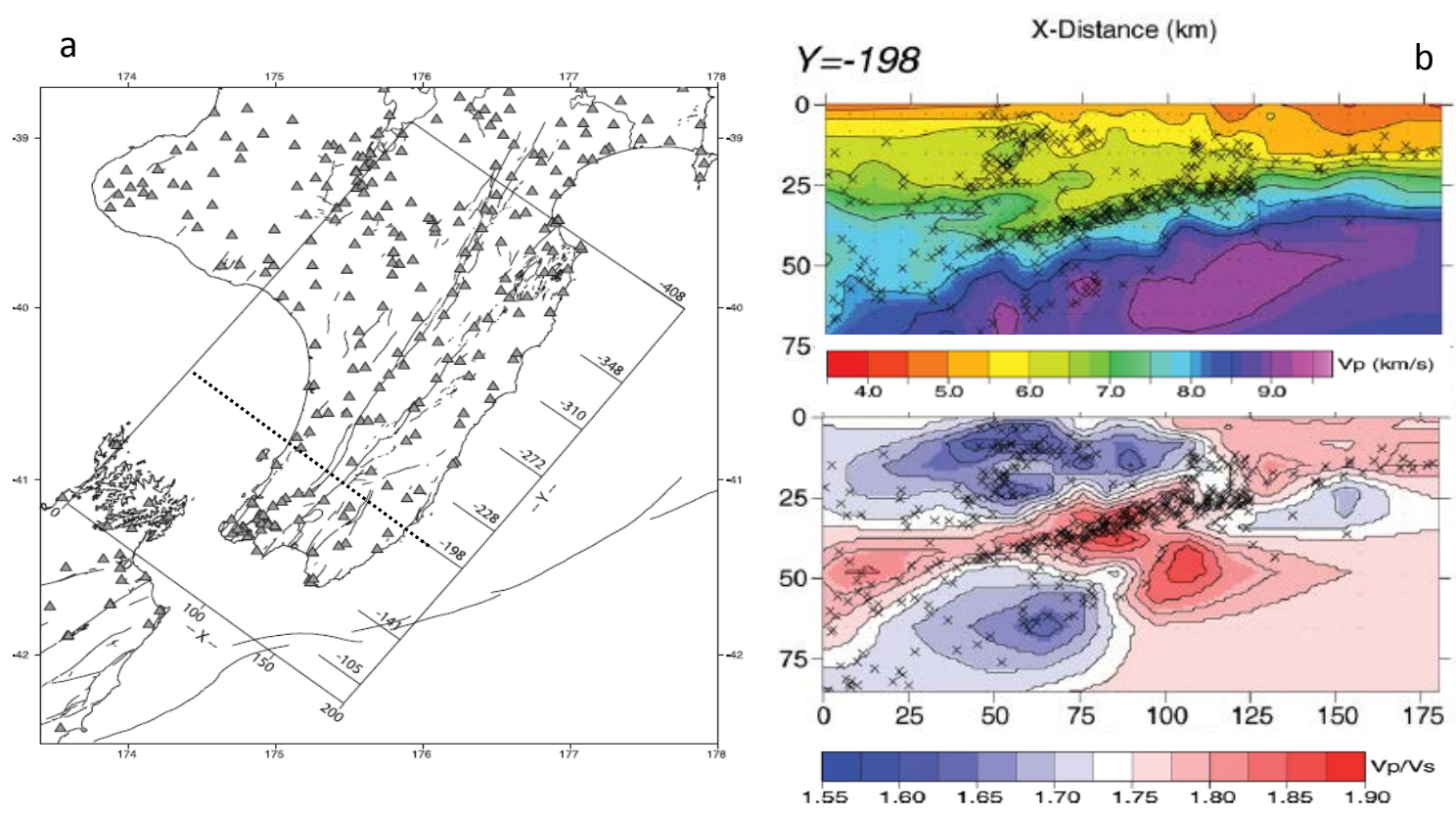

Figure 12 Image of Hikurangi Plate interface using local-earthquake tomography. a) Lower part of North Island New Zealand. Dotted black line shows position of transect at Y=-198. Triangles are seismic stations (permanent and temporary) used for the inversion. b) Gradational velocity inversion results across transect $Y=-198$. Both plots show final model SPI-D obtained by very fine grid inversion on the averaged model of four different inversions on fine grids. Black crosses are inversion hypocentres close to cross section. Top plot is Vp cross section; bottom plot is Vp/Vs cross section. (Figure from EberhartPhillips and Reyners, 2012)

The findings of Eberhart-Phillips and Reyners, (2012) reinforce those of Reyners and Eberhart-Phillips (2009) that fluids released by dehydration, and trapped on the plate interface by impermeable rock, result in high pore pressure in the layer at the top of the subducting slab, below the plate interface. The high $\mathrm{Vp} / \mathrm{Vs}$ may be indicative of an area of high pore pressure, with the overlying metamorphosed Rakaia terrane acting as a plausible impermeable layer. This area of high pore pressure appears to be related to those areas identified as having strong interseismic coupling. 


\subsection{SLOW SLIP EVENTS AND PLATE LOCKING}

Wallace et al., (2010) explain the term 'locked' (due to friction) as the state of the seismogenic zone between slip events; regardless of whether the slip event is instantaneous (such as a mega thrust earthquake) or one that occurs slowly, as seismic creep, over a longer period of time, called a 'slow slip event'; in this case the term 'locked' is interchangeable with the term coupled (with a co-efficient of 1, see Equation 1, Section 2.3).

\section{Slow earthquakes}

Slow earthquakes (e.g. Beroza and Ide, 2011) are low amplitude, nonimpulsive shaking events that occurs over hours, days or even weeks at a time. Slow slip events (SSE's) have been identified at subduction zones, such as the Nankai Trough and Cascadia (Beroza and Ide, 2011) as well as the Hikurangi margin (Douglas et al., 2005; McCaffrey et al., 2008). The seismic signals accompanying slow slip may be in the form of non-volcanic tremor (as distinct from volcanic tremor), a weak, persistent shaking, prominent at the $1-10 \mathrm{~Hz}$ frequency band (Beroza and Ide, 2011); and low frequency earthquakes (Gomberg et al., 2010; Beroza and Ide, 2011), with a characteristic low amplitude 'noisy' waveform showing a distinct first arrival across many stations (Beroza and Ide, 2011). SSE's also appear to show strong variances in their recurrence intervals, their duration, magnitude and depth (Wallace and Beavan, 2010).

New Zealand slow slip events have been observed only since 2002 (Douglas et al., 2005). McCaffrey et al., (2008) show that slow slip events at the Hikurangi margin have been identified at shallow depths of less than $15 \mathrm{~km}$, where estimated temperature may be as low as $100^{\circ} \mathrm{C}$ (unusually low compared to global SSE's). This indicates that temperature may not be the main control on these events. Also of interest is the depth of the transition from the portion of the plate that is locked and allows brittle stick-slip behaviour, to the portion that allows stable sliding.

SSE's on the Hikurangi margin have been identified as lasting from between six days and one-and-a-half years, with magnitudes between Mw 6.3-7.2 (Wallace and Beavan, 2010). The deepest, 25-60 km depth, longest duration and largest SSE's are identified as coming from the southern Hikurangi 
margin. These depths are close to those where there is a downdip transition from interseismic locking to aseismic creep, (Wallace and Beavan, 2010).

Slow slip events occurring on the southern Hikurangi margin are different in character from those recorded further north (Wallace and Beavan, 2010). An SSE, lasting 200 days, beneath the western coast of the Wellington region (Kapiti) was the first to be recorded in this area in 2003 (Beavan et al., 2007). This finding is very relevant to this project as some of the station locations used for the transect are located very close to the southern Hikurangi margin GPS station locations used to collect data for the slow slip study (Wallace and Beavan, 2010 a).

Wallace et al., (2010 b) identify the northern Hikurangi margin as 'one of the few places on earth where a subduction thrust fault dominated by steady aseismic creep occurs close to land'. The northern and central Hikurangi margin have more frequent, shallower, shorter duration and smaller magnitude SSE's than further south (Wallace and Beavan, 2010 a), indicating that there is likely both structural and physical controls on their occurrence, such as along strike variations in temperature, frictional properties and fluid properties (Wallace and Beavan, 2010).

The deep, westerly, downdip region (Figure 10 a) that is identified as having slow slip (also see Section 2.3) (Eberhart-Phillips and Reyners, 2012) that has exceeded $50 \mathrm{~mm}$ since 2002 correlates with areas where the Vp/Vs has a less abrupt gradient (Figure $10 \mathrm{~b}$ ). This is indicated on the figure by the $\mathrm{Vp} /$ Vs contours being spaced further apart (Figure $10 \mathrm{~b}$ ). This is in contrast to areas up-dip of the descending slab (to the east), associated with strong coupling, where the $\mathrm{Vp} / \mathrm{Vs}$ contours are closer, indicating a sharper velocity gradient. The area associated with strong coupling has the highest Vp/Vs (>1.85); the areas associated with slow slip still exhibits relatively high $\mathrm{Vp} / \mathrm{Vs}$, but it is the broader extent of the gradient (Eberhart-Phillips and Reyners, 2012) from low to high Vp/Vs that is indicative of the movement of fluids across the plate interface. Comparing the results of this thesis (see Chapter 8) with those of Eberhart-Phillips and Reyners', (2012) Y=-198 transect, the area associated with slow slip is mapped as being to the west of 
Kapiti Island); it is therefore unlikely to have been captured in my final CCP stacked image which has Kapiti Island as its most westerly extent . 


\section{CHAPTER 3}

\section{RECEIVER FUNCTION STUDIES}

\subsection{INTRODUCTION}

The receiver function technique has been used, and developed, by seismologists in diverse studies across the globe. The results of numerous global studies over the last thirty five years of research have assisted in analysing and interpreting geological structures beneath both a single seismic station and a line of closely spaced seismometers. The studies have all contributed to developing knowledge regarding the seismological structures related to subduction zones.

\subsection{DEVELOPMENT OF THE RECEIVER FUNCTION METHOD}

\subsubsection{CASCADIA SUBDUCTION ZONE}

The Cascadia subduction zone runs down the west coast of the American subcontinent, from Canada to northern California, separating the young, warm, Juan De Fuca plate from the North American plate. Receiver function studies in this area have been extensive. Early papers from studies in this region document the initial development of the receiver function technique.

Langston (1977) used converted P waves in an early receiver function study, to constrain a low velocity zone in the Corvallis and Puget Sound regions, at $45 \mathrm{~km}$ depth. Using just six earthquakes and one station, he concludes that using teleseismic earthquakes for direct time-domain modelling is a useful way to determine crust and upper mantle structure (Figure 13). He then developed the technique (Langston, 1979) to study structures under Mount Rainier, Washington. Using only one single station, but now with thirteen events, he constrained a high velocity contrast, dipping interface beneath the 
volcanic structures of Mount Rainier, interpreted to be the Moho. By 1988 Owens and Crosson (1988) investigated structures of less than $5 \mathrm{~km}$ depth, using data recorded at four seismic stations. They constrained the dip angle of a shallow velocity contact using receiver functions. Advances in technology over the following two decades allowed rapid progress to be made in the development of receiver function techniques by seismologists. An increase in the number of seismic stations, across wider areas, recording greater amounts of data, allowed further detail to be imaged and interpreted using the receiver function technique.

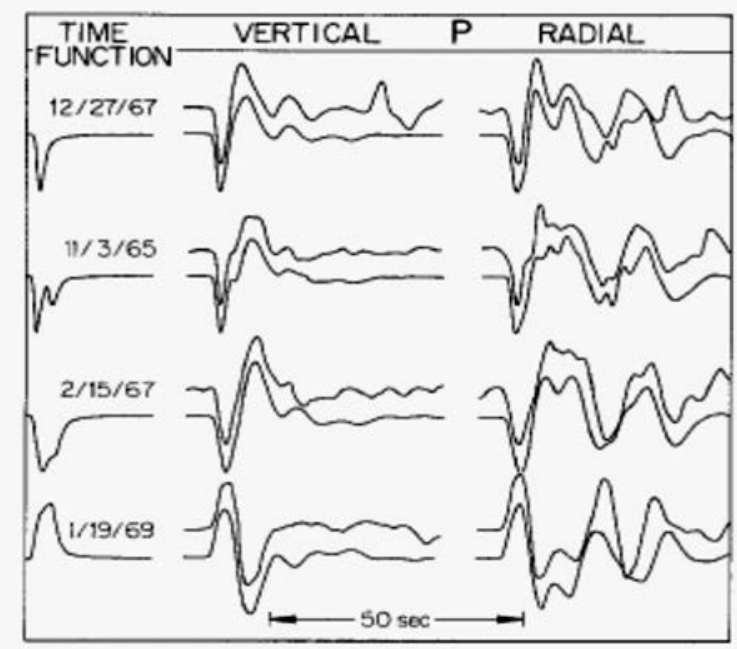

Figure 13 Example of early receiver function. Comparison of observed and synthetic final waveforms from four earthquakes for the horizontal and vertical P wave components. (Figure from Langston, 1977).

In 2009 Audet et al., used converted teleseismic P waves (receiver functions) to obtain evidence for hydration in the subducting crust of the Cascadia subduction zone. Anomalies with low shear wave velocity indicated areas of serpentinization. Observations of a negative velocity contrast at the top of the subducting oceanic crust together with a high Poisson's ratio (calculated from the abnormally high Vp/Vs ratios) within the subducting crust lead to the conclusion that the megathrust is a layer with low permeability; changing to one of higher permeability down dip. The up dip limit of overpressured oceanic crust was not constrained, but the downdip limit is around $35 \mathrm{~km}$ depth. Nikulin et al., (2009) use the multi-taper correlation method (Park and Levin, 2000) (the method used in this thesis) to compute $\mathrm{P}$ wave receiver functions for the Cascadia fore-arc along the North American margin in Oregon and Washington. Nikulin et al (2009) use data from eight 
permanent seismic stations, with between 72 and 600 events from each station to compute the receiver functions (Figure 14) (refer to Chapter 4 for explanation of receiver function methodology). The back azimuth and epicentral distance sweeps were compared to synthetic receiver functions (Figure 15), computed with a six layer velocity mode made using information from other studies of the same area.
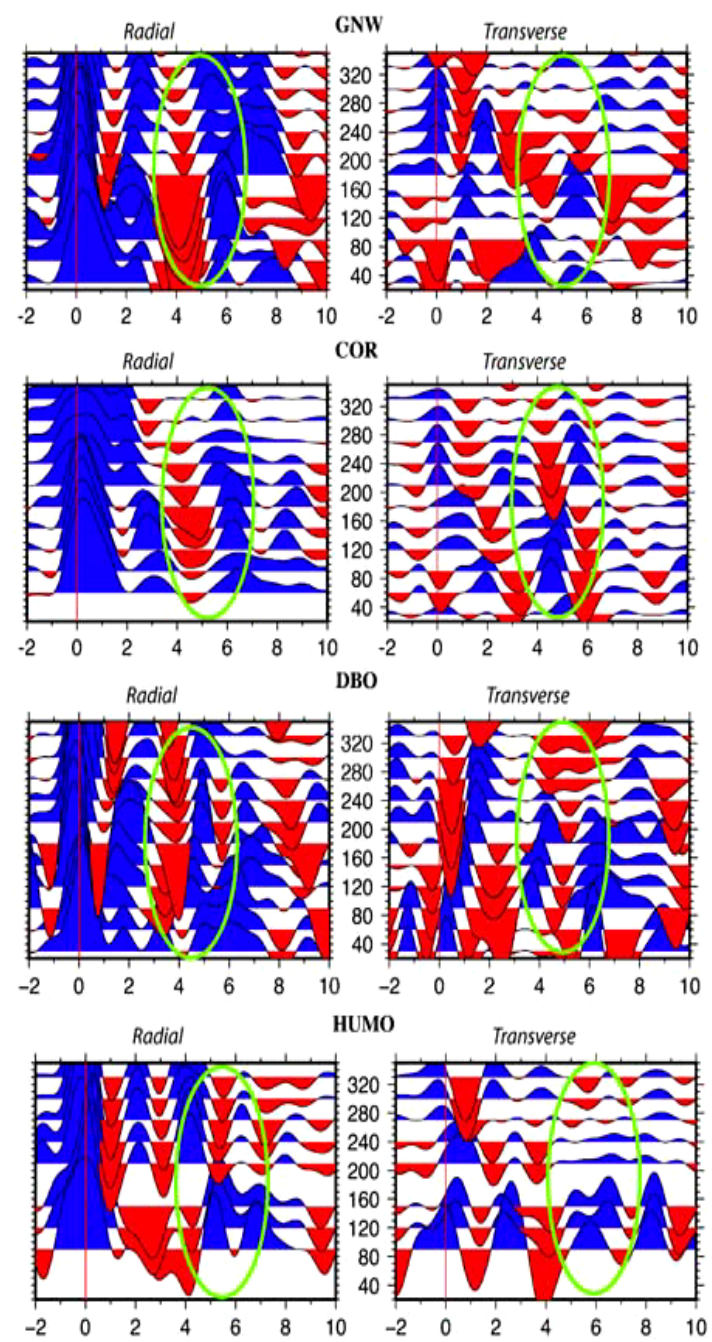

Figure 14 Back azimuth receiver function sweeps for four stations (GNW, COR, DBO, HUMO). RF's are limited to frequencies below $0.5 \mathrm{~Hz}$. Ovals mark areas of predicted times of converted phases associated with the top of the Juan De Fuca slab. (Figure from Nikulin et al., 2009).

Comparing the observed data with the synthetic receiver functions (see Chapter 7) allowed depths to the top of the subducting plate and deeper features associated with the subducted oceanic crust to be estimated. 


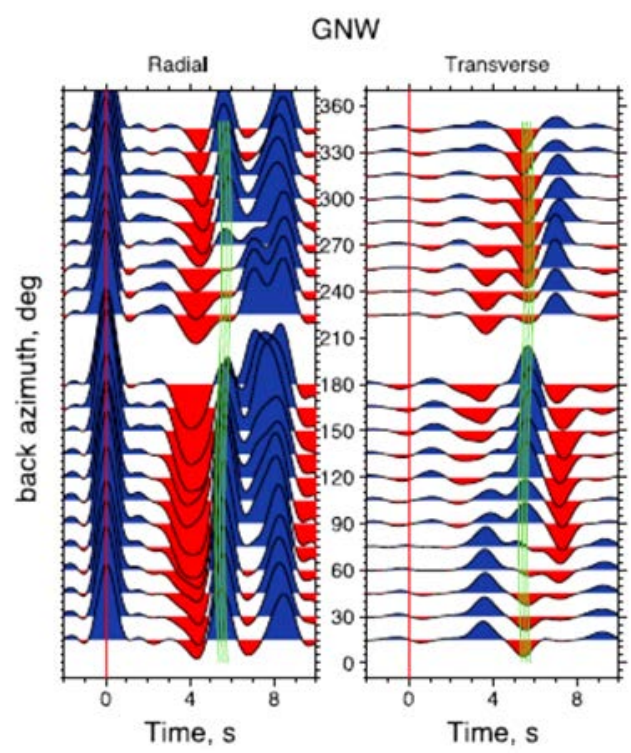

Figure 15 A back azimuth sweep of Receiver Functions computed from synthetic seismograms. (Figure from Nikulin et al, 2009).

Nikulin et al (2009) also found evidence in this region for an anisotropic, low velocity layer in the crust, that has been identified in other areas of the Cascadia megathrust (e.g. Audet et al., 2009) and a low velocity layer of serpentinite beneath one station (Figure 16).

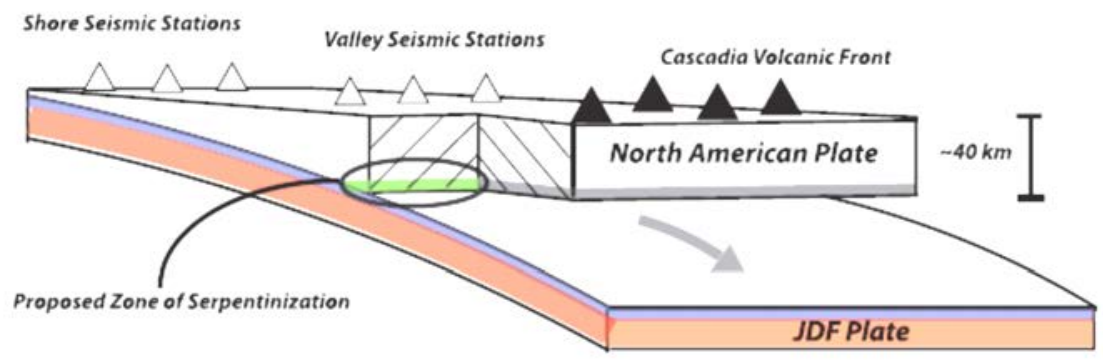

Figure 16 Overview of proposed finding in reference to regional tectonic setting. Zone of proposed serpentinization is shown as a green line below Valley Group stations inferred from RF signatures indicating lower seismic velocities, high Vp/Vs ratios and anisotropy. (Figure from Nikulin et al., 2009). 


\subsubsection{THE HIKURANGI SUBDUCTION ZONE NEW ZEALAND.}

Several studies have been published using receiver functions to investigate the Hikurangi subduction zone along the length of New Zealand. The following studies show how receiver function studies have contributed to the body of knowledge regarding the Hikurangi subduction zone.

Stuart et al., (1995) used nine three component seismometers in an ' $\mathrm{L}$ ' shaped array, arranged along strike and parallel with the dip direction of the subducting plate in the south of the North Island. The computed receiver functions indicated a high velocity layer, 8-10 km thick, above the cold fast lithosphere of the subducting plate. Observations by Stuart et al., (1995) regarding the microseismic noise contamination that dominates the broadband seismograms are interesting, as the issues regarding periodic noise contamination are challenging during the selection of suitable waveforms now, as then. Data collected as part of Stuart et al., (1995) Tararua Broadband array project is utilised in this thesis for stations LTW1, LTW2 and LTW3 (Figure 2 for station locations).

Savage, (1998) investigated the effects on receiver functions of crustal anisotropy and dipping boundaries using over 4 years of data from Geonet permanent station SNZO. SNZO is located in Wellington, but to the south of the study area for this thesis. In analysing the receiver function for the differing effects of dipping boundaries and anisotropy it is clear that there are visible differences to the patterns of both arrival times and amplitudes on both the transverse and radial receiver functions when stacked for back azimuth. In the case of both dipping boundaries and anisotropic layers the radial receiver functions are symmetric about a given back azimuth and the transverse receiver functions are asymmetric about the same back azimuth; the back azimuth acting as the axis of symmetry is that of the dip direction. In the case of dipping boundaries, on the transverse component, energy arrives at the time of the initial $\mathrm{P}$ phase, regardless of the depth of the dipping boundary; while as in the case of anisotropic material the energy arrives at the time of the initial P phase only when the anisotropy is present in the upper layer. For dipping layers symmetry is evident over a stack of $360^{\circ}$ of back azimuth. But to recognise anisotropy the periodicity is evident 
over $180^{\circ}$ of back azimuth. Both these symmetries are only evident on the transverse component stacks, not the radial.

Eberhart-Phillips and Reyners (1999) use converted S waves from local earthquakes to investigate the properties of subducted sediment at the shallow seismogenic zone of the subducting interface. The area of the study is the northeast Hikurangi margin of the Raukamara Peninsula, central North Island New Zealand. The high Vp/Vs zone at the plate interface was recognised by Reyners (1998), but to better constrain the layer thickness and resolve the character they use synthetics made with a variety of velocity models to compare to the observed data. Their results show that the plate interface has an overlying layer of low velocity (Vp 5.0-.535 km/s) material, $\sim 1-2 \mathrm{~km}$ thick. The authors state that it is a matter for debate as to the effect of subducted sediment on seismic coupling and the potential for large subduction thrust earthquakes. However two earthquakes that may be interpreted as subduction thrust earthquakes have occurred on the plate interface in this area, both in 1947. As the subducted sediment is likely to be too weak to allow such events, the best explanation is that they nucleated at subducted seamounts. Both the events occurred near large indentations in the margin that are interpreted as being from the impact of subducting seamounts. Eberhart-Phillips and Reyners (1999) show that the presence, or absence, alone of a slow velocity layer at the plate interface is not a complete explanation for the occurrence, or non-occurrence, of great earthquakes on the Hikurangi margin.

Horspool et al., (2006) use a joint inversion of receiver functions and surface wave velocities to investigate shear wave velocity structure in the northwestern area of New Zealand. The technique of using a joint inversion reduces the limitations inherent in both methods. Receiver functions alone are non-unique and give information solely regarding velocity contrasts between layers. Surface wave inversions complement the receiver function technique as they are responsive to average shear velocity with depth. The non-uniqueness problem of receiver function inversion refers to the fact that there is a velocity depth trade-off; a thick fast layer causes a similar response 
on the receiver function stack as a thin slow layer. In using an additional technique that constrains the velocity this problem is negated.

Savage et al., (2007) used P wave receiver functions from SNZO station (see Savage, 1998) located just north of the Cook Strait, sitiated to the south of the stations used in this thesis. Also used was data from Stuart et al (1995) collected from two L-shaped temporary arrays, The study examined both velocity structure and anisotropy.

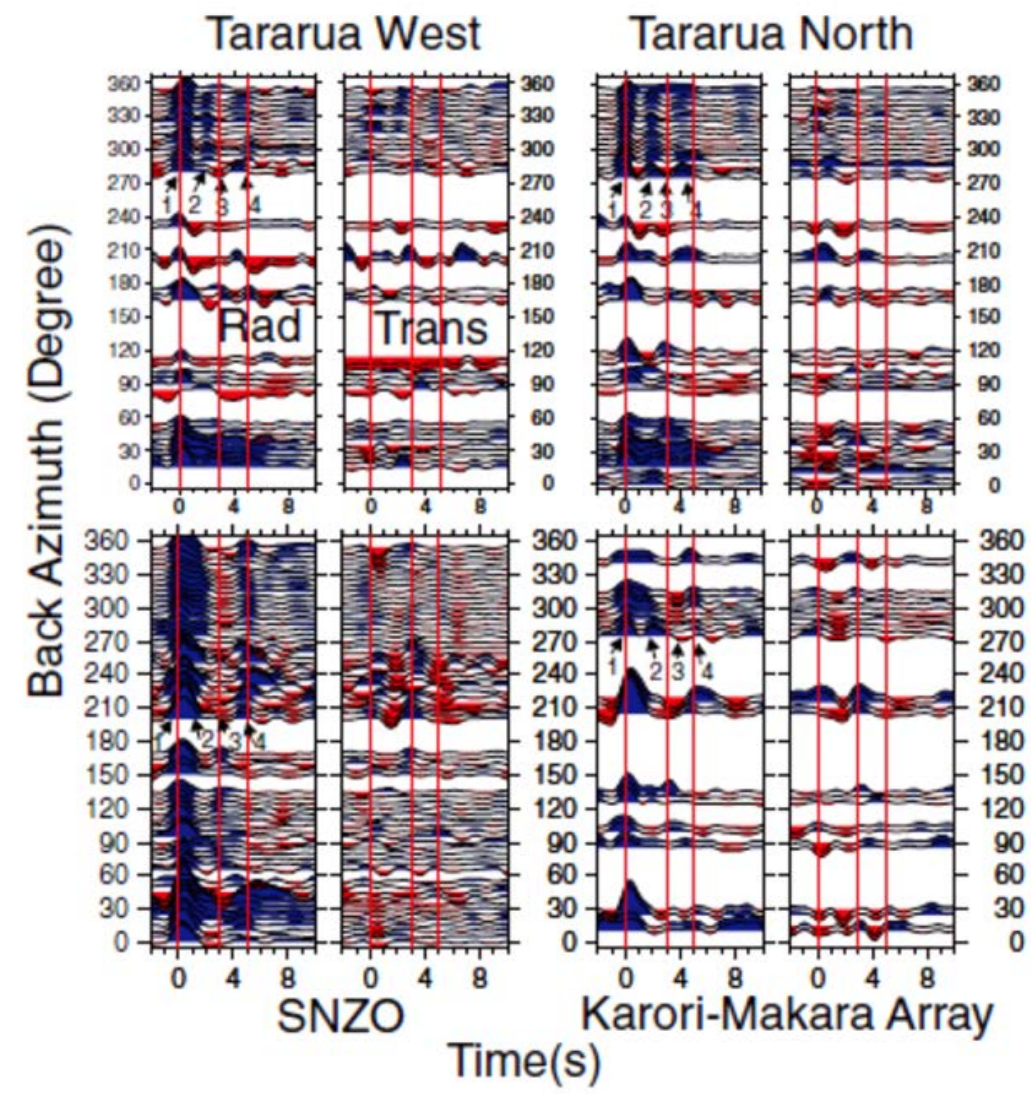

Figure 17 Receiver functions plotted as a function of back azimuth. Earthquakes of all epicentral distances are included. Plots are for four stations, (Tararua West; Tararua North; SNZO; Karori-Makara Array) each station pair has the radial component sweep on the left and the transverse component on the right. The vertical red lines labelled 1,2,3,4 are to enable comparison. (Figure from Savage et al., 2007).

Receiver functions were modelled using the multi-taper correlation method (Park and Levin, 2000), which was identified as being particularly useful in the noisy seismological environment of New Zealand. Savage et al (2007) examined several frequency bands but found that high frequencies, while providing coherent energy across most backazimuths at a given station were not as well 
correlated across stations. In order to concentrate on the main structures and to simplify analysis all results were presented with a cut-off frequency of $1 \mathrm{~Hz}$. On the radial receiver functions the strength of the direct arrival labelled 1 (Figure 17) varies with backazimuth because of the dip of the slab.

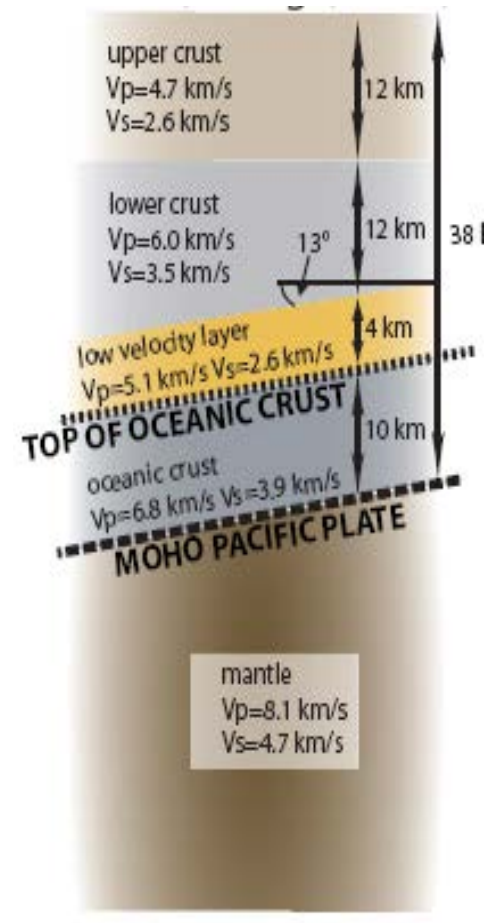

Figure 18 Schematic of best fit velocity and depth model for Tararua array summarising finding from Savage et al (2007). (Figure from Ewig, 2009).

Savage (2007) found four arrivals consistent across four stations (Figure 17). The arrivals labelled 1, 2, 3, 4 in Figure 17 correlate with the layers in Figure 18; arrival 2 being at $12 \mathrm{~km}$ depth; arrival 3 at $24 \mathrm{~km}$ depth, the top of the interpreted low velocity layer at the top of the slab; arrival 4 being the bottom of the $4 \mathrm{~km}$ thick low velocity layer lying at the top of the subducting oceanic crust. Bannister et al., (2007) also imaged the Hikurangi subduction zone using teleseismic receiver functions across the central North Island of New Zealand, an area that includes the Taupo Volcanic Zone (Figure 19). They used earthquake data from earthquakes with epicentral distances of between $25^{\circ}$ and $100^{\circ}$, and magnitudes greater than 5.5 and less than 7.5, recorded on thirty two broad-band seismometers and 42 short period seismometers. Using the multiple-taper correlation method (Park and Levin 2000) the migrated receiver functions show a northwest dipping low shear wave feature down to $60 \mathrm{~km}$ depth, interpreted as the subducted crust of the 
Pacific Plate. The final migration (Figure 19) shows a low velocity (negative amplitude) layer (LVL) above the subducting crust that is interpreted as representing crustal fluids that have been released during dehydration of the crust and mantle of the subducted plate. Fluid in the forearc mantle wedge may lead to serpentinzation of the mantle wedge, with an associated decrease in seismic velocity and density.
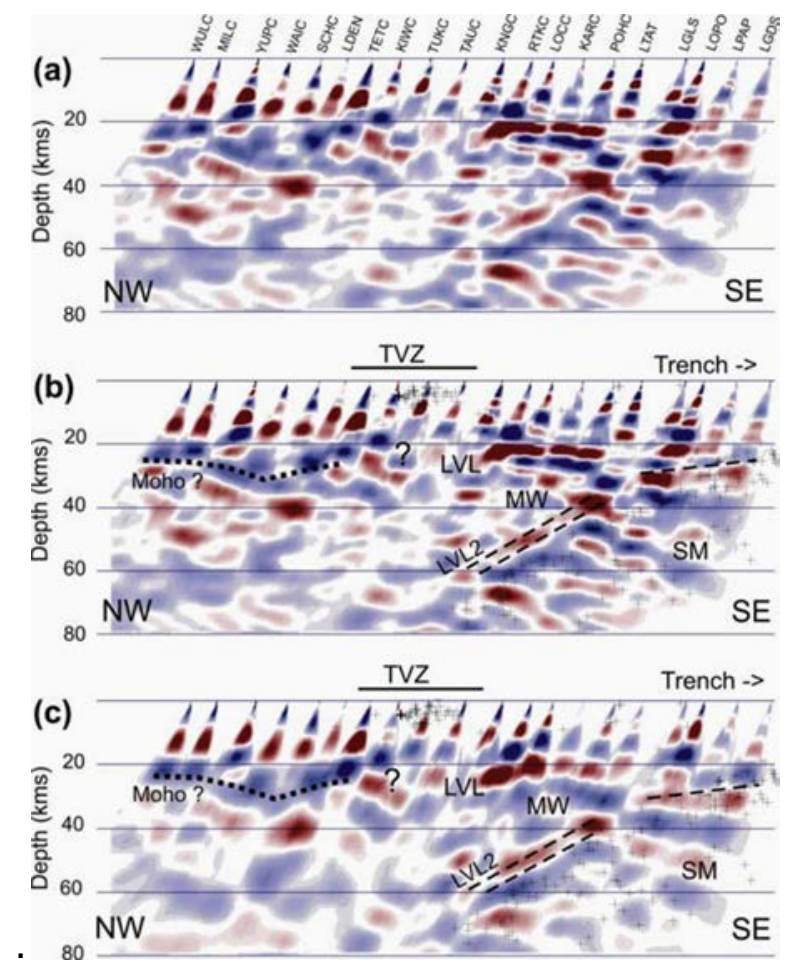

Figure 19 Image of the Hikurangi subduction zone using teleseismic receiver functions. Migration of receiver function bins using RF's from events with backazimuths from 280-340 . a) Shows $2 \mathrm{~Hz}$ high frequency cut off. Positive amplitudes are shown in blue and negative in red. Station names are a the top of the profile. b) is as a) but with interpretation overlain. LVL is low velocity layer; interpreted as crustal fluid; LVL2 is subducted crust; MW is forearc mantle wedge; SM is subducted mantle. c) is as a) but with a $1 \mathrm{~Hz}$ high frequency cut-off. (Figure from Bannister et al., 2007).

(Boyd et al., 2007) investigate subduction zone structures of the northern South Island and the southern North Island (including the region of interest in this study) using teleseismic receiver functions from broadband stations. Velocity impedances in the upper mantle are imaged using common conversion point (CCP) stacking. Boyd et al., (2007) also employ synthetic receiver functions to assist in distinguishing between the direct arrivals and multiples from the slab and crustal structures. The receiver functions are computed in the time domain, using the codes of Ligorria and Ammon (1999), and the CCP stacking method of Duecker and Sheehan (1998), 
together with two dimensional Kirchoff migration (Sheehan et al., 2000). The imaged transect lies along the southern Cook Strait, crossing the very northern tip of the South Island. A low velocity transition is imaged at the top of the subducting slab interface; the slab dipping steeply to the northwest. Seismogenic zones correlate with the low velocity layer. There are crustal discontinuities at $\sim 20 \mathrm{~km}$ and $\sim 35 \mathrm{~km}$ depth, which as well as being consistent with previous studies, may indicate lower crustal anisotropy.

Ewig (2009) used receiver functions together with $3 \mathrm{D}$ gravity modelling to investigate the crustal structure of the South Wanganui Basin situated in the west of the lower North Island of New Zealand; the western part of the transect used in this thesis correlates with Ewig's (2009) study area. Receiver functions were used primarily to help constrain the crustal thickness of the subducting slab beneath the South Wanganui Basin. Ewig (2009) used the multi-taper correlation method (Park and Levin, 2000) together with H-k stacking (Zhu and Kanamori, 2000) and common conversion point (CCP) stacking to produce an image of the subducting slab. He used data from four onshore stations, N6, W1, W2, W3, (east to west) that correspond to Savage's (2007) east-west Tararua stations, and with stations LTN6 (equivalent to N6 from Ewig, 2009), LTW1 (equivalent to W1 from Ewig, 2009), LTW2 (equivalent to W2 from Ewig, 2009) and LTW3 (equivalent to W3 from Ewig, 2009) used in this thesis. Ewig (2009) also analysed data from station KIW, offshore on Kapiti Island; this is the same station as used in this thesis, though the data set is from a different time period. The furthest west station used by Ewig (2009) was DUWZ, on Durville Island which lies offshore from the northern tip of the South Island of New Zealand. Data was band pass filtered between 0.5 and $2.0 \mathrm{~Hz}$ before calculating the receiver functions. All receiver functions were calculated with the cut-off frequency set to $1 \mathrm{~Hz}$. The CCP stack was made using the velocity model TARA, based on the forward modelling of Savage (2007), illustrated in Figure 20.

The receiver function analysis shows that the crust of the subducting Pacific plate beneath the stations is unusually thick, at around $10 \mathrm{~km}$, for oceanic crust (Figure 20). The receiver function results correlate well with those from the 3-D gravity modeling. The receiver function analysis also revealed a low velocity 
layer, up to $6 \mathrm{~km}$ thick, at the top of the subducting slab. This is interpreted as a zone of crushed material with subducted sediments. A Moho of $~ 39.5 \mathrm{~km}$ depth is proposed beneath station DUWZ.

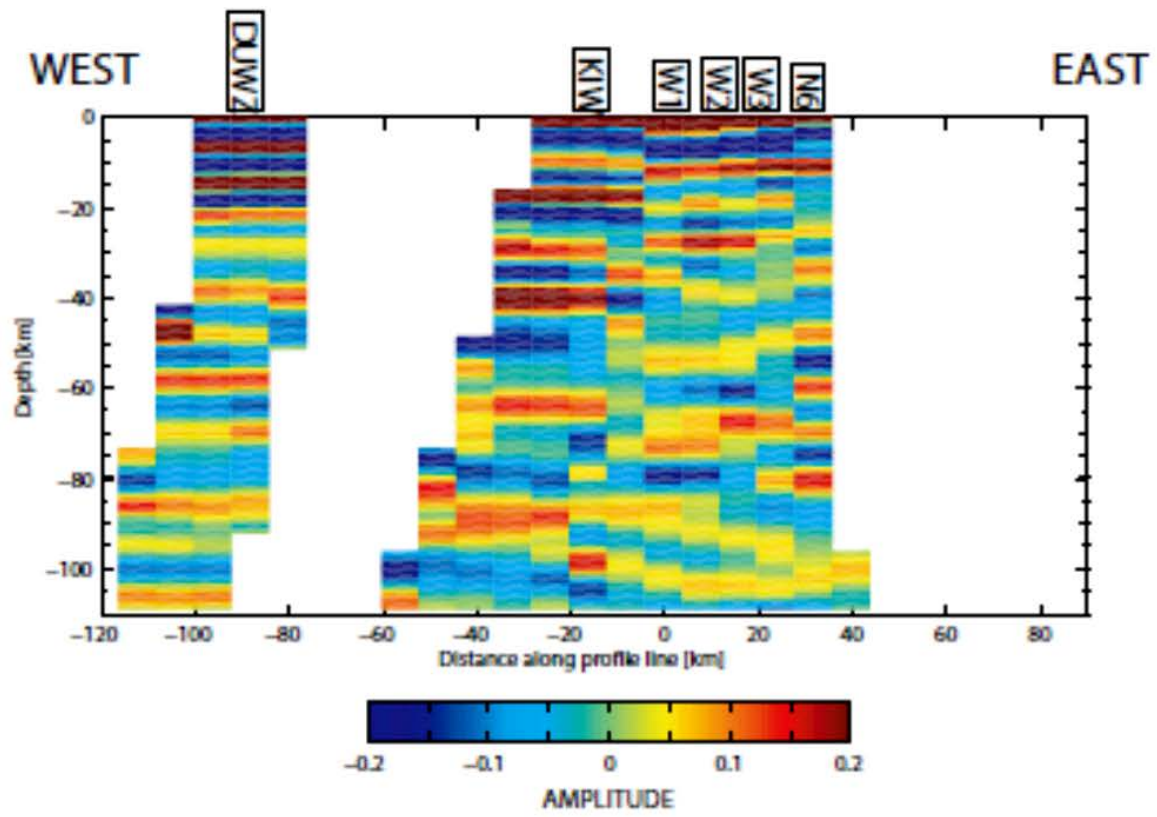

(a) CCP stack

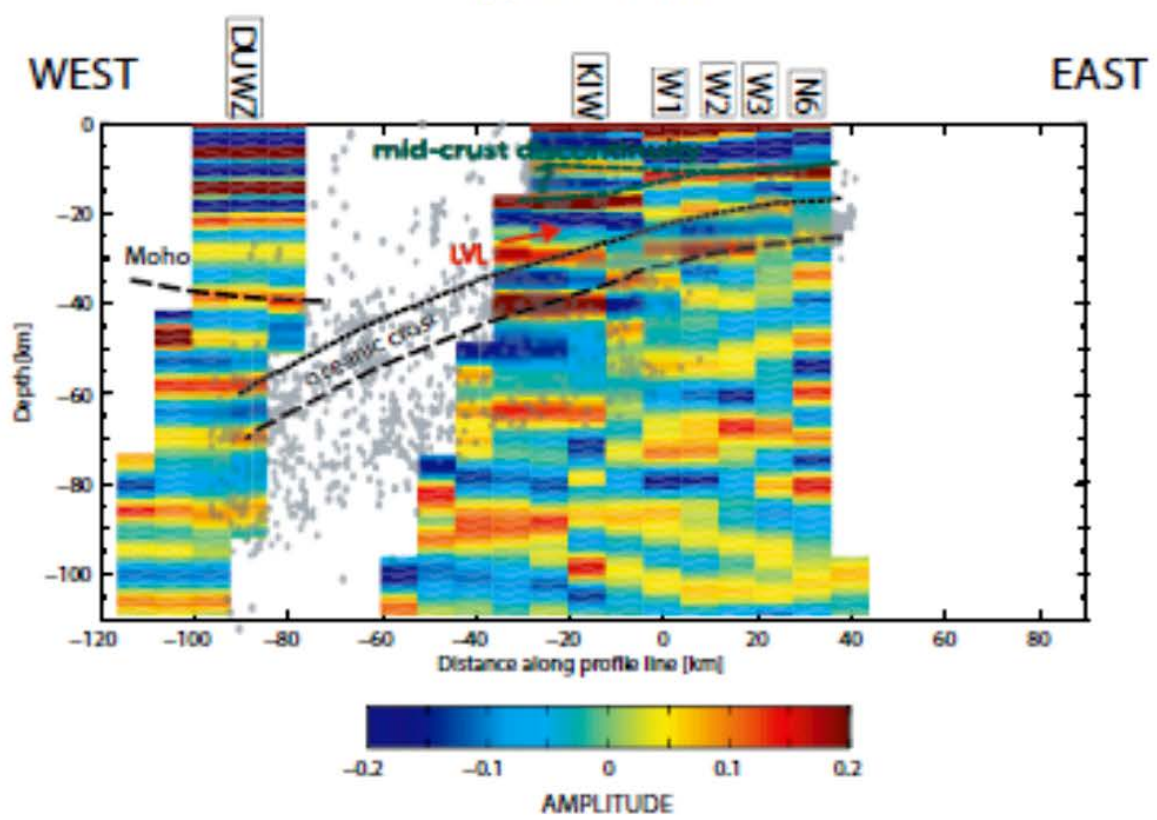

(b) CCPstack+interpretation+seismicity

Figure 20 CCP stack at $1 \mathrm{~Hz}$ using velocity model TARA (Savage, 2007) for stations along an east west profile that is the same as that used in this thesis with the exception of station DUWZ (the most westerly). Station W1 is the origin. a) is the uninterpreted stack. b) is the interpreted stack showing overlain seismicity (grey dots showing earthquakes after 1990); the black dashed line is the Moho; the dotted black line shows the top of the subducting crust. Green line shows midcrustal discontinuity. The mid crustal low velocity layer is labelled LVL. (Figure from Ewig, 2009). 


\subsection{SUMMARY}

Receiver function studies have been used to investigate a variety of structural features associated with subduction zones around the globe. As well as extensive investigations of the Cascadia (see Section 3.2.1) and Hikurangi margin (see Section 3.2.2) subduction zones, there have been numerous published receiver function studies of subduction zones around the globe, such as the Japan triple junction complex subduction zone (e.g. Niu et al, 2005; Kawakatsu and Wadata 2007; Wirth and Long, 2012); the structures beneath the Himalayas (e.g. Schulte-Peklum et al, 2005; Kumar et al., 2006) and the Nazca subduction zone of the central Andes (Yuan et al, 2000).

Receiver function methodology has become more sophisticated over the last two decades; the multiple-taper correlation method (Park and Levin, 2000) has become a popular method to compute robust and numerically stable receiver functions (see Chapter 4). Investigations are using increasing amounts of data, from ever more ambitious, wide ranging, seismological experiments; responding to the need for information regarding earthquake risk to the population. The developments in processing techniques, and data collection, allows the production of clearer and less ambiguous results regarding velocity impedance structures, and their relationship to seismogenic process.

It is clear from the studies above, that using receiver function methods in conjunction with both other imaging methods, such as CCP stacking, and a priori information, from different passive and active techniques such as tomography and seismic reflection, leads to excellent constraint of the resulting models and furthers our understanding of subduction processes. 


\section{CHAPTER 4.}

\section{RECEIVER FUNCTION METHOD}

\subsection{INTRODUCTION TO ISOTROPIC P WAVE RECEIVER FUNCTIONS}

Receiver functions analysis is a method that has been widely used by seismologists in the investigation of crust and upper mantle structure (e.g. Langston 1979; Owens and Zandt 1985; Duecker and Sheehan 1997; Zhu 1999; Niu 2005). The appeal of the method lies in the relative simplicity of the underlying theory, and the method's economic advantages of using teleseismic earthquakes as an energy source. There is also an advantage over controlled source methods in that the wave energy is approaching the seismometer from depth and therefore sampling deep structures. The interpretation of the deconvolved $\mathrm{P}$ to $\mathrm{S}$ wave conversions (the 'receiver functions') allows inferences to be made regarding the velocity structure and depth of interfaces directly below the receiver. However the inherent nonuniqueness of the solution, due to a velocity-depth trade-off, requires the use of a priori information to constrain the results (Ammon 1991). Improved computing methods have allowed the development of robust and reliable methods, such as the multi-taper correlation method (Park and Levin 2000) used in this project.

\subsection{THEORY}

Methods of computing and interpreting receiver functions have developed over the last three decades (e.g. Langston 1977; Park 1987; Randall 1989; Ammon 1991; Liggoria and Ammon 1999; Park and Levin 2000) (see 
Chapter 3) along with ever more sophisticated computing techniques, but the underlying physical principles remain the same.

Receiver functions are computed using teleseismic (greater than $1000 \mathrm{~km}$ ) earthquakes as a passive source. Data is collected on three component seismometers. The three components of ground motion are recorded using a vertical (Z) and two orthogonal horizontal (N, E) ground motion sensors over a wide frequency range. The signal recorded by the seismometer is a function of source, earth and instrument effects.

Broadband sensors utilised in this study record data over a wide maximum frequency range of between $0.016 \mathrm{~Hz}$ and $50 \mathrm{~Hz}$. However data recorded on three component instruments over a much narrower frequency band on short period sensors, (e.g. 1, 2 or $4.5 \mathrm{~Hz}$, depending on the individual instruments), still provides seismic data suitable for computing receiver functions.

\subsection{WAVE CONVERSION}

$\mathrm{P}$ wave receiver functions are calculated to take advantage of the phenomenon of wave conversion, (described by Burdick and Langston, 1977) (Figure 21).

At any interface a wave is refracted or reflected, and will produce converted wave types. In the case of upcoming P waves in an isotropic medium, as they interact with a seismic discontinuity, or impedance contrast, below the receiver, they will polarize to produce $\mathrm{P}$ to SV converted phases (Figure 21). In any media a $\mathrm{P}$ wave travels faster than an $\mathrm{S}$ wave, this difference in velocity between the two wave types results in a measurable time delay between the two arrivals at the receiver.

S wave polarization may be described as either SV, where the particle displacement is in the vertical plane, or SH for horizontally polarized waves (Stein and Wysession 2003). Both SV and SH have displacements that are perpendicular to the direction of wave propagation. 
$\mathrm{P}$ and SV waves are coupled with each other as they interact with a velocity impedance boundary. The four seismic modes produced from the interaction with the velocity structure are both reflected and refracted $\mathrm{P}$ and Ps waves (Fig 2).

The theory is described by Snell's law, described by equation 2, which states that the ratio of the sine of the angle of incidence $\left(i_{1}\right)$ (Figure 21) to the sine of the angle of refraction $\left(i_{2}{ }^{\prime}\right)$ is a constant for any two isotropic media that are divided by a common interface.

$$
\frac{\alpha_{1}}{\sin i_{1}}=\frac{\beta_{1}}{\sin j_{1}}=\frac{\alpha_{2}}{\sin i_{2}}=\frac{\beta_{2}}{\sin j_{2}}
$$

Equation 2 (Stein and Wysession, 2003).

Snell's law also indicates that a $\mathrm{P}$ wave incident on an interface will be reflected and refracted partly as a P wave and partly as an SV wave (Stein and Wysession, 2003).

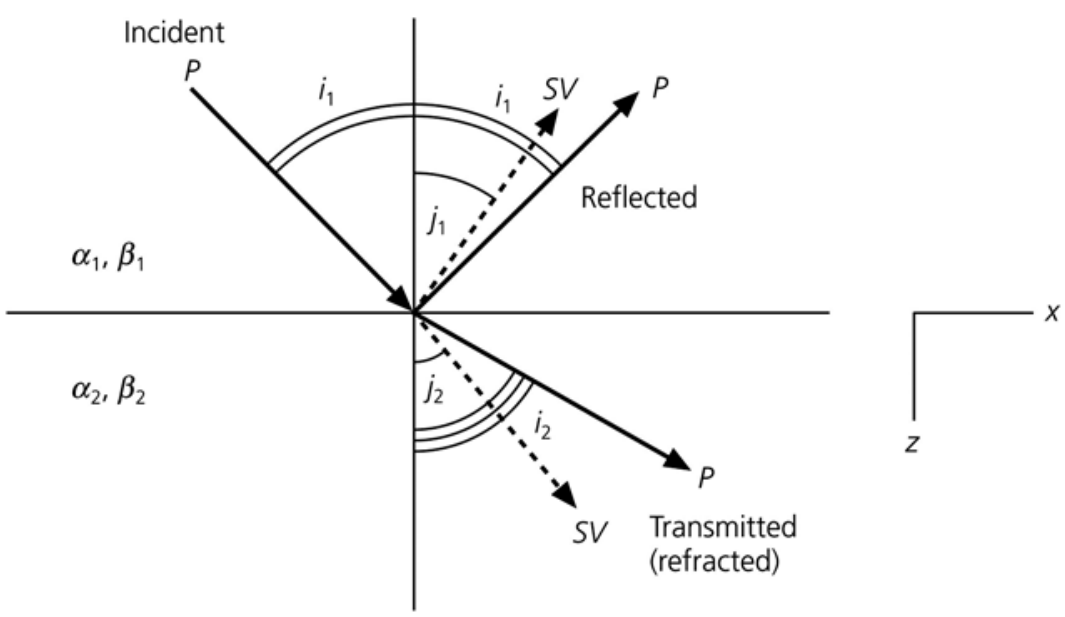

Figure 21 Wave conversion of $P$ wave incident on seismic velocity boundary.

Following Snell's law for waves propagating into a higher velocity medium. The incoming $\mathrm{P}$ wave generates transmitted and reflected $\mathrm{P}$ and $\mathrm{SV}$ waves. The reflected $\mathrm{P}$ wave has the same incident angle $\boldsymbol{i}_{1}$, as the incoming $\mathrm{P}$ wave. Because in each medium the $\mathrm{P}$ wave velocity is greater than the $\mathrm{S}$ wave velocity $\boldsymbol{j}_{1}<\boldsymbol{i}_{1}$ and $\boldsymbol{j}_{2}<\boldsymbol{i}_{2}$ (Figure from Stein and Wysession, 2003).

The amount of the wave that is reflected and refracted as transmitted and converted phases depends on two things; the incident angle of the plane 
wave to the impedance contrast, and the velocity contrast of the two media above and below the interface .

\subsection{USING TELESEISMS}

Teleseismic earthquakes are used for two reasons. The Ps conversions are relatively small and can be 'washed out' (Burdick and Langston, 1977) by the reaction of the earth to the stronger direct arrival. This effect is negated by using teleseisms, due to increasing attenuation and time delay between the phases over distance.

\subsection{ROTATION OF THE DATA}

Three component seismometers are usually positioned in the field so that the horizontal components are aligned with geographic (grid) North-South and East-West respectively*.

The SH and SV polarizations of the incoming teleseismic wave-train will be unlikely to correspond to the geographically aligned horizontal components of the seismometer. To maximise the signal the data is rotated during data processing. The horizontal projection of the SV displacement is called the radial direction. The orthogonal direction, corresponding to the $\mathrm{SH}$ displacement, is called transverse direction (Figure 22). When processing data for this project, the rotation was done after the data was 'picked' to mark the $\mathrm{P}$ wave on the vertical component. The rotation has the effect of separating the SV and $\mathrm{SH}$ waves. In the case of flat isotropic layers the transverse component will have little energy (Stein and Wysession, 2003).

\footnotetext{
* Account must be taken of the local magnetic declination, when using a magnetic compass to orientate the seismometer. In the study area, the lower North Island of New Zealand, the declination is $22^{\circ} \mathrm{W}$ of magnetic North. The instrument must also be levelled to horizontal. Any mis-orientation of sensors will have an effect and should be corrected during data processing.
} 


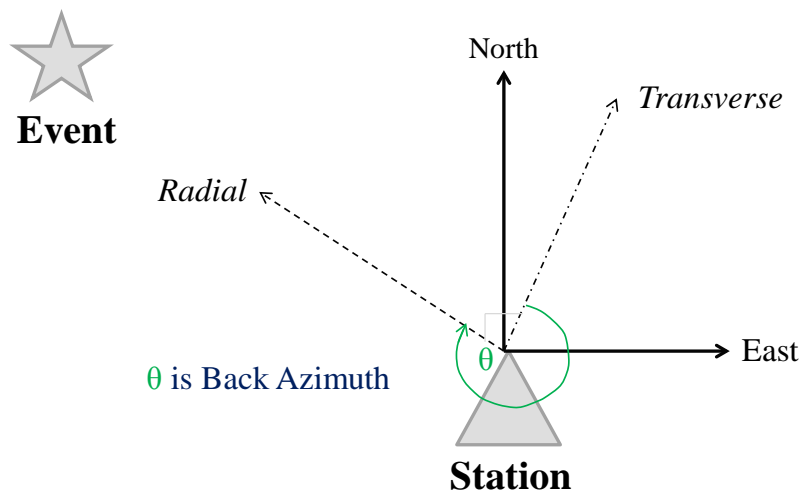

Figure 22 Showing rotation to radial and transverse components through the Back Azimuth.

The radial and transverse component is deconvolved from the vertical, having the effect of isolating the response of the crust and upper mantle directly below the receiver. It is this deconvolved radial and transverse element that is called the receiver function.

\subsection{Data Sampling to CREate a Single Station ReCEIVER Function STACK}

Receiver functions calculated from a single source event are unlikely to provide enough signal for detailed interpretation (e.g. Langston, 1977). The results from several teleseismic earthquakes, with arrivals from a range of back azimuths, may be collated and stacked for each receiver (e.g. Savage 2007). This allows the crust and upper mantle velocity structure to be inferred for the geological structures directly below the receiver. The amplitude of the receiver function depends on the incidence angle of the upcoming wave, and the size of the velocity contrast at the interface (Liggoria and Ammon, 1999). 

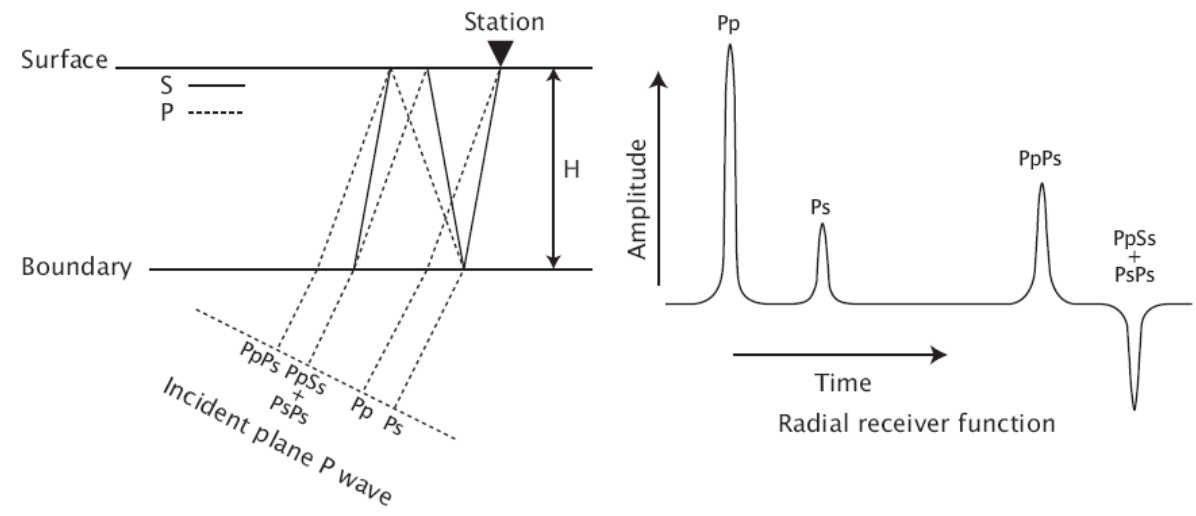

Figure 23 Illustrating raypaths for one incoming P wave phases and four of it's multiples, PpPs etc.

(Except for the first letter that is always capital, lower case letters denote an upcoming wave, capital letters denotes the down going wave). The top of the diagram shows receiver functions for these phases. (Figure after Ammon, 1991).

The depth and lateral extent of velocity structure that is sampled beneath a single receiver function stack is dependent on the depth of the velocity contrast, the time window of signal that is processed, and the signal to noise ratio.

Figure 24 shows the geometry of the ray path of a Ps converted mode and one multiple (PpPmp, presuming that the interface is the mantle), travelling through the top crustal layer. Though the PpPmp multiple is not often used in modelling (http://eqseis.geosc.psu.edu/ cammon/HTML/RftnDocs/rftn01.html) it does give a useful guide to the lateral limit of what may be modelled by the stacked receiver functions beneath a single station.

Teleseismic earthquakes are usually (but not exclusively) used as a source because they have a nearly vertical incident angle. However depending upon the actual incident angle there will be an amount of horizontal offset at depth; the amount of offset dictates the location of the material that is sampled by the receiver function, described by Snell's Law. The three dimensional volume that is sampled beneath a single station is an approximate 'cone' shape. The amount of material that is sampled in three dimensions is dictated not only by how much signa is analysed but also the 
range of back azimuths of the incoming source event, the dip of the interface and the depth of the deepest interface of interest. Figure 24 shows the ray paths of a one dimensional example and one multiple PpPmp. The lateral extent sampled by the multiple reverberation PpPmp (using ' $m$ ' assuming that the interface is the moho) averages the structure over a lateral distance that is close to three times the distance Xp (Figure 24).

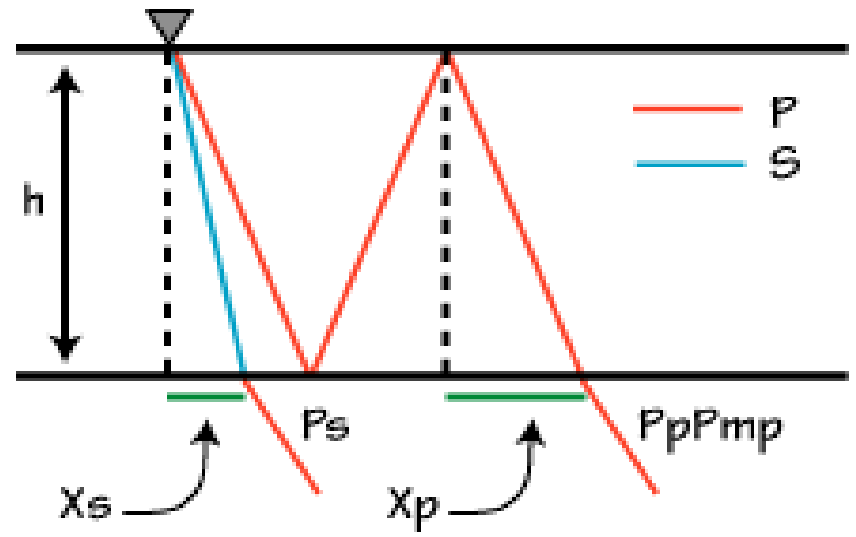

Figure 24 Ray paths of Ps converted mode and its Ppmp multiple.

Relationship to the lateral extent (Xs and Xp) of data sampled beneath a single station.

Figure from: http://eqseis.geosc.psu.edu/ cammon/HTML/RftnDocs/rftn01.html

For the distances Xs and Xp (Fig 16) Snell's Law states that:

$X s=h^{*} \tan \left(\operatorname{asin}\left(p^{*} V s\right)\right)$

$X p=h^{*} \tan \left(a \sin \left(p^{*} V p\right)\right)$

Equation 3 (a and b)

(http://eqseis.geosc.psu.edu/ cammon/HTML/RftnDocs/rftn01.html)

where $\mathrm{h}$ is the layer thickness; $\mathrm{p}$ is the ray parameter; $\mathrm{Vp}$ is the $\mathrm{P}$ wave velocity, Vs is the S wave velocity. Studying the Ps converted mode, using earthquakes from a range of different azimuth, can provide good lateral resolution of the crust mantle transition because of its close sampling beneath the seismometer. 
The term 'piercing point' describes the point at depth (mapped at the surface) where the ray pierces the interface (see Results Common Conversion Point Stacks. Piercing Points). The offset distance of the piercing point is dependent upon the ray parameter, the depth of the interface and the velocity of the wave as it travels between the boundary and the receiver.

The location of the piercing point for the offset $x$ is calculated using the equation:

$$
x=\frac{{ }^{2} V_{s} p}{\sqrt{1-\square V_{s}^{2} p^{2}}}
$$

Equation 4

Where $\mathrm{z}$ is the depth, and $V_{S}$ is the average $\mathrm{S}$ wave velocity between the interface and the receiver.

\subsection{INTERPRETATION OF RECEIVER FUNCTIONS}

For interpretation of the velocity structures modelled by the receiver functions it is necessary to distinguish between the direct arrival, the converted wave and its multiples.

\subsubsection{MOVEOUT, CONVERTED PHASES AND MULTIPLES}

The time delay (or moveout), observed on the receiver function stack, between direct arrivals (P) and their converted phases (Ps) decreases with increasing epicentral distance; whereas, in the case of multiple reverberations, the moveout increases with increasing epicentral distance.

This may appear counterintuitive, but with increasing epicentral distance ( $\theta 2$ in Figure 25) the upcoming wave arrives at a steeper angle (a smaller angle of incidence). (see Fig 17), spending less time in the (slower) crust and more time in the (faster) mantle, as does the following Ps converted phase, resulting in less of a time delay between the two.

However in the case of their multiple reverberations, they create a longer path in the crustal material, resulting in greater moveout with increasing epicentral distance.

But if the epicentral distance is shorter ( $\theta 1$ in Figure 25), (and the incident angle larger, (see inset) the direct arrivals and the following converted Ps 
phase spend longer time in the (slower) crust, (and little time in the faster mantle), resulting in a longer delay time (moveout) between these two phases (Figure 26 b). However (Figure 26 b) the multiples have to travel a shorter path and the relative time difference (from direct arrival P) is shorter, resulting in a smaller moveout.

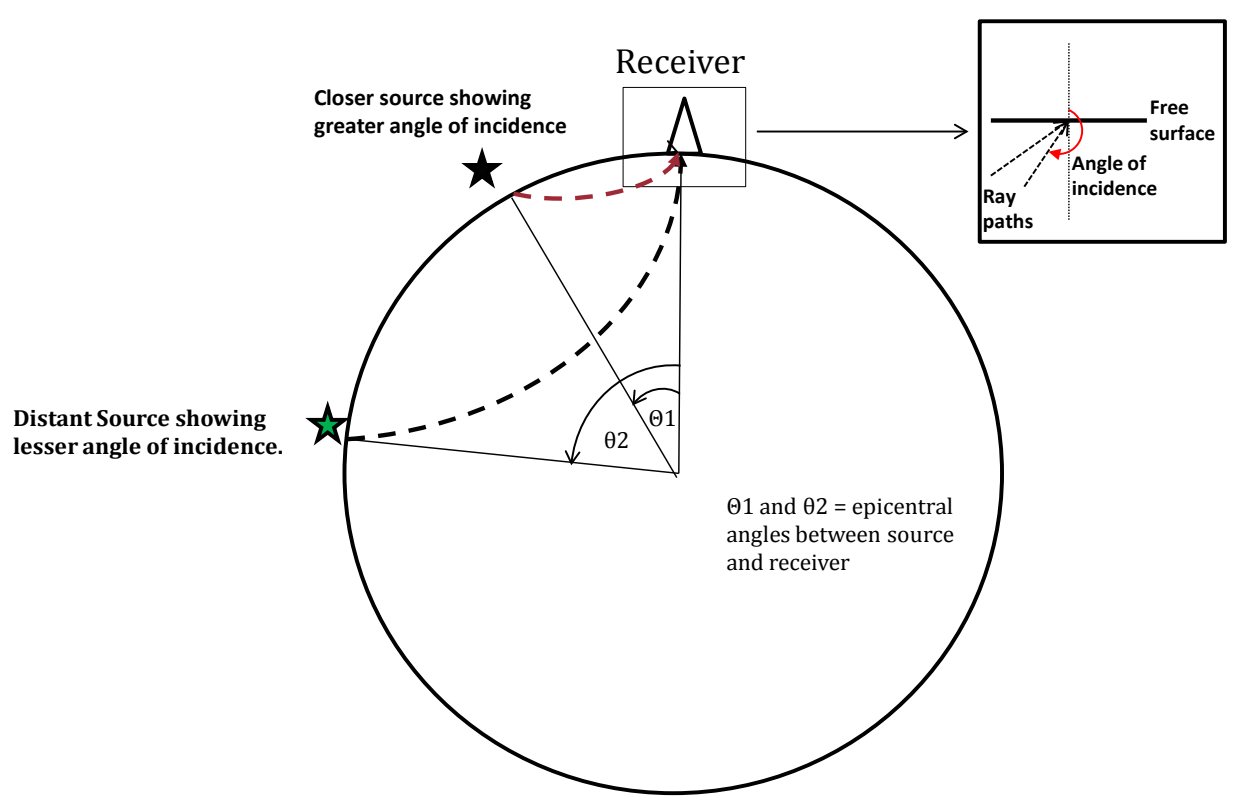

Figure 25 Schematic illustrating ray paths and incident angle associated with epicentral distances ( $\theta 1)$ and $(\theta 2)$.

The box (top right) shows an enlargement of the receiver site, showing the approaches of ray paths from both distant and close sources, and their incident angles (with respect to the normal to the free surface). 

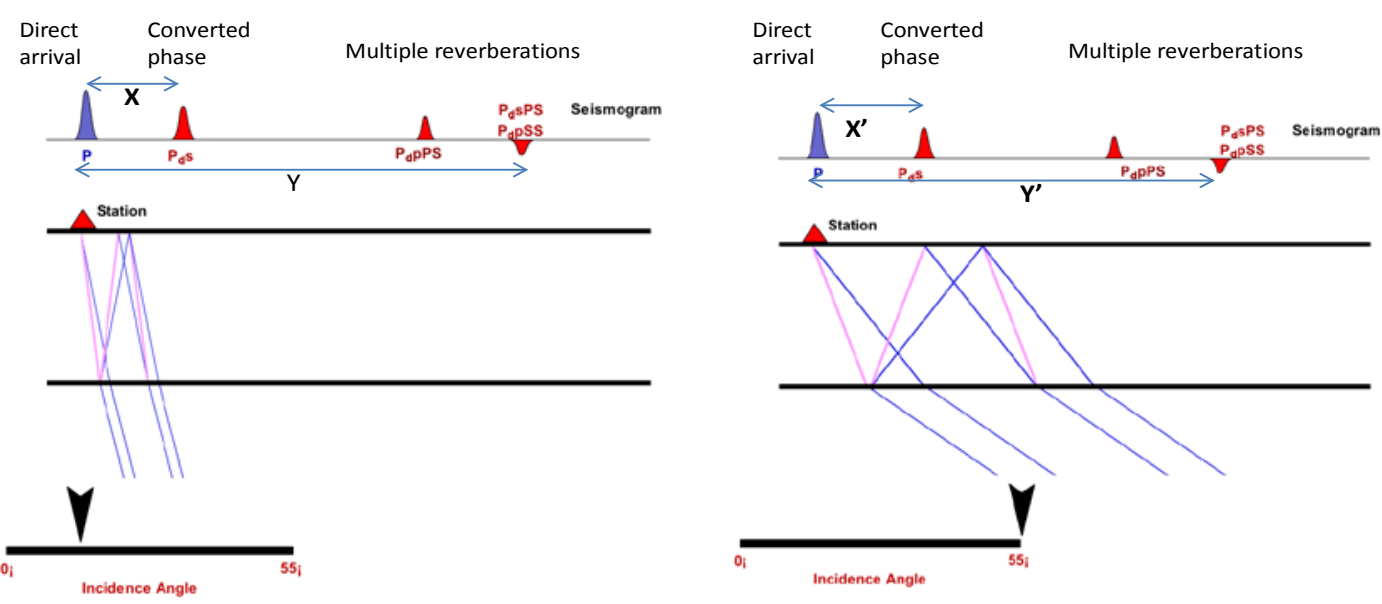

a) Steep incident angle (greater epicentral distance).

PdS has a smaller moveout than in b). PsPS ,PdsPS \& PdpSS have greater moveout, than b)

b) Shallow incident angle (lesser epicentral distance).

PdS has a greater moveout than in a) PsPS ,PdsPS \& PdpSS have smaller moveout, than a)

Figure 26 a) and b). Schematic associating incidence angle with epicentral distance. a) The distance $\mathrm{X}$ represents the moveout between the direct arrival and the converted phase (PdS). $\mathrm{X}^{\prime}$ is longer in $b$ ) than in a). (See text for explanation). In a) the distance Y represents the moveout between the direct arrival P and the multiple reverberations (PdpPS and PdsPS and PspSS). Y' is shorter than Y. Assuming $d$ is the discontinuity. Incidence angle is in degrees.

(Fig ref :http://www.colorado.edu/GeolSci/Resources/RF incidence angle.html)

\section{Dipping Interfaces}

In the case of flat isotropic layers all the energy from the converted phases is observed on the radial receiver function. The arrival time of the converted wave at the recording station, (relative to the first arriving P wave), is dependent on the strike, dip and depth of the interface (Langston, 1977. Savage, 1998).

In the presence of dipping layers, some of the energy is deflected; waves arriving from the up-dip direction will have a shorter distance to travel, and will show a shorter delay time than those arriving from down-dip. When the receiver functions are stacked according to back azimuth the moveout of the delay times will have a sinusoidal pattern (Nikulin et al., 2009). If the same receiver functions are stacked according to epicentral distance the moveout 
will be a function of both the dip and the epicentral distance. Some of the energy will also be apparent on the transverse receiver function (Cassidy, 1992; Savage, 1998). In the case of dipping boundaries the polarity reversals occur, at $180^{\circ}$ (back azimuth) intervals.

\section{Anisotropy}

Crustal anisotropy is primarily caused by rock foliation and aligned cracks (Babuska and Cara, 1991). Anisotropy results in splitting of the incoming S wave, with a fast direction and a slow direction observable. Polarity reversals on the transverse receiver function may be a result of the presence of anisotropy in the sampled rock. Where the anisotropy is present in the shallow layers the polarity reversals occur at $90^{\circ}$ (back azimuth) intervals (Savage, 1998). For further discussion on the effects of dipping boundaries and anisotropy (Savage, 1998), see Chapter 3, 3.22.

\section{Amplitude}

The amplitude of the arrivals is dependent upon both the size of the velocity contrasts at the interface that is producing the converted modes, and the incidence angle of the upcoming wave (http://eqseis.geosc.psu.edu/ cammon/HTML/RftnDocs/rftn01.html) (Figure 25).

The amplitude of the converted modes and the multiples will be relatively smaller than that of the directly arriving P waves. This is dependent upon the both the size of the contrast i.e. the difference in the velocity properties of the material at either side of the boundary, and the properties of the boundary itself i.e. if it is a sharp interface over a relatively small distance, or a gradational change over a wider distance. (http://eqseis.geosc.psu.edu/ cammon/HTML/RftnDocs/rftn01.html). 
- 53 - 


\section{CHAPTER 5}

\section{DATA PROCESSING}

\subsection{INTRODUCTION}

The method of computing receiver functions takes the raw data through several pre-processing stages before making the final receiver function analysis. The job flow for two of the different formats of raw data (Figure 27), Reftek and Earth data, used in this experiment differ in the preprocessing stages. The data downloaded from the New Zealand Geonet project already has the basic raw data processing done. The raw data from the 1990/1991 POMS project was not available; therefore data re-used in this project was received already in SAC (Seismic Analysis Code) format and pre-cut into earthquake events.

\begin{tabular}{|c|c|c|c|c|c|}
\hline $\begin{array}{l}\text { Station } \\
\text { name }\end{array}$ & Broadband & $\begin{array}{l}\text { Short } \\
\text { period }\end{array}$ & $\begin{array}{l}\text { Data Logger } \\
\text { type }\end{array}$ & $\begin{array}{l}\text { Sensor } \\
\text { type }\end{array}$ & Frequency range \\
\hline LE4 & $\mathrm{X}$ & & Reftek-130s & $\begin{array}{l}\text { Guralp } \\
\text { CMG } \\
40 T\end{array}$ & $\begin{array}{l}\text { Broadband. Corner } \\
\text { frequency } 0.033 \mathrm{~Hz} \\
\text { to } 50 \mathrm{~Hz}\end{array}$ \\
\hline T004 & $\mathrm{X}$ & & Reftek-130s & $\begin{array}{l}\text { Guralp } \\
\text { CMG } \\
\text { 3ESP }\end{array}$ & $\begin{array}{l}\text { Broadband. Corner } \\
\text { frequency } 0.016 \mathrm{~Hz} \\
\text { to } 50 \mathrm{~Hz}\end{array}$ \\
\hline T007 & $\mathrm{X}$ & & $\begin{array}{l}\text { Earthdata } \\
\text { PR6-24 }\end{array}$ & $\begin{array}{l}\text { Guralp } \\
\text { CMG } \\
40 T\end{array}$ & $\begin{array}{l}\text { Broadband. Corner } \\
\text { frequency } 0.033 \mathrm{~Hz} \\
\text { to } 50 \mathrm{~Hz}\end{array}$ \\
\hline LE3 & & $X$ & Reftek-130s & $\begin{array}{l}\text { Mark } \\
\text { L4C-3D }\end{array}$ & $\begin{array}{l}\text { Natural frequency } \\
\sim 1 \mathrm{~Hz}\end{array}$ \\
\hline T010 & $\mathrm{X}$ & & $\begin{array}{l}\text { Earthdata } \\
\text { PR6-24 }\end{array}$ & $\begin{array}{l}\text { Guralp } \\
\text { CMG } \\
40 T\end{array}$ & $\begin{array}{l}\text { Broadband. Corner } \\
\text { frequency } 0.033 \mathrm{~Hz} \\
\text { to } 50 \mathrm{~Hz}\end{array}$ \\
\hline LE2 & & $X$ & Reftek-130s & Mark & Natural frequency \\
\hline
\end{tabular}




\begin{tabular}{|c|c|c|c|c|c|}
\hline & & & & L4C-3D & $\sim 1 \mathrm{~Hz}$ \\
\hline T014 & $x$ & & $\begin{array}{l}\text { Earthdata } \\
\text { PR6-24 }\end{array}$ & $\begin{array}{l}\text { Guralp } \\
\text { CMG } \\
40 T\end{array}$ & $\begin{array}{l}\text { Broadband. Corner } \\
\text { frequency } 0.033 \mathrm{~Hz} \\
\text { to } 50 \mathrm{~Hz}\end{array}$ \\
\hline T016 & $x$ & & Reftek-130s & $\begin{array}{l}\text { Guralp } \\
\text { CMG } \\
40 T\end{array}$ & $\begin{array}{l}\text { Broadband. Corner } \\
\text { freq. } 0.033-50 \mathrm{~Hz}\end{array}$ \\
\hline T018 & $x$ & & $\begin{array}{l}\text { Earthdata } \\
\text { PR6-24 }\end{array}$ & $\begin{array}{l}\text { Guralp } \\
\text { CMG } \\
40 T\end{array}$ & $\begin{array}{l}\text { Broadband. Corner } \\
\text { frequency } 0.033 \mathrm{~Hz} \\
\text { to } 50 \mathrm{~Hz}\end{array}$ \\
\hline T020 & $x$ & & Reftek-130s & $\begin{array}{l}\text { Guralp } \\
\text { CMG } \\
40 T\end{array}$ & $\begin{array}{l}\text { Broadband. Corner } \\
\text { frequency } 0.033 \mathrm{~Hz} \\
\text { to } 50 \mathrm{~Hz}\end{array}$ \\
\hline T022 & $x$ & & Reftek-130s & $\begin{array}{l}\text { Guralp } \\
\text { CMG } \\
40 T\end{array}$ & $\begin{array}{l}\text { Broadband. Corner } \\
\text { frequency } 0.033 \mathrm{~Hz} \\
\text { to } 50 \mathrm{~Hz}\end{array}$ \\
\hline LTN6 & $x$ & & $\begin{array}{l}\text { Earthdata } \\
\text { PR6-24 }\end{array}$ & $3 \mathrm{ESP}$ & $\begin{array}{l}\text { Broadband. Corner } \\
\text { frequency } 0.016 \mathrm{~Hz} \\
\text { to } 50 \mathrm{~Hz}\end{array}$ \\
\hline LTN6 & & $X$ & Reftek-130s & L28 & $\begin{array}{ll}\text { Natural frequency } \\
\sim 4.5 \mathrm{~Hz} & \end{array}$ \\
\hline LTW1 & & $x$ & Reftek-130s & L22 & $\begin{array}{ll}\text { Natural frequency } \\
\sim 2.0 \mathrm{~Hz} & \end{array}$ \\
\hline $\begin{array}{l}\text { LTW1 } \\
*(\mathrm{POMS})\end{array}$ & $x$ & & $\begin{array}{l}\text { Reftek } \\
\text { R72a-02 }\end{array}$ & $\begin{array}{l}\text { CMG- } \\
3 T\end{array}$ & $\begin{array}{l}\text { resonant frequency } \\
0.033 \mathrm{~Hz}\end{array}$ \\
\hline LTW2 & & $x$ & Reftek-130s & L22 & $\begin{array}{ll}\text { Natural frequency } \\
\sim 2.0 \mathrm{~Hz} & \end{array}$ \\
\hline $\begin{array}{l}\text { LTW2**( }^{*}( \\
\text { POMS) }\end{array}$ & $x$ & & $\begin{array}{l}\text { Reftek } \\
\text { R72a-02 }\end{array}$ & $\begin{array}{l}\text { CMG- } \\
3 T\end{array}$ & $\begin{array}{l}\text { resonant frequency } \\
0.033 \mathrm{~Hz}\end{array}$ \\
\hline LTW3 & & $X$ & Reftek-130s & L22 & $\begin{array}{ll}\text { Natural frequency } \\
\sim 2.0 \mathrm{~Hz}\end{array}$ \\
\hline $\begin{array}{l}\text { LTW }^{* *}( \\
\text { POMS })\end{array}$ & $x$ & & $\begin{array}{l}\text { Reftek } \\
\text { R72a-02 }\end{array}$ & $\begin{array}{l}\text { CMG- } \\
3 T\end{array}$ & $\begin{array}{l}\text { resonant frequency } \\
0.033 \mathrm{~Hz}\end{array}$ \\
\hline TRWZ $^{* \star}$ & & $x$ & & $\begin{array}{l}\text { Mark } \\
\text { L4C-3D }\end{array}$ & $\begin{array}{ll}\text { Natural frequency } \\
\sim 1 \mathrm{~Hz}\end{array}$ \\
\hline MTW $^{\star \star}$ & & $X$ & & $\begin{array}{l}\text { Mark } \\
\text { L4C-3D }\end{array}$ & $\begin{array}{l}\text { Natural frequency } \\
\sim 1 \mathrm{~Hz}\end{array}$ \\
\hline $\mathrm{KIW}^{\star \star}$ & & $X$ & & $\begin{array}{l}\text { Mark } \\
\text { L4C-3D }\end{array}$ & $\begin{array}{l}\text { Natural frequency } \\
\sim 1 \mathrm{~Hz}\end{array}$ \\
\hline
\end{tabular}

Table 2. Station names and Instrumentation

Note: *LTW1; LTW2; LTW3 were redeployments of the stations of the same names deployed as part of the Leeds Tararua array (Stuart et al., 1995;

Reading et al. 2001). **TRWZ; MTW; KIW are all Geonet permanent stations. 


\subsection{EVENT DATABASE}

The initial step is to prepare a list of all $M>6.0$ teleseismic earthquakes that occurred over the complete time period of the seismometer deployment to create an event-database. The USGS catalogue (http://earthquake.usgs.gov/earthquakes/eqarchives/epic/epic circ.php) allows selection and download of the necessary parameters. The query parameters used for this experiment were a Global (worldwide) search for magnitude 6.0 to 10.0 ; to cover the time period beginning November 2009 and ending end November 2011. The resulting event list consisted of 389 separate earthquakes, listed with their time (hh,mm,ss.ds), latitude, longitude, magnitude and depth (km) (see Appendix, Events database). This list represents the event-database used in the subsequent data preparation algorithms (see Appendix).

\subsection{DATA PRE-PROCESSING}

\subsubsection{RAW DATA TO MINISEED TO SAC}

The raw data used to compute the receiver functions was collected on two different types of data loggers; Reftek-130s and Earthdata PR6-24. This resulted in the raw data being in two different formats, which required slightly different initial pre-processing techniques.

The flow chart below (Figure 27) illustrates the generic job flow used to prepare both types of data. 


\section{Preparing the data for receiver function analysis}

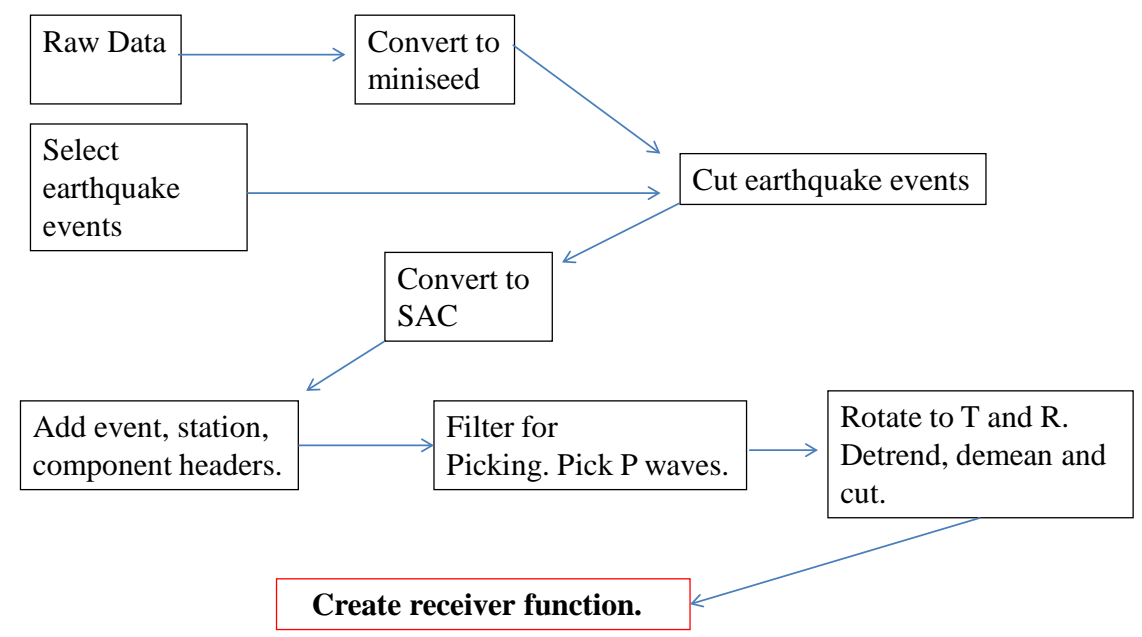

Figure 27 Job flow chart for receiver function data preparation.

\subsection{PREPARING THE REFTEK DATA.}

Reftek data is recorded on the Reftek-130s as day long, continuous files, with the date recorded as the Julian day.

The raw data is collated by station. Each data logger has an allocated DAS number; these numbers must be noted and included in an input file for the processing codes. The raw data undergoes basic pre-processing, taking it from Reftek to mini-SEED format, creating location and clock correction (refrate) files and the required structure for later processing.

The code mkeqcut (see Appendix) produces input files for cutting earthquakes from the continuous mini-SEED data. Distances in degrees and kilometres between an event and the station are calculated from the event and station data. Mkeqcut uses a system of cutting each earthquake event into 'blocks' of different lengths according to their Magnitude and distance.

Cutting the data containing the event record into hour long segments is done using the gui TkEqcut (see Appendix). The data cut is centred on the event origin time. This enables the inclusion of some pre-event noise, which is 
integral to the method used to create the final receiver function (Park and Levin 2000).

At the cutting stage the data is still in min-SEED format. Mini-SEED is a form of dataless SEED data that only contains the waveform, but with no station, channel or event meta-data. SEED is the international Standard for the Exchange of Earthquake Data, the standard format for the exchange of digital seismological data, primarily used for unprocessed motion data. (http://www.iris.edu/manuals/SEED appG.htm)

The cut data now contains all the potentially usable teleseismic earthquake data. This data is now reformatted into SAC (Seismic Analysis Code) and the headers containing the event latitude, longitude, magnitude, depth and origin time are added. The Seismic Analysis Code is developed for the study of time series data and sequential signals, functioning as an interactive program.

\subsection{PREPARING THE EARTH DATA}

The data recorded on the Earth data PR6-24 portable field recorder is written to miniSEED format in the form of discrete hour long files. This format does not hold any meta-data, which must be loaded separately. Usually data in this format is sent to IRIS (Incorporated Research Institutions for Seismology), where a dataless SEED file is prepared to load the metadata, and may be requested. However the SAHKE data has not been submitted to IRIS (to date) therefore this option was not available. IRIS is a university consortium for the acquisition, management and distribution for freely available seismic data, and has been involved in the SAHKE project.

Differences in the data format to that recorded by the Reftek data loggers mean that the processing job flow has to be substantially different to that used to process the Reftek data. The data has to be cut by taking the hourlong file containing the event. The data was first organised into station files and then changed to SAC format. Secondly the earthquake records were cut 
from the record and SAC headers added using a python script written specifically for this task (see appendix).

\subsection{GEONET DATA}

The data downloaded from the New Zealand Geonet project is already processed and arrives in SAC format. The waveform data was downloaded by requesting the GeoNet CWB (Common Waveform Buffer) data repository using Java. A script was created that requested teleseisms recorded during the period November 2009 to November 2011. The permanent GeoNet stations, KIW Kapiti Island; MTW Mount Morrison; and TRWZ Traveller (Figure 2 and Table 1), were selected because of their proximity to the SAHKE1 transect line (Figure 1). The station KIW, at Kapiti Island, is especially useful as it represents the most westerly extent of the transect. Station TRWZ represents the farthest east station See Fig 2 Map of station locations). The completeness and quality of the GeoNet seismic data were excellent and contributed significantly to the quality of the final result. Although the Mark L4C-3D sensors used for these stations are short period with a natural period of $1 \mathrm{~Hz}$ they record a broad enough frequency band to pick up the low frequencies needed for $1 \mathrm{~Hz}$ receiver functions.

\subsection{SECOND STAGE OF PROCESSING}

5.7.1 FILTERING, DETRENDING, DEMEANING, PICKING THE FIRST ARRIVALS, WINDOWING, TAPERING AND SORTING.

At this stage all the data sets (see above) are treated in the same manner. The cut SAC data is picked using a bandpass filter with corner frequencies of $0.02 \mathrm{~Hz}$ to $1.0 \mathrm{~Hz}$, between 1 and 50 seconds. Other filters (e.g. Bandpass with corner frequencies of $2 \mathrm{~Hz}$ and $5 \mathrm{~Hz}$ ) were trialled, but this was the most effective. This fairly wide low frequency filter acts to suppress some of the noise from higher frequencies. Unfortunately much of the recorded noise generated from the oceans, known as microseisms, peak at exactly the same frequency band that records the incoming teleseisms (Stuart et al., 1995. Shearer 2009.Ch11.2.p330). Kibblewhite and Ewans (1985) show the 
correlation between ocean noise from ocean waves generated $30 \mathrm{~km}$ off the west coast of New Zealand and an onshore long period seismometer. The presence of low frequency noise can dominate, leaving some of the traces with a low signal to noise ratio, making accurate picking difficult. The filter is left on after processing; because this filter is left on the receiver functions are best at frequencies below $1 \mathrm{~Hz}$. If the receiver functions were to be processed at higher frequencies the data would have to be re-picked and the filter removed to allow data above $1 \mathrm{~Hz}$. The data is further demeaned and detrended before the first arrivals are picked. The $\mathrm{P}$ wave is picked on the $\mathrm{Z}$ vertical component.

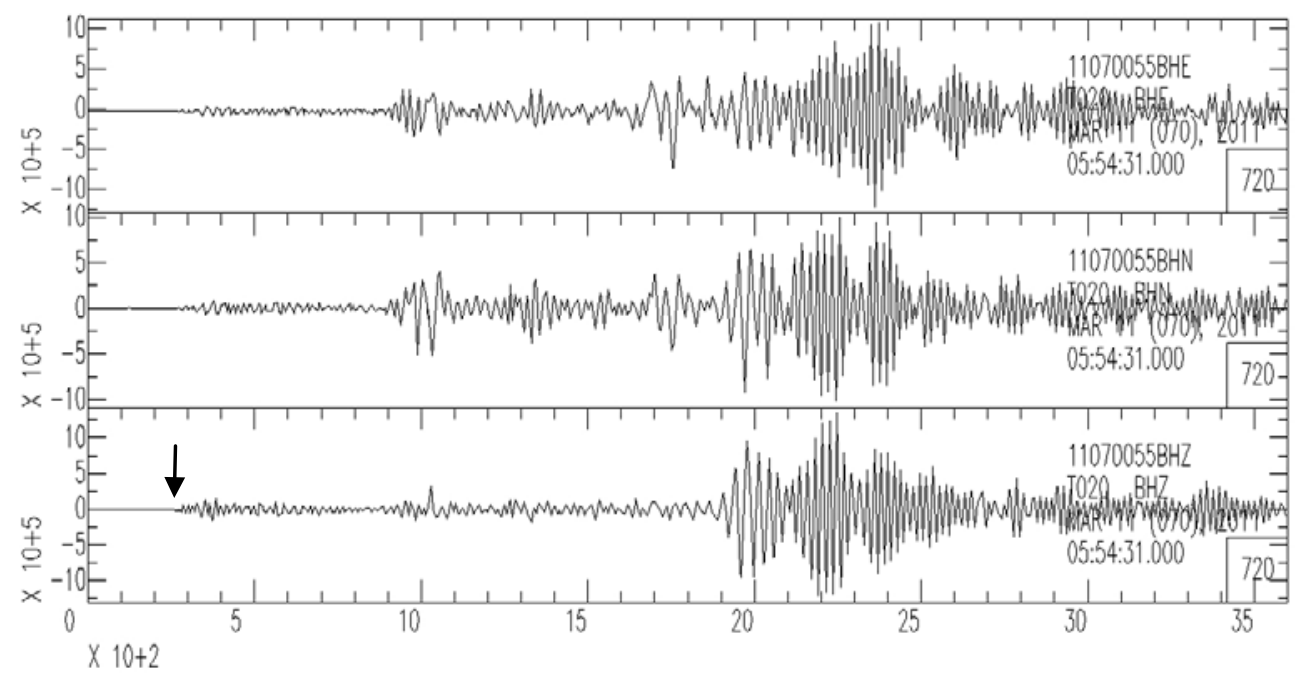

Figure 28 Three component (Z, N, E), hour long seismograms from the March 11, 2011 Japan earthquake Mw 9.0; recorded at station T020.

The arrow on the bottom (Z) component indicates the first arrival P wave.

Figure 28 shows that the incoming $\mathrm{P}$ wave is the first arrival, with the greatest energy on the vertical component. This is because the $\mathrm{P}$ wave is longitudinal with the particle motion parallel to the wave direction, which is in this instance, in the (sub) vertical direction. The $S$ waves show much more energy on the two horizontal, north and east, components, because of their transverse motion. 
The data is further cut, windowing the initial $\mathrm{P}$ wave and the following mode conversions from the rest of signal. The window used cuts 60 seconds before and 90 seconds after the $\mathrm{P}$ onset. The data is finally tapered using a cosine taper to the right and left fifth, (about 25 seconds). This helps avoid artefacts later in the processing. The picking SAC macro, which handles the filtering, picking, cutting and detrending was modified slightly from http://eqseis.geosc.psu.edu/ cammon/HTML/RftnDocs/prep01.html (see appendix). The macro also creates directories to allow the 'GoodOnes', with a clear P wave pick, to be easily separated from the 'Trash' files.

Traces selected as 'GoodOnes', to be used in the next phase of analysis, are rotated into the vertical radial-transverse component alignment. This creates new horizontal, radial and transverse components, with the radial aligned with the backazimuth (see Chapter $4,4.5$ ). The backazimuth (BAZ) is the angle, measured from North, between the station and the event. The vertical (Z) component remains vertical.

\subsection{FinAL STAGE OF PROCESSING: MULTIPLE TAPER SPECTRAL CORRELATION} METHOD

\subsubsection{THEORY}

The multiple taper correlation method (MTC) was developed by Park and Levin in 2000. Park and Levin (2000) state that 'Receiver functions are easy to define, but difficult to compute in a robust manner'. Their algorithm attempts to deal with insufficiencies inherent in other methods, and provides a numerically stable method, leading to a coherent result. The method computes the RF inversions in the frequency domain using multiple-taper correlation estimates instead of spectral division, and utilises pre-event noise for frequency dependent damping (Park and Levin, 2000). The major benefit of MTC method is not the noise damping however, but the ability to cross-correlate the horizontal and vertical components (see equations 6 and 7), instead of using straight spectral division, when estimating the RF. This 
gives numerical stability and gives RF-uncertainties (see equations 10 and 11) in the frequency domain.

The MTC method provides a robust way of separating the required signal from noise. The signal of interest, the P-to-S converted waves used for the receiver function (RF) analysis, is scattered, and may include multiple arrivals generated by velocity impedance layers beneath the station; the signal may also include out of plane energy and scattering from impedances due to heterogeneities from lateral variations. When there are several interfaces present, at various depths, it is difficult to separate the P-S phases from the multiples. This problem is particularly evident at frequencies above 1Hz (Abers, 1998). MTC provides an algorithm that distinguishes coherent and incoherent scattering on a signal from a single event recorded in three component seismograms. The traditional solution to signal enhancement is stacking. Though stacking is effective at reducing the impact of noise and enhancing signal, the MTC method actually recognizes the difference between coherent and incoherent signals on the horizontal and vertical seismic components, giving an additional weighting to the coherent signal in the frequency domain by weighting the inverse of the variance. (Park and Levin. 2000). This provides a more sophisticated solution than simple unweighted stacking, by avoiding the problem of microseism noise in the 0.1-0.5 $\mathrm{Hz}$ range, (http://www.ldeo.columbia.edu/ vadim/RF/RFmanual.html) giving an improved receiver function image.

The two other receiver function methods commonly used by other studies are time domain deconvolution (Burdick and Langston, 1977; Langston, 1977, 1979; Sheehan et al., 1995) and spectral division with water level damping (Clayton and Wiggins, 1976; Ammon, 1991). Spectral division without water level damping does not take noise into account, and is numerically unstable; though using the water level damping technique provides numerical stability, the water level has the effect of obscuring the low amplitude data. Deconvolution in the time domain tends to be dominated by signal that contains frequencies with the highest amplitudes, often leading to a limitation on the use of higher frequency data (Park et al., 1987. Park and Levin, 2000) 


\subsubsection{CALCULATING MULTIPLE-TAPER RECEIVER FUnCTIONS}

The following equation is used to calculate the receiver function, assuming that there are three time series of vertical, radial and transverse particle motion, $\mu(n \tau)$ where $n$ is the sampling number and $\tau$ is the sampling interval.

$Y_{\gamma}^{k}=\sum_{n=0}^{N-1} \mu_{n}^{\gamma} w_{n}^{(k)} e^{i 2 \pi f n \tau}$

Equation 5

For equation 5, Y is the Fourier spectra of the data, the MTC method works in the frequency domain where multi-taper spectral estimation is used; $f$ is frequency; $\gamma$ is the component $Z, R, T ; N$ is the number of samples and $w_{n}^{(k)}$ is the $k$ th slepian data taper for a user chosen time-band-width product $p$ (Lees and Park, 1995. Park and Levin, 2000). The frequency cutoff and the timebandwidth product $p$ are the only two free parameters when calculating the MTC RF estimate (Park and Levin, 2000).

Slepian tapers control the number and frequency width of the windows (Figure 29). We use three tapers ( $\mathrm{k}=3$ ) with $p$ at a value of $2.5 ; p$ scales the local average of spectral information about $f$ (Park et al. 1987). Figure 29 illustrates the three tapers with the $p$, or $\pi$, at a value of 2.5 . 


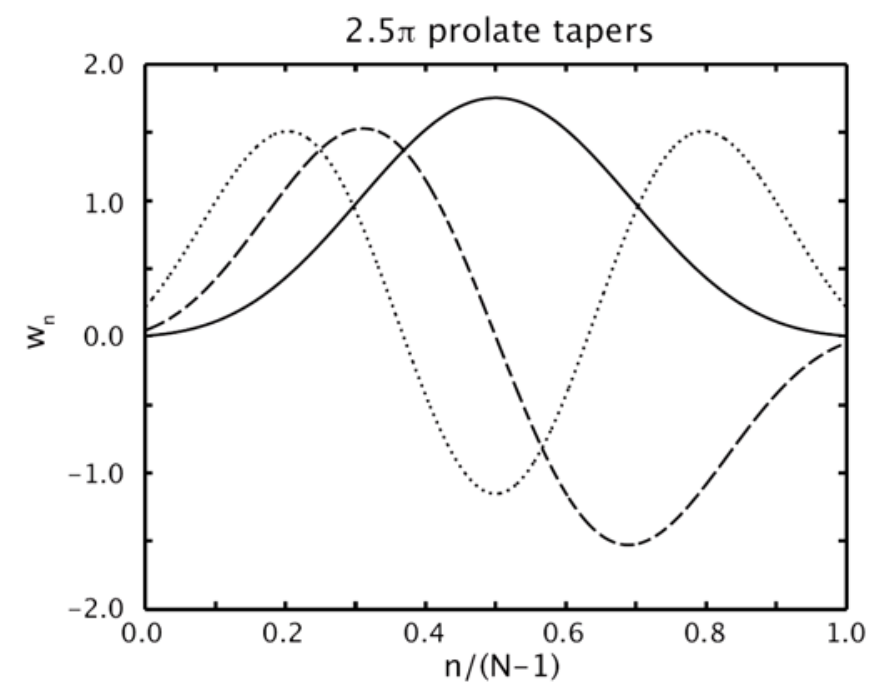

Figure 29 Prolate eigen tapers used for multi-taper correlation. Solid black line is the taper $\mathrm{k}=1$, dashed line is $\mathrm{k}=2$, dotted line is $\mathrm{k}=3 ; p=\pi=2.5$ (Figure from Salmon. 2008).

Multiplying the data by several tapers enables each taper to sample the data differently and optimises resistance to spectral leakage. This is achieved because the part of the data that is not sampled by the first taper is in part sampled by the second, and the data that has been discarded by the first two tapers is partly recovered by the third (and so on). Using multi-tapers gives a smoothed and consistent estimate of the data. It also avoids the problems of using a single taper which will give a relatively large variance, as well as weighting the data in the centre more heavily than at the ends (Park et al. 1987). Using multiple tapers is similar to using Fourier analysis, but is better for seismic data because the sine waves used in Fourier analysis are continuous, while as seismic data and slepian tapers have a limited time window (Park et al., 1987).

To estimate the coherence between the vertical and the horizontal, (radial and transverse), components the following equations are used: $C_{R}(f)$ is the coherence estimate for the radial component and $C_{T}(f)$ the coherence estimate for the transverse component. (Park and Levin, 2000) 


$$
C_{R}(f)=\frac{\sum_{K=0}^{K-1}\left(Y_{Z}^{(k)}(f)\right) * Y_{R}^{(k)}(f)}{\left(\left(\sum_{K=0}^{K-1}\left(Y_{R}^{(k)}(f)\right) * Y_{R}^{(k)}(f)\right)\left(\sum_{K=0}^{K-1}\left(Y_{Z}^{(k)}(f)\right) * Y_{Z}^{(k)}(f)\right)\right)^{1 / 2}}
$$

Equation 6

$$
C_{T}(f)=\frac{\sum_{K=0}^{K-1}\left(Y_{Z}^{(k)}(f)\right) * Y_{T}^{(k)}(f)}{\left(\left(\sum_{K=0}^{K-1}\left(Y_{T}^{(k)}(f)\right) * Y_{T}^{(k)}(f)\right)\left(\sum_{K=0}^{K-1}\left(Y_{Z}^{(k)}(f)\right) * Y_{Z}^{(k)}(f)\right)\right)^{1 / 2}}
$$

Equation 7

The closer the solution for the correlation estimates is to unity (the value \#1), the more correlated the components are. Low coherence between vertical and horizontal components is caused by noise; this noise may be caused by extra vibrations from the seismic signal itself, such as body wave conversions from nearby scatterers, or from background noise emanating from sources not associated with the signal.

The receiver functions are computed in the frequency domain using the following equations. $H_{R}(f)$ and $H_{T}(f)$ are the radial and transverse RFs. The damping factor $S_{O}(f)$ is a spectrum estimate of the pre-event noise on the vertical component; this is calculated using equation 5 .

$H_{R}(f)=\frac{\sum_{K=0}^{K-1}\left(Y_{Z}^{(k)}(f)\right) * Y_{R}^{(k)}(f)}{\left(\left(\sum_{K=0}^{K-1}\left(Y_{Z}^{(k)}\right) * Y_{Z}^{(k)}\right)\right)+S_{o}(f)}$

Equation 8

$H_{T}(f)=\frac{\sum_{K=0}^{K-1}\left(Y_{Z}^{(k)}(f)\right) * Y_{T}^{(k)}(f)}{\left(\left(\sum_{K=0}^{K-1}\left(Y_{Z}^{(k)}\right) * Y_{Z}^{(k)}\right)\right)+S_{o}(f)}$

Equation 9 
The coherences $C_{R}(f)$ (Equation 10) and $C_{T}(f)$ (equation 11) are used to calculate the formal uncertainties for the receiver functions in the frequency domain. The variance of the RF scales with its amplitude squared (Park and Levin, 2000).

$$
\operatorname{var}\left(H_{R}(f)\right)=\left(\frac{1-\left(C_{R}(f)\right)^{2}}{(K-1)\left(C_{R}(f)\right)^{2}}\right)\left|H_{R(f)}\right|^{2}
$$

Equation 10

$$
\operatorname{var}\left(H_{T}(f)\right)=\left(\frac{1-\left(C_{T}(f)\right)^{2}}{(K-1)\left(C_{T}(f)\right)^{2}}\right)\left|H_{T(f)}\right|^{2}
$$

Equation 11

The formal uncertainty is used to create the composite RFs in the frequency domain using different seismic traces in the form of a weighted linear combination. This allows the RF stack to be influenced most by those seismic records that have the greatest coherence (Park and Levin. 2000).

\subsubsection{PARAMETERS}

The Park and Levin (2000) algorithm allows the user to choose certain parameters during the processing. These are: the maximum frequency (fmax) in Hz: the time duration window for the analysis; the minimum number of events in an averaged bin, (e.g. 1 or 2); to rotate into LQT coordinates to isolate $\mathrm{P}$ and SV; to select the back-azimuth and epicentral distance limits; and to change the back-azimuth and epicentral bin widths. The LQT reference frame may be used at this stage of processing, if required, because the usual Z (vertical), R (radial), T (transverse) components may leave the presence of high amplitude Pp arrivals and multiples, by rotating the radial and vertical components into a reference frame with one component aligned with the propagation direction of the incoming $\mathrm{P}$ wave. 
This allows the $\mathrm{P}$ arrivals to be removed from the receiver function (Salmon, 2008). However the method of processing used for this thesis has already rotated the data to the great circle path (GCP) using SAC, at the picking stage (see 5.7.1), therefore it is not necessary to rotate the data using the option discussed above.

For this study all the RFs are computed using an $80 \mathrm{~s}$ time window with ten seconds of pre-event noise. One event is used per averaged bin of $10^{\circ}$. The co-ordinate system was not rotated to LQT for any of the final results (see above). The back-azimuth (BAZ) limits selected were $0^{\circ}$ to $360^{\circ}$ to allow all relevant data to be taken into account for interpretation. Epicentral distances of between $0^{\circ}$ and $180^{\circ}$ were plotted allowing for all available data to be interpreted. The BAZ and epicentral bin widths are spaced at $5^{\circ}$ intervals with a $10^{\circ}$ overlap. Bin averaging allows each RF from a particular event to contribute to two adjacent bins. RF's were computed with an fmax of $0.5 \mathrm{~Hz}$ to $2 \mathrm{~Hz}$ (acting as a low pass filter) to allow frequency dependence to be observed. All receiver function stacks for individual stations are shown with fmax of $1 \mathrm{~Hz}$.

Figure 30 ilustrates five individual, unstacked radial receiver functions. It shows the results of the data processing up to, and before the stacking stage. Compare to Figure 28, the unprocessed three component seismic data. Figure 31 illustrates the same five traces as shown in Figure 30, but this time stacked using the MTC algorithm (Park and Levin, 2000) according to epicentral distance and back azimuth, showing radial and transverse sweeps. 


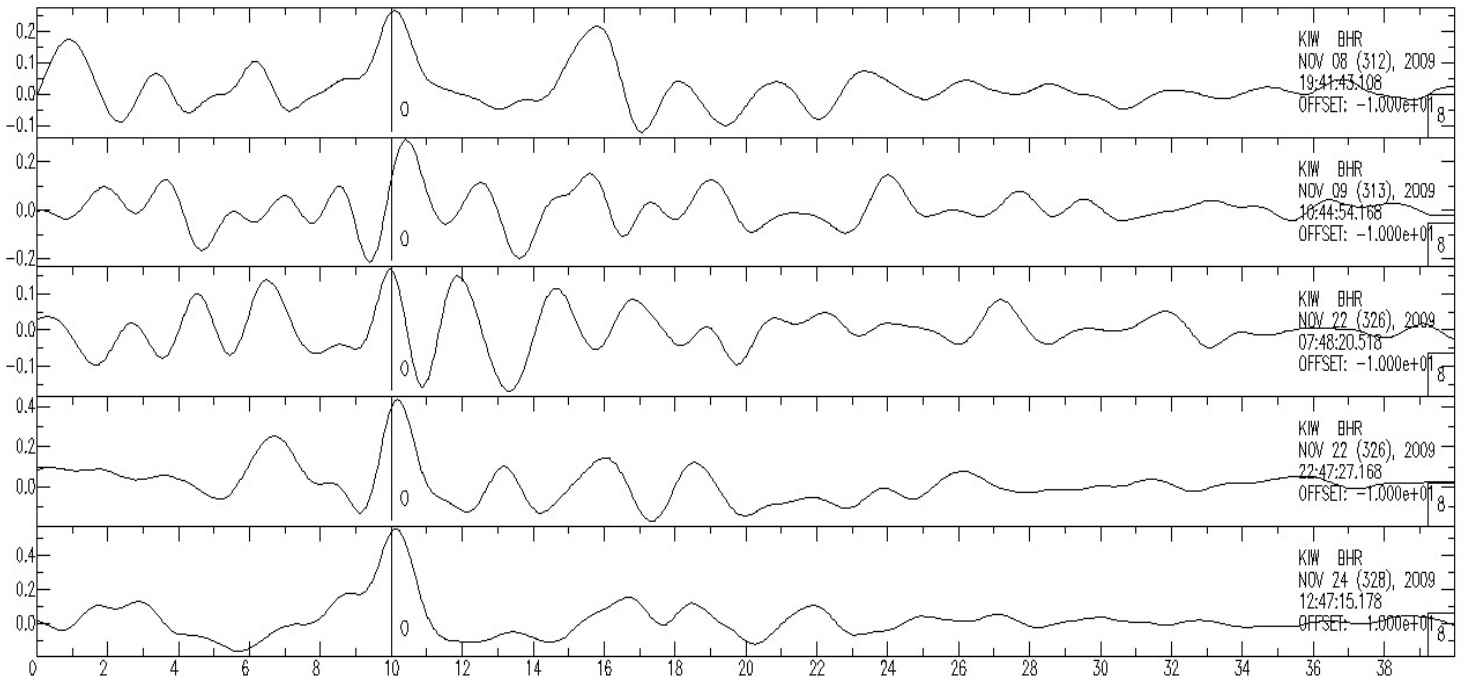

Figure 30 Five individual unstacked radial receiver functions from station KIW using earthquake events recorded in November 2009. Computed using multi-taper correlation with $1 \mathrm{~Hz}$ low pass filter. The vertical line 0 shows the position of the picked $P$ wave.

EPICENTRAL DISTANCE

RADIAL

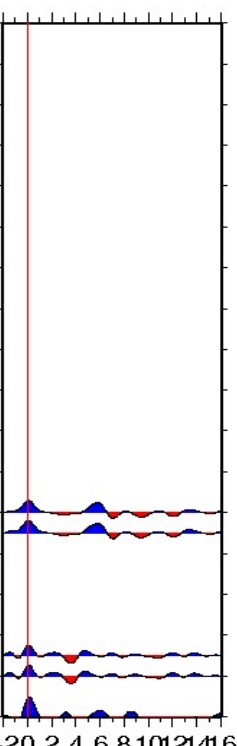

$-20246810121416$

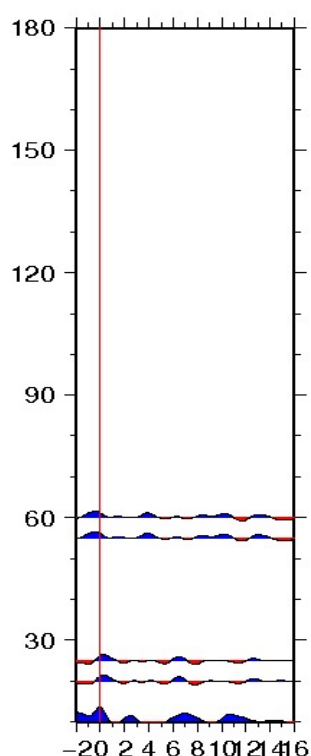

$-2024681012416$

\section{BACK AZIMUTH}

RADIAL

TRANSVERSE
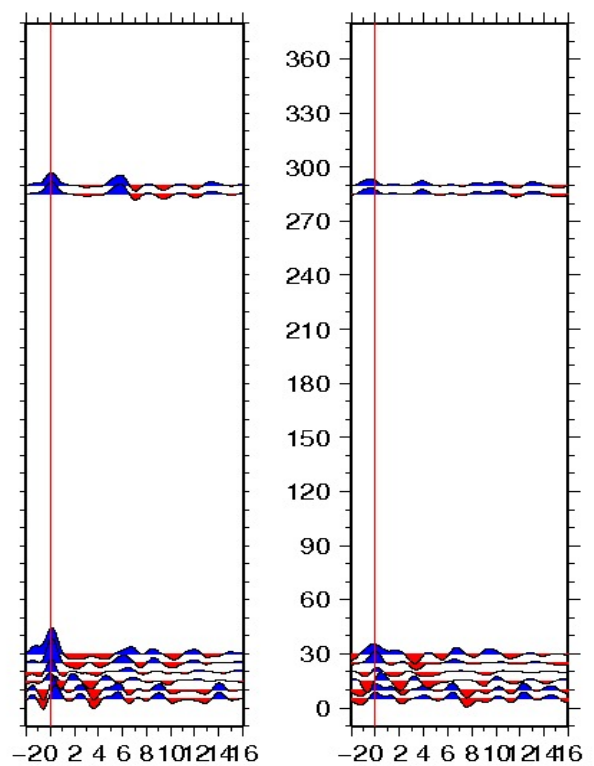

Figure 31 The same five traces from KIW as illustrated in Figure 30. Stacked using Park and Levin's (2000) multiple taper correlation method with coherence weighting. The left two stacks are stacked by epicentral distance, with the radial and transverse components to the left and right respectively. The right hand two stacks are stacked by back azimuth with the radial and transverse components to the left and right respectively. Time is shown along the bottom axis, with degrees on the vertical. They are stacked with $5^{\circ}$ bin spacing, averaged over $10^{\circ}$ so that each trace contributes to the adjoining bin. 


\subsection{COMMON CONVERSION POINT STACKING METHOD}

\subsection{THEORY}

Common conversion point (CCP) stacking was developed by Duecker and Sheehan (1998), and further developed by Zhu (2000), to stack P-S receiver functions, recorded by a dense seismic array along a $140 \mathrm{~km}$ profile of the San Andreas Fault, down to a depth of $50 \mathrm{~km}$. The method uses the same philosophy as Common Depth Stacking (CDP) and migration that are applied in reflection seismology; but instead of using reflected waves from an active source it uses the deconvolved, converted wave forms computed as receiver functions (Zhu, 2002). Zhu (2000) produced an image of the Mohorovicic discontinuity at around $30 \mathrm{~km}$ depth, offset by the cross cutting San Andreas Fault. The technique Zhu developed requires the ray parameters of the individual receiver functions to be calculated using an appropriate velocity model. The CCP algorithm corrects for the incident angle effect and then reads the amplitude at each point on the receiver function. Each point is then assigned to the location on the ray path corresponding to where the conversion occurred. It uses an appropriate time delay with respect to the direct $\mathrm{P}$ wave. The amplitude at each of these points represents velocity impedance change of the medium at the conversion point. For the optimum results the array should have closely spaced stations and a good azimuthal distribution of earthquakes. Typically the $\mathrm{P}$ to $\mathrm{S}$ conversion at a depth of 30 $\mathrm{km}$ has a piercing point around $7 \mathrm{~km}$ away, (see Method. Data sampling to create a single station receiver function stack). In an ideal situation the stations should be placed at around half that distance to allow the ray paths to cross over and provide a smoothed, averaged result. In this study the eastern stations are most densely spaced with 14 stations over approximately $45 \mathrm{~km}$ of profile, providing an average spacing of $3.2 \mathrm{~km}$. This optimal station spacing is reflected in the quality of the final result. The western half of the profile does not have such a dense station spacing, with four stations over around $45 \mathrm{~km}$ of profile, never the less this does allow for the ray paths to cross at depths of below $20 \mathrm{~km}$. Average amplitudes and variances are then obtained along the profile by averaging each bin. The size 
of the horizontal bins depends on the wavelength of the receiver function; the vertical binning is determined by the sampling rate. It is crucial that all the data used in the stack has the same sampling rate. Data originally recorded at a different sampling rate i.e. data from Leeds Tararua Array (Stuart et al., 1995) are resampled to have the same rates.

\subsubsection{PARAMETERS USED IN THIS STUDY}

The ray parameter for a spherical earth is calculated using Snell's Law, which states that a seismic ray that encounters a velocity impedance boundary dividing two layers with different elastic properties splits into different parts, with some of the energy being reflected, and some refracted into the adjacent layer.

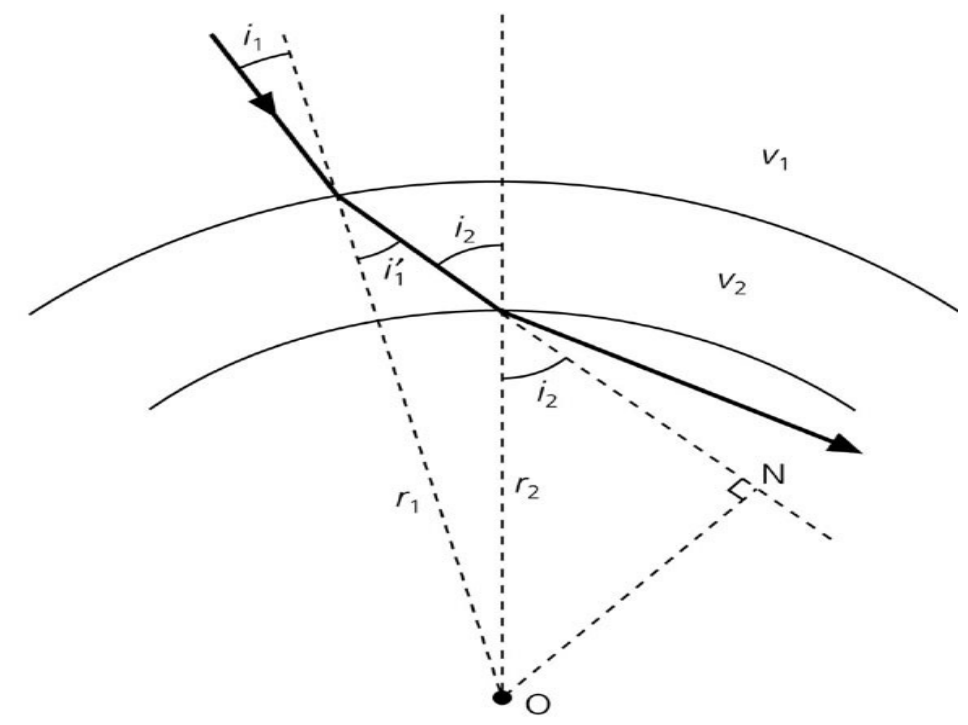

Figure 32 Geometry of Snell's Law for a spherical earth. (Figure from Stein and Wysession, 2003).

To calculate ray parameters the earth must be treated mathematically as a series of concentric layers (Figure 32)

If $r_{1}$ and $r_{2}$ are the connecting distances from the ray path to the centre of the earth. $v_{1}$ and $v_{2}$ are the velocities for the two layers and $i_{1} \quad i_{1}^{\prime}$ and $i_{2}$ are the angles shown then Snells Law states: 


$$
\frac{r_{1 \sin i_{1}}}{v_{1}}=\frac{r_{1 \sin i_{1}^{\prime}}}{v_{2}}
$$

But if $r_{1} \sin i_{1}$ is equal to $r_{2} \sin i_{1}$ because they are both equal to the length 0 $\mathrm{N}$ the equation may be written as:

$$
\frac{r_{1} \sin i_{1}}{v_{1}}=\frac{r_{1} \sin i_{1}^{\prime}}{v_{2}}
$$

Equation 13

Therefore the ray parameter $(p)$ for a spherical earth is defined as:

$$
p=\frac{r \sin i}{v}
$$

Where $r$ is the radial distance from the centre of the earth $(6371 \mathrm{~km}), \mathrm{v}$ is the velocity at that point, and $i$ is the incidence angle between the ray path and the radius vector (Stein and Wysession, 2003).

Ray parameters were calculated for all receiver functions using the TauP package (based on the method of Buland and Chapman, 1983). The velocity model used is the New Zealand Standard model (NZST) (see Chapter 7). (http://info.geonet.org.nz/display/appdata/Hypocentre+Derivation).

TauP computes the ray parameter as seconds per degree. The CCP stacking algorithm requires that the ray parameters are in seconds per kilometre. Therefore all the ray parameters must be divided by the value 111 . This is calculated by using the following:

$$
2 \pi r=c \quad \text { therefore } \quad \frac{\mathrm{c}}{360}=111 \quad \text { Equation } 15
$$

Where $r$ is the radius of the earth, assumed to be $6371 \mathrm{~km}$ and $\mathrm{c}$ is circumference of the earth in $\mathrm{km}$.

The ray parameter is constant along the ray path.

When computing the common conversion point stacks for this study the following parameters are used:

Low pass corner of 0.4 , high pass of 1.5 , the back azimuth range is from $0^{\circ}$ to $360^{\circ}$ to accommodate all available data, the maximum depth used is $150 \mathrm{~km}$. 
The profile azimuth is $129^{\circ}$. The bin width along the $\mathrm{x}$ (horizontal) profile is chosen as $8 \mathrm{~km}$, and along the $\mathrm{y}$ (vertical) it is $10 \mathrm{~km}$. The latitude and longitude of the array centre is that of station LTN6, -41.1033 (lat) and 175.3238 (lon). The sample rate of all the files is $0.01 . V p / V s$ is varied according to the velocity model (see Chapter 8). 
- $73-$ 


\section{CHAPTER 6}

\section{RECEIVER FUNCTION OBSERVATIONS}

\subsection{SINGLE STATIONS STACKS}

The following receiver function plots are arranged with the most easterly station, (Wairarapa Coast) first, in station order, through to the most westerly station (offshore Kapiti Island). (Figure 33.)

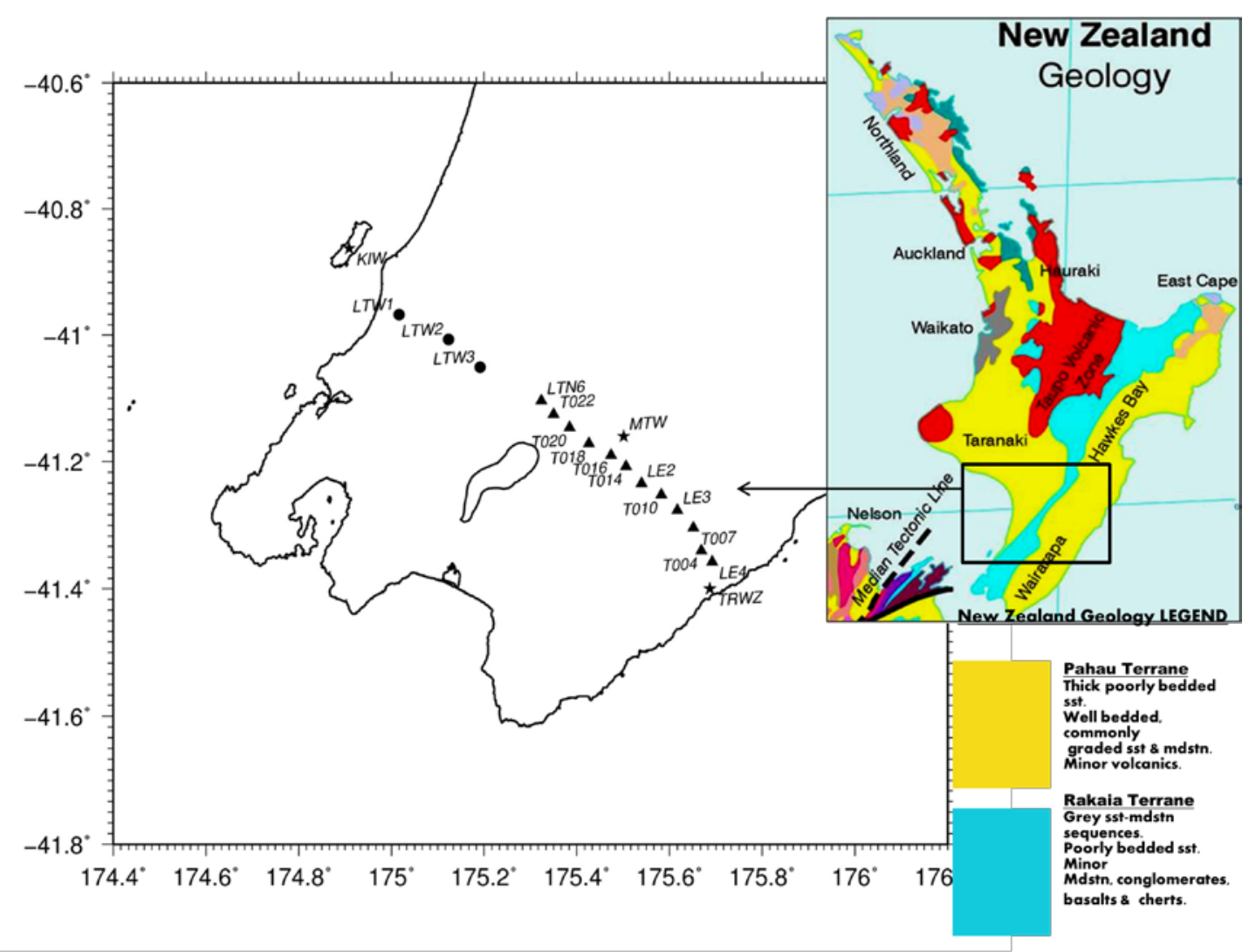

Figure 33 Station locations and geology of the North Island New Zealand. Station names correspond to the following receiver function plots. Geological Map from http://www.otago.ac.nz/geology/images/nz-igns-north.jpg. Geological descriptions from Q Map Wellington (Begg and Johnson, 2000). 


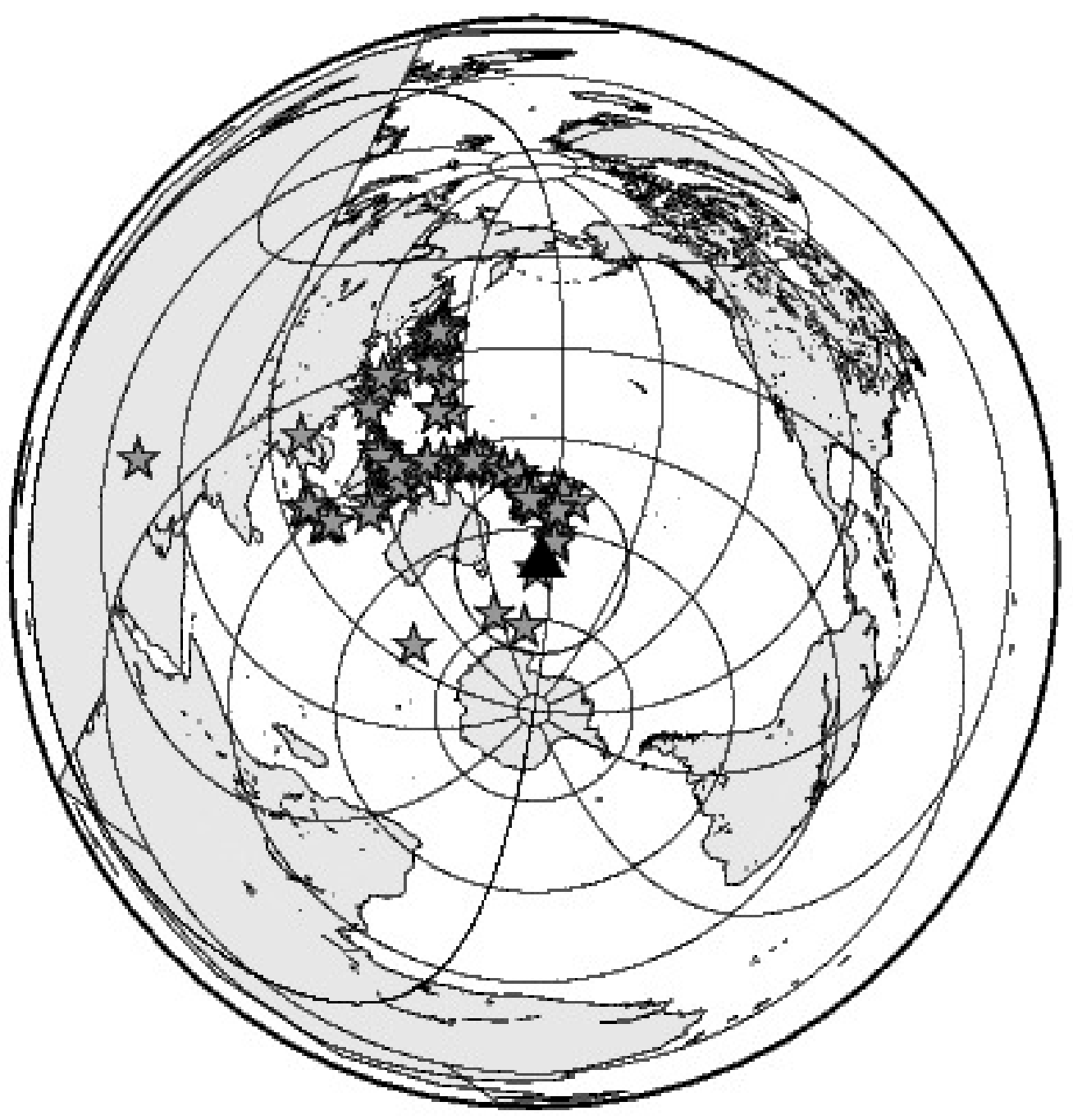

Figure 34 Teleseismic events used for receiver function analysis. A selection of the earthquakes located in this figure are used to create the receiver function plots for all stations as listed in Table 3 below. The circle around New Zealand represents $300 \mathrm{~km}$ distance for reference. 
Table 3 Receiver Function Events (dates and number) per station.

\begin{tabular}{|l|l|l|l|}
\hline Station Name & $\begin{array}{l}\text { Date of first } \\
\text { event used in } \\
\text { RF stack }\end{array}$ & $\begin{array}{l}\text { Date of last } \\
\text { event used in } \\
\text { RF stack }\end{array}$ & $\begin{array}{l}\text { Total } \\
\text { number of } \\
\text { events } \\
\text { used to } \\
\text { create RF } \\
\text { stack. }\end{array}$ \\
\hline TRWZ & $05 / 11 / 2009$ & $11 / 03 / 2011$ & 92 \\
\hline LE4 & $22 / 11 / 2009$ & $25 / 10 / 2010$ & 58 \\
\hline T004 & $03 / 03 / 2010$ & $10 / 07 / 2011$ & 106 \\
\hline${ }^{*}$ T007 & $09 / 02 / 2010$ & $03 / 05 / 2010$ & 26 \\
\hline LE3 & $22 / 11 / 2009$ & $26 / 06 / 2011$ & 32 \\
\hline T010 & $07 / 02 / 2010$ & $12 / 10 / 2010$ & 37 \\
\hline **LE2 & $\mathrm{n} / \mathrm{a}$ & $\mathrm{n} / \mathrm{a}$ & $\begin{array}{l}\text { No data } \\
\text { used* }\end{array}$ \\
\hline T014 & $07 / 02 / 2010$ & $17 / 06 / 2010$ & 25 \\
\hline T016 & $26 / 02 / 2010$ & $21 / 10 / 2011$ & 139 \\
\hline MTW & $05 / 11 / 2009$ & $14 / 11 / 2011$ & 156 \\
\hline T018 & $26 / 02 / 2010$ & $09 / 06 / 2010$ & 12 \\
\hline T020 & $05 / 03 / 2010$ & $22 / 08 / 2011$ & 110 \\
\hline T022 & $15 / 02 / 2010$ & $02 / 11 / 2011$ & 63 \\
\hline LTN6*** & $18 / 02 / 1991$ & $15 / 05 / 1992$ & 13 \\
& $05 / 03 / 2010$ & $13 / 12 / 2010$ & 13 \\
\hline LTW3 & $09 / 02 / 1991$ & $12 / 07 / 1992$ & 37 \\
\hline LTW2 & $09 / 02 / 1991$ & $12 / 07 / 1992$ & 42 \\
\hline LTW1 & $08 / 11 / 2009$ & $14 / 11 / 2011$ & 142 \\
\hline KIW & $03 / 08 / 1992$ & 34 \\
\hline
\end{tabular}

$*_{\mathrm{T} 007}$ receiver function is rotated by $270^{\circ}$ as a correction because of mis-alignment of the station during deployment.

** No events used from station LE2. There was insufficient 'pickable' data from both array and broadband stations. I attempted to rotate the data, but it did not improve.

***Station LTN6 was deployed in 1991/92 as part of the POMS project (Stuart, 1995) and redeployed in 2010 for the SAHKE project. The two sets of data were compatible to be merged into a single receiver function. 
TRWZ $1 \mathrm{~Hz}$
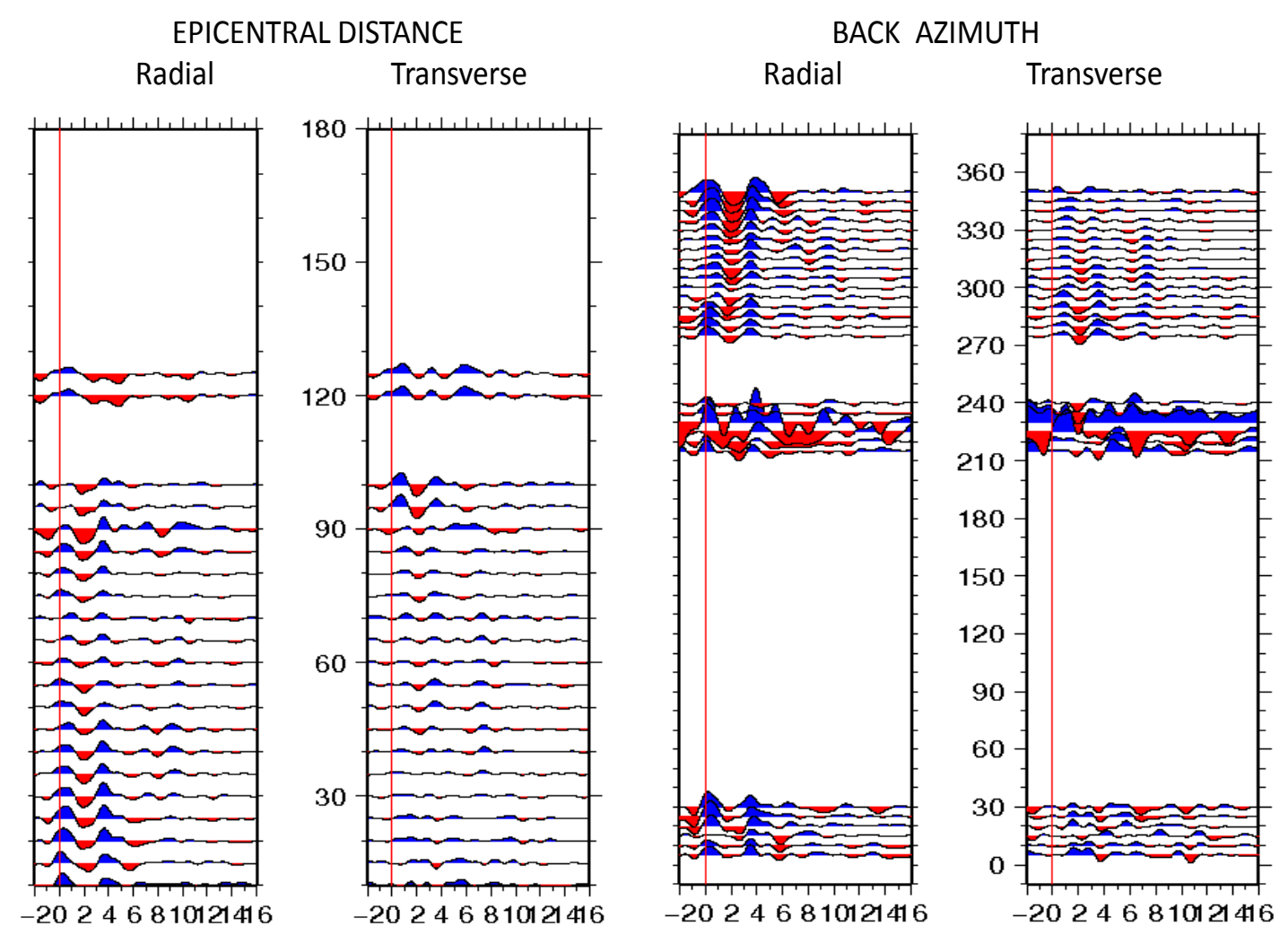

Figure 35 TRWZ Receiver Function Stack.

Blue indicates a positive phase. Red indicates a negative phase. Left-hand pair are stacked according to epicentral distance; the numbers on the vertical scale are degrees of epicentral distance; the horizontal scale is time (seconds); radial and transverse components (labeled) are left and right respectively. Right-hand pair are stacked according to back-azimuth; the numbers on the vertical scale are degrees of back azimuth; the horizontal scale is time (seconds); radial and transverse components (labeled) are left and right respectively.

\subsubsection{TRWZ}

TRWZ is the most easterly station, lying close to the east coast of the

Wairarapa, North Island New Zealand. The underlying geology immediately below this station is Pahau Terrane (Figure 33).

\section{Epicentral distance}

On the stack arranged by epicentral distances there is good coverage up to $100^{\circ}$, with a gap between $100-120^{\circ}$, just one event from $120-125^{\circ}$ and nothing from epicentral distances greater than $125^{\circ}$. The radial receiver 
functions show a positive amplitude peaked phase sequence at 0 seconds time delay (0s), and a strong negative peaked phase sequence at 2 s. Moveout of this negative phase decreases as the epicentral distance increases. Both the 0 s and the 2 s peak show a double peak at distances 120 $125^{\circ}$. The strong negative is followed by a strong positive at $\sim 3.8 \mathrm{~s}$ up to $100^{\circ}$, but not at $120-125^{\circ}$. The amplitude on both the transverse and radial stack decreases from $0-70^{\circ}$, then increases again. There is coherent energy on the transverse component; this is following the same pattern as the radial component.

\section{Back Azimuth}

On the stack arranged by back azimuth there are coherent sequences between $275-350^{\circ}$. As the back azimuth sweep represents a $360^{\circ}$ circle the apparent gaps on the plot between $0^{\circ}$ and $360^{\circ}$ are in fact not real gaps in the data, as $360^{\circ}$ back azimuth on the ground is the exact equivalent to $0^{\circ}$ back azimuth. The data sweep may be regarded as continuous from $270^{\circ}$ to $30^{\circ}$ back azimuth. On the radial component the $275-350^{\circ}$ section shows a positive peak phase sequence at 0 s delay time and a negative amplitude peaked phase sequence at $2 \mathrm{~s}$, followed by another positive at $\sim 3.8$ and a weaker negative at $6 \mathrm{~s}$. The amplitude is strong at $350^{\circ}$, but decays towards $300^{\circ}$, where it reaches a minimum, and then gets stronger as the BAZ decreases. On the transverse component the amplitude decays steadily, especially on the $\sim 3 \mathrm{~s}$ negative peak, from $270^{\circ}$ through to $350^{\circ}$. At $215-240^{\circ}$ the energy becomes less coherent and noisier, although the strong $2 \mathrm{~s}$ negative phase sequence is still clear. There is no BAZ coverage from 215$30^{\circ}$. Below $30^{\circ}$ the $0 \mathrm{~s}$ is strong on the radial but not on the transverse. There is more energy on the radial overall, with the exception of the section from $215-240^{\circ}$ where the energy on both components is similar. 


\section{LE4 $1 \mathrm{~Hz}$}

EPICENTRAL DISTANCE

Radial

Transverse

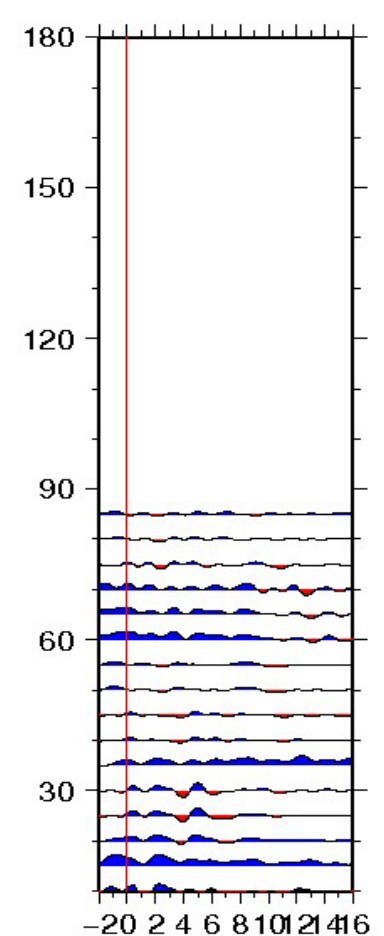

$-2024681012416$

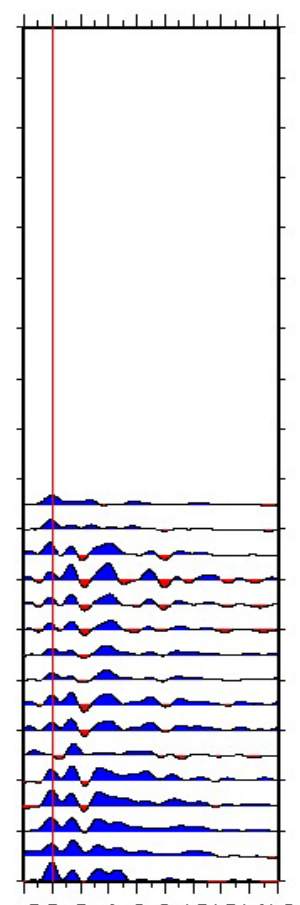

$-20246810121416$

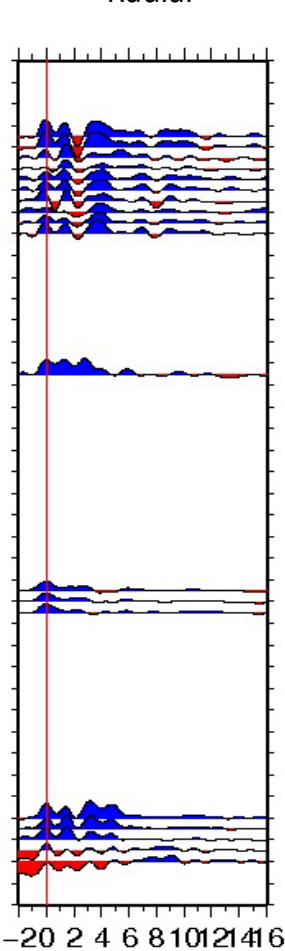

BACK AZIMUTH

Transverse

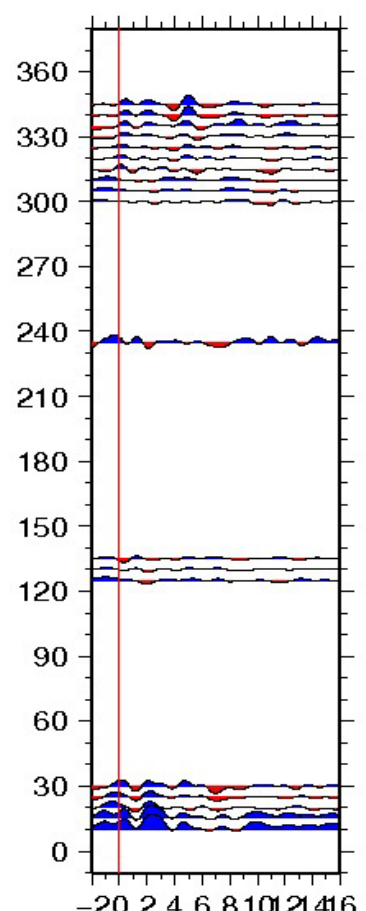

Figure 36 LE4 Receiver Function Stack.

Blue indicates a positive phase. Red indicates a negative phase. Left-hand pair are stacked according to epicentral distance; the numbers on the vertical scale are degrees of epicentral distance; the horizontal scale is time (seconds); radial and transverse components (labeled) are left and right respectively. Right-hand pair are stacked according to back-azimuth; the numbers on the vertical scale are degrees of back azimuth; the horizontal scale is time (seconds); radial and transverse components (labeled) are left and right respectively. 


\subsubsection{LE4}

LE4 is close to the east coast of the Wairarapa, North Island New Zealand. The underlying geology immediately below this station (Figure 33) is the Pahau Terrane. LE4 is surprisingly different from station TRWZ in spite of their close proximity.

\section{Epicentral distance}

On the stack arranged by epicentral distances there is good coverage up to $85^{\circ}$, with nothing above that. The radial receiver function shows a positive amplitude phase sequence at 0 seconds time delay, followed by another positive phase sequence at $\sim 1.5 \mathrm{~s}$, and strong negative peaks at $2 \mathrm{~s}$. The strong negative is followed by a strong positive at $\sim 3.75 \mathrm{~s}$. The amplitude on the radial decreases from $0-50^{\circ}$, then increases again. There is a weak negative arrival at $\sim 5 \mathrm{~s}$ between $55-65^{\circ}$. There is very little coherent energy on the transverse component; the amplitude decreases to almost nothing at $50^{\circ}$. There is a very weak negative on the transverse component at $\sim 4 \mathrm{~s}$ at $10-40^{\circ}$.

\section{Back Azimuth}

On the back azimuth stack there are three blocks of coherent energy between $300-355^{\circ}, 125-135^{\circ}$, and $10-30^{\circ}$, with a single trace at $235^{\circ}$. The radial component sections all show a positive phase sequence at 0s delay time and a negative amplitude phase sequence at $1.5 \mathrm{~s}$, coherent between $300-355^{\circ}$, followed by another broader wavelength positive at $\sim 3.8 \mathrm{~s}$. The trace at $235^{\circ}$ is noisy and incoherent compared with the radial component, with a very small amount of energy apparent. 


\section{T004 $1 \mathrm{~Hz}$}

EPICENTRAL DISTANCE

Radial

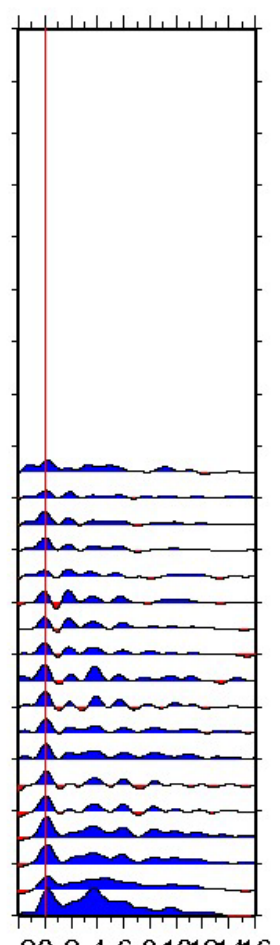

Transverse

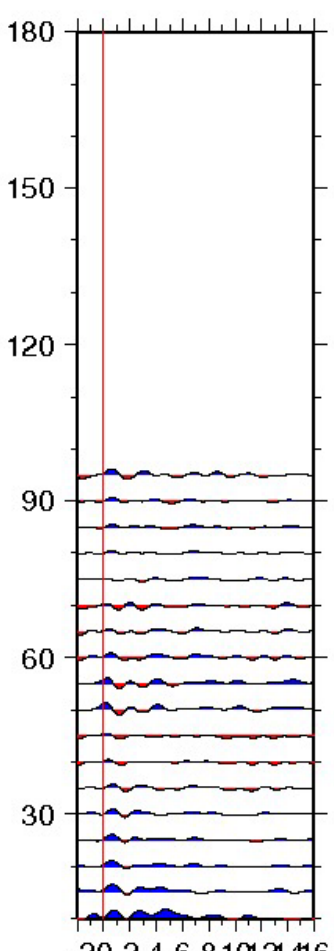

BACK AZIMUTH

Radial
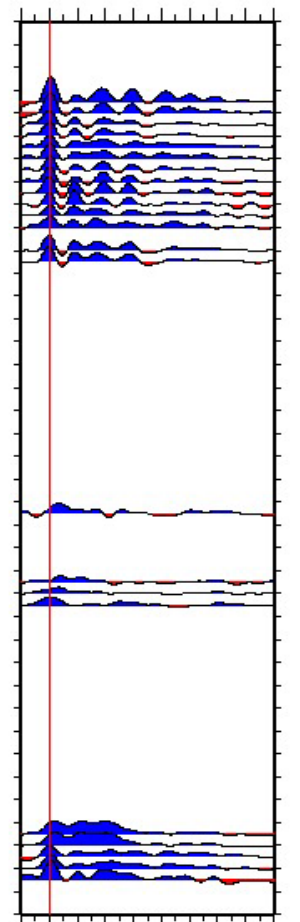

$-20246810121416$
Transverse

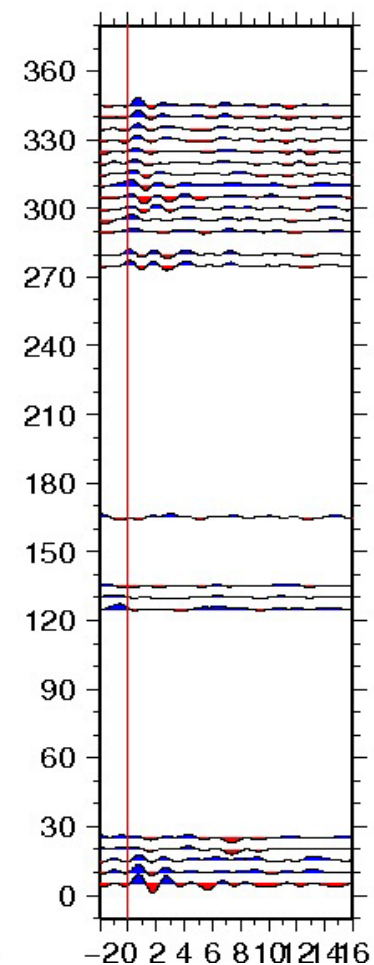

Figure 37 T004 Receiver Function Stack.

Blue indicates a positive phase. Red indicates a negative phase. Left-hand pair are stacked according to epicentral distance; the numbers on the vertical scale are degrees of epicentral distance; the horizontal scale is time (seconds); radial and transverse components (labeled) are left and right respectively. Right-hand pair are stacked according to back-azimuth; the numbers on the vertical scale are degrees of back azimuth; the horizontal scale is time (seconds); radial and transverse components (labeled) are left and right respectively. 


\section{$6.2 .3 \mathrm{~T} 004$}

T004 is on the coastal region of the east coast of the Wairarapa, North Island New Zealand. The underlying geology immediately below this station (Figure 33) is Pahau Terrane

\section{Epicentral distance}

On the epicentral distances stack there is good coverage up to $95^{\circ}$. The radial receiver function shows a positive amplitude phase sequence at 0 seconds time delay (0s), and a weak negative phase sequence at $\sim 1 \mathrm{~s}$. At distances below $30^{\circ}$ the signal is less coherent. The weak negative is followed by a positive at $\sim 2 \mathrm{~s}$ and $\sim 4 \mathrm{~s}$. The amplitude on the radial increases above $30^{\circ}$. There is a very small amount of coherent energy on the transverse component.

\section{Back Azimuth}

On the back azimuth stack there is coherent energy between $290-345^{\circ}$. This section shows a positive phase sequence at 0s delay time and a strongly coherent negative amplitude phase sequence at $\sim 1$ s, followed by another positive at $\sim 2.0 \mathrm{~s}$ and a weaker negative at $3 \mathrm{~s}$. 


\section{T007 $1 \mathrm{~Hz}$ (rotated 270 degrees)}

\section{EPICENTRAL DISTANCE}

Radial

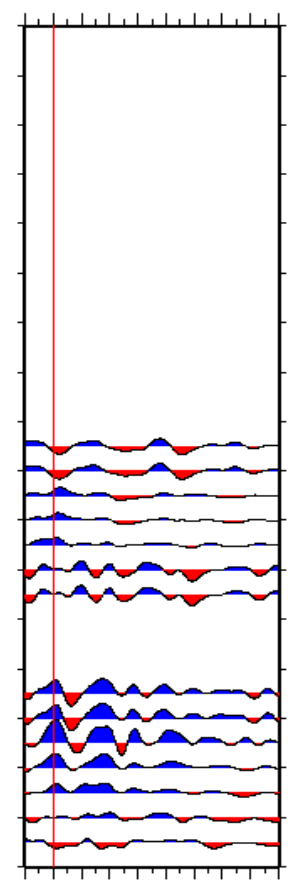

$-20246810121416$
Transverse

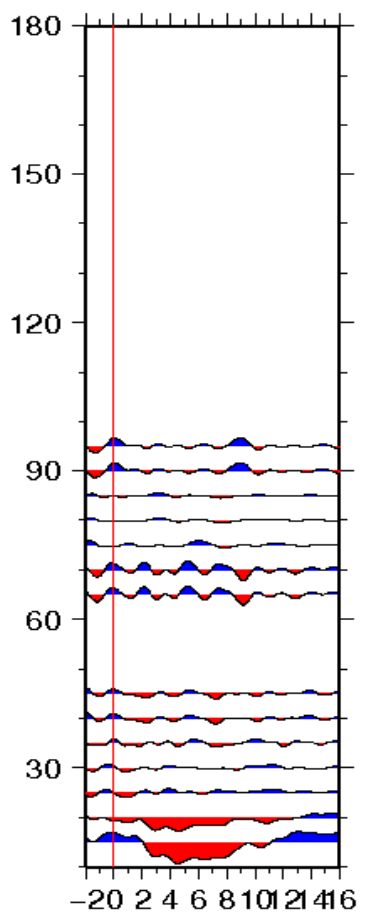

BACK AZIMUTH

Radial

Transverse

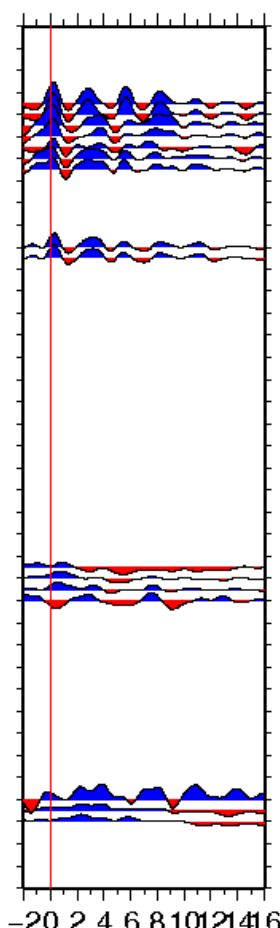

Figure 38 T007 Receiver Function Stack.

Blue indicates a positive phase. Red indicates a negative phase. Left-hand pair are stacked according to epicentral distance; the numbers on the vertical scale are degrees of epicentral distance; the horizontal scale is time (seconds); radial and transverse components (labeled) are left and right respectively. Right-hand pair are stacked according to back-azimuth; the numbers on the vertical scale are degrees of back azimuth; the horizontal scale is time (seconds); radial and transverse components (labeled) are left and right respectively. 


\subsubsection{T007}

T007 is quite close to the east coast of the Wairarapa, North Island New Zealand. The underlying geology immediately below this station (Figure 33) is Pahau Terrane.

\section{Epicentral distance}

On the epicentral distances stack there is coverage up to $95^{\circ}$, with a gap in coverage between $45-65^{\circ}$. The radial receiver function shows a positive amplitude phase sequence at $0 \mathrm{~s}$, except at 90 and $95^{\circ}$ and $65-70^{\circ}$. At $30-45^{\circ}$ there is a strong negative phase sequence at $1.75 \mathrm{~s}$, with a positive following at $\sim 3.75 \mathrm{~s}$, the amplitudes of positive and negative are the strongest at the $30-45^{\circ}$ interval. The amplitudes are weakest on both radial and transverse at $80^{\circ}$. There is some coherent energy on the transverse component, with the poles reversed as compared to the radial component.

\section{Back Azimuth}

On the back azimuth stack there is coherent energy between $270-345^{\circ}$, with a gap in the coverage at $290-320^{\circ}$. On the radial component the $270-345^{\circ}$ section shows a positive phase sequence at 0s delay time and a strong negative amplitude phase sequence at $\sim 1.6 \mathrm{~s}$, followed by another positive at $\sim 3.0$ s and a weaker negative at $\sim 4.5$ s. The section at BAZ $120-145^{\circ}$ is less coherent, with a negative at $0 \mathrm{~s}$ at $120^{\circ}$. 


\section{LE3 $1 \mathrm{~Hz}$}

EPICENTRAL DISTANCE

Radial

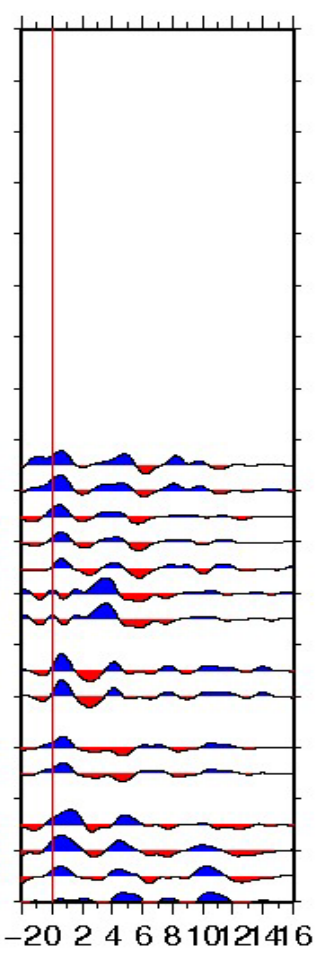

Transverse

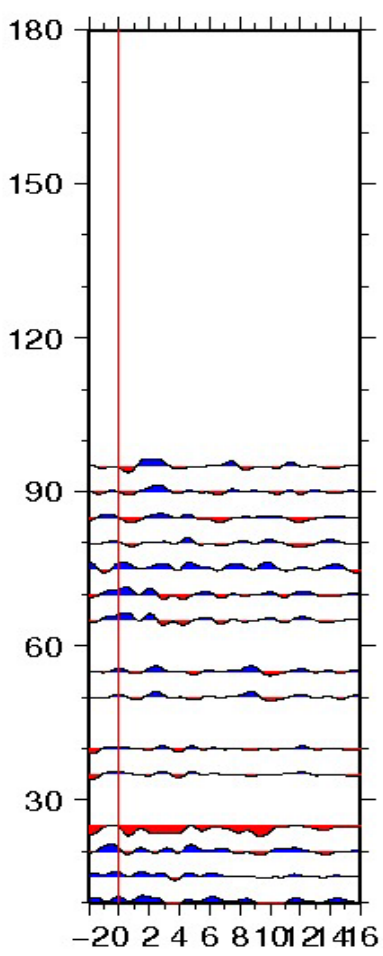

Radial

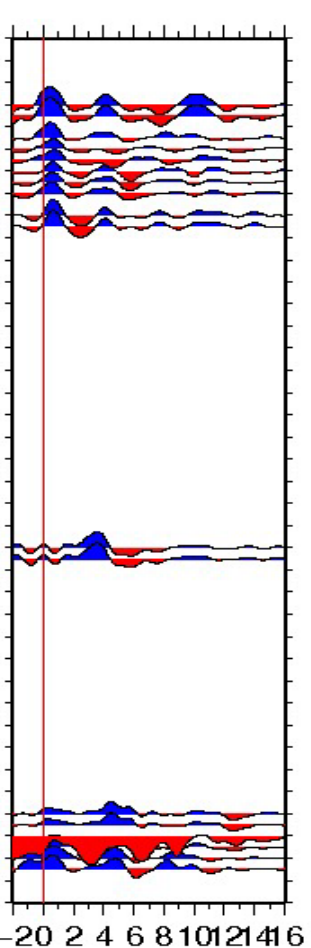

BACK AZIMUTH

Transverse

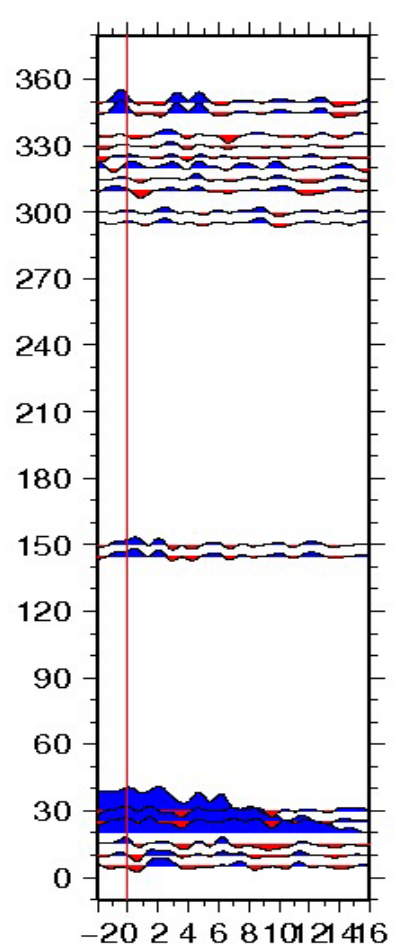

Figure 39 LE3 Receiver Function Stack.

Blue indicates a positive phase. Red indicates a negative phase. Left-hand pair are stacked according to epicentral distance; the numbers on the vertical scale are degrees of epicentral distance; the horizontal scale is time (seconds); radial and transverse components (labeled) are left and right respectively. Right-hand pair are stacked according to back-azimuth; the numbers on the vertical scale are degrees of back azimuth; the horizontal scale is time (seconds); radial and transverse components (labeled) are left and right respectively. 


\subsubsection{LE3, T010, T014, T016 AND MTW}

LE3, T010, T014, T016 and MTW all lie inland from the east coast of the Wairarapa, North Island New Zealand, traversing the Wairarapa basin. The underlying geology immediately below these stations (Figure 33) is Pahau Terrane.

All these stations show a marked similarity in their delay times and polarity, indicating there is some homogeneity of structure beneath these five stations.

\section{Epicentral Distance}

On the radial component all stations (LE3, T010, T014, T016 and MTW. See Figures 32, 33, 34, 35 and 36) show a positive amplitude phase sequence at $0 \mathrm{~s}$. This is followed by a negative arrival sequence at $\sim 2 \mathrm{~s}-2.5 \mathrm{~s}$, strong and coherent for all the stations except T010, where it is very weak. This is followed by a strongly coherent positive amplitude phase sequence at $4 \mathrm{~s}$. The coherent negative peak following this is at $\sim 6$ s for LE3and T010 and 5s for T014, T016 and MTW. All the stations, with the exception of T014 show very little energy on the transverse component. T014 shows coherent energy without the expected pole reversal on the transverse stack.

\section{Back Azimuth}

All the stations have a similar back azimuthal coverage; with receiver functions from $270-350^{\circ}$, two or three traces between $120^{\circ}$ and $150^{\circ}$ and several from between $10^{\circ}$ and $30^{\circ}$.

LE3, T010 and T014 have a strong positive arrival on the radial component arriving at $\sim 0.2 \mathrm{~s}$. T016 and MTW have a strong positive phase sequence at 0s. At $\sim 2$ s, in the larger back azimuths $\left(270-350^{\circ}\right)$ there is a coherent negative phase sequence. This is less evident at the lower back azimuths. 


\section{$\mathrm{T} 0101 \mathrm{~Hz}$}

EPICENTRAL DISTANCE

Radial

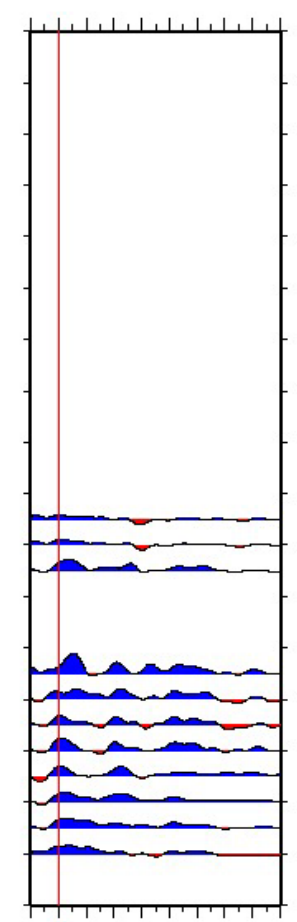

$-20246810121416$
Transverse

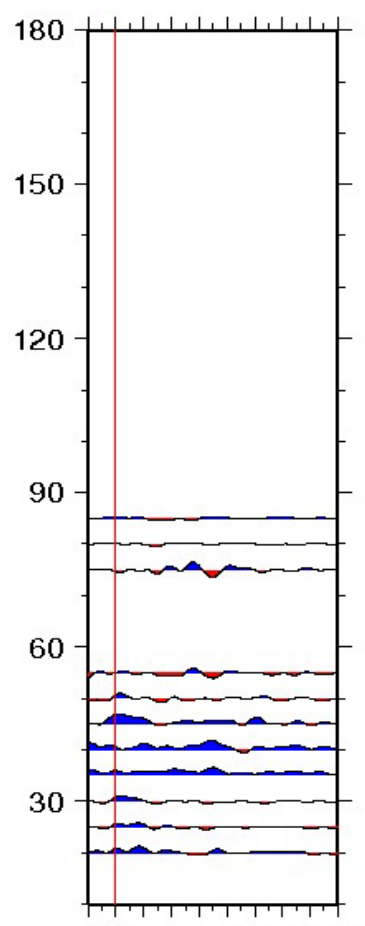

$-20246810121416$
BACK AZIMUTH

Radial

Transverse

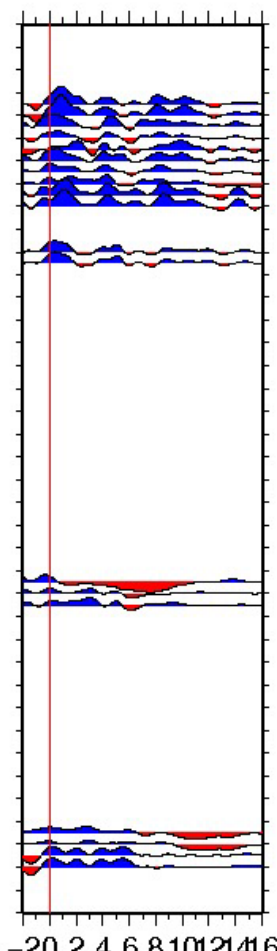

Figure 40 T010 Receiver Function Stack.

Blue indicates a positive phase. Red indicates a negative phase. Left-hand pair are stacked according to epicentral distance; the numbers on the vertical scale are degrees of epicentral distance; the horizontal scale is time (seconds); radial and transverse components (labeled) are left and right respectively. Right-hand pair are stacked according to back-azimuth; the numbers on the vertical scale are degrees of back azimuth; the horizontal scale is time (seconds); radial and transverse components (labeled) are left and right respectively. 
EPICENTRAL DISTANCE

Radial

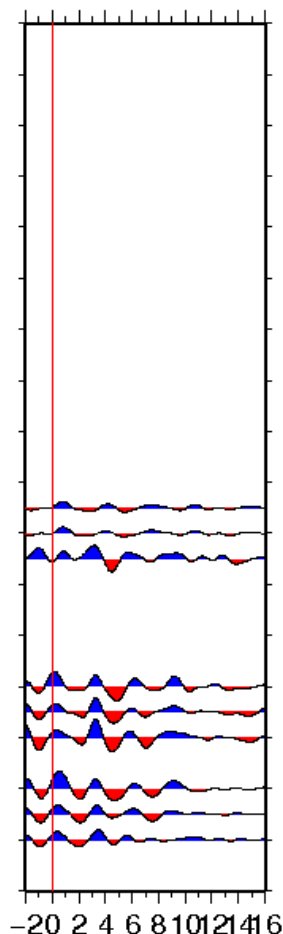

$\mathrm{T} 014 \mathrm{~Hz}$

Transverse

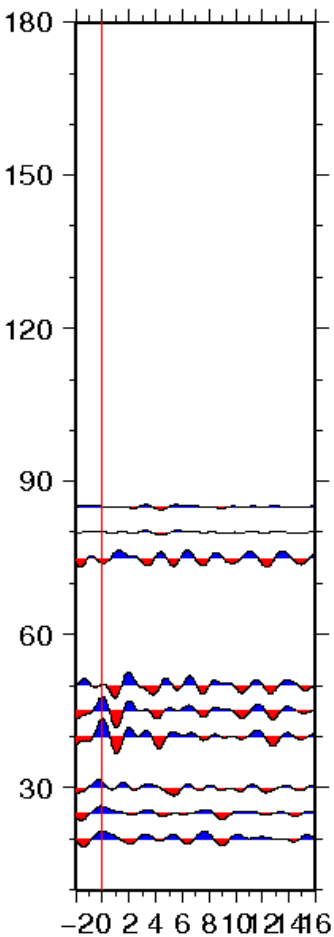

BACK AZIMUTH

Radial

Transverse

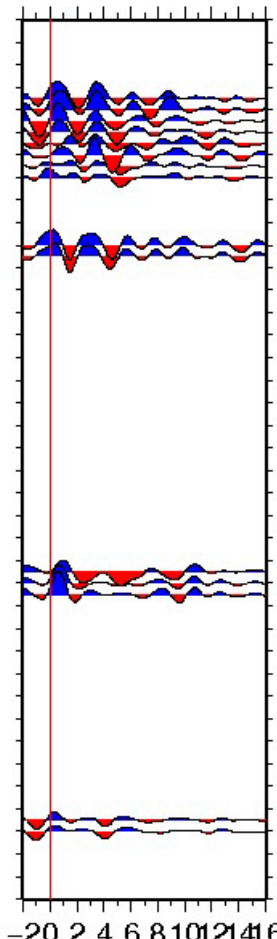

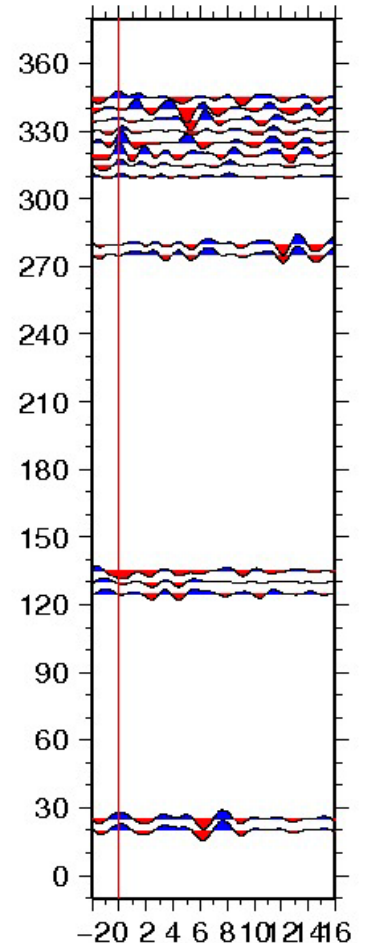

Figure 41 T014 Receiver Function Stack.

Blue indicates a positive phase. Red indicates a negative phase. Left-hand pair are stacked according to epicentral distance; the numbers on the vertical scale are degrees of epicentral distance; the horizontal scale is time (seconds); radial and transverse components (labeled) are left and right respectively. Right-hand pair are stacked according to back-azimuth; the numbers on the vertical scale are degrees of back azimuth; the horizontal scale is time (seconds); radial and transverse components (labeled) are left and right respectively. 


\section{T016 1Hz}

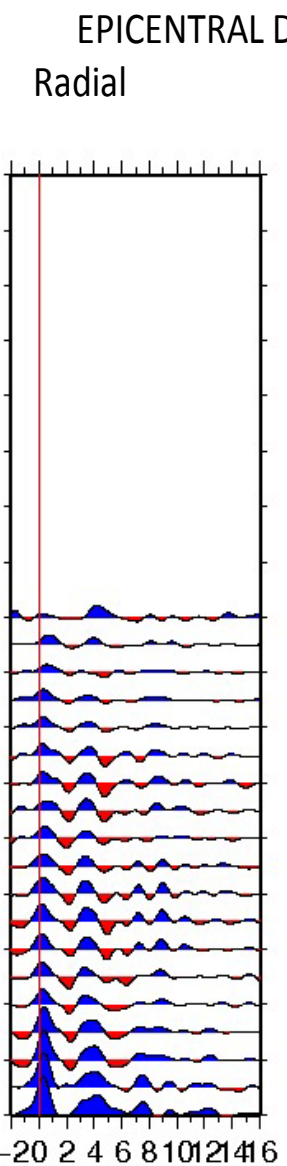

Transverse

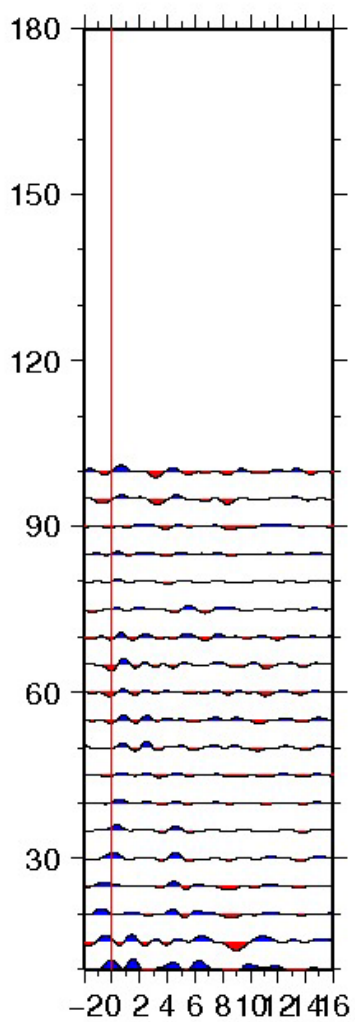

BACK AZIMUTH

Radial

Transverse
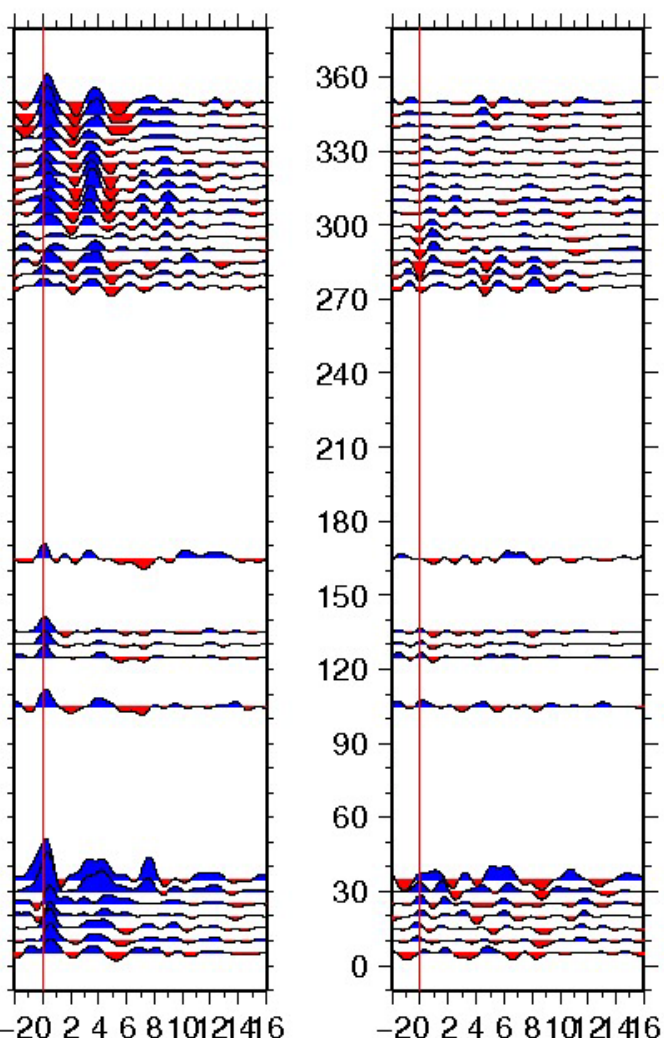

Figure 42 T016 Receiver Function Stack.

Blue indicates a positive phase. Red indicates a negative phase. Left-hand pair are stacked according to epicentral distance; the numbers on the vertical scale are degrees of epicentral distance; the horizontal scale is time (seconds); radial and transverse components (labeled) are left and right respectively. Right-hand pair are stacked according to back-azimuth; the numbers on the vertical scale are degrees of back azimuth; the horizontal scale is time (seconds); radial and transverse components (labeled) are left and right respectively. 


\section{MTW $1 \mathrm{~Hz}$}

EPICENTRAL DISTANCE

Radial

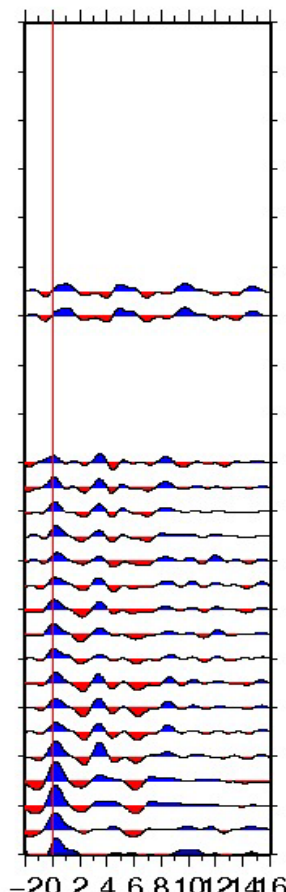

Transverse

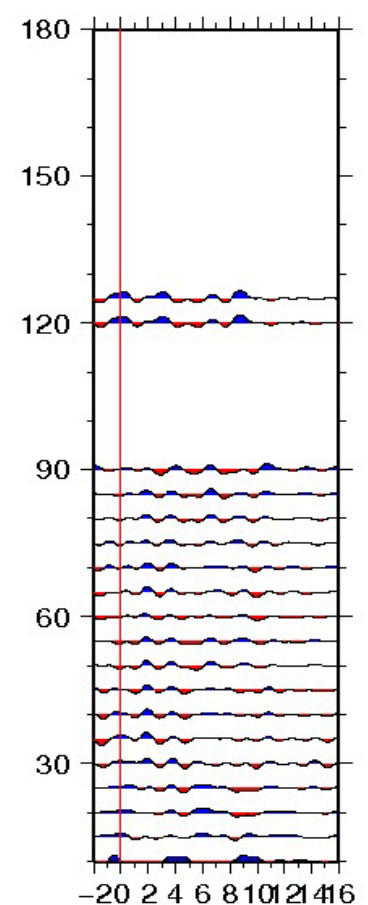

BACK AZIMUTH

Radial

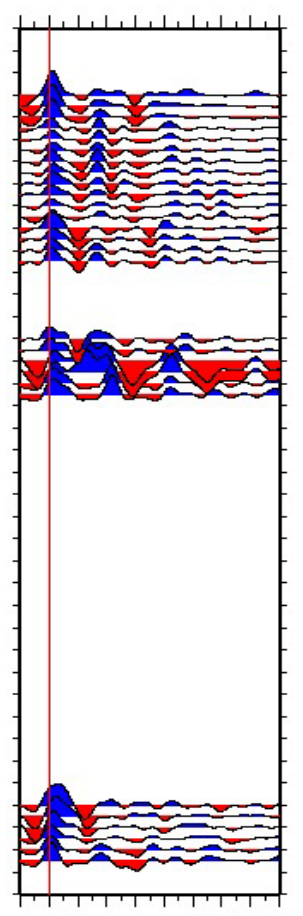

$-20246810121416$
Transverse

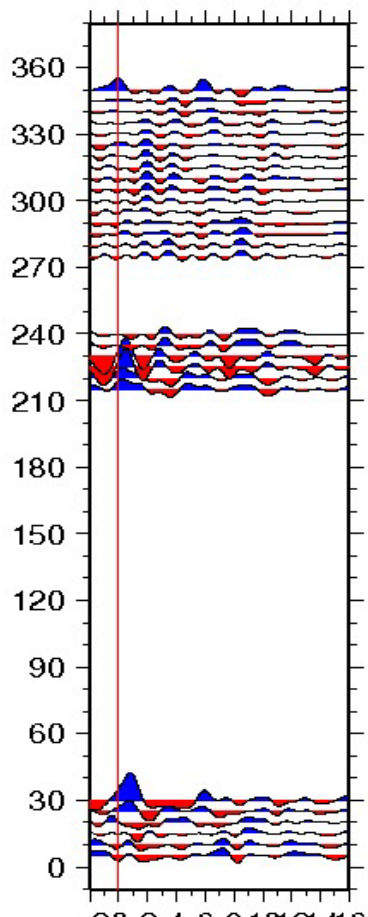

Figure 43 Receiver Function Stack.

Blue indicates a positive phase. Red indicates a negative phase. Left-hand pair are stacked according to epicentral distance; the numbers on the vertical scale are degrees of epicentral distance; the horizontal scale is time (seconds); radial and transverse components (labeled) are left and right respectively. Right-hand pair are stacked according to back-azimuth; the numbers on the vertical scale are degrees of back azimuth; the horizontal scale is time (seconds); radial and transverse components (labeled) are left and right respectively. 
$\mathrm{T} 0181 \mathrm{~Hz}$

EPICENTRAL DISTANCE

Radial

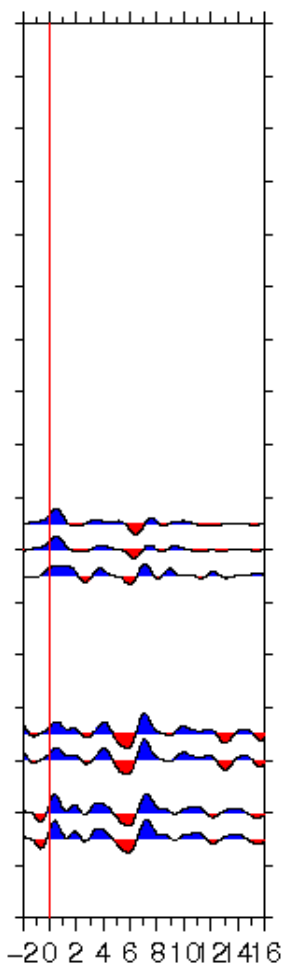

Transverse

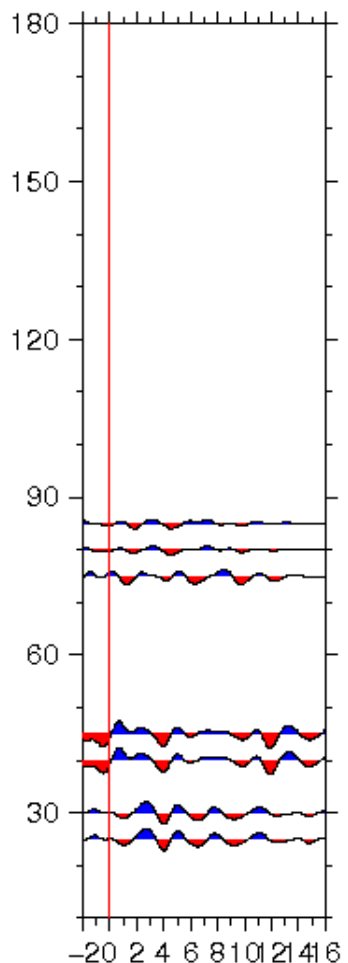

BACK AZIMUTH

Radial

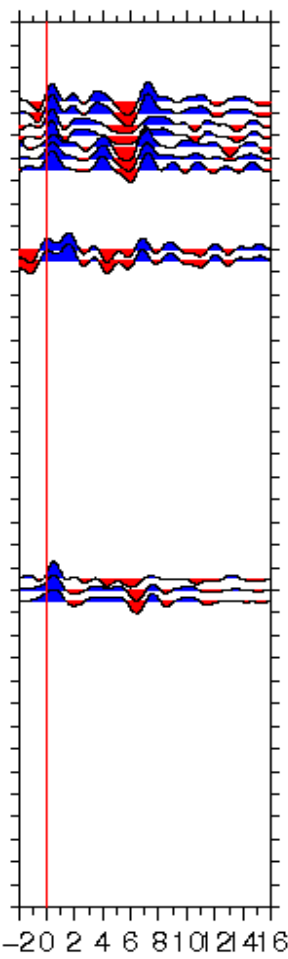

Transverse

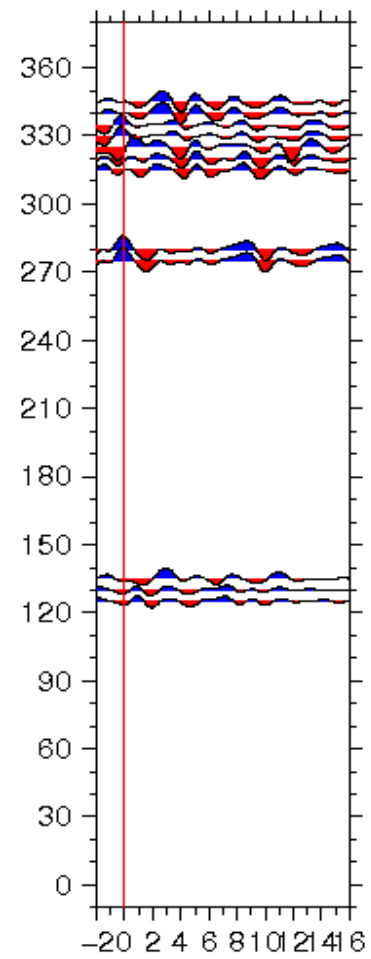

Figure 44 T018 Receiver Function Stack.

Blue indicates a positive phase. Red indicates a negative phase. Left-hand pair are stacked according to epicentral distance; the numbers on the vertical scale are degrees of epicentral distance; the horizontal scale is time (seconds); radial and transverse components (labeled) are left and right respectively. Right-hand pair are stacked according to back-azimuth; the numbers on the vertical scale are degrees of back azimuth; the horizontal scale is time (seconds); radial and transverse components (labeled) are left and right respectively. 


\subsubsection{T018}

T018 is situated in the central Wairarapa basin, to the east of the axial ranges. The underlying geology (Figure 33) is Pahau Terrane.

T018 has sparse coverage at less than $90^{\circ}$ epicentral distance. There is a coherent sequence at $310-340^{\circ}$ back azimuth, with two traces at $270-280^{\circ}$, and three traces at $125-140^{\circ}$. This poor coverage is because the stack consists of just 12 events, the least number of all the stations.

\section{Epicentral Distance}

On the radial component there is a positive double peaked sequence at $0 \mathrm{~s}$ and 2 s. There is a very weakly negative sequence between this and another positive amplitude sequence at $\sim 5 \mathrm{~s}$. At $6 \mathrm{~s}$ there is a strong coherent negative phase sequence. There is some energy on the transverse component.

\section{Back Azimuth}

A strong positive phase sequence at $\sim 8 \mathrm{~s}$ is preceded by a strong negative phase sequence at $\sim 6.3 \mathrm{~s}$. This negative shows a double peak at $270-280^{\circ}$. The preceding positive is low amplitude, with a coherent positive at 0 s. The transverse component shows some energy. 


\section{T020 1Hz}

EPICENTRAL DISTANCE

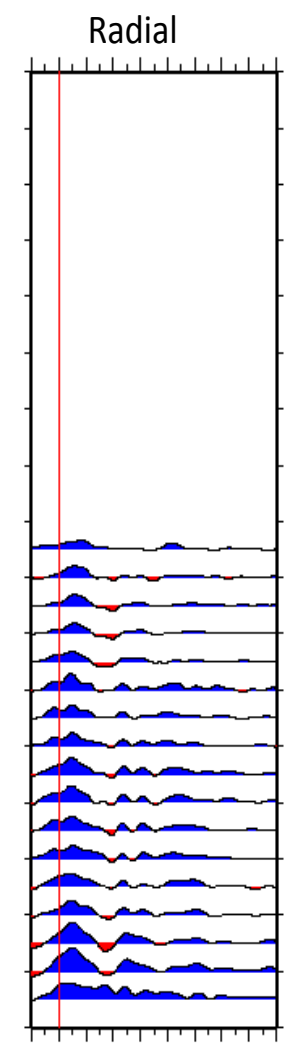

$-20246810121416$
Transverse

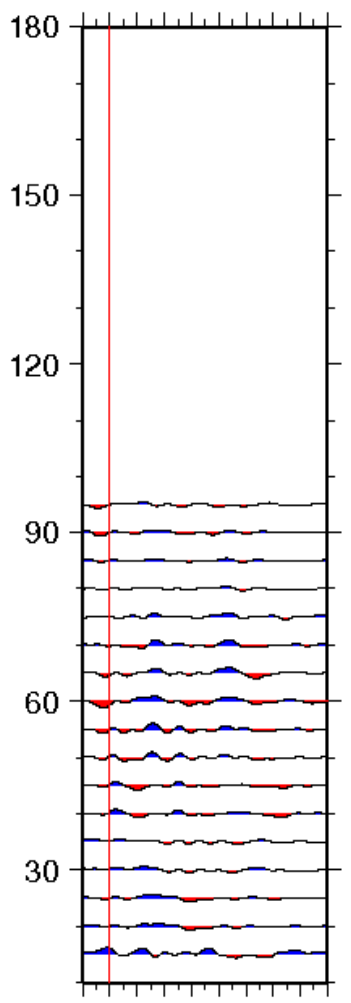

$-20246810121416$

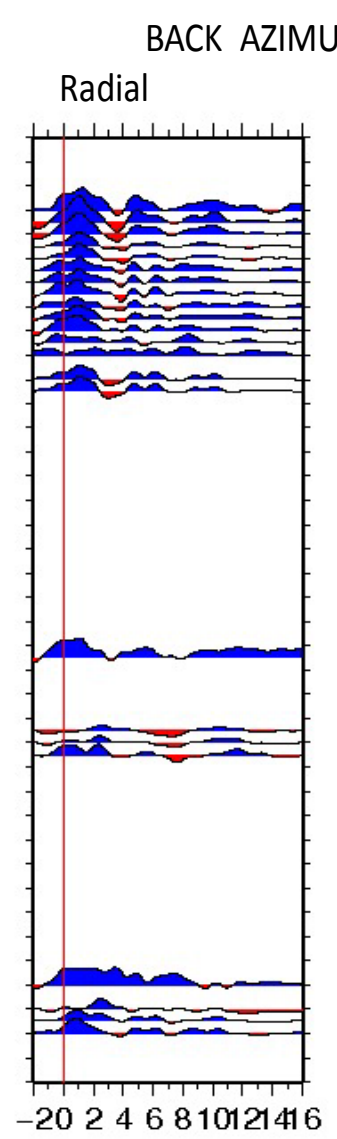

BACK AZIMUTH

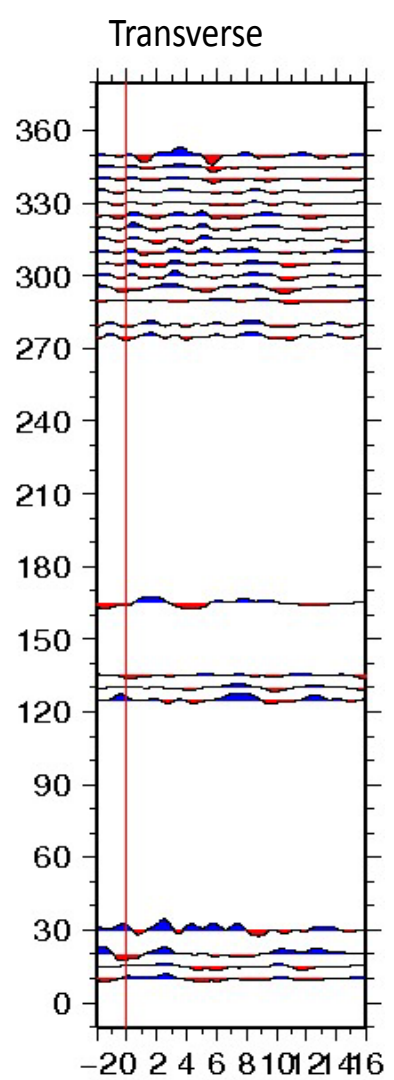

\section{Figure 45 T020 Receiver Function Stack.}

Blue indicates a positive phase. Red indicates a negative phase. Left-hand pair are stacked according to epicentral distance; the numbers on the vertical scale are degrees of epicentral distance; the horizontal scale is time (seconds); radial and transverse components (labeled) are left and right respectively. Right-hand pair are stacked according to back-azimuth; the numbers on the vertical scale are degrees of back azimuth; the horizontal scale is time (seconds); radial and transverse components (labeled) are left and right respectively. 


\subsubsection{T020}

Station T020 is situated in the Wairarapa basin, to the east of the axial ranges, just north of Lake Wairarapa. The underlying geology (Figure 33) is Pahau Terrane.

The station has good coverage for epicentral distances up to $95^{\circ}$, and back azimuthal ranges of $270-350^{\circ}$. Back azimuthal coverage below $160^{\circ}$ is sparse.

\section{Epicentral Distance}

On the radial component there is a strong positive double, or triple peaked sequence at $0 \mathrm{~s}$ and $2 \mathrm{~s}$. There is a very weakly negative sequence between this and another positive amplitude sequence at $\sim 4.2 \mathrm{~s}$. At $6 \mathrm{~s}$ there is another weakly positive phase sequence. There is very little energy evident on the transverse component.

\section{Back Azimuth}

A coherent positive phase sequence at $\sim 8 \mathrm{~s}$ is preceded by another positive phase sequence at $\sim 6 \mathrm{~s}$. The two positive peaks merge as a double peak at back azimuths greater than $330^{\circ}$.This is preceded by a very weak, but coherent negative phase sequence at $\sim 4 \mathrm{~s}$. The preceding strong multi peaked positive covers from $0-2 \mathrm{~s}$, with a polarity reversal evident at $130^{\circ}$. The transverse component shows some energy. 
T022 $1 \mathrm{~Hz}$

EPICENTRAL DISTANCE

Radial

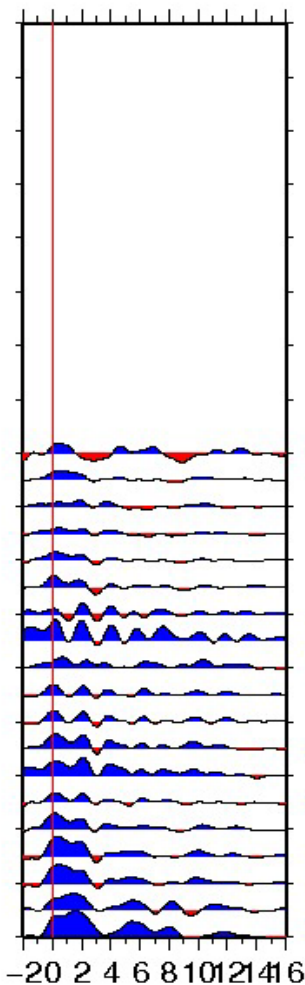

Transverse

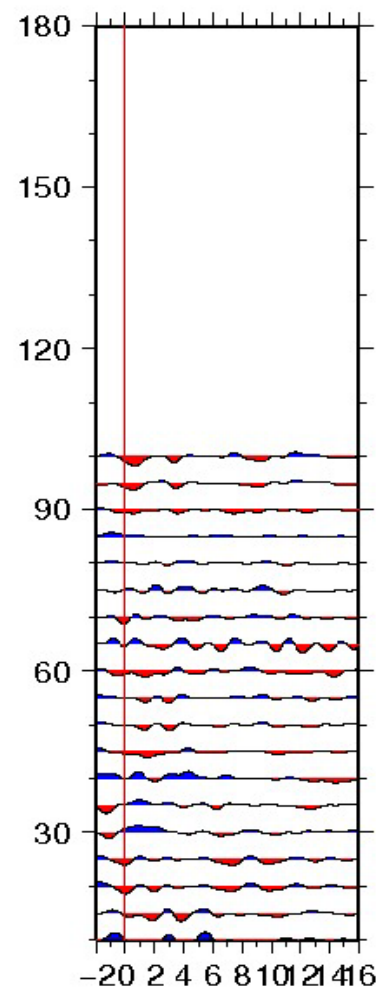

BACK AZIMUTH

Radial
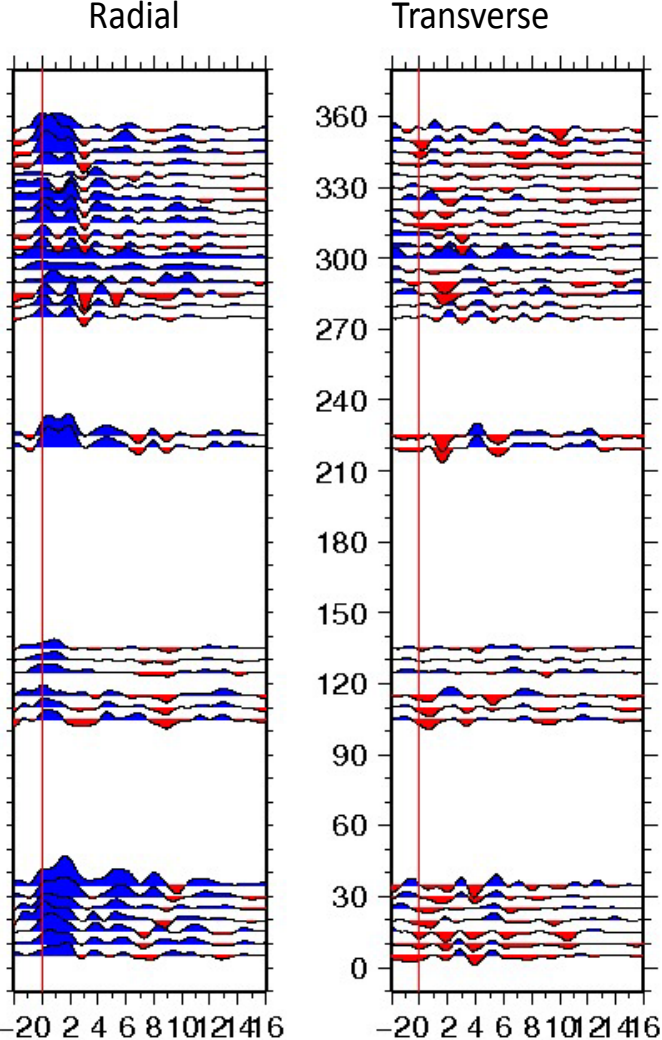

Figure 46 T022 Receiver Function Stack.

Blue indicates a positive phase. Red indicates a negative phase. Left-hand pair are stacked according to epicentral distance; the numbers on the vertical scale are degrees of epicentral distance; the horizontal scale is time (seconds); radial and transverse components (labeled) are left and right respectively. Right-hand pair are stacked according to back-azimuth; the numbers on the vertical scale are degrees of back azimuth; the horizontal scale is time (seconds); radial and transverse components (labeled) are left and right respectively. 


\section{LTN6 $1 \mathrm{~Hz}$}

EPICENTRAL DISTANCE Radial

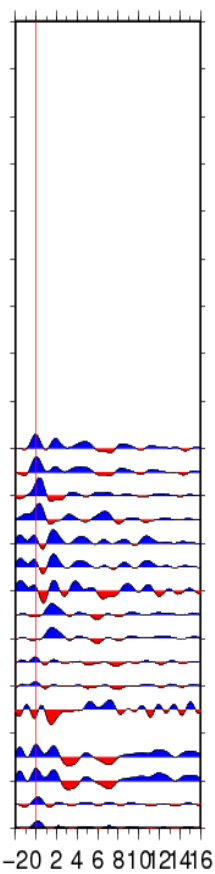

Transverse

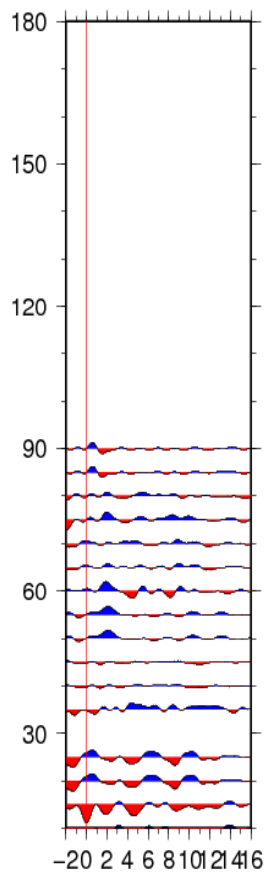

BACK AZIMUTH

Radial Transverse

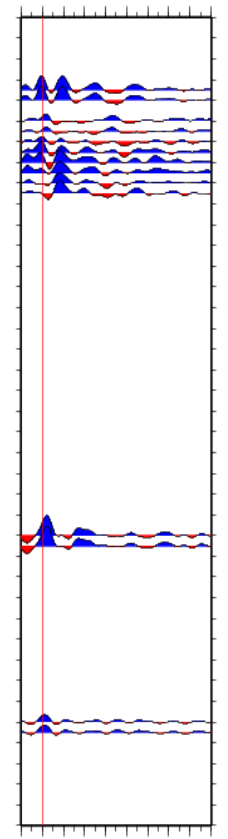

$-20246810121416$

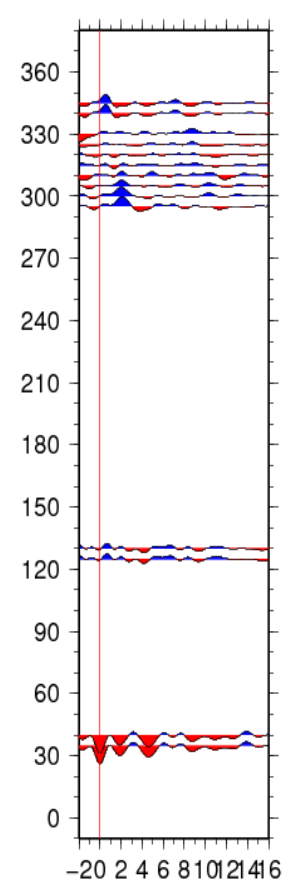

Figure 47 LTN6 Receiver Function Stack.

Blue indicates a positive phase. Red indicates a negative phase. Left-hand pair are stacked according to epicentral distance; the numbers on the vertical scale are degrees of epicentral distance; the horizontal scale is time (seconds); radial and transverse components (labeled) are left and right respectively. Right-hand pair are stacked according to back-azimuth; the numbers on the vertical scale are degrees of back azimuth; the horizontal scale is time (seconds); radial and transverse components (labeled) are left and right respectively. 


\subsubsection{T022 AND LTN6}

T022 and LTN6 lie at the foot of the axial ranges, at the western edge of the Wairarapa basin. The underlying geology (Figure 33) is Pahau Terrane. Both stations share characteristics of amplitude and timing of their phase sequences.

\section{Epicentral distance}

On the stacks arranged by epicentral distances there is good coverage up to $100^{\circ}$ on T022 and $90^{\circ}$ on LTN6. The transverse radial receiver functions show a positive amplitude peaked phase sequence at 0.5 seconds time delay $(0.5 \mathrm{~s})$. This initial arrival at both stations has a flat double peaked amplitude, with a pole reversal observed on LTN6 at epicentral distance $35-40^{\circ}$. This is followed by a coherent negative phase sequence at $\sim 3 \mathrm{~s}$ on T022, and a very weak negative phase sequence on LTN6 observed only between $30-60^{\circ}$. The energy flattens out after this phase, with a very weak positive observed on both stations; with the exception of the trace at $65^{\circ}$ on T022 which has amplitude peaks that are not in concord with the other receiver function traces at T022 or LTN6.

\section{Back Azimuth}

Both T022 and LTN6 show the strong flat topped double peaked waveform at 0s. After this positive waveform LTN6 is incoherent and low amplitude; but T022 shows a strongly coherent negative phase sequence at $\sim 2.6 \mathrm{~s}$, running from $100-355^{\circ}$ of back azimuth. 


\section{LTW3 $1 \mathrm{~Hz}$}

EPICENTRAL DISTANCE

Radial

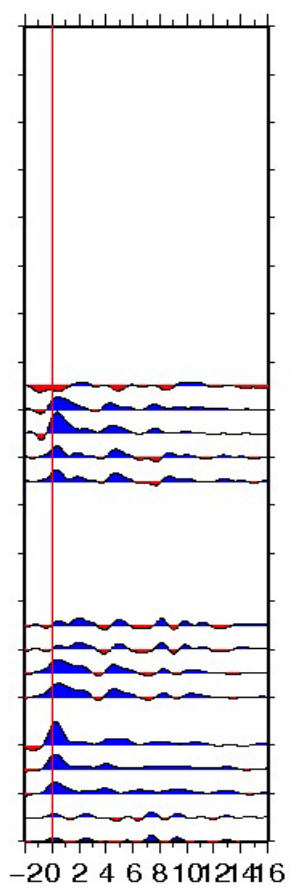

Transverse

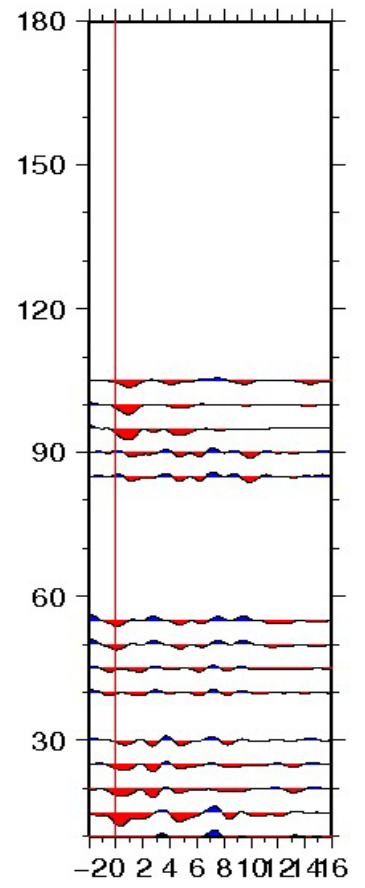

BACK AZIMUTH

Radial

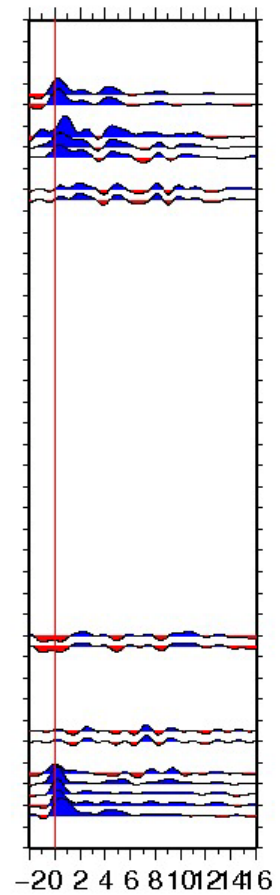

Transverse

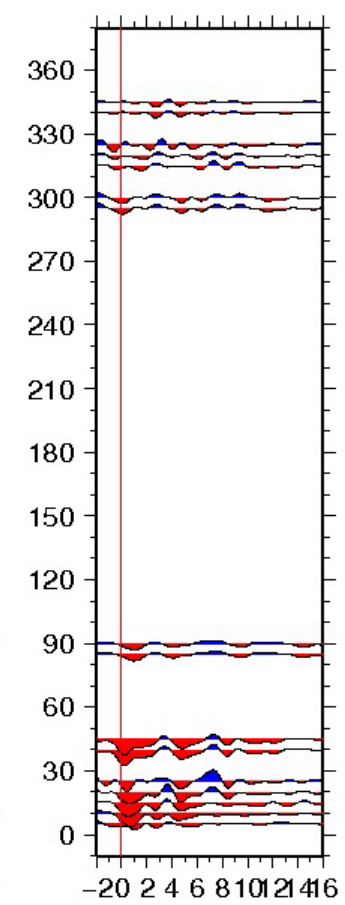

\section{Figure 48 LTW3 Receiver Function Stack.}

Blue indicates a positive phase. Red indicates a negative phase. Left-hand pair are stacked according to epicentral distance; the numbers on the vertical scale are degrees of epicentral distance; the horizontal scale is time (seconds); radial and transverse components (labeled) are left and right respectively. Right-hand pair are stacked according to back-azimuth; the numbers on the vertical scale are degrees of back azimuth; the horizontal scale is time (seconds); radial and transverse components (labeled) are left and right respectively. 


\subsubsection{LTW3}

LTW3 lies on the Tararua ranges, in the central western part of the transect. The underlying geology for this area is (Figure 33) is Rakaia Terrane.

\section{Epicentral Distance}

LTW3 shows coverage from $85-105^{\circ}$ of epicentral distance, and from $0-55^{\circ}$, with a gap from $40-50^{\circ}$. There is a strong positive amplitude arrival at $0 \mathrm{~s}$, showing a double peaked form. This is followed by a weak negative sequence at $\sim 3.5 \mathrm{~s}$, a positive at $5 \mathrm{~s}$ and another weak negative phase sequence, with some double peaks at $7 \mathrm{~s}$. The trace at $105^{\circ}$ shows a polarity reversal. The transverse component shows low energy, compared to the radial component.

\section{Back Azimuth}

The back azimuth stack is coherent with energy observed as far as a delay time of 12s. Back azimuthal coverage is patchy, with no events from between back azimuths of $90-290^{\circ}$. Coherent positive and negative phase sequences are observed on the radial component, particularly in the section from 290$345^{\circ}$. There is a polarity reversal at $80-90^{\circ}$. The transverse component shows fairly low energy compared to the radial component. 


\section{LTW2 $1 \mathrm{~Hz}$}

EPICENTRAL DISTANCE

Radial

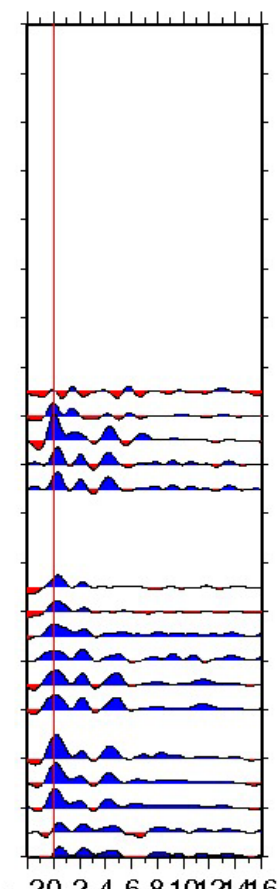

Transverse

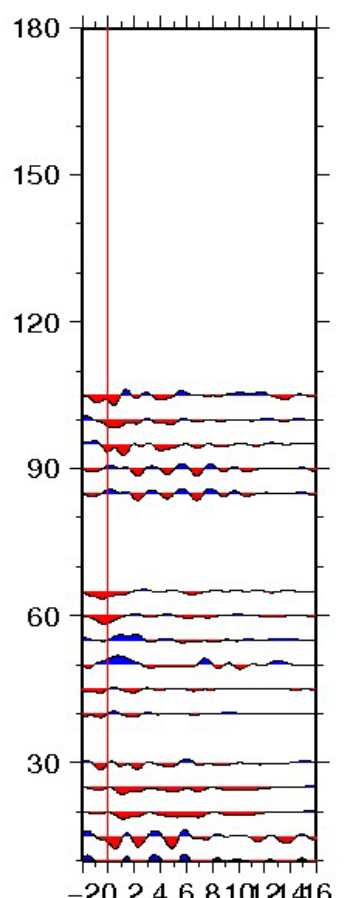

BACK AZIMUTH

Radial

Transverse

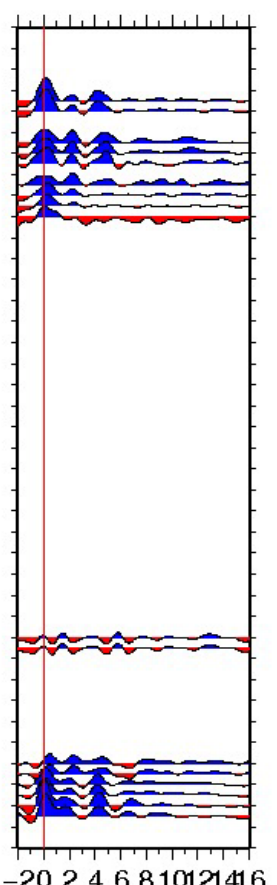

Figure 49 LTW2 Receiver Function Stack.

Blue indicates a positive phase. Red indicates a negative phase. Left-hand pair are stacked according to epicentral distance; the numbers on the vertical scale are degrees of epicentral distance; the horizontal scale is time (seconds); radial and transverse components (labeled) are left and right respectively. Right-hand pair are stacked according to back-azimuth; the numbers on the vertical scale are degrees of back azimuth; the horizontal scale is time (seconds); radial and transverse components (labeled) are left and right respectively. 


\subsubsection{LTW2}

LTW2 lies on the Tararua ranges, in the central western part of the transect. The underlying geology for this area is (Figure 33) is Rakaia Terrane.

\section{Epicentral Distance}

LTW2 shows coverage from $0-105^{\circ}$ of epicentral distance, with gaps in coverage from $30-40^{\circ}$ and from $65-85^{\circ}$. There is a strong positive amplitude arrival at 0 s, showing a strong double peaked form. This is followed by a weak, but coherent negative sequence at $\sim 3 \mathrm{~s}$, a positive at $4.5 \mathrm{~s}$ and another very weak negative phase sequence, with some double peaks at $7.5 \mathrm{~s}$. The trace at $105^{\circ}$ shows a polarity reversal (as did the same trace n LTW3).

\section{Back Azimuth}

Coherent positive and negative phase sequences are observed on the radial component, particularly in the section from $290-345^{\circ}$. The coherent positive phase sequences are observed at 0,2 and 5 s delay times. A negative phase sequence is observed at 3s. Back azimuthal coverage is patchy, with no events from between back azimuths of 90-290 . 
LTW1 $1 \mathrm{~Hz}$

EPICENTRAL DISTANCE

Radial

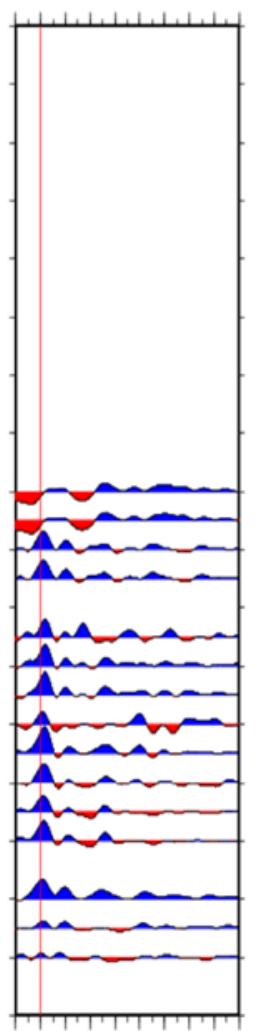

$-20246810121416$

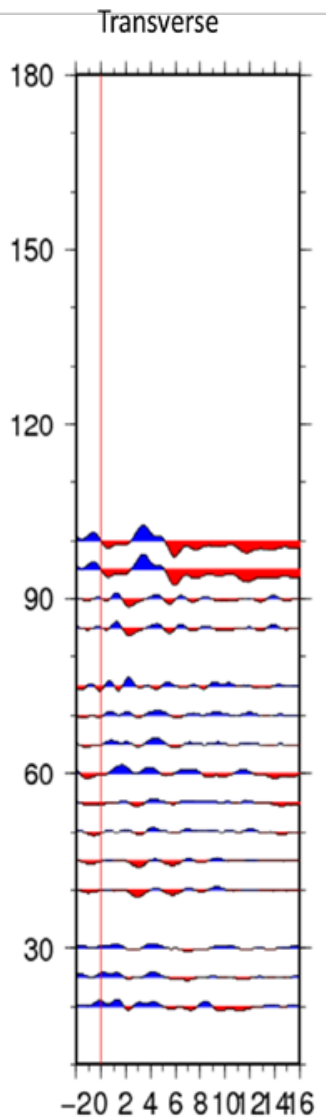

EPICENTRAL DISTANCE Radial

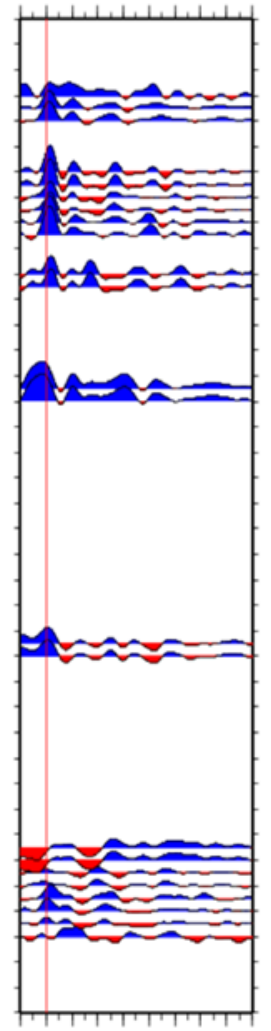

$-20246810121416$
Transverse

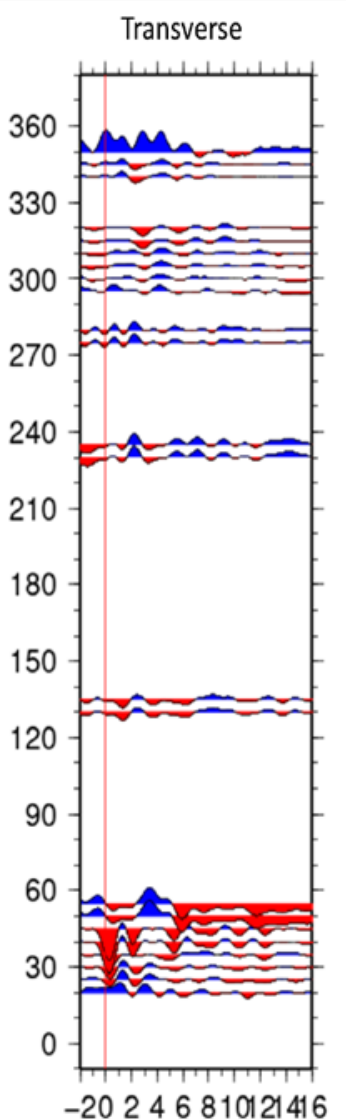

Figure 50 LTW1 Receiver Function Stack.

Blue indicates a positive phase. Red indicates a negative phase. Left-hand pair are stacked according to epicentral distance; the numbers on the vertical scale are degrees of epicentral distance; the horizontal scale is time (seconds); radial and transverse components (labeled) are left and right respectively. Right-hand pair are stacked according to back-azimuth; the numbers on the vertical scale are degrees of back azimuth; the horizontal scale is time (seconds); radial and transverse components (labeled) are left and right respectively. 


\subsubsection{LTW1}

LTW1 lies on the eastern coastal ranges, and is the mainland station closest to the Kapiti (eastern coast) on the central western end of the transect. The underlying geology for this area (Figure 33) is Rakaia Terrane.

\section{Epicentral Distance}

LTW1 shows patchy coverage from $0-125^{\circ}$ of epicentral distance, with gaps in coverage from $30-40^{\circ}$, from $55-65^{\circ}, 70-85^{\circ}$ and $105-120^{\circ}$. There is a strong positive amplitude arrival at 0 s, showing a pole reversal at $100-125^{\circ}$ though this may be a result of noise. This is followed by a weak, but coherent negative sequence at $\sim 1.2 \mathrm{~s}$, a positive at $2 \mathrm{~s}$ and another weakly negative phase sequence, at $3.8 \mathrm{~s}$. The traces at $100-125^{\circ}$ showing polarity reversal are similar to the polarity reversals observed on LTW3 and LTW2 at $105^{\circ}$.

\section{Back Azimuth}

Coherent positive and negative phase sequences are observed on the radial component, particularly in the section from $295-350^{\circ}$. The coherent positive phase sequences are observed at 0,2 and $\sim 4.5 \mathrm{~s}$ delay times. A negative phase sequences are observed at $3 \mathrm{~s}$ and $8 \mathrm{~s}$. Back azimuthal coverage is patchy, with no events from between back azimuths of 90-295 . 


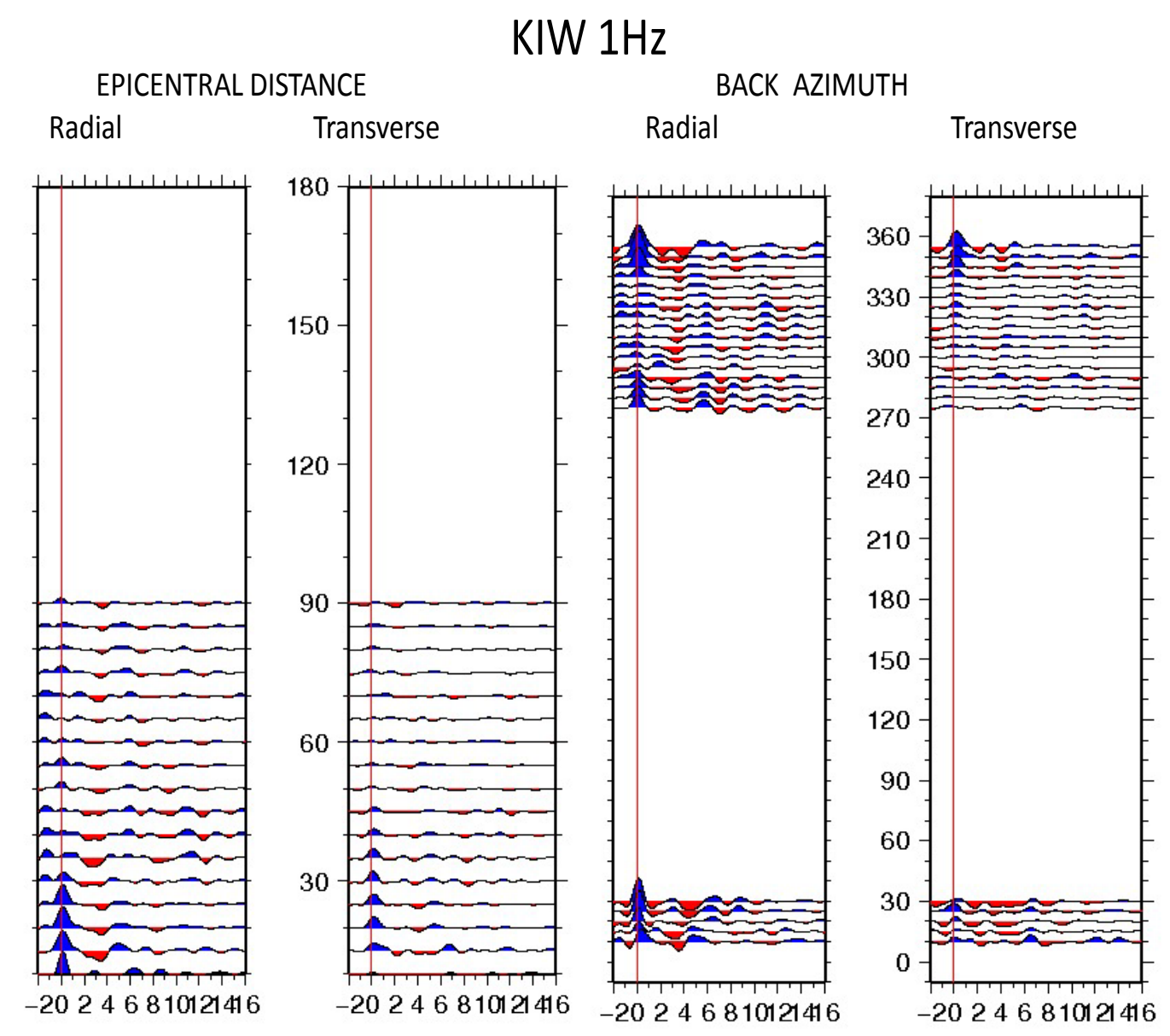

Figure 51 KIW (1Hz) Receiver Function Stack.

Blue indicates a positive phase. Red indicates a negative phase. Left-hand pair are stacked according to epicentral distance; the numbers on the vertical scale are degrees of epicentral distance; the horizontal scale is time (seconds); radial and transverse components (labeled) are left and right respectively. Right-hand pair are stacked according to back-azimuth; the numbers on the vertical scale are degrees of back azimuth; the horizontal scale is time (seconds); radial and transverse components (labeled) are left and right respectively. 


\subsubsection{KIW}

KIW station is situated offshore on Kapiti Island. The underlying geology (Figure 33) is Rakaia Terrane.

\section{Epicentral Distance}

KIW shows good coverage from $0-90^{\circ}$ of epicentral distance. There is a positive amplitude arrival at 0s, showing a decrease in amplitude with increasing epicentral distance. This is followed by a distinctive double peaked coherent negative sequence at $\sim 2-4 \mathrm{~s}$ that also decays in amplitude with increasing epicentral distance. A weak positive phase sequence follows at 5.5s and another very weak negative phase sequence following $7.5 \mathrm{~s}$. The transverse component shows low energy, as compared to the radial component.

\section{Back Azimuth}

Coherent positive and negative phase sequences are observed on the radial component, particularly in the section from $275-355^{\circ}$. The double peaked negative phase sequence is observed at 2-4s; the double peaks are particularly strong at $325-355^{\circ}$. Back azimuthal coverage shows no events from between $30-275^{\circ}$.

\subsection{QUALITY CONTROL OF RECEIVER FUNCTION PLOTS.}

All receiver function plots have undergone extensive quality control throughout all processing stages from raw data to stacked receiver functions. The quality control procedures lead to the abandonment of data from station LE2 (see Table 3). Poor quality traces were removed from all station, leaving the best quality receiver functions to be stacked into the final versions

Park and Levin (2000) comment that evidence of negative peaks at 0 s on the radial receiver function, and that this may be evidence of a poor receiver function. However a small set of back azimuths in this thesis do gives a low value at $0 \mathrm{~s}$, this may occur if the upcoming $\mathrm{P}$ wave comes in perpendicular to the boundary of a dipping plate. There may also be an initial P wave offset from the 0 s when you have a sediment-filled valley, as in the case of the Wairarapa 
(e.g. Sheehan et al., 1995). Savage (2007) illustrates examples of synthetic RF stacks showing low $\mathrm{P}$ at 0 seconds, due not only to anisotropy but also to the angle of incidence.

Receiver functions from close epicentral distances have been left in the stacks e.g. TRWZ (Figure 35); LE4 (Figure 36); T004 (Figure 37) etc. These low amplitude traces do not produce any negative effect on the traces from further epicentral distances; furthermore their presence serves to prove the receiver function theory regarding the effect of epicentral distance on the quality of the individual receiver function (Figure 25, Chapter 4). 


\section{- 107 -}




\section{CHAPTER 7}

\section{FORWARD MODELING WITH SYNTHETICS}

\subsection{INTRODUCTION}

Receiver functions are non-unique with seismic velocities trading off with interface depths that would fit the observed receiver function stacks (Ammon 1990. Savage, 2007). Therefore forward modelling synthetic receiver functions, using a selection of feasible velocity models, to allow a 'best fit' model to be chosen, is a reasonable approach to the non-uniqueness problem.

Synthetic receiver functions were created to allow the comparison of three different velocity models (see Table 4) with the observed receiver functions, and to allow a best fit velocity model to be employed in the common conversion point (CCP) stacking method. To create the synthetic models a ray theoretical method is used that can include both dipping and anisotropic layers (Frederiksen and Bostock, 2000); however only isotropic modelling was conducted here. This method allows the modelling of multiple phases.

\subsubsection{PARAMETERS}

The synthetics were modelled using a ray parameter from $40^{\circ}$ of epicentral distance (4440 km distance) and the location of the KIW station. This distance was chosen as it represents a cluster of events that are used in my receiver function stack. All three synthetics were modelled using a dip of $5^{\circ}$ (Ansell and Bannister, 1996. Nicol and Beavan, 2003). $5^{\circ}$ is estimated as the dip of the shallow, up-dip section of the Wadati-Beniof zone as it descends beneath the southern end of the North Island of New Zealand. The KIW (Ewig, 2009) velocity model is also run with a $30^{\circ}$ dip (Ansell and Bannister, 1996) (Figure 53). Ewig (2009) also uses this dip when modelling the crust 
below station KIW see Chapter 3, 3.2.). The three different velocity models were chosen as they have all been successfully used in previous New Zealand geophysical investigations (see Chapter 3, 3.2.2).

\subsubsection{NEW ZEALAND STANDARD MODEL}

The New Zealand Standard model (see Table 4 and Figure 52) is a simple three layer, one dimensional (1D) model used by GNS to calculate the travel times of rays passing through and immediately below the crust. When creating the CCP stack, for depths below $33 \mathrm{~km}$ Moho, as defined by this model the velocities are merged with those of the Jeffreys-Bullen Tables (British Association for the Advancement of Science, 1958).(http://info.geonet.org.nz/display/appdata/Hypocentre+Derivation).

\subsubsection{KIW (EWIG, 2009)}

The four layer, 1D, KIW model (Ewig 2009) (see Table 4 and Figure 53) was developed by Ewig (2009) as the best fit model for his Kapiti Island Station (KIW) receiver function stack. Ewig noted that this model was the only one out of the selection of models he examined that re-produced the double peaked negative polarity phase sequence observed on the receiver function. It is interesting to note that two different data sets, Ewig (2009) and this study, both recorded at KIW, modelled as receiver function stacks, contain the same double peaked negative phase sequence.

\subsubsection{OC14D20 (SAVAGE, 2007)}

The five layer OC14D20 velocity model (see Table 4 and Figure 55) was developed by Savage (2007). Savage uses the name ANI_OC14D20, the prefix 'ANI' refers to anisotropy. As this model is computed not taking anisotropy into account the name of the velocity model has been contracted to OC14D20. This model was one of several used to investigate both seismic velocities and anisotropy (using receiver functions) from data recorded on an L shaped array. Three of the station locations (W1, W2 and W3) in the Savage (2007) array are the same as stations LTW1, LTW2 and LTW3 used in this study. Model OC14D20 has the top of a low velocity layer (LVL) at 21 $\mathrm{km}$, and a layer interpreted to be the oceanic Moho at $35 \mathrm{~km}$, for an oceanic crustal thickness of $14 \mathrm{~km}$ (Savage, 2007). The model is the best fit for 
positive polarity Ps from the LVL at $60-180^{\circ}$ back azimuth on Savage's receiver functions.

All have parameters $1 \mathrm{~Hz}$. Bin width $5^{\circ}$

\begin{tabular}{|l|l|l|l|l|l|l|}
\hline $\begin{array}{l}\text { Model } \\
\text { Name }\end{array}$ & $\begin{array}{l}\text { Thickness } \\
(\mathrm{m})\end{array}$ & $\begin{array}{l}\text { Density } \\
\left(\mathrm{kg} / \mathrm{m}^{\wedge} 3\right)\end{array}$ & $\begin{array}{l}\text { P wave } \\
\text { velocity } \\
(\mathrm{m} / \mathrm{s})\end{array}$ & $\begin{array}{l}\text { S wave } \\
\text { velocity } \\
(\mathrm{m} / \mathrm{s})\end{array}$ & $\begin{array}{l}\text { Interface } \\
\text { strike }\end{array}$ & $\begin{array}{l}\text { Interface } \\
\text { Dip } \\
\text { (degrees })\end{array}$ \\
\hline $\begin{array}{l}\text { New } \\
\text { Zealand } \\
\text { Standard* }\end{array}$ & 12000 & 2720 & 5500 & 3300 & 045 & 5 \\
\hline & 21000 & 2920 & 6500 & 3700 & 045 & 5 \\
\hline & 0 & 3350 & 8100 & 4600 & 045 & 5 \\
\hline
\end{tabular}

*http://info.geonet.org.nz/display/appdata/Hypocentre+Derivation

\begin{tabular}{|l|l|l|l|l|l|l|}
\hline $\begin{array}{l}\text { Model } \\
\text { Name }\end{array}$ & $\begin{array}{l}\text { Thickness } \\
(\mathrm{m})\end{array}$ & $\begin{array}{l}\text { Density } \\
\left(\mathrm{kg} / \mathrm{m}^{\wedge} 3\right)\end{array}$ & $\begin{array}{l}\text { P wave } \\
\text { velocity } \\
(\mathrm{m} / \mathrm{s})\end{array}$ & $\begin{array}{l}\text { S wave } \\
\text { velocity } \\
(\mathrm{m} / \mathrm{s})\end{array}$ & $\begin{array}{l}\text { Interface } \\
\text { strike }\end{array}$ & $\begin{array}{l}\text { Interface } \\
\text { Dip } \\
(\text { degrees })\end{array}$ \\
\hline $\mathrm{KIW}^{*}$ & 25000 & 2500 & 5800 & 3100 & 045 & 5 \\
\hline & 5600 & 2400 & 4400 & 2100 & 045 & 5 \\
\hline & 10000 & 2930 & 6700 & 4000 & 045 & 5 \\
\hline & 0 & 3370 & 8100 & 4700 & 045 & 5 \\
\hline
\end{tabular}

*(Ewig, 2009)

\begin{tabular}{|l|l|l|l|l|l|l|}
\hline $\begin{array}{l}\text { Model } \\
\text { Name }\end{array}$ & $\begin{array}{l}\text { Thickness( } \\
\mathrm{m})\end{array}$ & $\begin{array}{l}\text { Density } \\
\left(\mathrm{kg} / \mathrm{m}^{\wedge} 3\right)\end{array}$ & $\begin{array}{l}\text { P wave } \\
\text { velocity } \\
(\mathrm{m} / \mathrm{s})\end{array}$ & $\begin{array}{l}\text { S wave } \\
\text { velocity } \\
(\mathrm{m} / \mathrm{s})\end{array}$ & $\begin{array}{l}\text { Interface } \\
\text { strike }\end{array}$ & $\begin{array}{l}\text { Interface } \\
\text { Dip } \\
\text { (degrees) }\end{array}$ \\
\hline $\begin{array}{l}\text { OC14D2 } \\
0^{*}\end{array}$ & 6700 & 2307 & 4694 & 2640 & 045 & 5 \\
\hline & 14300 & 2690 & 6030 & 3450 & 045 & 5 \\
\hline & 4000 & 2402 & 5100 & 2550 & 045 & 5 \\
\hline & 10000 & 2930 & 6750 & 3860 & 045 & 5 \\
\hline & 0 & 3370 & 8140 & 4570 & 045 & 5 \\
\hline
\end{tabular}

*(Savage, 1998)

Table 4. Parameters of Velocity Models 


\subsection{SYNTHETIC PLOTS}

\subsubsection{SYNTHETIC PLOT FOR NEW ZEALAND STANDARD MODEL. outr_baz.grid scale 1 outr_baz.grid scale 1}
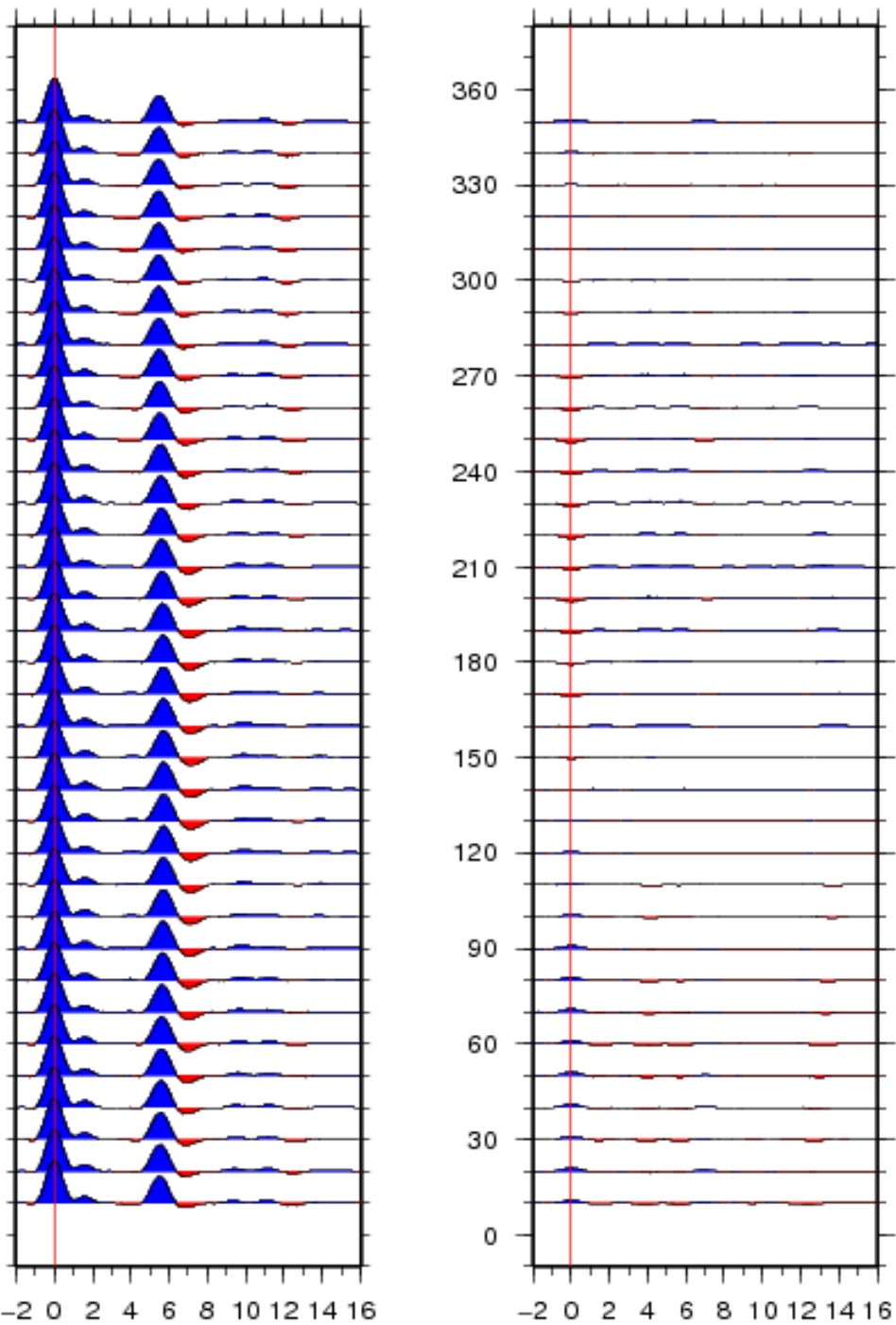

Figure 52 Synthetic Receiver Function for NZSM. 
7.2.2 SYNTHETIC PLOT FOR VELOCITY MODEL KIW WITH 30 DEGREE DIP

outr_baz.grid scale 1

outr_baz.grid scale 1

KIW (Ewig (2009) 30 deg Dip
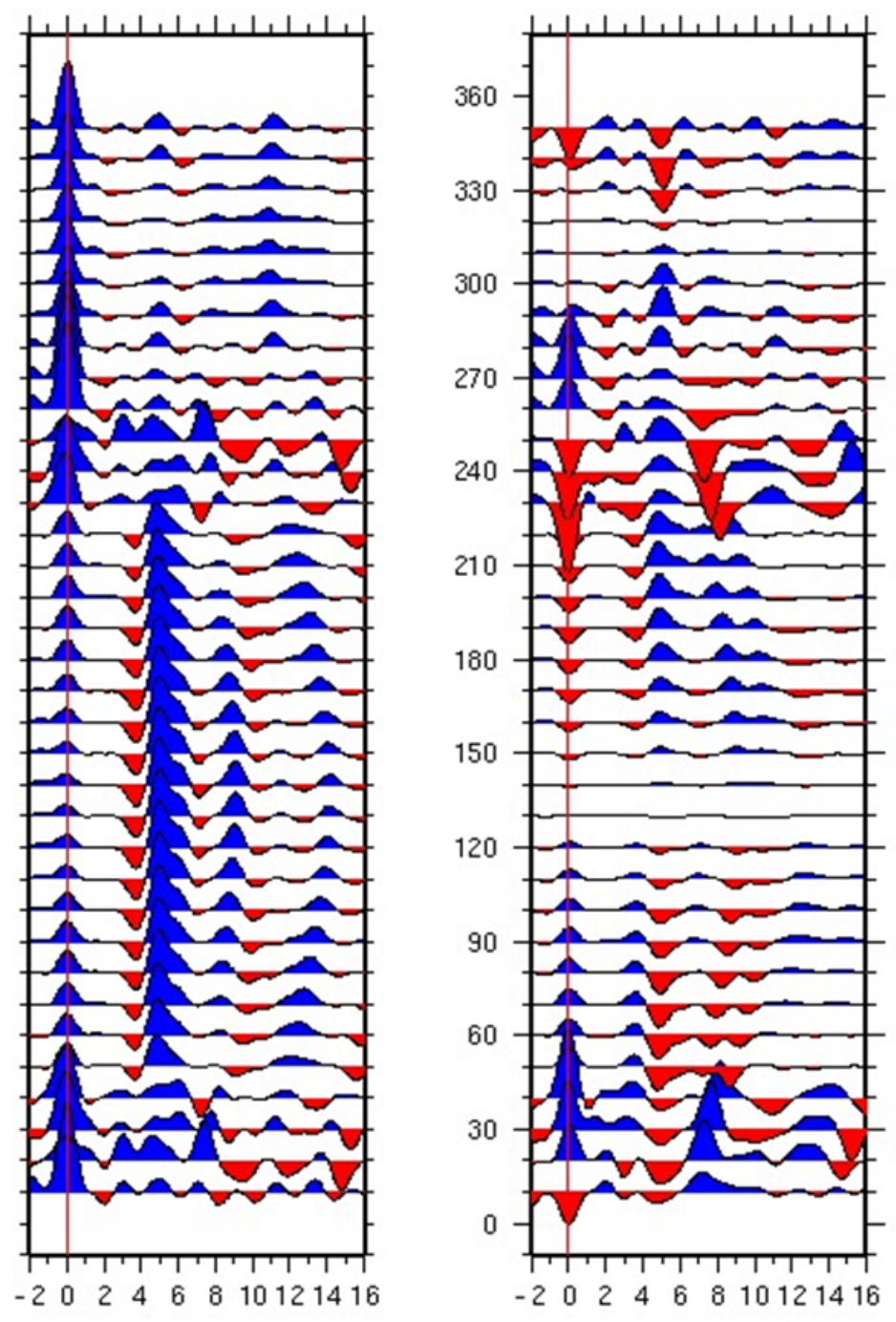

Figure 53 Synthetic Receiver Function for velocity model KIW (Ewig, 2009) with 30 degree dip. 
outr_baz.grid scale 1

outr_baz.grid scale 1

KIW (Ewig (2009) 5 deg Dip
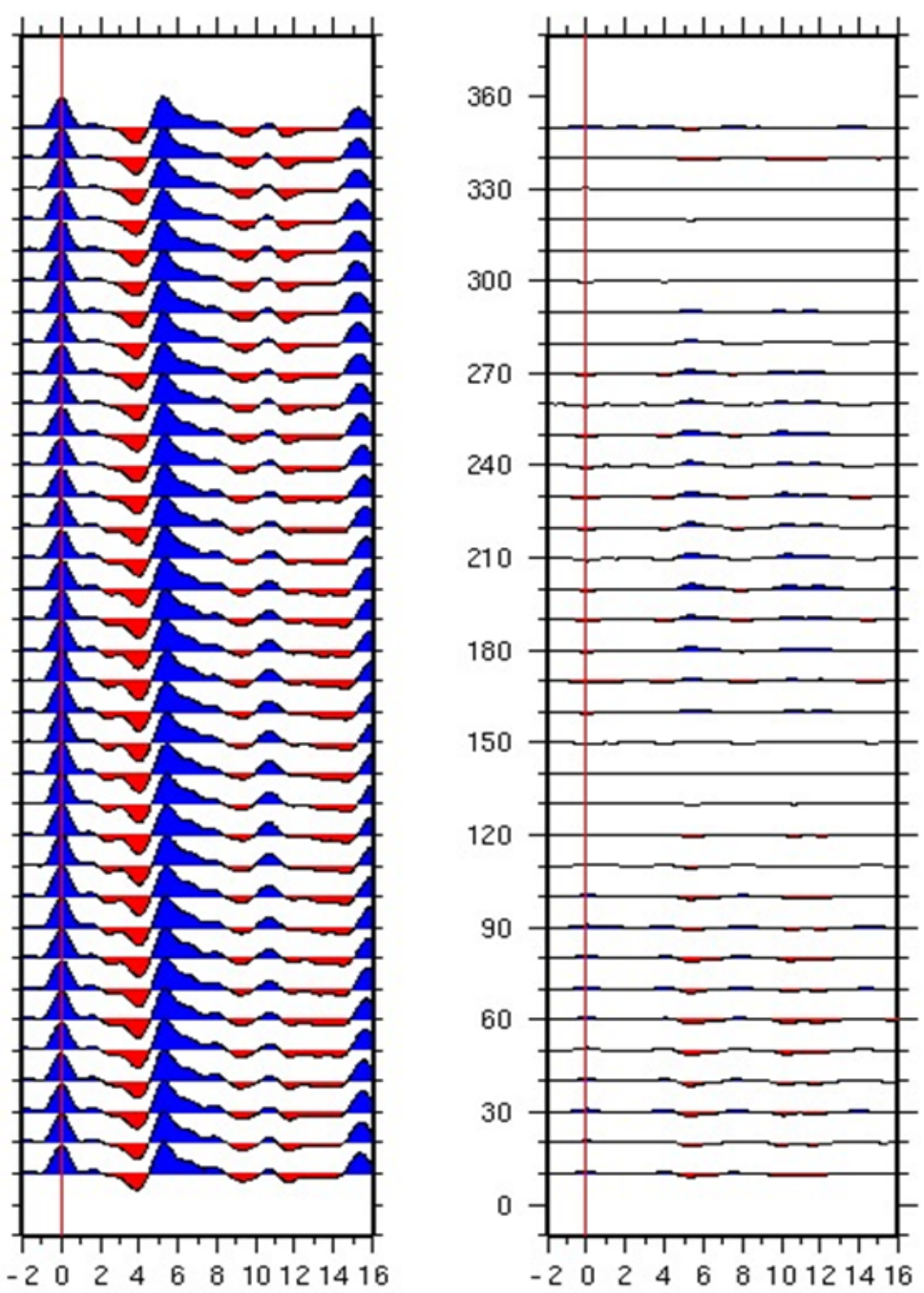

Figure 54 Synthetic Receiver Function for velocity model KIW (Ewig 2009) with 5 degree dip. 
7.2.4 SyNTHETIC Plot FOR VELOCITY ModEL OC14D20.

outr_baz.grid scale 1

outr_baz.grid scale 1

OC14D20 5 deg dip
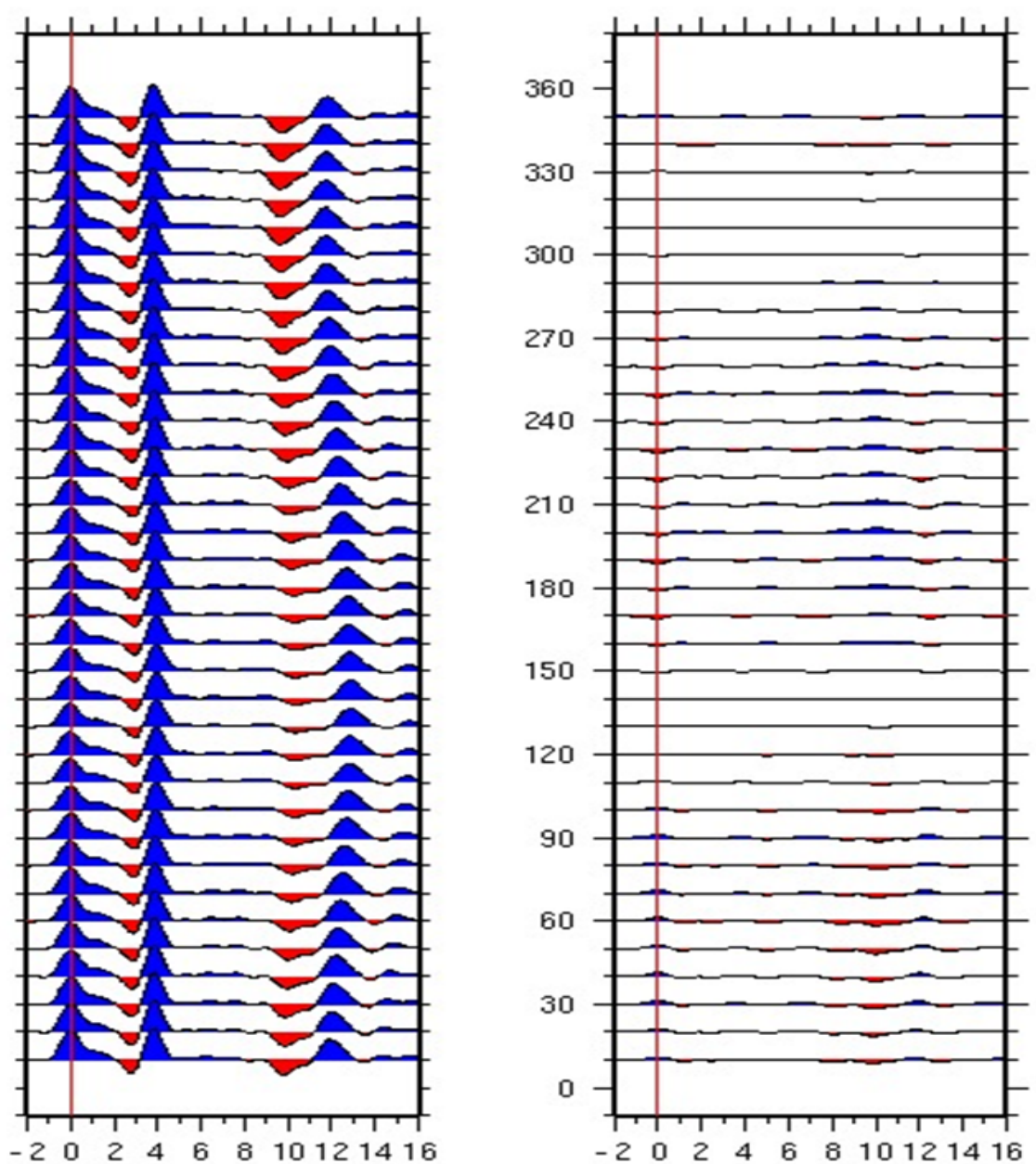

Figure 55 Synthetic velocity model for velocity model 0C14D20 


\subsection{INTERPRETATION.}

The New Zealand Standard model gives a good representation of the first arrival at between 0 and 3 seconds delay time as a double peaked positive phase sequence, with a strong arrival at between 5 and $6 \mathrm{~s}$ that models the $21 \mathrm{~km}$ boundary. This is similar to that observed at stations T018, T020 and T022, LTN6 and the shorter epicentral distances $\left(<30^{\circ}\right)$ of LTW1 (see Chapter 6). However the number of layers used in this module is clearly not sufficient to model the complexity inferred by the observed receiver functions.

The model KIW with a $5^{\circ}$ dip (Figure 54) gives a strong negative polarity, double peaked phase sequence arriving between $\sim 1.75 \mathrm{~s}$ and $\sim 4.2 \mathrm{~s}$. This negative polarity sequence is preceded by a strong positive at $0 \mathrm{~s}$, and followed by a double peaked positive polarity phase sequence arriving between $4.2 \mathrm{~s}$ and $\sim 8.5 \mathrm{~s}$. This sequence is similar to that observed at KIW where there is a distinctive double peaked coherent negative sequence at $\sim 2-4$ s that decays in amplitude with increasing epicentral distance. However the following positive phase in the real data is less strong, and only showing a double peak at $>30^{\circ}$ epicentral distance. Though this model is a good representation for the station KIW, it is not in concordance with receiver functions from other stations in this study.

The KIW synthetic modelled with a $30^{\circ}$ dip has similarities with three of the stations in the central region of the transect; LTW3, T020 and T018 all show a negative polarity arrival at $\sim 4 s$, with a positive polarity double peaked sequence following at $\sim 5 \mathrm{~s}$.

Model OC14D20 shows a strong double positive amplitude phase sequence at $0 \mathrm{~s}$ to $\sim 2 \mathrm{~s}$. This is followed by a negative polarity peak at $\sim 2.5 \mathrm{~s}$ delay time. This is followed by a strong amplitude positive peak arriving at $4 \mathrm{~s}$. This model has a markedly good fit for observed receiver functions (on the epicentral distance stack) from stations LE3, T010, T014, T016 and MTW. These receiver function stacks all, with the exception of MTW, show a positive phase sequence, with either a broad wavelength, or a double peak, 
at 0 s to $\sim 2$ s. LE3, T010, T014, T016 and MTW all show a coherent negative at $\sim 2$-2.5s. This model is also a reasonable fit for station LTW1, though it does not show the second negative peak, at $\sim 4.7$ s observed at this station. At LTW2 the negative peak arrives later than the model, at $\sim 3$ s. Station LTW3 has a very weak negative polarity arrival at $\sim 3.2 \mathrm{~s}$.

\subsection{CONCLUSION}

Overall the synthetic that offers the best fit for the majority of the observed receiver functions is the velocity model OC14D20. It is interesting to note that this model is a better match for the group of stations further to the east (LE3, T010, T014, T016 and MTW) than the stations that it was originally developed to model (LTW1, LTW2, LTW3). 
- 117 -

7- 


\section{CHAPTER 8}

\section{COMMON CONVERSION POINT STACKS}

\subsection{INTRODUCTION}

Common conversion point 'super stacks' of all the receiver functions from all the stations across the entire transect were computed using the three differing velocity models used to create the synthetic receiver functions (see Chapter 7.). These models are the New Zealand Standard Model (NZST), KIW (Ewig, 2009) and OC14D20 (Savage, 2007).

Images using the three different velocity models are presented in this chapter for comparison. Their associated plots of averaged receiver functions binned for ray parameter and for back azimuth are also presented. The best and final plot, made with velocity model OC14D20 at $1 \mathrm{~Hz}$ is presented and interpreted.

\section{Parameters}

When computing the common conversion point stacks for this study the following parameters are used: Low pass corner of 0.4 , high pass of 1.5, the back azimuth range is from $0^{\circ}$ to $360^{\circ}$ to accommodate all available data, the maximum depth used is $150 \mathrm{~km}$. The profile azimuth is $129^{\circ}$. The latitude and longitude of the array centre is that of station LTN6, -41.1033 (latitude) and 175.3238 (longitude). The sample rate of all the files is 0.01 . Vp/Vs is varied according to the velocity model. 


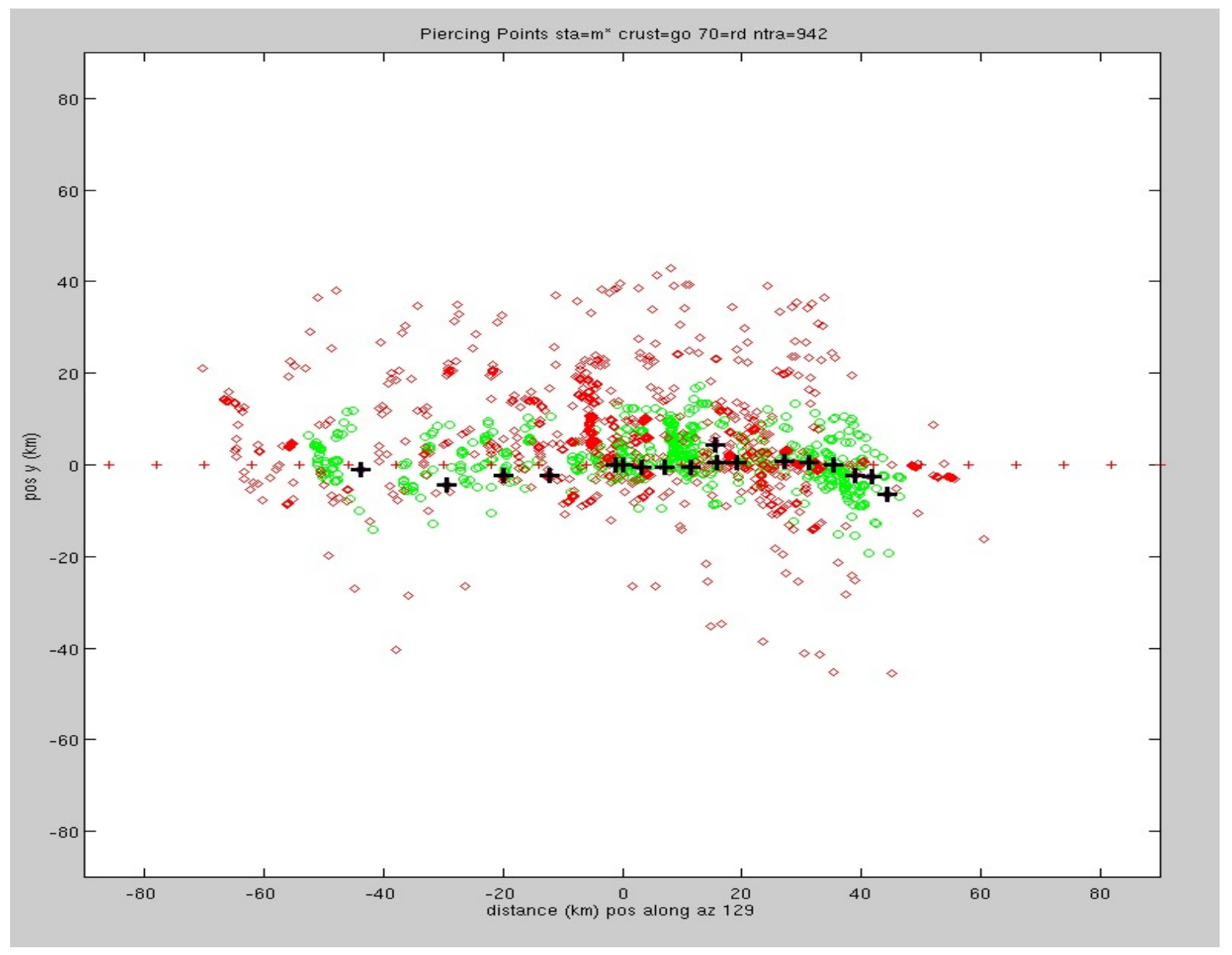

Figure 56 Showing Piercing Points for all receiver functions. Surface view of piercing points. Green circles are piercing points for $30 \mathrm{~km}$ depth. Red Diamonds are piercing points for $70 \mathrm{~km}$ depth. The $\mathrm{X}$ axis (labelled; distance (km) pos along az 129), is distance in $\mathrm{km}$; the 0 point is the centre of the transect at station LTN6, lat.-41.1033, lon175.3238. The Y axis (labelled; pos y (km)) is distance in $\mathrm{km}$; 0 is the transect profile (marked with red + ) at azimuth $129^{\circ}$. Black + are station locations.

Overall the spread of the two groups of piercing point, (red diamonds piercing at $70 \mathrm{~km}$ depth and green circles piercing at $30 \mathrm{~km}$ depth), shows that rays arriving at the deeper $(70 \mathrm{~km})$ layer sample a greater area than those arriving at the shallower layers. This observation is in agreement with receiver function theory (see Chapter 4, 4.6).

The plot of piercing points (Figure 56) shows a lateral spread along the $\sim 100$ $\mathrm{km}$ transect of $>120 \mathrm{~km}$. To the west (left side of the plot), of the most westerly station (KIW), there is an observable horizontal spreading of piercing points at both $70 \mathrm{~km}$ depth (red diamonds), and 30km (green 
circles) that is greater than the spread on the easterly (right side) end of the transect.

The north-south spread of piercing points is asymmetric, with a greater number of piercing points observed to the north of the transect line. This pattern of scatter is a consequence of the fact that the greatest number of teleseismic earthquakes used to make the receiver functions originate from the north-west quadrant (see Chapter 6. Figure 34).

The overall density of the piercing points is a reflection of both the number of earthquakes used and the spread of the stations. The densest distribution of piercing points is around the stations covering the eastern half of the transect.

Figure 57 shows a common conversion point (CCP) stack with the ray paths superimposed over the image. The station locations (grey triangle) are along the top margin; the ray paths arrive at the individual stations. The projection of the ray paths demonstrates the theory of lateral sampling (see Chapter 4.6). The accuracy of the final image is in part due to the amount of data that is sampled at any one point; the density of sampling points is shown by the 'criss-crossing' of the individual ray paths as they come up through the layers. The more rays that sample an individual reference point on a layer the more reliable the final model is likely to be. 


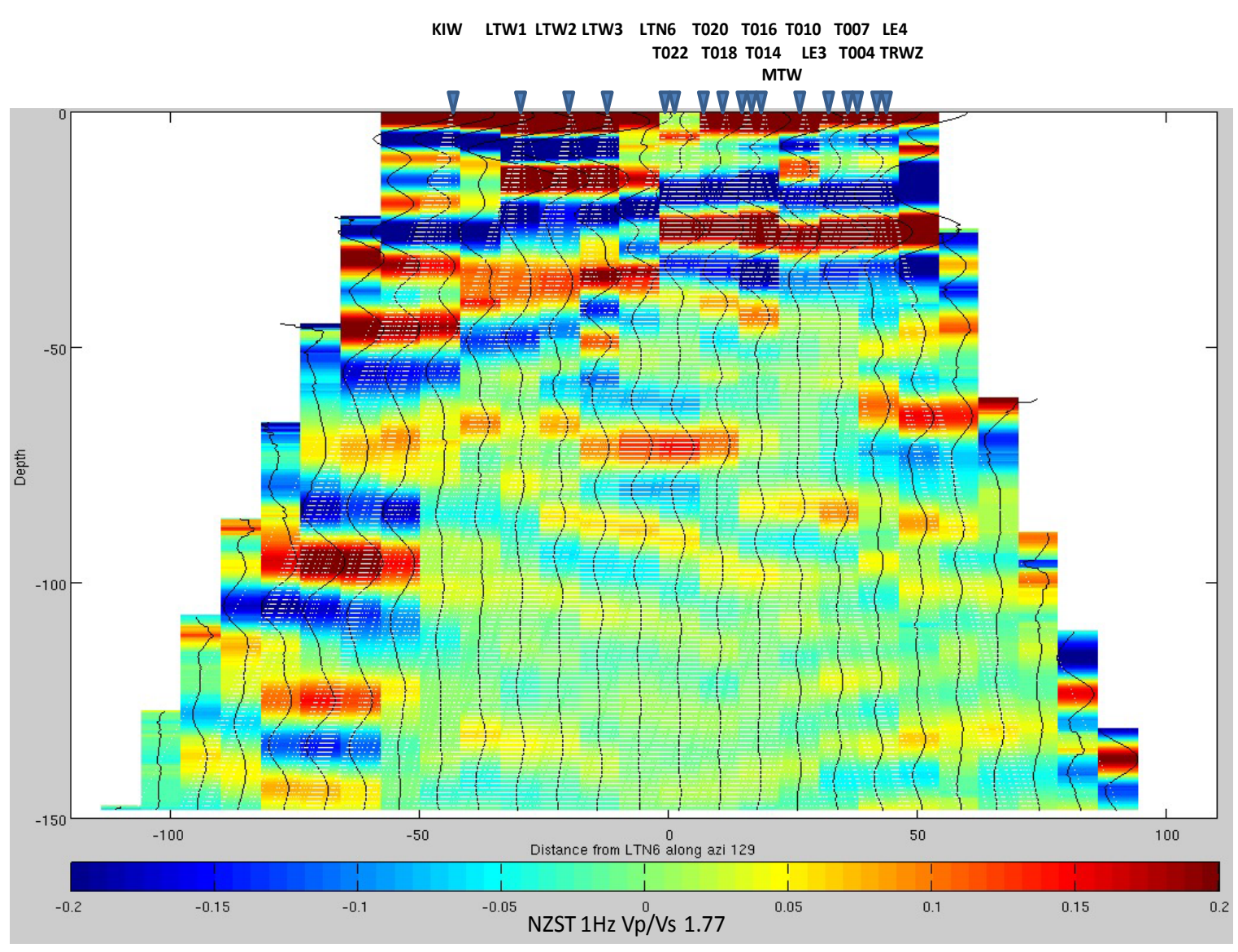

Figure 57 CCP Stack using NZST 1Hz. Vp/Vs = 1.77 Showing ray paths and Station Locations.

Ray paths are faint white lines. Stations are inverted grey triangles, with names above. Red colours show positive phases, blue colours show negative phases.

The resolution of the image is best at mid-crustal to upper mantle depths, around $10 \mathrm{~km}$ to $70 \mathrm{~km}$ depth, where the ray paths are crossing over more frequently. The resolution for the shallowest layers is best directly below each station; lateral detail of shallow crustal features will be lost where there is no sampling between the stations. Where the stations are spaced more closely, that is in the eastern half of the transect, the ray paths begin to cross at shallower depths, allowing greater lateral resolution.

\subsection{DISCUSSION OF CCP STACK MADE USING NZST VELOCITY MODEL}

The New Zealand Standard velocity model (see Chapter 7, Figure 52 and Table 4) works well modelling the data at $1 \mathrm{~Hz}$. Salmon (2008) uses this 
velocity model for her interpretation of structures using similar methods to this study.

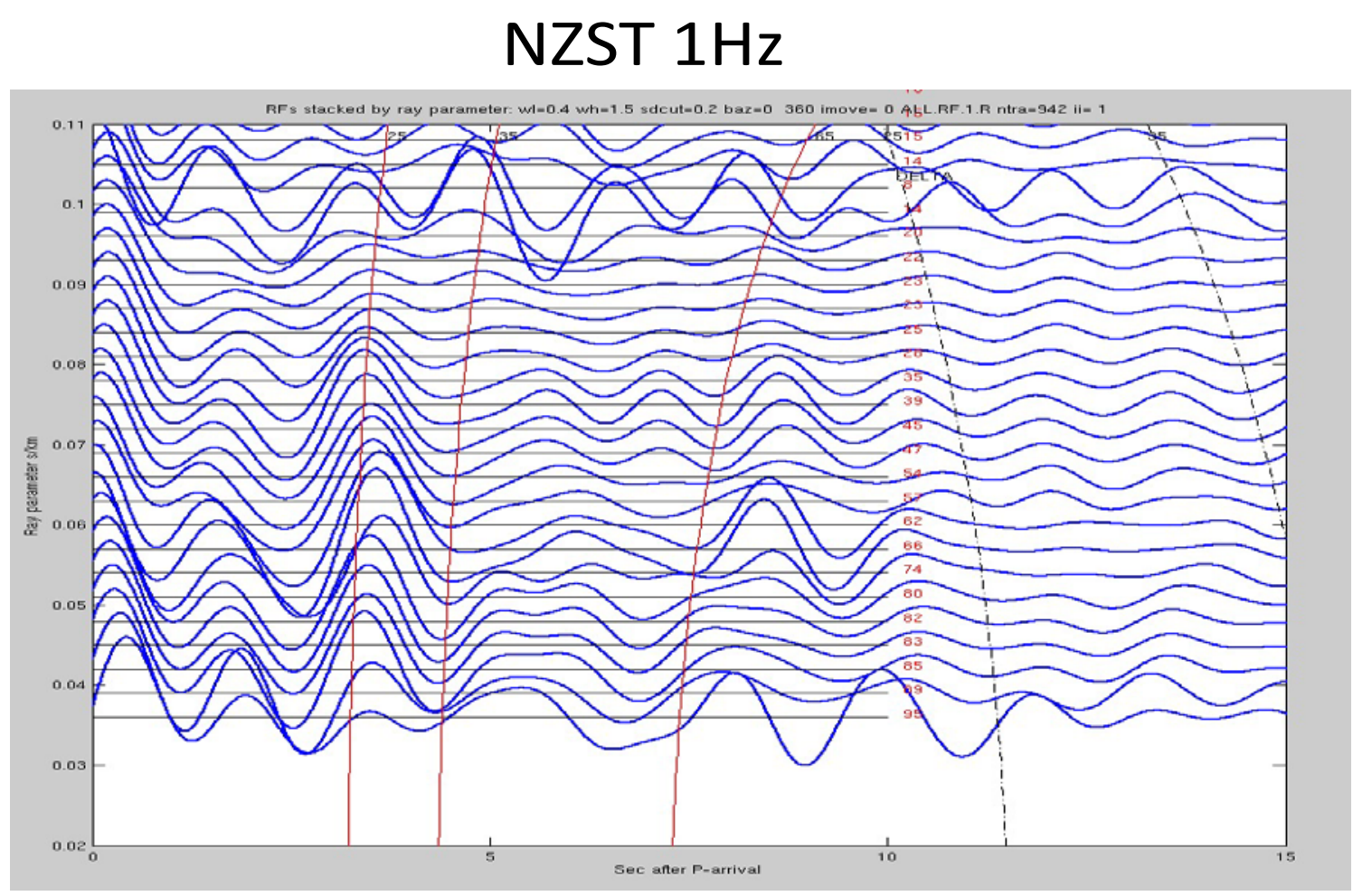

Figure 58 NZST 1Hz Receiver Function Stacked by Ray parameter.

Receiver Functions for all stations stacked using velocity model NZST at 1Hz. For depths up to $95 \mathrm{~km}$. The solid red lines are the moveout curves for Ps conversions, at 25, 35 and $65 \mathrm{~km}$ respectively, (plotted as default and do not reflect the NZSTM velocity model). The dotted black lines are the moveout curves for PpPs multiples at $25 \mathrm{~km}$ and $35 \mathrm{~km}$ depth respectively (plotted as default they do not reflect the velocity model). The horizontal axis shows delay time in seconds after the P-arrival. The vertical axis shows slowness of the incoming ray by ray parameter.

Figure 58 shows the receiver functions for all stations stacked in ray parameter bins computed with velocity model NZST. Each 'wiggle' represents an averaged trace of all the receiver functions, for all the stations, for that particular ray parameter. The model provides coherent $\mathrm{P}$ to $\mathrm{S}$ converted phases, showing moveout increasing with decreasing ray parameter. Ray parameters decrease with increasing epicentral distance. The PpPs multiple moveout curves at 25 and $35 \mathrm{~km}$ depth indicate that 
moveout that decreases with increasing ray parameter (or decreasing distance), however these lines are plotted as default and do not reflect the NZSTM velocity model. The coherency overall is very good. The larger ray paramters, 0.1 to 0.11 represent the closest source events. The coherency of these events is less than those of the more distant events. This is to be expected and is in agreement with receiver function theory regarding the more shallow incident angle of rays arriving from a closer source. (See Chapter 4 4.6).

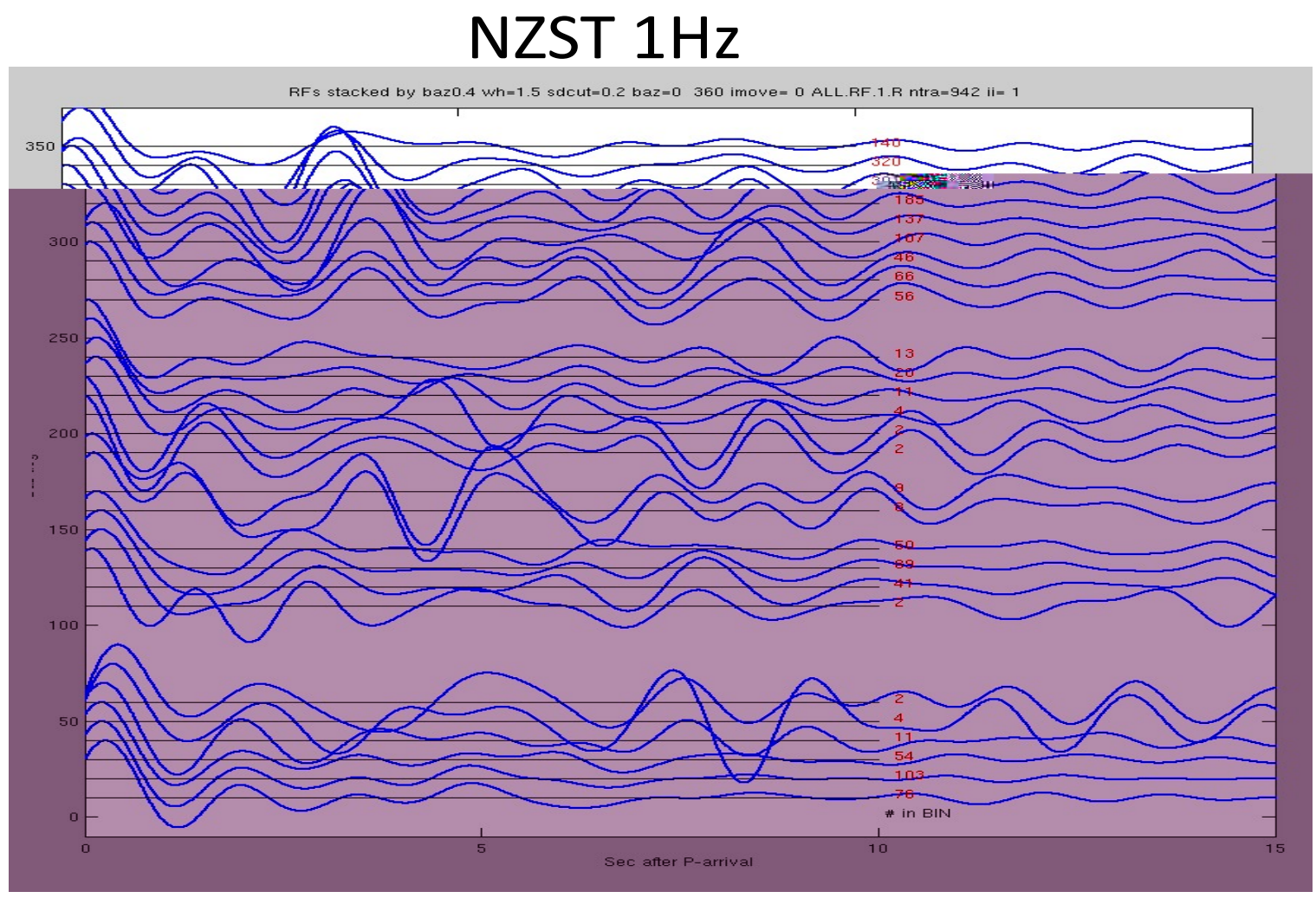

Figure 59 NZST 1Hz Receiver Functions stacked according to Back Azimuth.

Red numbers are number of traces in bin. The horizontal axis shows delay time in seconds after the Parrival. The vertical axis shows direction of the source event by back azimuth.

Figure 59 shows shows the averaged receiver functions binned by back azimuth. Each 'wiggle' represents an averaged trace of all the receiver functions, for all the stations, for the stated back azimuth. The coherenecy of the traces is best for back azimuths above $300^{\circ}$. There is a flattening of amplitude for traces from back azimuths around $150^{\circ}$ in the 5 second region. Traces tend to show the best coherency with other traces from a close backazimuth. This tendency indicates that it is the inhomogeneity of structure form different back azimuths 
that has an effect on the wavelength and amplitude of the receiver function 'wiggle'. This in in accordance with receiver function theory, (see Chapter 4 4.6).

8.3 COMPARISON OF CCP STACKS CREATED USING KIW (EWIG, 2009) MODEL AND NZST MODEL.

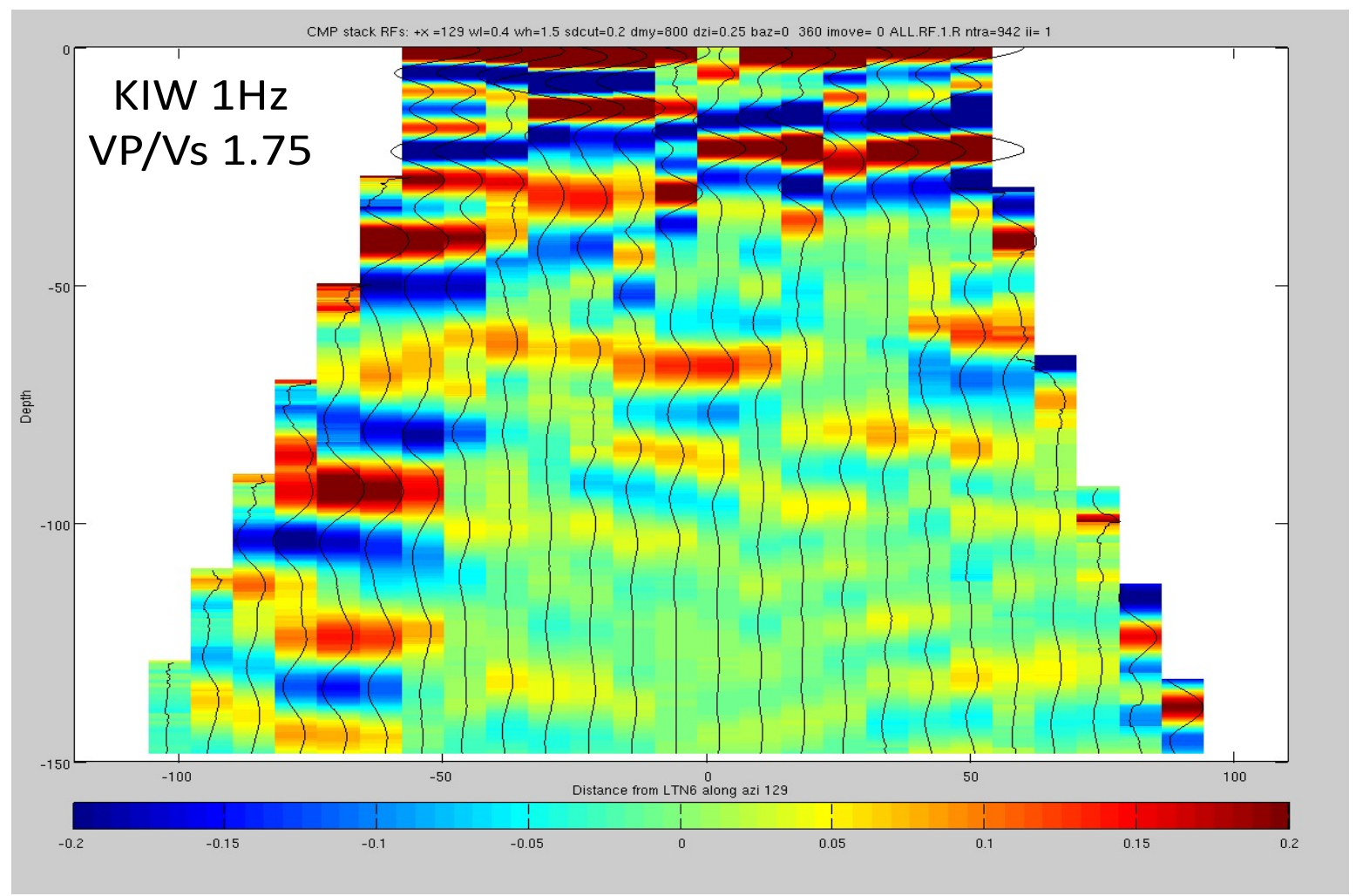

Figure 60 CCP stack using KIW velocity model. 1Hz stack. Vp/Vs 1.75.

Red colours show positive phases, blue colours show negative phases.

Observable differences to the CCP stack created using velocity model NZST (Figure 57) and KIW (Figure 60) are subtle. The differences are mainly apparent beneath station KIW (Figure 57 for station location). The velocity model KIW was originally developed by Ewig, 2009) as a best fit for structures beneath this station. Compared to NZST the imbricated high velocity structures (see Figure 57, the structures are interpreted with the solid black line) beneath station KIW are $\sim 10 \mathrm{~km}$ shallower. These structures also appear somewhat smoother to the far west (left) of the image than in NZST. The large offset in the same structure, just to the west of 
station LTN6 remains unaffected by the change in velocity model. There is a small loss of velocity in this same structure beneath station LTW3. NZST is computed using a Vp/Vs of 1.77 (see below for discussion).

8.3.1 COMPARISON OF KIW (EWIG ,2009) WITH OC14D20 (SAVAGE, 2007) MODEL; AND THE EFFECTS OF VP/VS RATIOS.

In comparing the KIW model (Figure 60) with the best fit OC14D20 model (Figure 64) the differences are subtle. However, the two CCP stacks created using different velocity models are also computed using different Vp/Vs ratios; NZST uses Vp/Vs 1.77 and KIW uses Vp/Vs 1.75. It may be that the observed differences in structure between the two models are due all, or in part to the different Vp/Vs; the amount of difference cannot be ascertained because of the two variables of velocity and Vp/Vs in the two models.

Zhu (2000), when discussing the relationship between CCP stacking and velocity models comments that 'since the direct $\mathrm{P}$ arrival time is used as the reference time for Ps, the results are not sensitive to P velocity. They are, however, very sensitive to the crustal Vp/Vs ratio'. 


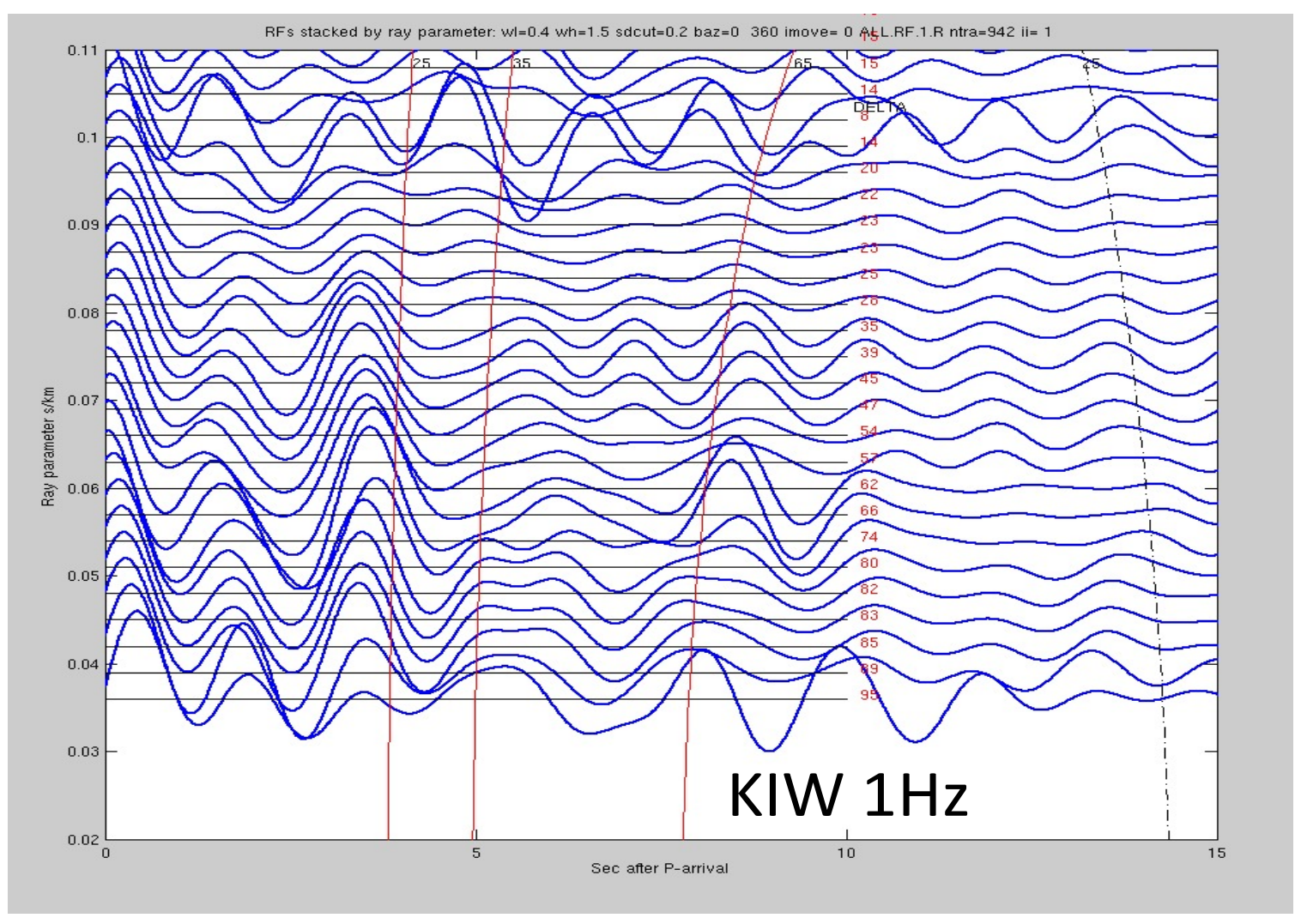

Figure 61 Receiver functions stacked using Ray Parameters. Receiver Functions for all stations stacked using KIW velocity model at $1 \mathrm{~Hz}$. For depths up to $95 \mathrm{~km}$. The solid red lines are the moveout curves for Ps conversions, at 25, 35 and $65 \mathrm{~km}$ respectively. The dotted black line is the moveout curves for the PpPs multiples at $25 \mathrm{~km}$ depth.

Figure 61 shows the receiver functions for all stations stacked in ray parameter bins computed with velocity model KIW. Each 'wiggle' represents an averaged trace of all the receiver functions, for all the stations, for that particular ray parameter. The model provides coherent $\mathrm{P}$ to $\mathrm{S}$ converted phases, showing moveout increasing with decreasing ray parameter. The curved red lines are set as defaults by the program for boundaries at $25 \mathrm{~km}$, $35 \mathrm{~km}$ and $65 \mathrm{~km}$. These red lines are not the actual boundaries, merely guidelines to indicate moveout. The peaks in the averaged receiver functions suggest that there is a boundary slightly shallower than $25 \mathrm{~km}$ depth as they are arriving slightly before the $25 \mathrm{~km}$ red line. The coherency overall is very good. The larger ray parameters, 0.1 to 0.11 , represent the closest source events. The coherency of these events is less than those of the more distant events. It is clear here that the average peaks at 3.5s arrive earlier than the arrival expected for the first layer in the model. 


\subsection{CCP STACKS MADE USING VELOCITY MODEL OC14D20.}

Figure 62 shows the CCP stacks made using the velocity model OC14D20 computed using a $\mathrm{Vp} / \mathrm{Vs}$ ratio of 1.72 at $1 \mathrm{~Hz}$.

Comparing the Vp/Vs 1.72 ratio model (Figures 62, uninterpreted) with the Vp/Vs 1.77 model (Figure 64, interpreted) shows that the higher ratio model (Figure 64) returns shallower depths than the lower ratio model (Figure 62). For example the high velocity layer, interpreted in Figure 64 with the solid black line, has a maximum depth of $\sim 46 \mathrm{~km}$, while the Figure 62 shows a maximum depth of $>50 \mathrm{~km}$. This supports the assertion by Zhu (2000) that the CCP method is more sensitive to $\mathrm{Vp} / \mathrm{Vs}$ ratio than it is to $\mathrm{P}$ wave velocity.

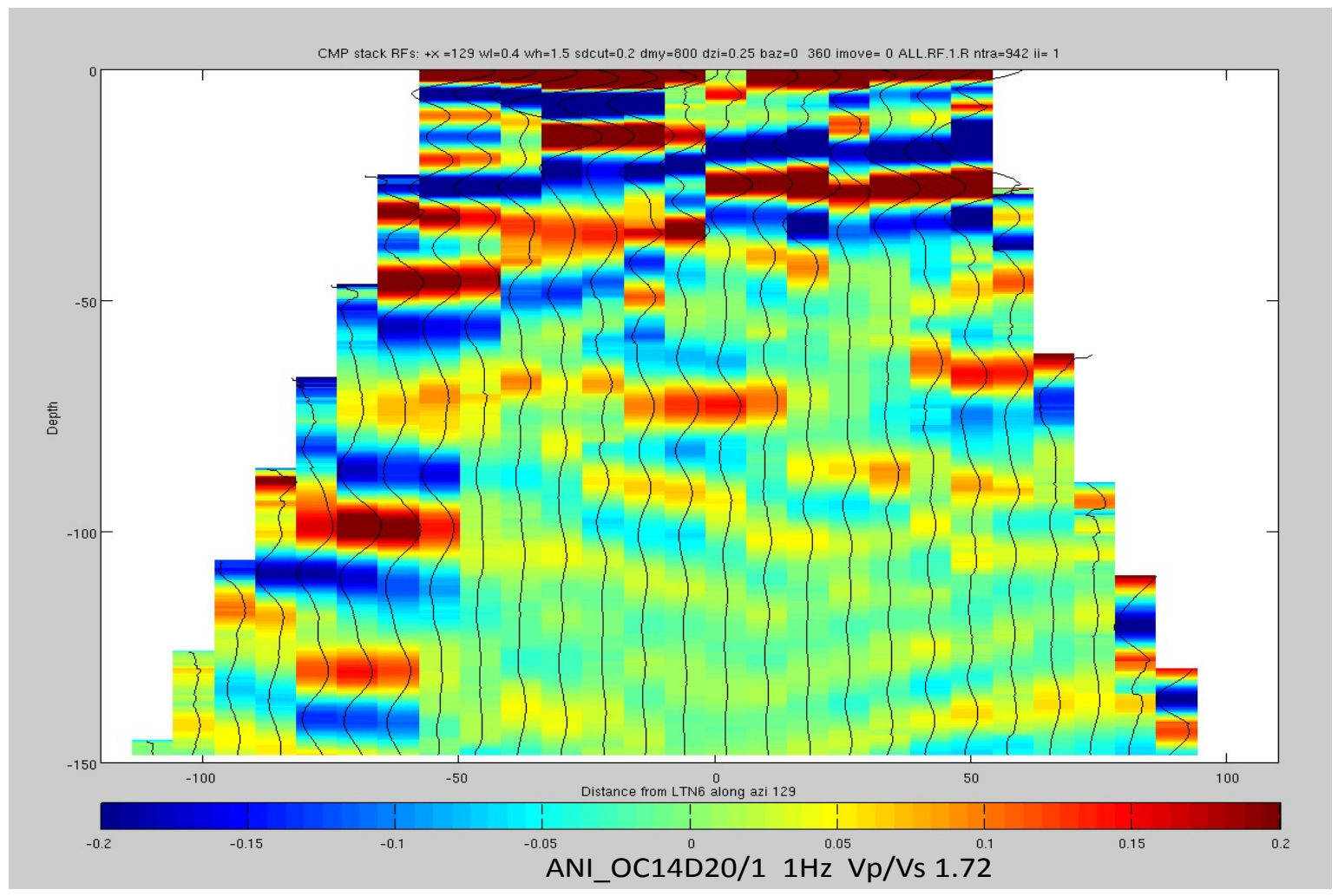

Figure 62 CCP stack using OC14D20 Velocity Model. Red colours show positive phases, blue colours show negative phases. 


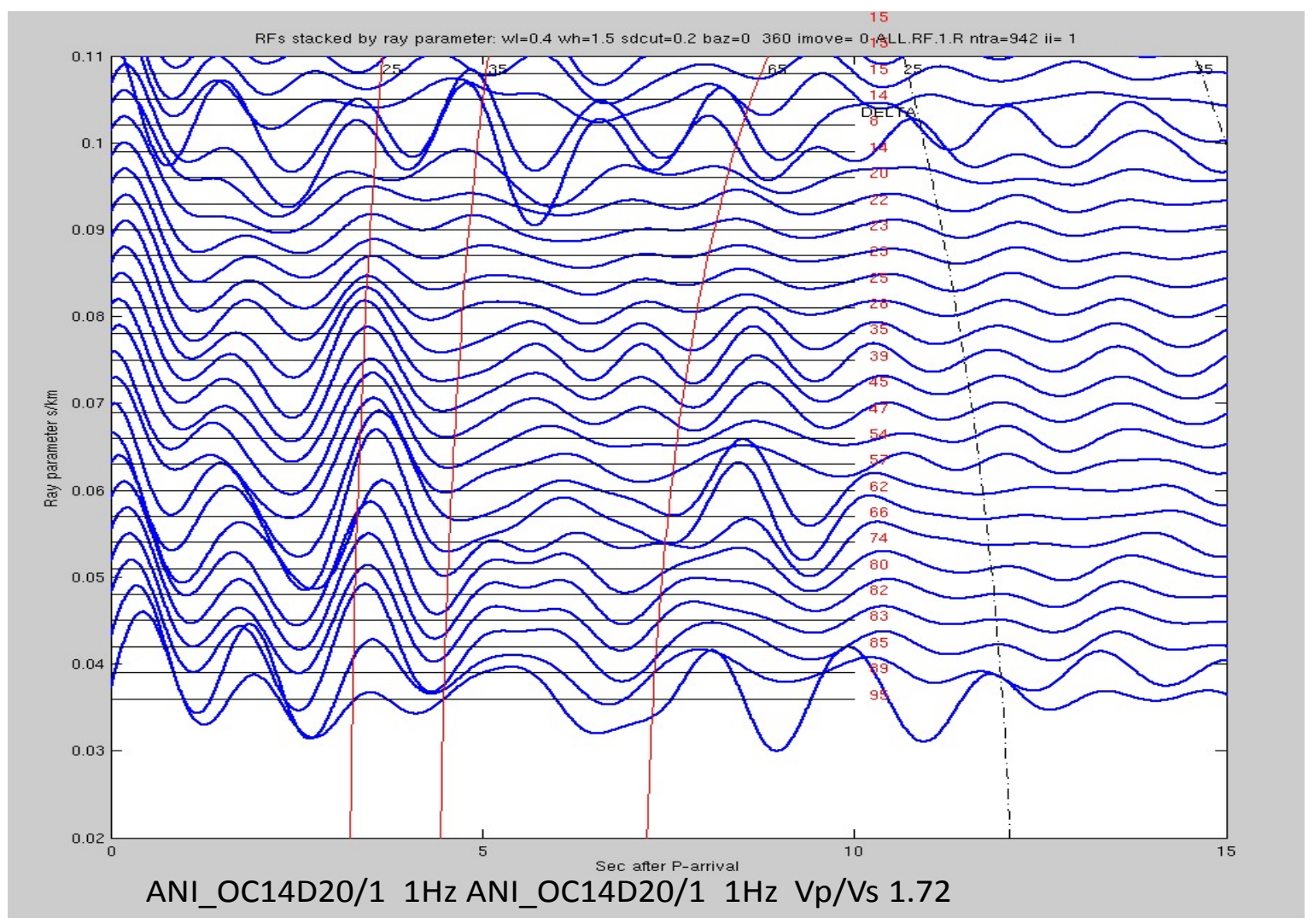

Figure 63 Receiver Functions stacked using OC14D20 at 1Hz. Receiver Functions for all stations stacked using 0C14D20 velocity model at $1 \mathrm{~Hz}$. For depths up to $95 \mathrm{~km}$. The solid red lines are the moveout curves for Ps conversions, at 25, 35 and $65 \mathrm{~km}$ respectively. The dotted black line is the moveout curves for the PpPs multiples at $25 \mathrm{~km}$ depth.

The model 0C14D20 (Savage, 2007) has boundaries at $7 \mathrm{~km}, 21 \mathrm{~km}, 25 \mathrm{~km}$ and $35 \mathrm{~km}$. The good fit of this velocity model to the stacked CCP data is reflected by Figure 63; the red moveout curves are plotted as default, at $25 \mathrm{~km}, 35 \mathrm{~km}$ and 65 $\mathrm{km}$. The positive peaks at around $25 \mathrm{~km}$ and the negative at around $35 \mathrm{~km}$ (this is a dipping boundary and the data is averaged across the whole transect for this figure so the fit is not expected to be exact) are a good fit for the moveout curves. This indicates that this velocity model is a good fit for this data set. 


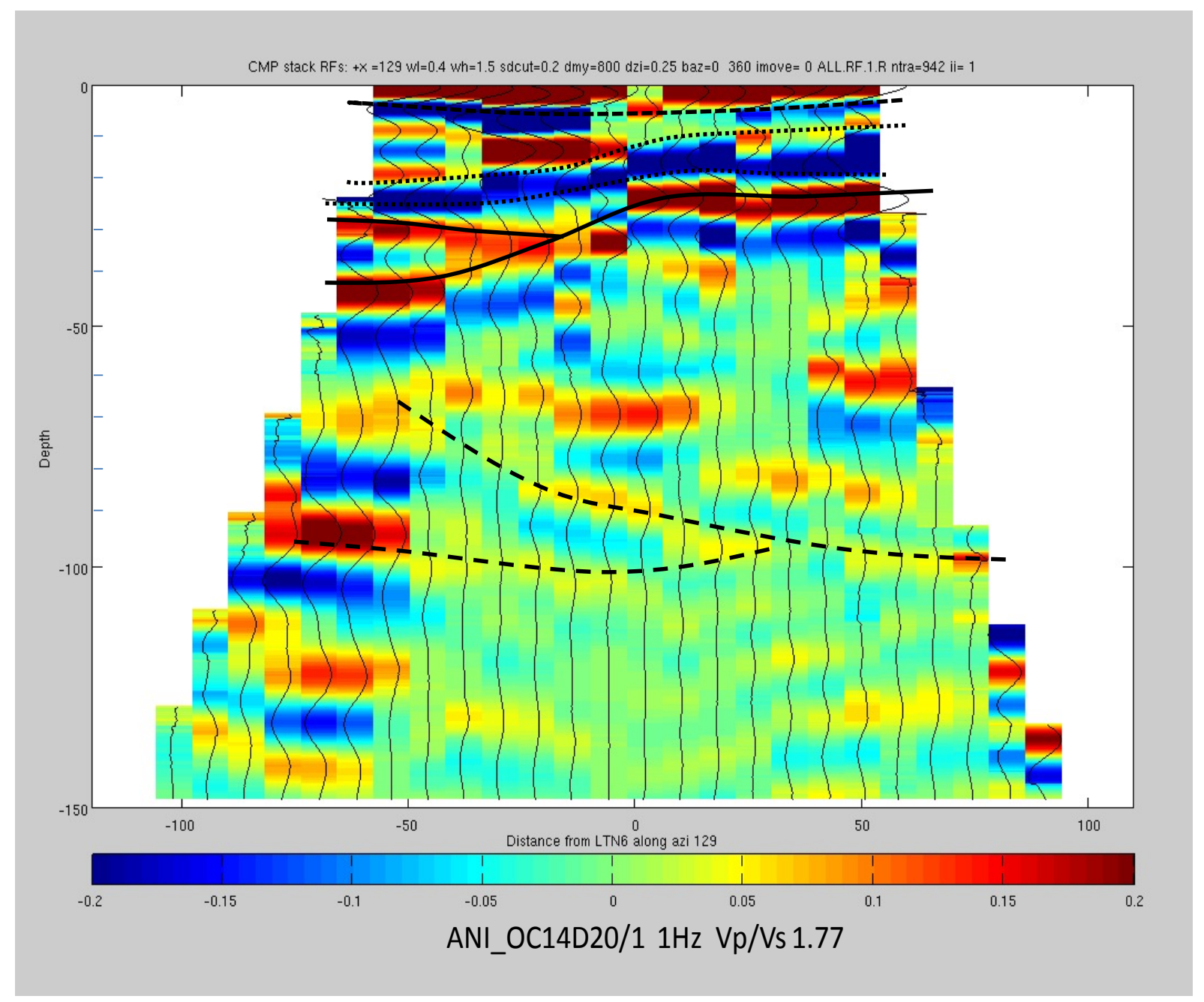

Figure 64 Best and Final CCP stack. Interpreted using 0C14D20 at $1 \mathrm{~Hz}$ with a VP/Vs =1.77. Dashed black line showing discontinuities in the upper mantle at depths $<100 \mathrm{~km}$, dipping in the opposite direction to the dip of the downgoing slab. Solid black line showing down going slab with imbricated structure to the west (left). Small black dotted line delineating top and bottom of the low velocity layer (LVL) at the top of the down going slab. Short dashes indicate a low velocity layer at shallow crustal depths. 


\section{CHAPTER 9}

\section{INTERPRETATION AND DISCUSSION}

\subsection{INTERPRETATION}

\subsubsection{OC14D20 (SAVAGE, 2007) 1HZ VELOCITY MODEL CCP STACK.}

The 0C14D20 velocity model provides the best and final model that is interpreted in Figure 64

Thickness estimates given in this section are measured directly from the image and scaled with the depth axis. However some of the apparent thickness is a factor of the resolution provided by $1 \mathrm{~Hz}$ wavelength, rather than the actual thicknesses (Savage, 2007).

\subsubsection{UPPER-CRUSTAL LOW VELOCITY LAYER}

The low velocity layer (LVL) (Figure 64 short black dashes), is observed at a maximum crustal depth of $10 \mathrm{~km}$, below the westerly (LTW1, 2, 3) stations. The layer does not appear to dip a great deal across the transect. It is very strongly evident beneath the four westerly stations that lie on the Rakaia Terrane greywacke. This layer is not strong beneath the centre of the transect, but re-appears as a thinner layer beneath the easterly stations.

This upper-crustal LVL is above a layer interpreted by Savage (2007) as a 'mid-crustal positive'; this only appears (as a distinct dark red layer) beneath stations LTW1, LTW2 and LTW3. Savage (2007) interprets this as an alteration in the type of greywacke, or a schist layer. Because this positive layer is only apparent beneath those stations that lie on the Rakaia Terrane 
(Figure 33 Station locations and geological map of New Zealand) this supports Savage's assertion that this layer is associated with an alteration in the greywacke.
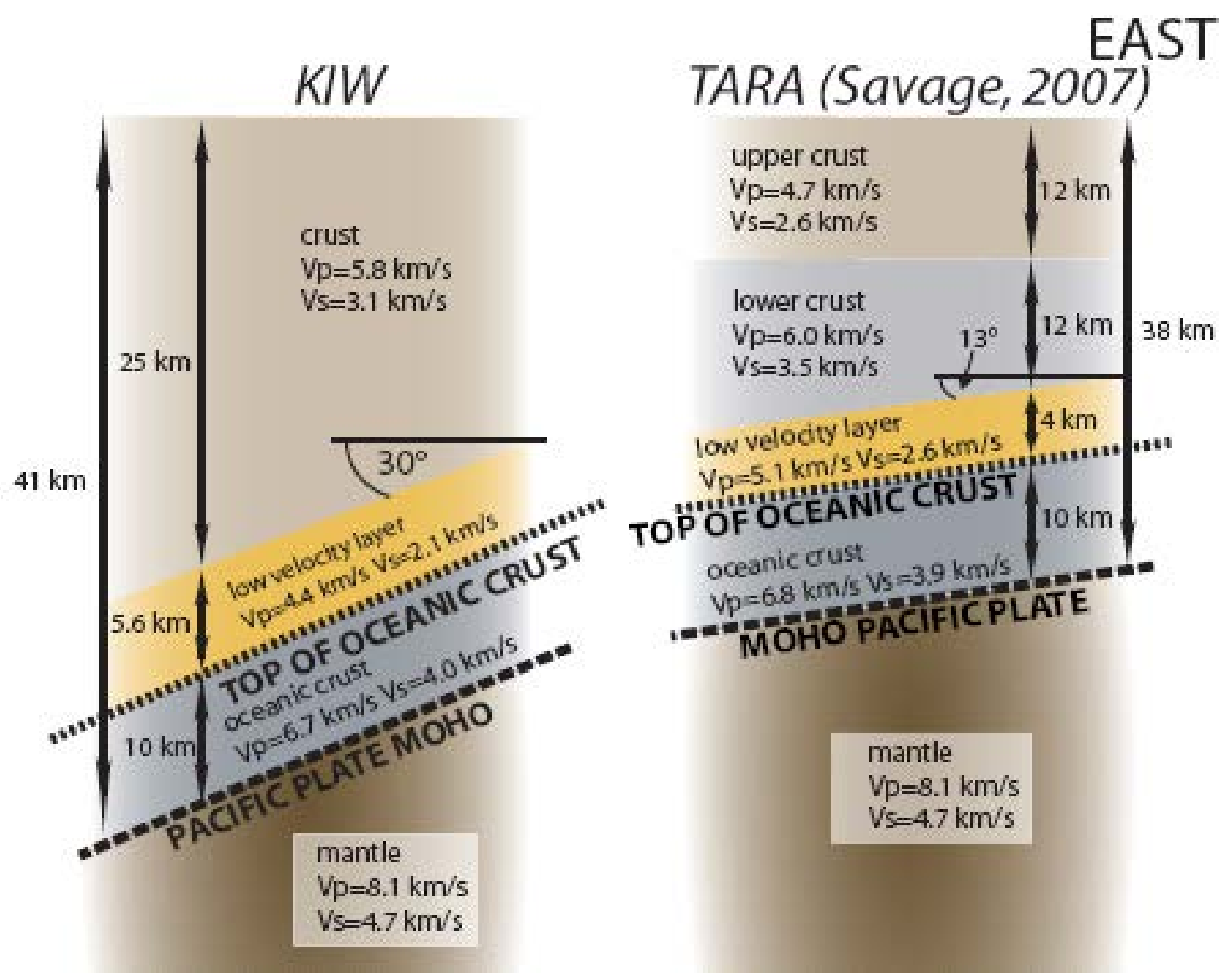

Figure 65 Schematics of velocity models Savage (2007) and Ewig (2009). (Figure from Ewig, 2009).

\subsubsection{LOW VELOCITY LAYER ABOVE THE SUBDUCTING OCEANIC CRUST.}

The presence of a low velocity layer (LVL) imaged in dark blue (Figure 65), above the top of subducting oceanic crust is observed along the full length of the transect. The LVL is interpreted on Figure 64 lying between the two lines of small black dots. The layer dips to the west, with a very shallow dip on the easterly section and an offset, or greater dip, beneath the centre of the transect. This coincides with the region where the underlying geology changes from Rakaia Terrane in the west to Pahau Terrane in the east. The 
layer then flattens out to a shallower dip at the most westerly extent of the transect.

The LVL has been recognised before in other studies lying below stations KIW, LTW1, LTW2 andLTW3 by Savage (2007) and Ewig (2009) (Figure 65) (see Chapter 3 Figure 20) also (see Chapter 3, 3.2.2). Savage comments that this layer is of smaller amplitude beneath the Tararua stations (the aforementioned LTW1, LTW2 andLTW3) than at station SNZO, which lies at the far south of the North Island of New Zealand. Savage comments that the smaller amplitude observed in the Tararuas may be caused by a thinner layer, shallower dip or smaller velocity contrast than beneath SNZO. Boyd et al., (2007) (see also Chapter 3, 3.3.2) also locate an LVL at the top of the slab in the Southern section of the Hikurangi Trough. It is imaged using receiver functions and CCP stacking above the shallow section of the descending slab below the Cook Strait, and beneath the Moho off shore to the north of the top of the South Island. A layer interpreted as subducting sediment at the plate interface is imaged by Barker et al., (2009) (using active source seismology), and further interpreted by Wallace et al., (2009). This layer lies on the southern and central sections of the offshore Hikurangi margin. Wallace comments that it is unclear whether the amount of subducted sediment actually does change significantly along the margin'. Eberhart-Phillips and Reyners, (1999) recognise a thin, $\sim 5 \mathrm{~km}$ thickness, layer with 'unusual material properties' directly above the Hikurangi plate interface in the Northeast (Raukumara Peninsula) of the North Island of New Zealand. It is interpreted as likely to be a layer of subducted sediment. More recently the findings of Eberhart-Phillips and Reyners, (2012) reinforce those of Reyners and Eberhart-Phillips (2009) using tomographic techniques to image structures below the southern North Island and the central North lsland. They investigate the nature of interplate coupling and find there is an area of low $\mathrm{Vp} / \mathrm{Vs}$ that is impermeable and traps fluids released by dehydration, on the plate interface resulting in high pore pressure in the subducting slab, below the plate interface. The high $\mathrm{Vp} / \mathrm{Vs}$ may be indicative of an area of high pore pressure, with the overlying metamorphosed Rakaia terrane acting as a plausible impermeable layer. This area of high pore pressure 
appears to be related to those areas identified as having strong interseismic coupling.

The presence of an LVL at the top of the subducting slab is not confined to the Hikurangi margin in New Zealand. Kawakatsu et al., (2007) find seismic evidence from the subduction zone beneath northeast Japan indicating that hydrated minerals form a channel on the top of the subducting plate. This is imaged as a low velocity zone at the top of the subducting slab using receiver functions and CCP stacking.

\subsubsection{THE SUBDUCTING OCEANIC CRUST}

The layer on Figure 64, marked by a solid black line is interpreted as the subducting oceanic crust (the slab). The layer at the base of the crust, marking the top of the solid part of the mantle is the sharp, positive polarity Mohorovicic discontinuity, (the Moho). This high velocity (red on the image) layer dips towards the west with a significant offset in the central region. Beneath the eastern stations the descending slab seems to have very little dip; in this region it appears slightly variable in thickness, $\sim 8 \mathrm{~km}$ at the thinnest and $\sim 12 \mathrm{~km}$ at the thickest point. This fits with the findings of Ewig (2009) and Savage (2007) who both estimate thicknesses of $10 \mathrm{~km}$ for this layer (Figure 65 ). The depth to the top of the oceanic crust is $\sim 22 \mathrm{~km}$ to $\sim 24$ $\mathrm{km}$ (deepest below station MTW) below the eastern section. Below the western section the layer appears to bifurcate. Henrys et al., (2012) interpret this apparent bifurcation as the intrusion of the overlying Australian Plate (Figure 66). Figure 66 is from Henrys et al., (2012) unpublished SAHKE preliminary results. (See section 9.2). This study estimates that the depth to the lower 'arm' beneath station KIW is $\sim 45.5 \mathrm{~km}$. The depth to the top of the Moho beneath the Tararua Stations is estimated at $\sim 34 \mathrm{~km}$. This is deeper than Savage (2007) estimates at $28 \mathrm{~km}$ (see Fig 60), also deeper than Henrys et al., (2012).

\subsubsection{THE GUTENBERG DISCONTINUITY. STRUCTURES BENEATH THE MOHO}

Figure 64 shows evidence of coherent structures at depths $\sim 100 \mathrm{~km}$ interpreted using the dashed black line on the figure. This layer appears to dip towards the east, the opposite direction to the descending slab. A 
possible explanation for this layer may be that it is the Gutenberg discontinuity (Gutenberg 1959) that lies at the lithosphere-asthenosphere boundary (the LAB).

Global plate tectonic theory assumes that the solid lithosphere, consisting of the crust and uppermost solid mantle, has the capacity to move over the top of the weaker asthenosphere. Global plate tectonic models indicate that at a depth of $\sim 50-100 \mathrm{~km}$ there is a low velocity zone (LVZ), where there is a decrease of $P$ wave velocity (Gutenberg, 1959). This decrease is not observed as a sharp interface but as a decrease over a depth interval before the velocity increases again (Gutenberg, 1959, Mussett and Khan, 2000). This may indicate the presence of partially molten mantle rocks. This is taken to be the bottom of the plate.

Figure 64 shows discontinuities that indicate there are observable, coherent structures at depths of 50-100 km. However they appear as positive velocity increases not decreases, which does not fit in with Gutenberg's theory.

The LAB has been observed using both $\mathrm{S}$ and $\mathrm{P}$ wave receiver functions beneath the oceanic lithosphere (Kawakatsu et al., 2009) and using S wave receiver functions beneath the continental Tibetan Plateau (Kumar et al., 2006). Though $S$ wave receiver functions are used more frequently to image upper mantle discontinuities, because $\mathrm{P}$ to $\mathrm{S}$ converted phases may be masked by multiples from the crust; studies using the multi-taper correlation method and $\mathrm{P}$ wave receiver functions, such as this, have been used to estimate structures within mantle depths (Bourguignon, 2009).

\subsection{COMPARISON WITH ACTIVE SOURCE RESULTS FROM THE SAHKE PROJECT.}

The paper by Henrys et al., (2012, unpublished) uses the active source SAHKE data set using wide angle seismic reflection and refraction data to interpret the same structures as in this project. Comparing the two sets of results enables the interpretations to be further constrained.

Henrys et al., (2012) identify phases corresponding to the base of the downgoing Hikurangi ocean crust to the west of Featherston (corresponding 
with my station LTN6) across the Tararuas, beneath my stations LTW1, LTW2 and LTW3. Henrys et al., (2012) also identify a 'distinct change in character and dip' from east to west beneath Featherston. This is in accord with results from this study where there is also a change in dip at this point. This study also identifies a distinct difference in crustal structure to the west where there is a strong LVL at mid crustal depth, sandwiched between two high velocity layers; whereas to the east the change to the top of the LVL is gradational and less distinct. Henrys et al., (2012) give depths of $10 \mathrm{~km}$ to the plate interface at the Wairarapa Coast, deepening to $>25 \mathrm{~km}$ beneath Kapiti. This study estimates the depth to the top of the low velocity layer at the most easterly extent of the receiver function transect as $10 \mathrm{~km}$ and to the top of the LVL at the most westerly end as $\sim 24 \mathrm{~km}$.

Henrys et al., (2012) comment that the region of the intersection between the subducting Hikurangi Plateau and Australian plate, beneath and to the west of Kapiti Island is complex, with additional phases identified as 'radiating' from this region. This description is in accordance with the findings of this study regarding this region below station KIW.

Also in accordance with the receiver function image is the description from Henrys et al., (2012) regarding imbricated structures beneath the Tararuas at depths of 12-15 km. Though this is not interpreted on Figure 64 these structures are observable, as a bifurcation of the mid crustal positive at the far western end of the transect, at depths of 10-15 km.

Henrys et al., (2012) find a low velocity 'triangular zone' above the descending slab beneath the Tararuas. This study images the LVL at the top of the slab, thickening to the east, below the Tararua stations, LTW1, LTW2 and LTW3 before the dip increases. Henrys et al., (2012) also comment that the $12 \mathrm{~km}$ depth layer beneath the Tararua Stations does not appear under Kapiti, which is also in accordance with the findings from this study.

Henrys et al., (2012) comments that the findings of a low velocity zone at the top of the slab by Savage (2007) is consistent with the active source dataset, but Savages estimates of $10 \mathrm{~km}$ thickness for the thickness of the crust is less than the $15 \mathrm{~km}$ of Henrys et al., (2012). The interpretation of receiver 
function data in this study shows that the depth to the top of the LVL (the crustal thickness) beneath the Tararua Stations is estimated at $\sim 18 \mathrm{~km}$. This is deeper than both Savage's (2007) estimates at $10 \mathrm{~km}$ and Henrys et al., (2012) estimates at $15 \mathrm{~km}$.

Receiver function data is not well suited to imaging vertical to sub-vertical faults; therefore it is impossible to comment on any similarities regarding the location of major faults in the region. The large offset at the centre of the transect, beneath station LTN6 does however appear to be around the same location as an offset interpreted by Henrys et al., (2012) as being the Wellington fault. The offset in the CCP stack could be explained by the discrepancy in the number of receiver functions modeled at the stations in this region; however this cannot explain the offset modeled by Henrys et al.

Over all the agreement between this dataset and the active source data is impressive, with more similarities apparent than differences.

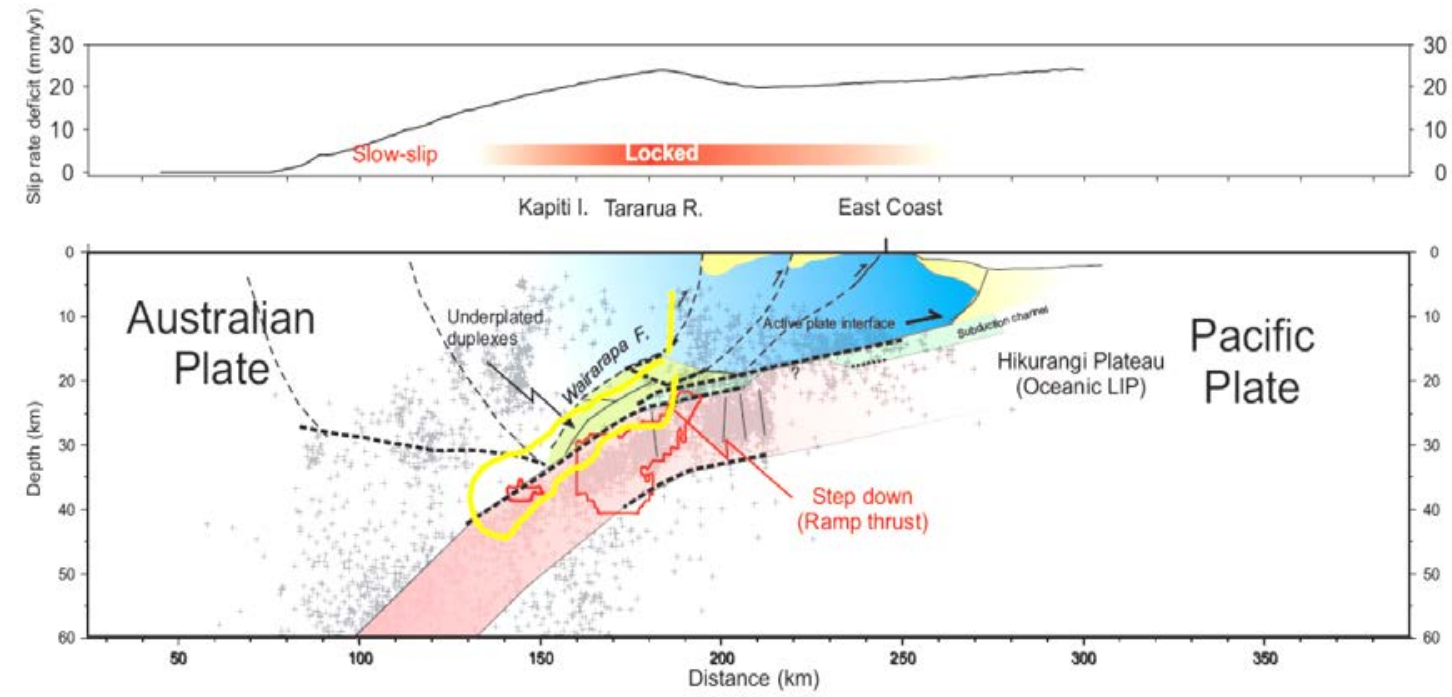

Figure 66 Figure from (unpublished) SAHKE preliminary results using controlled source seismic data. (Henrys et al., 2012).

\subsection{DISCUSSION}

At the beginning of this thesis I introduced some fundamental questions regarding subduction seismogenesis (taken from the SAHKE project summary document). Clearly providing definitive answers to these fundamental 
seismological questions is outside the scope of this study. Nevertheless the stated wider objective of this study was to add to the body of knowledge regarding subduction zone seismogenesis in general. Using the results that I have obtained by the calculation, analysis and interpretation of the receiver functions and the CCP stacked image, integrated with knowledge from previous investigations of subduction zone seismogenesis, I can offer some tentative answers to the following questions.

\section{What controls the occurrence and breadth of interseismic coupling?}

Controls on the occurrence and breadth of interseismic coupling are along strike changes, documented by previous studies (e.g. Reyners, 1998; Barnes et al., 1998; Nicol and Beavan, 2003; Wallace et al., 2004; Wallace et al., 2009; Reyners et al., 2011). These indicate that the southern section of the Hikurangi margin is strongly coupled. Observations of this segment also indicate a shallow slab dip, (Eberhart-Phillips and Reyners, 1997) giving a large region where fore-arc continental crust is directly above the descending plate (Barnes et al., 1998); a buoyant subducting crust (Cloos, 1993; Barnes et al., 1989); and a strong overlying plate (Barnes et al., 1998). It is not known exactly what properties, or combination of properties, have influence over the amount of interseismic coupling and build up of stress. My results confirm that there is a very shallow dip in the eastern section of the transect beneath the Wairarapa. This section is identified in previous studies as being strongly coupled e.g. Reyners, 1998 and Wallace et al., 2004. The shallowness of the dip appears to indicate that the thickened subducting crust may be more buoyant in this area. It is estimated that the thickness of the Hikurangi Plateau is $\sim 12 \mathrm{~km}$ (Davy, 1992). This is thicker than the estimated 5-7 km oceanic crust thickness measured beyond the north-east of the plateau (Davy, 1992). The material subducting below the North Island of New Zealand is contiguous with the off shore Hikurangi Plateau; therefore a relationship regarding thickness and buoyancy may be proposed. The observed thickness, taken from the $1 \mathrm{~Hz}$ receiver functions (Fig 59) estimates the thickness of the LVL, on top of the descending oceanic Moho to be $\sim 12 \mathrm{~km}$. 
The actual 'strength' of the overlying plate is not verifiable using receiver function data. However the crustal structure of high velocity layers 'sandwiching' a low velocity layer, as observed beneath the Tararua stations may provide strength to the structures.

Can the presence or absence of fluids affect coupling on the plate interface?

The presence and distribution of fluid is likely to have an effect on frictional regimes. High pore pressures are likely to be associated with clusters of seismicity and may be linked with the presence of impermeable rock (Reyners and Eberhart-Phillips, 2009). Fluids may also be associated with low velocity layers (Eberhart-Phillips and Reyners, 1999 and Bannister et al., 2007) which are surmised to cause a weak zone with low rigidity and possibly low seismicity. Whilst I cannot conclude as to whether the presence of fluids has an effect on the degree of coupling or not, my results do confirm the presence of a low velocity zone lying at the top of the subducting slab that may be a fluid rich layer (see discussion above).

\subsection{CONCLUSION}

Using receiver function analysis and common conversion point stacking to image the structures associated with the Hikurangi subduction zone beneath the Wellington region of the North Island of New Zealand has provided a good quality image that confirms some of the findings of other studies in the region. In particular the findings of Henrys et al., (2012), using active source data from the SAHKE project, regarding depths and thicknesses appear to be verified.

Using synthetic receiver functions to model three different velocity models allowed a conclusion regarding the best fit model (OC14D20 from Savage, 2007) for the transect as a whole. However creating CCP stacks using the three models, but using two different Vp/Vs ratios (Vp/Vs 177 and 1.72) for 
the best fit, OC14D20, model confirms the assertion of Zhu (2000) that CCP stacking is more sensitive to the choice VP/Vs ratio than velocity model.

Using the Vp/Vs ratio of 1.77 allows depths that are very close to those proposed by Henrys et al., (2012). This finding leads to the conclusion that the structures beneath the Wellington region probably have relatively high overall Vp/Vs of 1.77.

\subsection{OPPORTUNITIES FOR FURTHER WORK}

The frequency range of the analysis used in this study is limited to a cut off of 1 $\mathrm{Hz}$ because of the filtering during the picking phase (see Chapter 5, 5.7.1) using a band pass filter of between $0.02 \mathrm{~Hz}$ and $1.0 \mathrm{~Hz} .1 \mathrm{~Hz}$ receiver functions have been successfully used by other authors (e.g. Savage, 2007 and Ewig, 2009) (see chapter 3, 3.2.2). Ewig (2009) uses a bandpass filter of between 0.5 and $1.5 \mathrm{~Hz}$ for his CCP stack. Salmon (2008) states that higher frequency receiver functions (up to $2.5 \mathrm{~Hz}$ ) provide more detail for shallow structure, while lower frequency receiver functions $(<1.0 \mathrm{~Hz})$ give a better representation for deeper structure, but does not indicate to what depths she means by 'shallow' and 'deep'. Nikulin et al., (2009) (see chapter 3, 3.2.1) limited their results to $0.5 \mathrm{~Hz}$, but Bannister et al., (2007) used a cut off of $2 \mathrm{~Hz}$ to image the subducting slab (Figure 19, Chapter 3).

The broadband stations used in this project (see Table 2, chapter 5) have corner frequencies of between $0.033 \mathrm{~Hz}$ and $50 \mathrm{~Hz}$; therefore data from these stations would not be limited in theory. The data from the short period stations has a natural period of $\sim 2.0 \mathrm{~Hz}$ (see Table 2) therefore is limited.

Park and Levin (2000) tested their method against two other popular methods for receiver function estimation, time-domain deconvolution and spectral division and found that their method was suitable to be used for resolving higher frequencies, up to $4.0 \mathrm{~Hz}$ because of greater resistance to signal generated noise. Signal generated noise tends to increase with higher frequencies (park and Levin, 2000). 
There is scope for further work, therefore, using the broadband data and the MTC method (Park and Levin, 2000) to make further analyses at higher frequencies to potentially provide more detail for the shallower structures. But the choice of $1 \mathrm{~Hz}$ for this thesis is prudent given the choices made by authors in previous receiver function studies. 
- 141 - 


\section{REFERENCES}

Abers, G.A. (1998). Array measurements of phases used in receiver-function calculations: importance of scattering. Bulletin of the Seismological Society of America. 87. 313-318

Ammon, C.J., Randall G.E., Zandt G. (1990). On the non-uniqueness of receiver function inversion. Journal of Geophysical Research. Vol 95, B10. 15303-15318.

Ammon, C.J. (1991). The isolation of receiver effects from teleseismic P waveforms. Bulletin of the Seismological Society of America. Vol 81, 6. 2504-2510.

Ansell, J.H., Bannister, S.C. (1996). Shallow morphology of the subducted Pacific plate along the Hikurangi margin, New Zealand. Physical Earth planet International. 93. 3-20.

Audet, P., Bostock, M.G., Christensen, N.I., Peacock, S.M. (2009). Seismic evidence for over pressured subducted oceanic crust and megathrust fault sealing. Nature (letters). 457. doi:10.1038/nature07650

Babuska, V., Cara, M. (1991). Seismic anisotropy in the earth. Kluwer Academic., Norwell, Mass.

Bannister, S., Reyners, M., Stuart, G., Savage, M. (2007). Imaging the Hikurangi subduction zone, New Zealand, using teleseismic receiver functions: crustal fluids above the forearc mantle wedge. Geophysical Journal International, 169: 602-616. doi: 10.1111/j.1365-246X.2007.03345.x

Barker , D. N. H., Sutherland, R., Henrys, S., Bannister, S.(2009). Geometry of the Hikurangi subduction thrust and upper plate. North Island, New Zealand. Geochemistry. Geophysics. Geosystems. 10, Q02007. doi:10.1029/97JB01384

Barnes, P.M., Mercier De Lepinay. (1997). Rates and mechanics of rapid frontal accretion along the very obliquely convergent southern Hikurangi margin, New Zealand. Journal of Geophysical research. Vol 102. B11. 24931-24952.

Barnes, P.M., Mercier De Lepinay, B., Collot, J-Y., Delteil, J., Audru, J-C. (1998). Strain partitioning in the transition area between oblique subduction and continental collision, Hikurangi margin, New Zealand. Tectonics, Vol 17, 4. 534-557. 
Beanland, S. (1995). The North Island dextral fault belt, Hikurangi subduction margin, New Zealand. PhD Thesis. Lodged in the Library Victoria University, Wellington.

Barnes, P.M., Lamarche, G., Bialas, J., Henrys, S., Pecher, I., Netzeband, G.L., Greinnert, J., Mountjoy, J.J., Pedley, K., Crutchley, G. (2010). Tectonic and geological framework for gas hydrates and cold seeps on the Hikurangi subduction margin, New Zealand. Marine Geology 272, 26-48

Beanland, S., Melhuish, A., Nicol, A., Ravens, J. (1998).Structure and deformational history of the inner forearc region, Hikurangi subduction margin, New Zealand. New Zealand Journal of Geology \& Geophysics. Vol. 41: 325-342

Beavan, J.L., Wallace, L., Douglas, A., Fletcher, H. (2007). Slow slip events on the Hikurangi subduction interface, New Zealand. Dynamic Planet: Monitoring and Understanding a Dynamic Planet with Geodetic and Oceanographic tools: IAG symposium, Cairns, Australia, 22-26 August, 2005. Int. Assoc .Geodet. symp., Vol 130. P.Tregoning \& C.Rizos Ed. Pp438-444, Springer Berlin.

Begg, J.G.; Johnston, M.R. (compilers) 2000: Geology of the Wellington area: scale 1:250,000. Lower Hutt: Institute of Geological \& Nuclear Sciences. Institute of Geological \& Nuclear Sciences 1:250,000 geological map 10.64 p. + 1 folded map

Beroza, G.C., Ide, S. (2011). Slow earthquakes and nonvolcanic tremor. Annual Review of Earth and planetary sciences. 2011. 39:271-296

Bourguignon, S. (2009). Lithospheric deformation at the South Island oblique collision, New Zealand. PhD Thesis. Lodged at the library Victoria University, Wellington, New Zealand.

Boyd, O.S., Savage, M.K., Sheehan, A.F., Jones, C.H. (2007). Illuminating the plate interface structure beneath Cook Strait, New Zealand, with receiver functions. Journal of Geophysical Research. Vol 112. B06310, doi:10.1029/2006JB004552, 2007

Buland, R., Chapman, C.H. (1983). The computation of Seismic travel times. Bulletin of the Seismological Society of America. 73, 5. 1271-1302.

Burdick, L.J., Langston, C.A. (1977). Modeling crustal structure through the use of converted phases in teleseismic body-wave forms. Bulletin of the Seismological Society of America. Vol. 67, 3: 677-691.

Cassidy, J.F., (1992). Numerical experiments in broadband receiver function analysis. Bulletin of the Seismological Society of America. 82.1453-1474.

Clayton, R.W., Wiggins, R.A. (1976). Source shape estimation and deconvolution of teleseismic body waves. Geophysical Journal of the Royal Astronomical Society. 47. 151-177. 
Cloos, M. (1993). Lithospheric Buoyancy and collisional orogenesis: Subduction of oceanic plateaus, continental margins, island arcs, spreading ridges, and seamounts. Geological Society America Bulletin. 105, 715-737.

Cochran, U., Berryman, K., Zachariasen, J., Mildenhall, D., Hayward, B., Southall, K., Hollis, C., Barker, P., Wallace, L., Alloway, B., Wilson, K. (2006). Paleoecological insights into subduction zone earthquake occurrence, eastern North Island, New Zealand. Geological Society of America Bulletin: v. 118:no. 9/10: 1051-1074; doi: 10.1130/B25761.1

Cole, J.W., Lewis, K.B. (1981). Evolution of the Taupo-Hikurangi subduction system. Tectonophysics. 72. 1-21.

Davey, F.J., Hampton, M., Childs, J.R., Fisher, M.A., Lewis, K.B., Pettinga, J.R. (1986). Structure of a growing accretionary prism. Hikurangi Margin. New Zealand. Geology. 14. 663-666

Davy, B., Wood, R. (1994). Gravity and magnetic modelling of the Hikurangi Plateau. Marine Geology. 118, 139-151.

Davy, B., Hoernle, K., Werner, R. (2008). Hikurangi Plateau: Crustal structure, rifted formation, and Gondwana subduction history. Geochemistry Geophysics Geosystems. Vol 9. 7. doi:10.1029/2007GC001855

De Mets, C., Gordon, R.G., Argus, D.F., Stein, S. (1990). Current plate motions. Geophysics Journal International. 101. 425-478.

De Mets, C., Gordon, R.G., Argus, D.F., Stein, S. (1994). Effects of recent revisions to the geomagnetic reversal time scale on estimates of current plate motions. Geophysical Research Letters. 21. 2191-2194.

Douglas, A., Beavan, J., Wallace, L., Townend, J. (2005). Slow slip on the northern Hikurangi subduction interface. Geophysical Research Letters. 32. L16305, doi:10.1029/2005GL023607

Duecker , K.G., Sheehan, A.F. (1998). Mantle discontinuity structure beneath the Colarado Rocky mountains and high plains. Journal of Geophysical Research. 103. 7153-7169.

Dzierma, Y., Thorwart, M.M., Rabbel, W., Flueh, E.H., Alvarado, G.E., Mora, M.M. (2010). Imaging crustal structure in south central Costa Rica with receiver functions. Geochemistry, Geophysics, Geosystems.

Eberhard-Phillips, D., Reyners, M. (1997). Continental subduction and threedimensional crustal structure: The northern South Island, New Zealand. Journal of Geophysical Research. 102, B6. 11, 843-11,861 
Eberhard-Phillips, D., Reyners, M. (1999). Plate interface properties in the northeast Hikurangi subduction zone, New Zealand, from converted seismic waves. Geophysical Research Letters. 26. 2565-2568.

Eberhard-Phillips, D., Reyners, M., Chadwick , M., Stuart, G. (2008). Three-dimensional attenuation structure of the Hikurangi subduction zone in the central North Island, New Zealand. Geophysical Journal International. 174, 418-434.

Eberhard-Phillips, D., Reyners, M. (2012). Imaging the Hikurangi Plate interface region, with improved local-earthquake tomography. Geophysical Journal International. 190, 1221-1242. doi : 10.1111/j.1365-246X.2012.05553.x

Ewig, E. (2009). Lithospheric shortening and ductile deformation in a back-arc setting: South Wanganui Basin, New Zealand. A thesis submitted to the Victoria University of Wellington in fulfilment of the requirements for the degree of Doctor of Philosophy in Geophysics. Institute of Geophysics. Victoria University of Wellington.

Frederiksen, A., Bostock, m. (2000). Modelling teleseismic waves in dipping anisotropic structures. Geophysical Journal International, 141(2), 401-412.

Furlong, K. P., Kamp, P. J. (2009). The lithospheric geodynamics of plate boundary transpression in New Zealand: Initiating and emplacing subduction along the Hikurangi margin and the tectonic evolution of the Alpine Fault system. Tectonophysics. 474. 449-462.

Goldstein, P., D. Dodge, M. Firpo, Lee Minner (2003) “SAC2000: Signal processing and analysis tools for seismologists and engineers, Invited contribution to "The IASPEI International Handbook of Earthquake and Engineering Seismology", Edited by WHK Lee, H. Kanamori, P.C. Jennings, and C. Kisslinger, Academic Press, London.

Gutenberg, B. (1959). Physics of the Earth's Interior. Academic Press, New York.

Hasegawa, A., Umino, N., Takagi, A. (1978). Double-planed deep seismic zone and upper-mantle structure in the northeastern Japan arc. Geophysical Journal of the Royla Astronomical Society. 54. 281-296.

Hasemi, A.H., Ishii, H., Takagi, A. (1984). Fine structure beneath the Tohuku district, north-eastern Japan arc, as derived by the inversion of P-wave arrival times. Tectonophysics.101.245-265

Horspool, N.A., Savage, M.K., Bannister, S. (2006). Implications for intraplate volcanism and back-arc deformation in northwestern New Zealand, from joint inversion of receiver functions and surface waves. Geophysics Journal International. 166, 1466-1483 
Igarashi, T. (2009). Seismic velocity discontinuities in the crust and uppermost mantle beneath the Kanto district, central Japan, identified from receiver function imaging and repeating earthquake activity. Gondwana Research. 16. 491-503.

Kawakatsu, H., Wadata, S. (2007). Seismic evidence for deep-water transportation in the mantle. Science. Vol 316, 1468-1471.

Kawakatsu, H., Kumar, P., Yasuko, T., Masanao, S., Kanazawa, T., Araki, E., Kiyoshi, S. (2009). Seismic evidence for sharp lithosphere-asthenosphere boundaries of oceanic plates. Science. 324: 499-501

Kearey, P., Vine, F,J. (2003). Global Tectonics. 2nd Edition. Blackwell Science Ltd. ISBN 0-86542-924-3

Kibblewhite, A.C., Ewans, K.C. (1985). Wave-wave interactions, microseisms and infrasonic ambient noise in the ocean. J. Acoust. Soc. Am. 85, 5, 1935-1945

Kumar, P., Yuan, X., Kind, R., Ni, J. (2005). Imaging the colliding Indian and Asian lithospheric plates beneath Tibet. Journal of Geophysical Research. Vol 111. B06308, doi:10.1029/2005JB003930, 2006

Lamb, S. (2011). Cenozoic tectonic evolution of the New Zealand plate-boundary zone: A paleomagnetic perspective. Tectonophysics. 509. 135-164.

Langston, C.A. (1977). Corvallis, Oregon, crustal and upper mantle receiver structure from teleseismic P and S waves. Bulletin of the Seismological Society of America. 67: 713-724.

Langston, C.A. (1979). Structure under Mount Rainier, Washington, inferred from teleseismic body waves. Journal of Geophysical Research. 84, B9: 4749-4762.

Lees, J., Park, J. (1995). Multiple-taper spectral analysis: a stand-alone C- subroutine. Computers and Geosciences. 21, 199-236.

Lewis, K.B., Pettinga , J.R., (1993). The emerging, imbricate frontal wedge of the Hikurangi margin. In: Balance, P.F(Ed). South Pacific Sedimentary Basins. Sedimentary basins of the world 2. Basins of the south Pacific. Elsevier, Amsterdam, pp.225-250.

Ligorria, J.P., Ammon, C.J., (1999). Iterative deconvolution and receiver-function estimation. Bulletin of the Seismological Society of America. 89, 5, 1395-1400.

Lin, F.-C., Ritzwoller, M. H., Townend, J., Bannister, S. and Savage, M. K. (2007). Ambient noise Rayleigh wave tomography of New Zealand. Geophysical Journal International, 170: 649-666. doi: 10.1111/j.1365-246X.2007.03414.x

McCaffrey, R. (1997). Influences of recurrence times and fault zone temperatures on the age-rate dependence of subduction zone seismicity. Journal of Geophysical Research. 102, B10: 22839-22854 
McCaffrey, R., Wallace, L., Beavan. (2008). Slow slip and frictional transition at low temperature at the Hikurangi subduction zone. Nature Geoscience. Vol 1. 316320

Morgan, J.K., Karig, D.E. (1995). Decollment processes at the Nankai accretionary margin, southeast Japan: Propagation, deformation and dewatering. Journal of Geophysical Research, 100.15.221-15.231.

Mussett, A.E., Khan, M.A. (2000). Looking into the Earth; An introduction to Geological Geophysics. Cambridge University Press. ISBN 0-521-78-85-3

Neal, C.R., Mahoney, J.J., Kroenke, L.W., Duncan, R.A., Petterson, M.G. (1997). The Ontong Java Plateau. Geophysical Monograph 100. 183-216.

Nicol, A., Beavan,J. (2003). Shortening of an overriding plate and its implications for slip on a subduction thrust, central Hikurangi margin, New Zealand. Tectonics. Vol 22. 6. 1070, doi:10.1029/2003TC001521, 20

Nicol, A., Mazengarb, C., Chanier, F., Rait, G., Uruski, C., Wallace, L. (2007). Tectonic evolution of the active Hikurangi subduction margin, New Zealand, since the Oligocene. Tectonics Vol. 26, TC4002, doi:10.1029/2006TC002090, 2007.

Nicol, A., Wallace, L.M., (2007). Temporal stability of deformation rates: Comparison of geological and geodetic observations, Hikurangi subduction margin, New Zealand. (2007). Earth and Planetary Science Letters 258, 397-413.

Nikulin, A., Levin, V., Park, J. (2009). Receiver function study of the Cascadia megathrust: Evidence for local serpentinization. Geochemistry Geophysics Geosystems. 10, 7. Doi:10.1029/2009GC002376

Niu, F., Levander, A., Sangwon, H., Obayashi, M. (2005). Mapping the subducting Pacific beneath southwest Japan with Hi-net receiver functions. Earth and Planetary Science Letters 239. 9-17.

Okaya, D. (2010) Seismic Array Hikurangi Experiment (SAHKE) funding proposal. Unpublished.

Owens, T.J., Crosson, R.S. (1988). Shallow structure effects on Broadband Teleseismic $P$ waveforms. Bulletin of the Seismological Society of America. 78, 1, 96-108.

Owens, T. J., G. Zandt, and S. R. Taylor. (1984). Seismic evidence for an ancient rift beneath the Cumberland Plateau, Tennessee: A detailed analysis of broadband teleseismic P waveforms, Journal of Geophysical Research., 89, 7783-7795. 
Owens, T. J., S. R. Taylor, and G. Zandt. (1987). Crustal structure at regional seismic test network stations determined from inversion of broadband teleseismic $P$ waveforms. Bulletin of the Seismological Society of America. 77, 631-662.

Park, J., Lindberg, C.R., Vernon, F.L. (1987). Multi-taper spectral analysis of High Frequency seismograms. Journal of Geophysical Research. 92, B12, 1267512684.

Park, J., Levin, V. (2000). Receiver functions from multiple-taper spectral correlation estimates. Bulletin of the Seismological Society of America. 90, 6, 1507-1520.

Qingju, W., Yonghua, L., Ruiqing, Z., Rongsheng, Z. (2007). Wavelet modelling of broadband receiver functions. Geophysics Journal International. 170, 534-544.

Randall, G.E. (1989) Efficient calculation of differential seismograms for lithospheric receiver functions. Geophysics Journal International. 99, 469-481.

Reading, A.M., Gubbins, D., Mao W. (2001) A multiphase seismic investigation of the shallow subduction zone, southern North Island, New Zealand. Geophysics Journal International. 147, 215-226.

Reyners, M., Robinson, R., McGinty, P. (1997). Plate coupling in the northern South Island and southernmost North Island, New Zealand, as illuminated by earthquake focal mechanisms. Journal of Geophysical Research, Vol 102. B7. 15197-15210

Reyners, M. (1998). Plate coupling and the hazard of large subduction thrust earthquakes at the Hikurangi subduction zone, New Zealand. New Zealand Journal of Geology and Geophysics. 41:4, 343-354

Reyners, M., Eberhart-Phillips, D., Stuart, G. and Nishimura, Y. (2006), Imaging subduction from the trench to $300 \mathrm{~km}$ depth beneath the central North Island, New Zealand, with Vp and Vp/Vs. Geophysical Journal International, 165: 565583. doi: 10.1111/j.1365-246X.2006.02897.x

Reyners, M., Eberhardt_Phillips D. (2009). Small earthquakes provide insight into plate coupling and fluid distribution in the Hikurangi subduction zone, New Zealand. Earth and Planetary Science Letters. 282, 299-305.

Reyners, M., Eberhard-Phillips, D., Bannister S. (2011). Tracking repeated subduction of the Hikurangi Plateau beneath New Zealand. Earth and Planetary Science Letters. 311, 165-171

Rodgers, D. W., Little, T.A. (2006). World's largest coseismic strike-slip offset; the 1855 rupture of the Wairarapa Fault, New Zealand, and implications for displacement/length scaling of continental earthquakes. Journal of Geophysical research. 111, B12408. doi 
Salmon. M. (2008). Crust and upper mantle inhomogeneities beneath western North Island, New Zealand: Evidence from seismological and electromagnetic data. Phd Thesis lodged in the Library, Victoria University Wellington.

Savage, M. (1998). Lower crustal anisotropy or dipping boundaries? Effects on receiver functions and a case study in New Zealand. Journal of Geophysical Research. Vol 103. B7. P15069-15087.

Savage, M. K., Park, J. \& Todd, H. (2007). Velocity and anisotropy structure at the Hikurangi subduction margin, New Zealand from receiver functions. Geophysical Journal International, 168: 1034-1050. doi: 10.1111/j.1365246X.2006.03086.X

Schmerr, N. (2012). The Gutenberg Discontinuity: melt at the LithosphereAsthenosphere Boundary. Science. 335, 1480. DOI: 10.1126/science.1215433

Schulte-Pelkum, V., Monsalve, G., Sheehan, A., Pandey, M.R., Sapkota, S., Bilham,R. (2005). Imaging the Indian subcontinent beneath the Himalaya. Nature (Letters). 435. Doi:10.1038/nature03678

Seward, A., Henrys, S., Henderson, M., Sutherland, R., Stern, T., Savage, M., Mochizuki, K., Sato, H., Iwasaki, T. Kennedy, C. and Bassett, D., (2010). Seismic Array HiKurangi Experiment (SAHKE), Field Acquisition Report, GNS Science Report.2010/48.62p.

Shearer, P.M. (2009) Introduction to Seismology. $2^{\text {nd }}$ Edition. Cambridge University Press.

Sheehan, A.F., Abers, G. A., Jones, C.H., Lerner-Lam, A.L. (1995). Crustal thickness variations across the Colorado Rocky Mountains from teleseismic receiver functions. Journal of Geophysical Research. 100, b10. 20391-20404.

Stein, S., Engeln, J. F., De Mets, C., Gordon, R. C., Woods, D., Lundgren, P., Argus, D., Stein, C., Wiens, D. A. (1986). The Nazca-South American convergence rate and the recurrence of the Great 1960 Chilean earthquake. Geophysical Research Letters. Vol 13, 8. 713-716.

Stein, S. and Wysession, M. (2003). An introduction to Seismology, Earthquakes and Earth structure. Blackwell Publishing. Australia. ISBN978-0-86542-078-6

Stratford, W. R. and Stern, T. A. (2006). Crust and upper mantle structure of a continental backarc: central North Island, New Zealand. Geophysical Journal International, 166: 469-484. doi: 10.1111/j.1365-246X.2006.02967.x

Stuart. G.W., Francis, D., Gubbins, D., Smith, G. (1995). Tararua Broadband Array, North Island, New Zealand. Bulletin of the Seismological Society of America. Vol 85. 325-333.

Suzuki, M., Yagi,Y.(2011).Depth dependence of rupture velocity in deep earthquakes. Geophysical Research Letters. 38,L05308, do0.1029/2011GL046807

Taylor, B. (2006). The single largest oceanic plateau; Ontong Java-Manihiki-Hikurangi. Earth Planet. Sci letters. 241. 372-380 
Uchida, N., Nakajima, J., Hasegawa, A., Matsuzawa, T. (2009). What controls interplate coupling?: Evidence for abrupt change in coupling across a border between two overlying plates in the NE Japan subduction zone. Earth and Planetary Science Letters. 283, 111-121

Wallace, L. M., Beavan J., McCaffrey R., Darby D. (2004). Subduction zone coupling and tectonic block rotations in the North Island, New Zealand. Journal of Geophysical Research. 109, B12406, doi:10.1029/2004JB003241.

Wallace, L. M., Reyners, M., Cochran, U., Bannister, S., Barnes, P.M., Berryman, K., Downes, G., Eberhart-Phillips, D., Fagereng, A., Ellis, S., Nicol, A., McCaffrey, R., Beavan, R.J., Henrys, S., Sutherland, R., Barker, D.H.N., Litchfield, N., Townend, J., Robinson, R., Bell, R., Wilson, K., Power, W., (2009). Characterizing the seismogenic zone of a major plate boundary subduction thrust: Hikurangi Margin, New Zealand. Geochemistry. Geophysics. Geosystems. 10, Q10006, doi:10.1029/2009GC002610, 2009.

Wallace, L.M., Beavan, J. (2010 a). Diverse slow slip behaviour at the Hikurangi subduction margin, New Zealand. Journal of Geophysical Research. Doi 1029/2010JB007717.

Wallace, L.M., Bell, R., Townend, J., Ellis, S., Bannister, S., Henrys, S., Sutherland, R., Barnes, P. (2010 b). Subduction systems revealed: Studies of the Hikurangi margin. EOS Transactions. American Geophysical Union. Vol 91. 45.

Walcott, R.I. (1998). Modes of oblique compression: Late Cenozoic tectonics of the South Island, New Zealand. Reviews of Geophysics. Vol. 36. 1, PP. 1-26,1998 doi:10.1029/97RG03084

Wilson, C.K., Jones, C.H., Molnar, P., Sheehan, A.F., Boyd, O.S. (2004). Distributed deformation in the lower crust and upper mantle beneath a continental strikeslip fault zone: Marlborough fault system. South Island, New Zealand. Geology.v.32. 10. 837-840. doi: 0.1130/G20657.1;4

Wirth, E.A., Long, M.D. (2012).Multiple layers of seismic anisotropy and a low-velocity region in the mantle wedge beneath Japan: Evidence from teleseismic receiver functions. Geochemistry, Geophysics, Geosystems. Vol 13.8 Q08005, doi:10.1029/2012GC004180

Wood, R., Davy, B. (1994). The Hikurangi Plateau. Marine Geology. 118. 153-173

Yamasaki, T., Seno, T. (2003). Double seismic zone and dehydration embrittlement of the subducting slab. Journal of Geophysical Research. 108. B4, 2212. Doi:10.1029/2002JB001918, 2003

Yang Shen., Sheehan, A.F., Duecker, K.G., de Groot-Hedlin, C., Hersh, G. (1998). Mantle discontinuity beneath the soouthern eastern Pacfic rise from P-to-S converted waves. Science 280, 1232. doi:10.1126/science.280.5367.1232 
Yuan, X., Sobolev, S.V., Kind, R., Oncken, O., Bock, G., Asch, G., Schurr, B., Graeber, F., Rudloff, A., Hanka, W., Wylegalla, K., Tibi, R., Haberland, Ch., Rietbrock, A., Geiese, P., Wigger, P., Rower, P., Zandt, G., Beck, S., Wallace, T., Pardo, M., Comte. (2000). Nature (Letters). 408, 958-961

Yinshuang Ai., Dapeng Zhao., Xing Gao., Weiwei Xu. (2005). The crust and upper mantle discontinuity structure beneath Alaska inferred from receiver functions. Physics of the Earth and Planetary Interiors, 150. 339-350.

Zhao ,D., Hasegawa, A., Kanamori, H. (1994). Deep structure of Japan subduction zone from local, regional, and teleseismic events. Journal of Geophysical research. 99. B11. 22313-22329.

Zhu Lupei. (2000). Crustal structure across the San Andreas fault, southern California from teleseismic converted waves. Earth and Planetary Science letters. 183190.

Zhu, L., Kanamori, H. (2000). Moho depth variation in southern California from teleseismic receiver functions. Journal of Geophysical Research B: Solid Earth. 105(B2), 2969-2980.

\section{WEBSITES}

Ammon, C.J. (1997). An overview of Receiver-Function Analysis.

http://eqseis.geosc.psu.edu/ cammon/HTML/RftnDocs/rftn01.html Penn State University. Department of Geosciences. Earthquake Seismology Group. Accessed 08/2012

http://earth.geology.yale.edu/ jipark/recfunk.html Recfunk_manual Website of Yale University. Department of Geology and Geophysics. Accessed 05/2011

http://www.colorado.edu/GeolSci/Resources/RF incidence angle.html Website of Colorado State University. Accessed 07/2012

http://earthquake.usgs.gov/earthquakes/eqarchives/epic/epic circ.php Website of the United States geological Survey. Accessed 2011 and 2012.

http://www.passcal.nmt.edu/instrumentation/Sensor/sensor info.html IRIS PASSCAL, PASSCAL sensor information, Website 
- 152 - 


\title{
APPENDIX 1
}

\author{
A.1 HoW TO CHANGE THE RAW REFTEK DATA TO MINISEED AND SELECT AND CUT \\ YOUR EARTHQUAKE EVENTS.
}

Softwares needed for processing using this method: Matlab; Passcal; SAC (Seismic Analysis Code); Sismoutil; Taup

\section{A1.1 CREATE THE EVENT DATABASE.}

Download data from USGS (for teleseisms) as a .csv (comma separated variables) file. To enable this database to be utilised by mk_evtfile.sh (and create the evtfile used by tkeqcut) the format must be as follows: the time must be comma separated eg153047.44 (hhmmss.ms) must be 15,30,47.44 the command to do this is

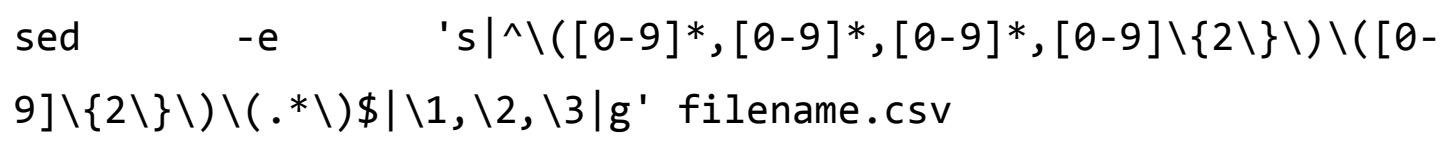

This will output to the screen as standard output. To write to a file e.g. earthquakes.csv add >earthquakes.csv onto the end of this command. The output of this will still have to be altered to remove all digits that start with 0 (e.g. ,01 ) to remove the zero so they read e.g. ,1 Do not forget to replace, 00 with , 0 .

\section{A1.2 SELECT RAW DATA}

Broadband transect data is copied from the SAHKE data main file.

Select station to be processed and copy data into a directory containing all the codes for processing the data.

\section{A1.3 PRE-PROCESSING REFTEK DATA}

Before you can start processing the newly created dasfile must be altered to include the das number for the station you are about to process. The event file must have all events (teleseisms > M6) covering the same time period as the recorded data 


\section{A1.4 CHANGING REFTEK TO MINI-SEED}

The input files needed are; config_rt.sh ; station.info file; event_database.csv; mkeqcut_s; mk_pos; prep_rt; distsA; add_daz.s; mk_evtfile.sh(see config_rt.sh for comments as to format of station.info file).

You must ensure that the station file (named after the station ie T0040), has another file inside it named after the das number with an $r$ suffix. This file must contain the day files.

Run config_rt.sh, this calls the other relevant scripts automatically.

Output files are Err_files; Events: Log_files; mseed_data; PCF_files; REF_data; Stations (contains copy of station.info file); dasfile

If there is no data in the Log_file after the code has run it means that there is an error and it has not run properly.

\section{A1.5 SELECTING AND CUTTING THE EARTHQUAKE EVENTS}

Next run the code mkeqcut_s* inside the station file.

When this is complete run tkeqcut which brings up a guided user interface (Gui). All the information to run the Gui is in comments at the bottom of the config_rt.sh code file.

After doing the cut events for block 10 (cut events M6.0-6.9), it needs to be repeated for block 11 (cut events 7.0-10.0) (see mkeqcut_s for parameters).

Convert into sac files using convert_raw.sh. The station file (st_file) must be completed with station name, latitude, longitude and elevation (details for SAHKE stations are in the SAHKE Field report [GNS]).

When convert_raw.sh has stopped the data in all_sac need to be checked using SAC. Check the traces are correct and the station headers loaded.

The event headers (stime evtime lat lon z mag) need to be loaded in to the sac files. This is done using the script add_hdr_modi.sh. 


\section{A1.6 P WAVE PICKING USING SAC}

To prepare the data for creating the receiver functions run the macro 'The_sac_macro1' this will open up the macro and display the trace for all three components. To pick the $\mathrm{P}$ wave click on trace and position mouse over pick and enter T1, followed by q, to quit the trace. The macro will then taper the trace (which will be redisplayed). It will ask if you want to send the file to the trash bin. If yes enter T, and to send to 'Trash', if it is good (i.e. with a coherent signal and a reasonable pick) enter $\mathrm{N}$ and send to 'GoodOnes'. The macro will automatically move onto the next one and display the next trace to be picked.

\section{A1.7 CREATE RECEIVER FUNCTIONS}

Create a data file named in_recpick. This has to contain the full pathname for all the radial (.r suffix) files that you have picked. Ensure that the last line of the file is 'stop'. To run type recfunk09_pick and it will run the code interactively.

Run at $1 \mathrm{~Hz}$ and 80 seconds to start with, binsum 2 is good. Epicentral distances are binned at 10 degree intervals but are better at $5 \mathrm{deg}$ intervals.

To plot using SAC and GMT (General Mapping tool) softwares. Use the codes RFwig_epi.plot and RFwig_baz.plot.

Use the command csh RFwig_epi.plot outt_epi.grid outr_epi.grid 1 This will build the plot file RFwig-epi.ps. outt_epi.grid etc have been created automatically by recfunk09_pick. The csh at the start opens the C shell in which this must run, and the ' 1 ' at the end is the scaling factor, this may be altered to suit the data. To plot use (ghostscript) gs RFwig-epi. This will create the plots. Save using ksnap (screen shot). Repeat for the baz files. 


\section{APPENDIX 2}

\section{A2 TECHNICAL INFORMATION REGARDING TKEQCUT}

Tkeqcut is a front-end gui (guided user interface) to configure input for segymerge and qmerge.

Tkeqcut was developed by the Incorporated Institutions for Seismology (IRIS) Program for Array Seismic Studies of the Contintnetal Lithosphere (PASSCAL)

using python.

Link for PASSCAL open-source software is http://www.passcal.nmt.edu/ftp/software/passoft/linux/

Tkeqcut Version: 2008.180

Tkeqcut has four notebook windows to all entry of all necessary information:Setup, Das_file, Event_file, help.

Required parameters are: Data directories of segy and miniseed data; sample rate of input data; Sample rate tolerance; Input recrod length (s); Event record length (s), length of output data records.

Author of tkeqcut is Bruce Beaudoin ,bruce@passcal.nmt.edu 


\section{APPENDIX 3}

\section{A3 BASH SCRIPTS}

Scripts used to convert raw Reftek data to miniseed format and then select and cut earthquake events.

\section{A3.1 CONFIG_RT.SH}

\#\#process raw data using Sonja's method: created by sapi 2010 \#\# altered by Sapi $\mathrm{K}$ and Caro $\mathrm{H}$ to process SAHKE data 2011 \#\#\#\#Important points:

\#\#create a master directory that contains \#following directories and files (scripts):

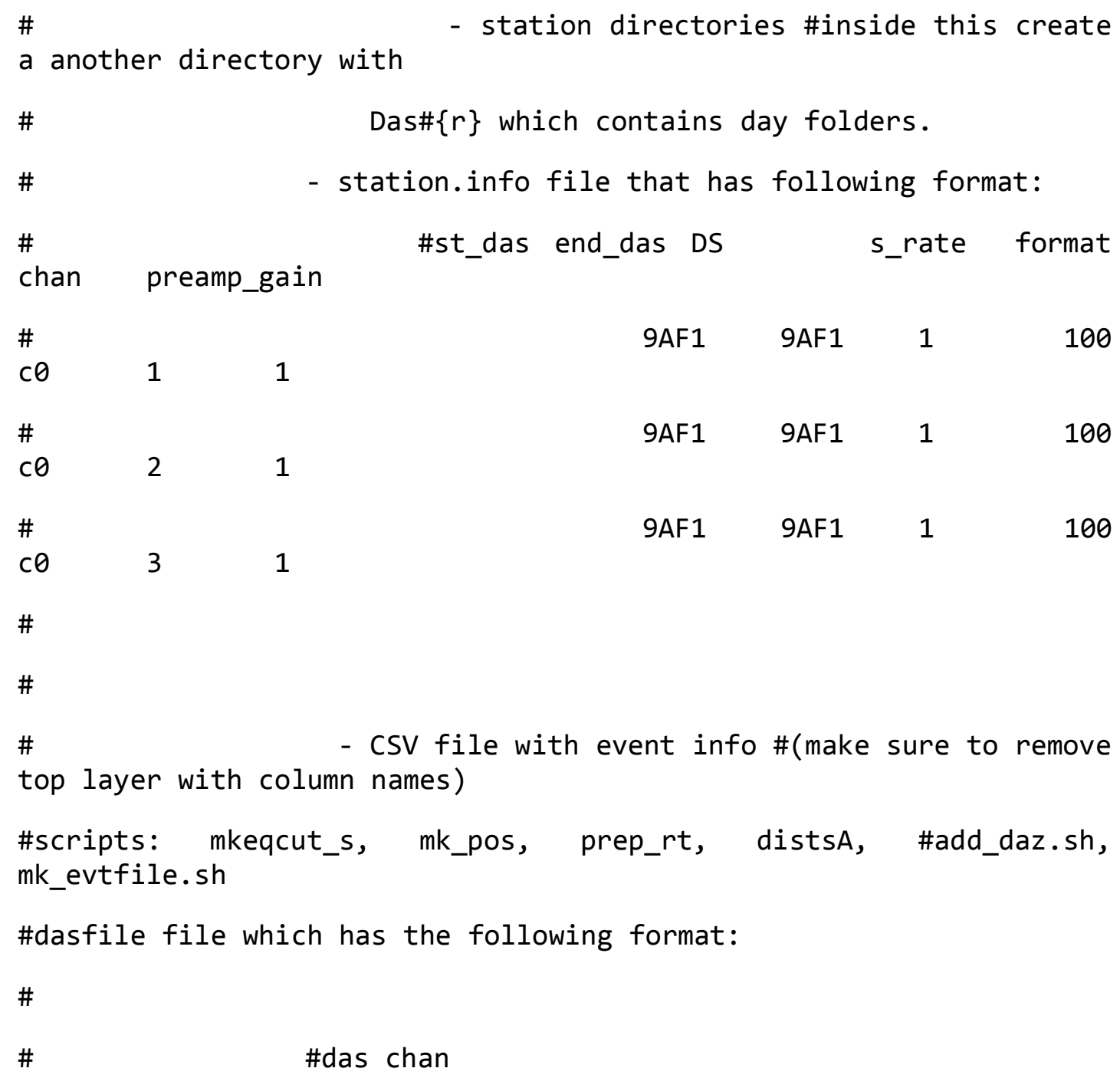


\#

\#

\#

\section{!/bin/bash}

$p t=` p w d `$

\#Process single station at a time. Enter station

\#that you want to process data

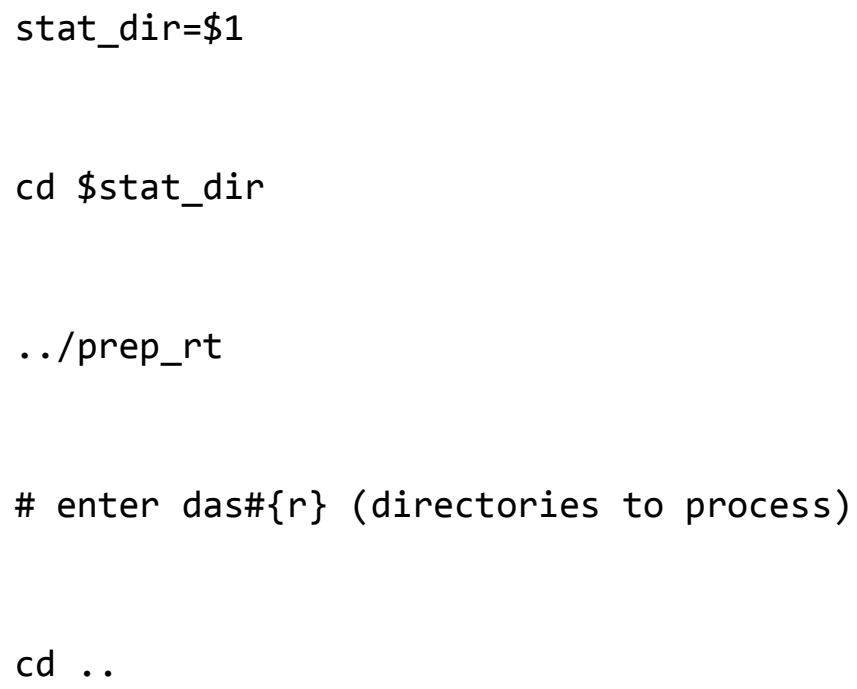


\#create event file using CSV file

\#\#\#\#\#\#\#\#\#specific format\#\#\#\#\#\#\#

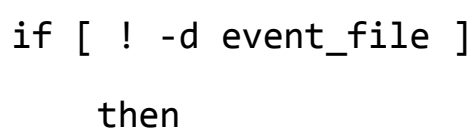

\#awk $-F$, ' \{printf $\% d \% d, \% d / \% d / \% d, \% d: \% d: \% 0.2 f$, $\% .3 f, \quad \% .3 f, \quad 0,1 f, \quad 0, \quad \% s, \quad \% .1 f \backslash n "$ $, \$ 1, \$ 2, \$ 9, \$ 10, \$ 11, \$ 12, \$ 13, \$ 14, \$ 17, \$ 20, \$ 28, \$ 42, \$ 44\}^{\prime}$ event.txt > eve_daz_file

\#\$pt/add_daz.sh eve_daz_file

\#some parts are changed to process Caroline's data:

\#this will create a file: eve_daz_file.daz

\# put event id (1)\& cuspID(2), M? later on

\#(introduce a unique set

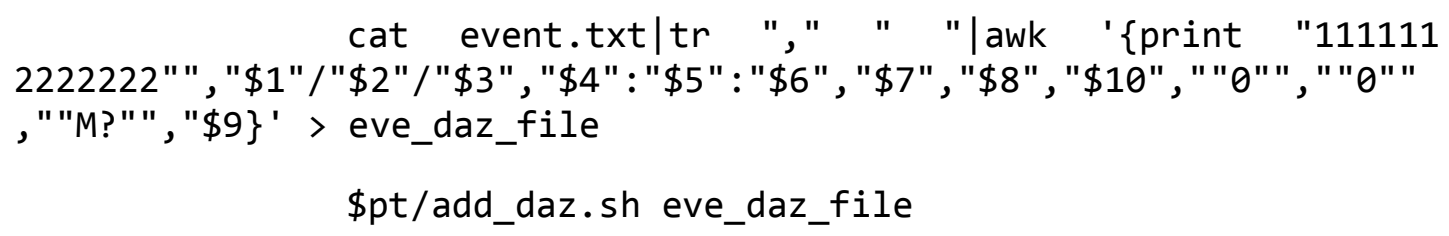


event_input.daz

cat eve_daz_file.daz|sed -e 's///,/g;s/ *//g' >

echo \$stat_dir

cp event_input.daz \$pt/\$stat_dir

\#clean up

rm eve_daz_file.daz

cd . .

fi

\# run mkeqcut file inside the station-file using \#following command, and also das\#

\#cp dasfile \$stat_dir

\#cd \$stat_dir

\#now run command (command line):

\#../mkeqcut_s* $\{$ das\# $\}$

\# Next type tkeqcut at command prompt

\#add station directory to this path: \#/Volumes/stage2/users\#data/halllucy/test_SAHKE/cut_evts/station

\#then do tkeqcut

\#in tkeqcut:press setup and remove the existing

\#path for data directories

\#press find and setup the path for Miniseed

\#directory inside the station ( make sure the

\#path is correct.

\#click DASS button and then press find: select

\#the dassfile inside the station directory 
\#press event button and select eqcut file \#(block\#.das\#.eqcut file could find in

\#station/event path)

\#press setup button again

\#next press Build Trace db button on the right

\#hand side

\#after building trace: fill the format Gui

\# \#sample rate 100

\# \#input record length: 3600

\# \#output record length:

\# \#press cut events button

\#go to cut_events and convert into sac files

\#using convert_raw.sh, give st_file with station \#name,stlat,st lon and elevation

A3.2 PREP_RT

\#!/bin/sh

\# \# Sonja, June 2005

\#SCRIPT to do basic preprocessing for raw REFTEK data

\# Raw data must be in directories containing the \#DAS\#

\# You need to have a station.info file

\#containing a header line:

\# st_das end_das DS s_rate format chan \#preamp_gain 
\# Information includes:

\# 1: rt130cut to get data in right format. Produces one big file!

\# 2: ref2mseed produces mseed files (back to single \#files)

\# 3: refrate to get time correction file

\# 4: position to get position of instrument (intermediate value of GPS locs)

\# output should be checked

\# 5: creating the structure for later processing

\# After this script has been run, headers can be modified or events can be cut

\# -> fixhdr, eqcut

need=/usr/local/packages/etc/needsh

\$need passcal

\$need matlab

\$need sismoutil

cp ../station.info .

if [ ! -s "station.info" -a ! -s "Stations/station.info" ]

then

echo "Station file missing!!!!"

echo "Please add info to template file 'station.info'"

echo "\# st_das end_das DS s_rate format chan preamp_gain" >station.info

exit

fi

echo "Enter directories (containing the daily files) to process (space separated):"

read station_list 
\# set dir names

dir $=`$ pwd`

rt130=\$dir/RT130_data

mseed=\$dir/Mseed_data

ref=\$dir/REF_data

stn_info=\$dir/Stations/station.info

$\log =\$$ dir $/$ Log_files

err $=\$$ dir/Err_files

rating $=\$$ dir $/ P C F \_$files

script_path=/Volumes/data/wni/WNI/

script_path2=/Volumes/stage2/users-data/halllucy/SAHKE_data

\# CREATE processing structure

if [ -s "station.info" ]

then mkdir Stations

mv station.info Stations

fi

mkdir \$mseed \$ref \$log \$err \$rating

mkdir Events

\# CONVERT to reftek format

for station in \$station_list

do echo \$station_list

echo \$station

rt130cut - $v$-r \$station

done

mv*.ref \$ref 
\# CONVERT to mseed format

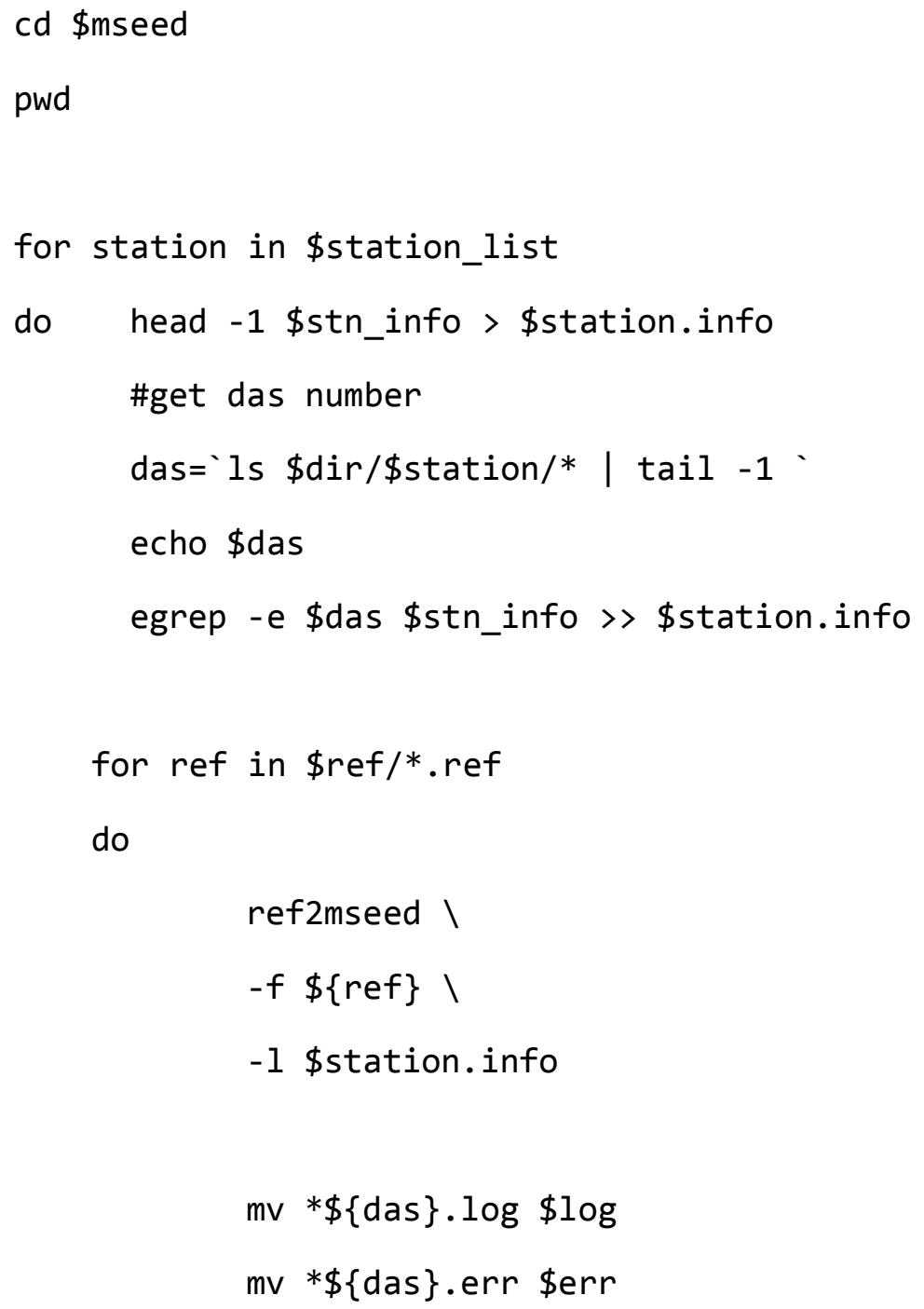

done

\# GET location info

\# (here two different codes used, to compare !

\$script_path2/mk_pos \$dir \$das

position $\$ \log / * \$$ das.log $>\$$ das.position

done 
\# CLOCK CORRECTION

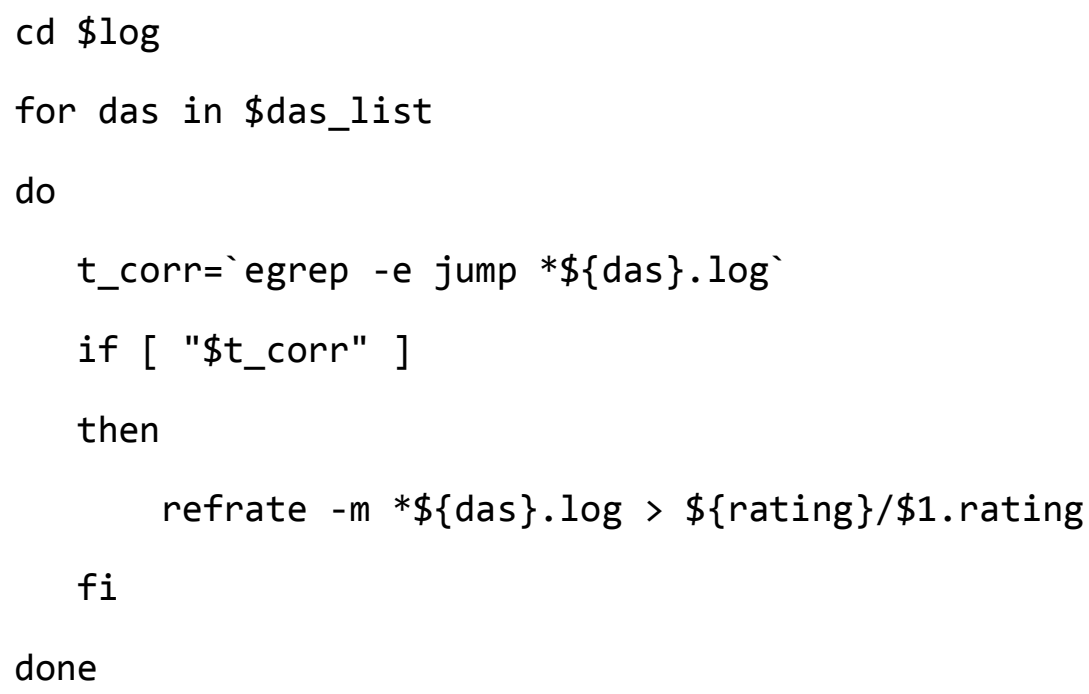

\section{A3.3 ADD_DAZ.SH}

\# To add distance and BAZ information

\# uses files in the WEED format, comma \#separated, eventlat/lon in $\$ 5, \$ 6$

file $=\$ 1$

out $=\$ 1$.daz

\# give station coordinates to calculate DISTANCE \#and BAZ

station_lat= station_lon= \#echo "LAT LON" >latlon.txt awk -F, '\{print $\$ 4, \$ 5\}$ ' $\$$ file > latlon.txt 
\#HERE uses STATION lat lon to use for calculation with dists \#event file should be called events

cp \$file events

./distsA \$station_lat \$station_lon

\# remove header line from output file dist.out \#and add line number

awk 'FNR $>1$ \{ print NR-1, $\$ 1 ", ", \$ 2 ", ", \$ 3\}$ ' dists.out >tmp.a

\#add line number to event file also for joining

awk '\{print NR, $\$ 0$ ","\}' events | sed 's/,/,/g'>tmp.b

join tmp.b tmp.a | awk ' $\{$ for $(i=2 ; i<=N F ; i++)$ printf "\%s ", $\$ i$; printf "\n"; \}' > \$out

\#cat \$out|sed -e 's///,/g;s/ *//g' > event_input.daz

\# OUTPUT FILE events.dist as the format:

\#catalog \#date \#time \#lat \#depth \#generico \#generic0 \#magtype \#magnitude

\#distance(deg) \# distance( $(\mathrm{km})$ \#BAZ

\rm tmp.a tmp.b

$\# \backslash \mathrm{rm}$ events

$\backslash \mathrm{rm}$ dists.out 


\section{A3.4 DISTSA}

$\# ! / \mathrm{bin} / \mathrm{sh}$

\# Creates a file with distances in deg and $\mathrm{km}$ between a point (event) given by 'evlat' and 'evlon'

\# and several others (stations) given by 'stations' .

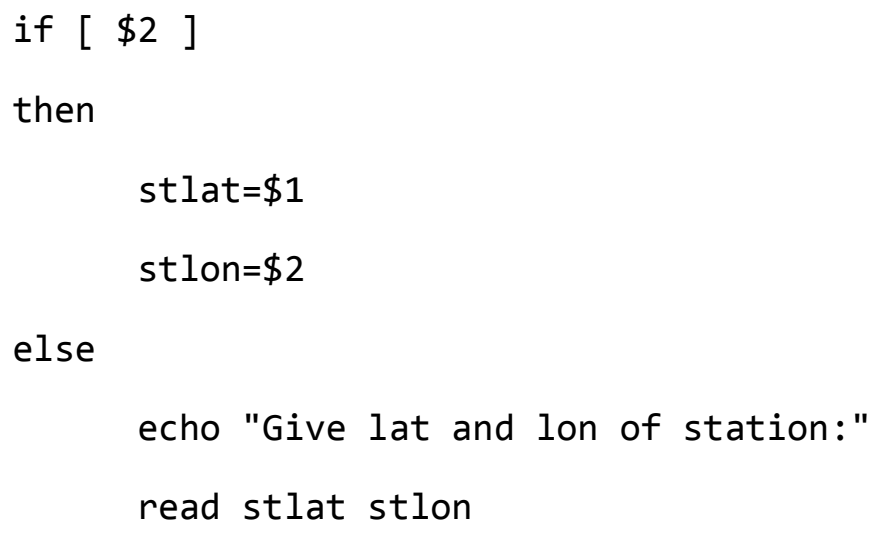


cat \$events lawk '\{print $\$ 3\}$ ' >tmp3

echo "Distances between events in \$events and stations, lat=\$evlat lon=\$evlon in deg and km, also backazimuth">\$output

sdiff -w 60 tmp3 tmp2 | sed -e 's/// /g' >>\$output

\#cat \$tmp | grep KARC |nawk $\{\$ 1, \$ 2, \$ 3\} \mid$ cat \$residuals |grep KARC Inawk ' print $\$ 3$, KARC $\}$

rm tmp* 


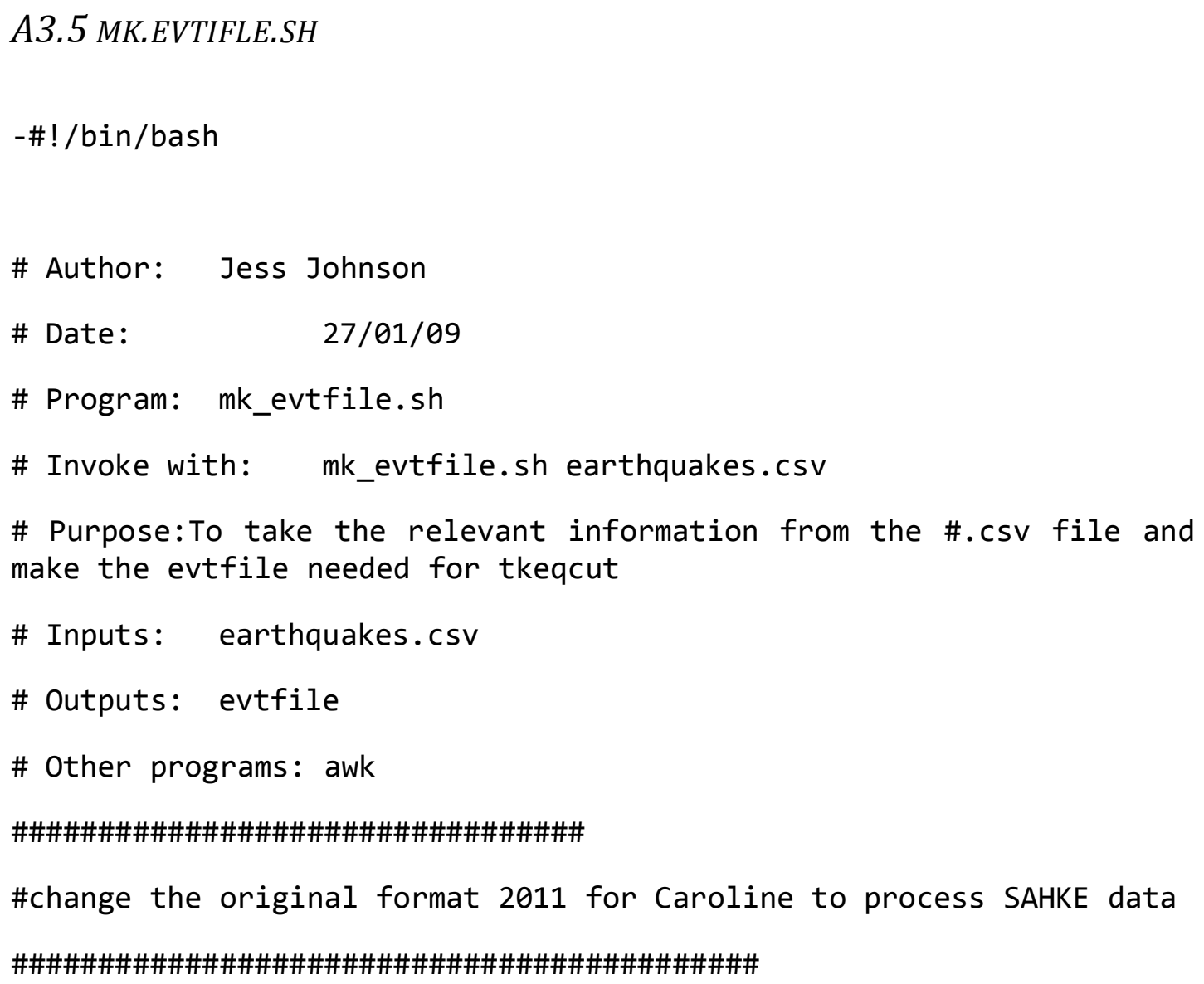




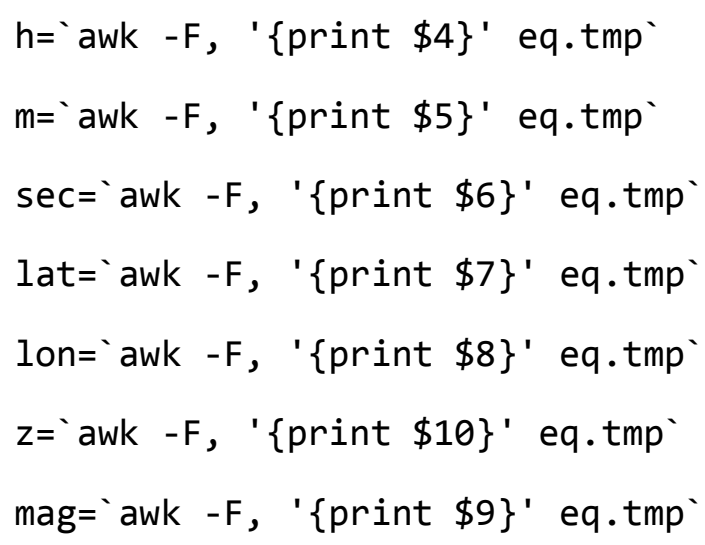




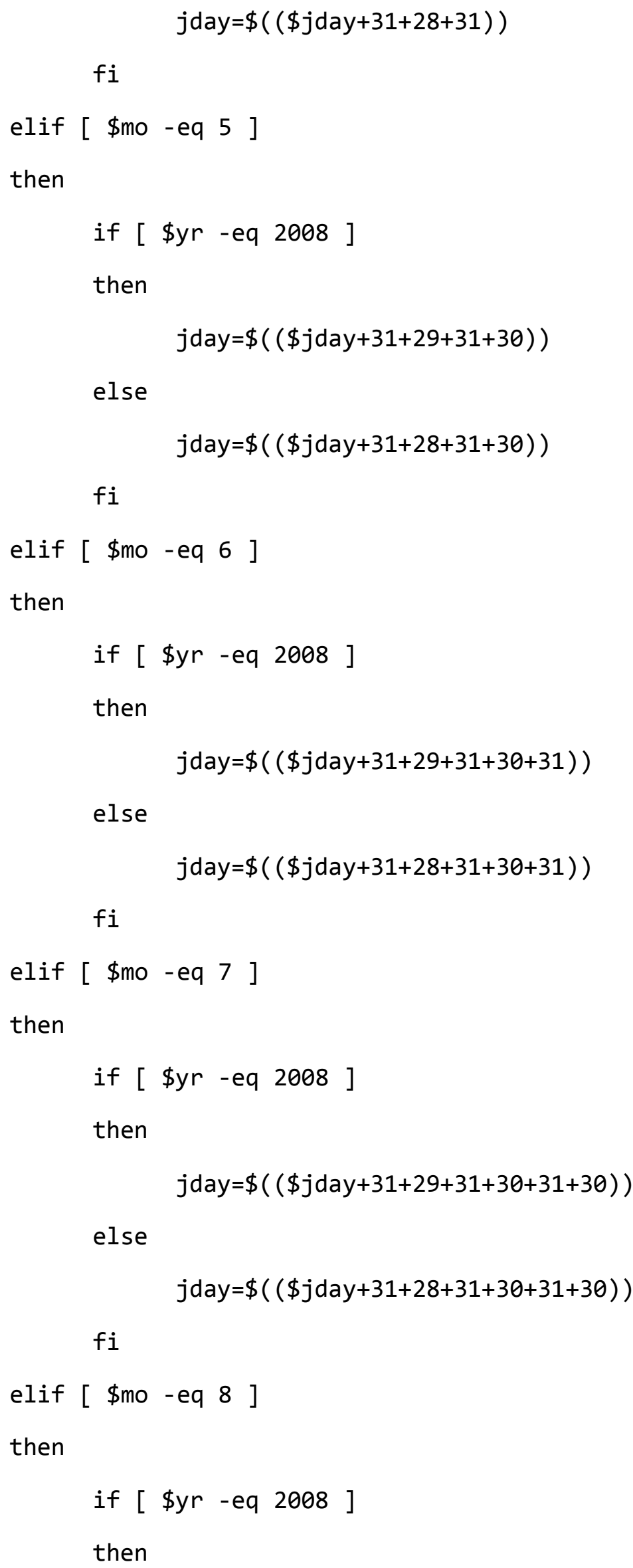




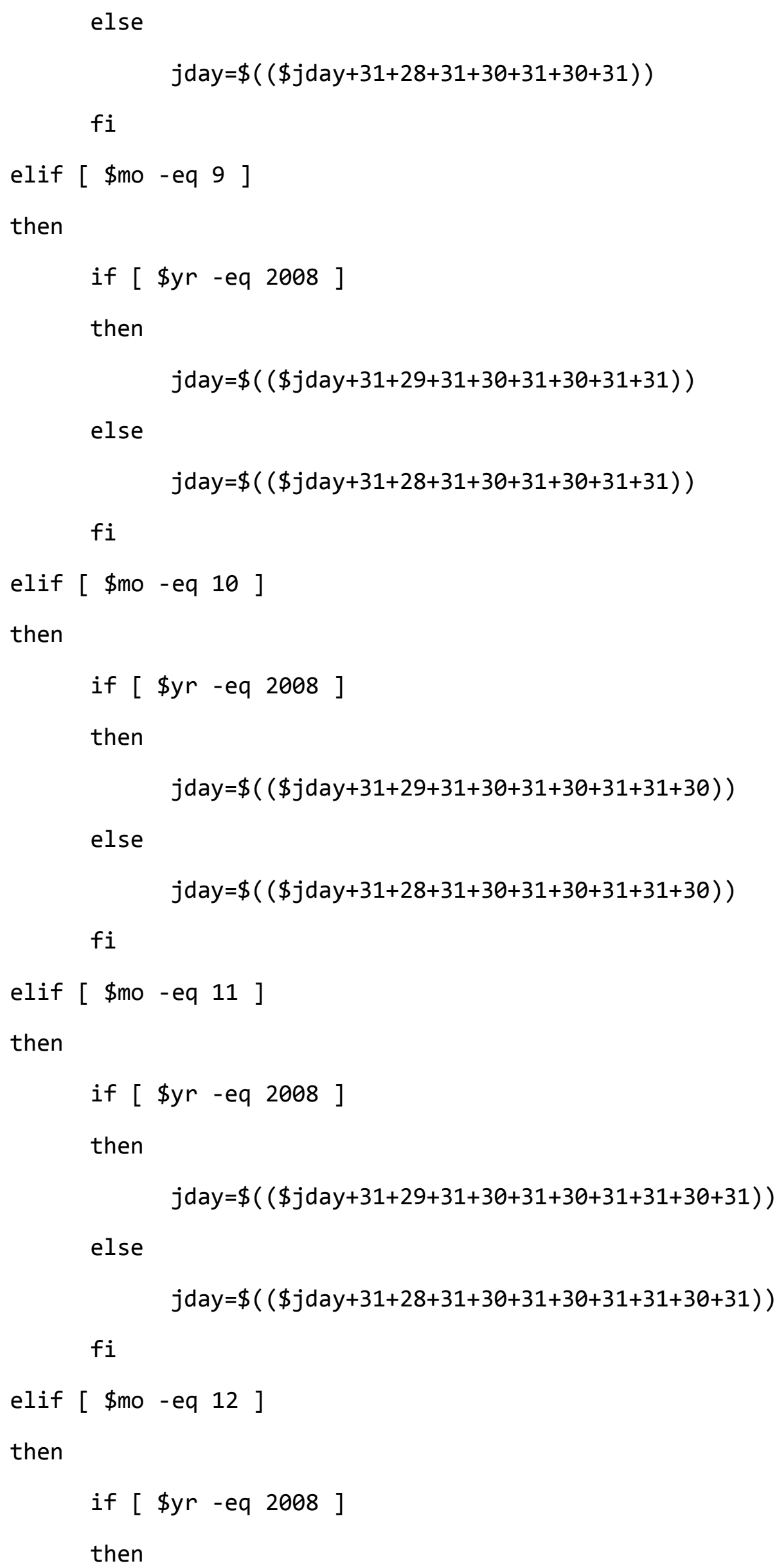




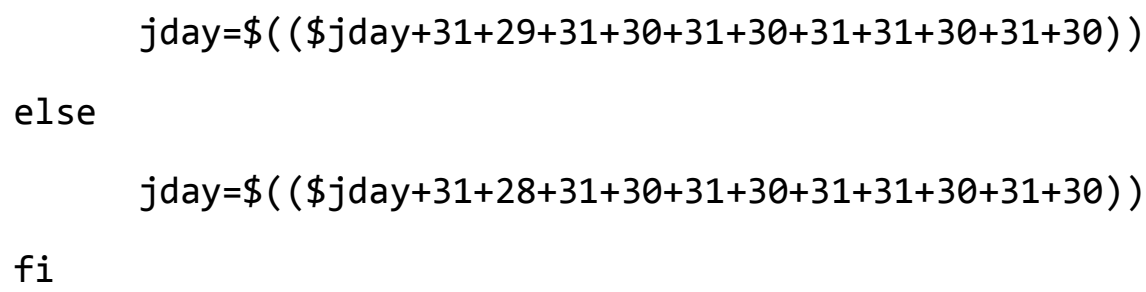


echo "111111 \$sttime \$evtime \$lat \$lon \$z \$mag" >> evtfile echo "111111 \$sttime \$evtime \$lat \$lon \$z \$mag"

fi

done $<\$ c s v$

rm eq.tmp

A3.6 MK_POS

$\# ! /$ bin/csh

\# input arguments are:

\# 1- the directory where data are located

\# 2- the das\#

set $\operatorname{dir}=\$ 1$

set das $=\$ 2$

set $\operatorname{src}=" \$$ dir $/ \log$ files $/ * \$$ das $\}. \log "$

egrep -e GPS \$src lawk '\{print $\$ 4\}$ ' $>\$$ das $\}$.lat

egrep -e GPS \$src lawk '\{print $\$ 5\}$ ' >\$das\}.Ion 


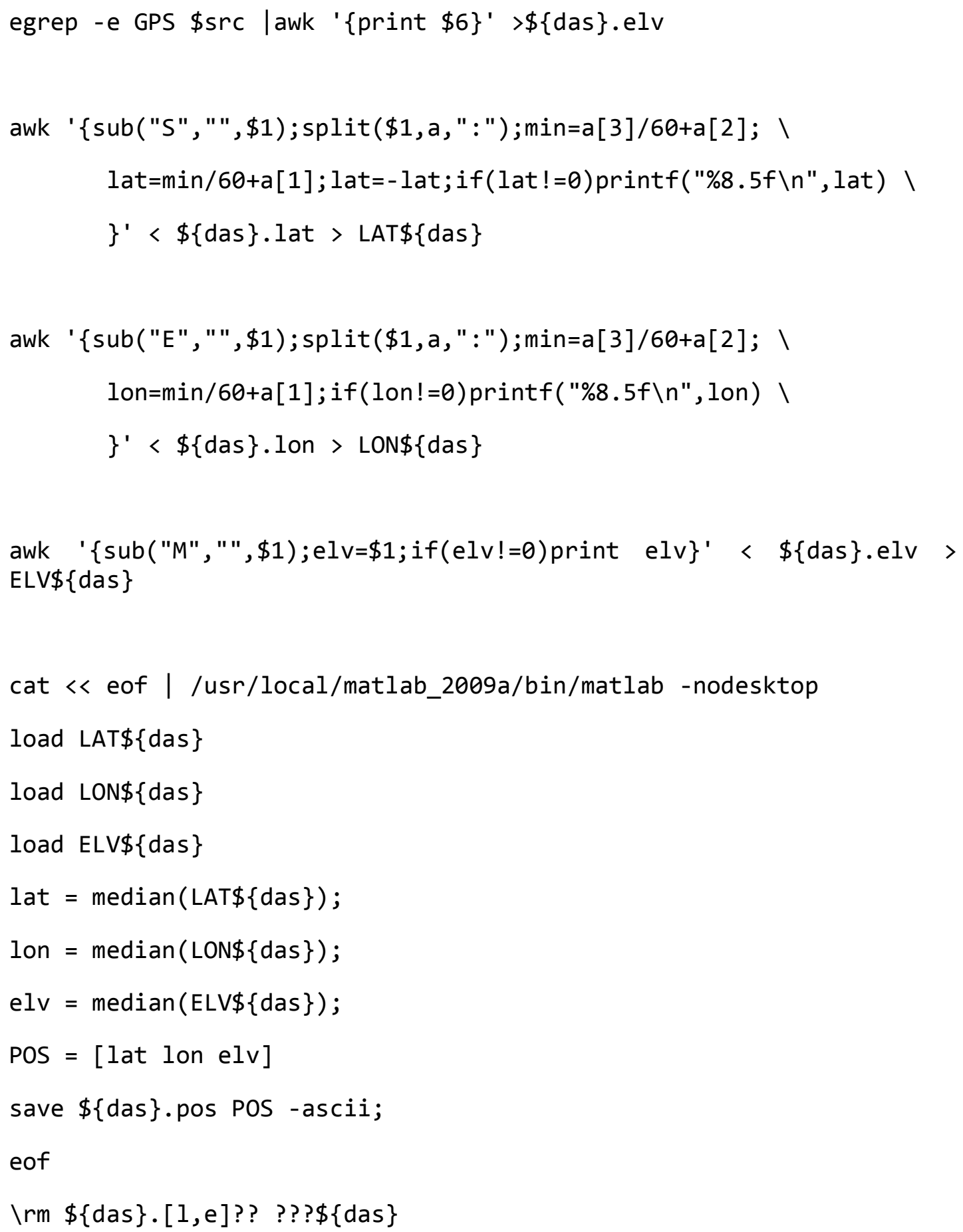




\section{A3.7 MKEQCUT_S}

$\# ! / \mathrm{bin} / \mathrm{sh}$

\# To Produce input files for cutting earthquakes from \#continuous mseed data using "EQCUT"

\# HERE only use for the one station at a time, always \#using the same event file

\# USAGE: mkeqcut daslist

\# You can only process events files covering 1 \#leapyear and you have to set the variable for it!

\# INPUT: event file in format:

\# Events can be cut in different length according to \#their Magnitude and distance. Following block \#structure is the same as used for ORION processing

\#(s.a. Manual for Orion data processing). Parameters can be changed.

$\begin{array}{rrrrrrr}\text { \# } & \text { BLOCK } & \text { M } & \text { dist(deg) } & \text { start_cut } & \text { length } \\ \# & 1 & 2.0-2.91 .5 & 60 & & 180 & \\ \# & 2 & 3.0-3.43 & 60 & 300 & \\ \# & 3 & 3.5-4.45 & 60 & & 480 & \\ \# & 4 & 4.5-4.718 & & 60 & & 900 \\ \# & 5 & 4.8-4.930 & 60 & & 900 & \\ \# & 9 & 5.0-5.9100 & 300 & & 1500 & \\ \# & 10 & 6.0-6.9 & 180 & 300 & & 3600 \\ \# & 11 & 7.0-10.0 & 180 & 300 & & 7200\end{array}$

\# DEFINE VARIABLES 
dir_path=../event_file

echo \$dir_path

$\mathrm{ft}=/$ Volumes/stage2/users-data/halllucy/SAHKE_data

\# FORMAT eventfile: txt txt, yyyy/mm/dd, hh:mm:ss.s,

lat, lon, depth, 0,0 , Mtype, M

eventfile=\$dir_path/event_input.daz

leapyear $=2004$

\# for mseed data channels are always $1 \mathrm{C} 1,1 \mathrm{C} 2,1 \mathrm{C} 3$

channels="1C1, 1C2, 1C3"

\# for block1

$M 0=2.0$

$M 1=2.9$

$\mathrm{d} 1=1.5$

start $1=60$

length $1=180$

\# for block2

$M 2=3.4$

$d 2=3.0$

start $2=60$

length $2=300$ 
\# for block3

$M 3=4.4$

$d 3=5$

start $3=60$

length $3=480$

\# for block4

$M 4=4.7$

$d 4=18$

start $4=60$

length4=900

\# for block5

$M 5=4.9$

$d 5=30$

start $5=60$

length $5=900$

\# for block9

$M 9=5.9$

$d 9=100$

start9 $=300$

length $9=1500$

\# for block10 
$M 10=6.9$

$\mathrm{d} 10=180$

start $10=300$

length10=3600

\# for block11

$M 11=10$

$\mathrm{d} 11=180$

start $11=300$

length11=7200

\# GIVE USAGE if no input parameters or non existing event file

if $[-z " \$ 1 "]$

then

echo " USAGE: \$0 daslist"

echo " FORMAT daslist: das1, das2, ..., dasn"

echo " eventfile used is \$eventfile"

echo " FORMAT eventfile: txt txt, yyyy/mm/dd, hh:mm:ss.s, lat, lon, depth, 0,0 , Mtype, M" $1>\& 2$

exit 1

fi

if [ ! -d "Events" ]

then mkdir Events

elif [ -s "\$1"]

then mv \$1 Events

fi

cp \$eventfile ./Events

events $=. /$ Events $/$ basename \$eventfile` 


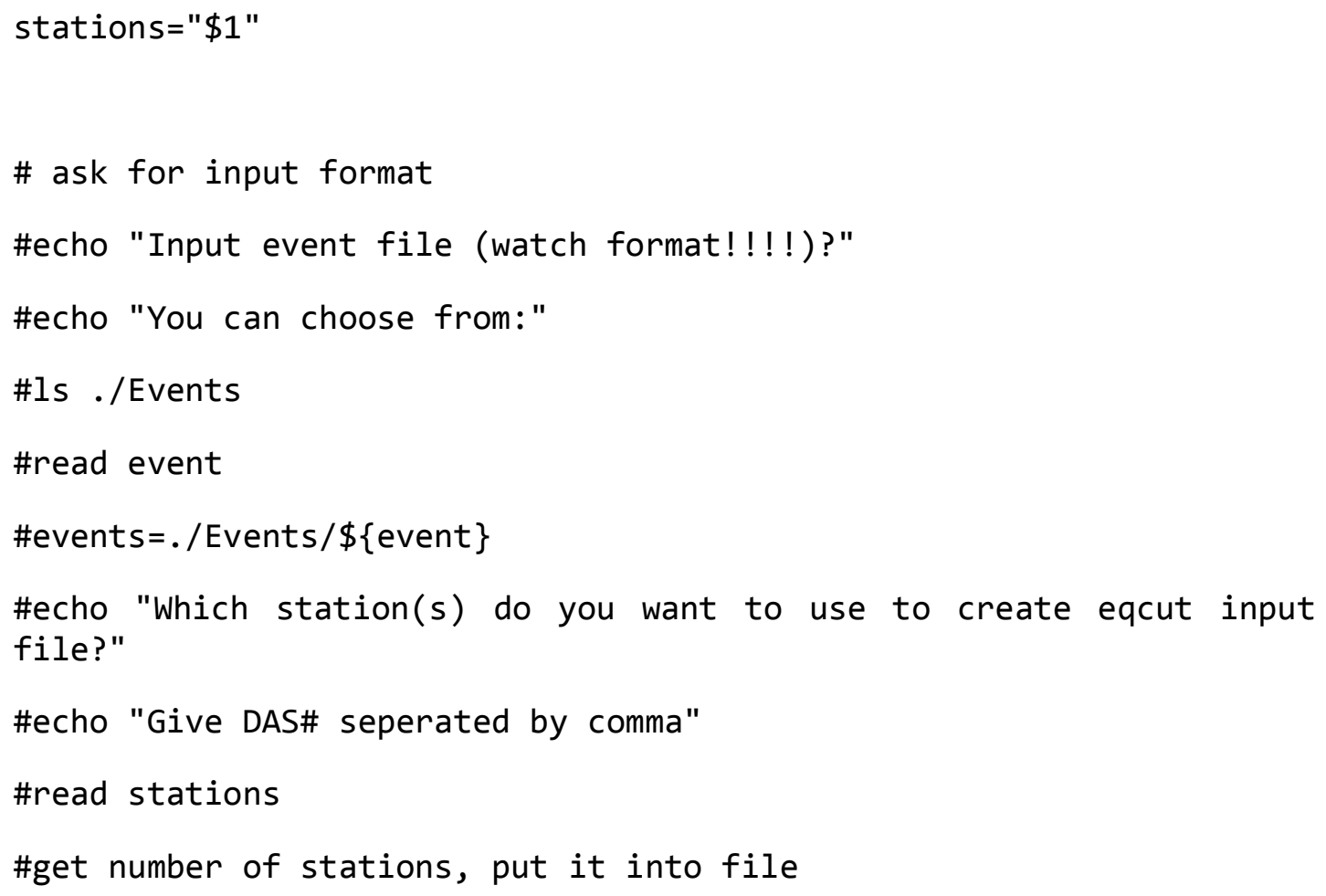


awk $-\mathrm{v}$ das $=\$$ das_nb $-\mathrm{v}$ chan $=\$$ channels ' print das, chan, $\$ 1, \$ 2$, $\$ 3\}^{\prime}<$ Mseed_data/\$das_nb.pos >>Events/das.eqcut

\# create script to calculate distances

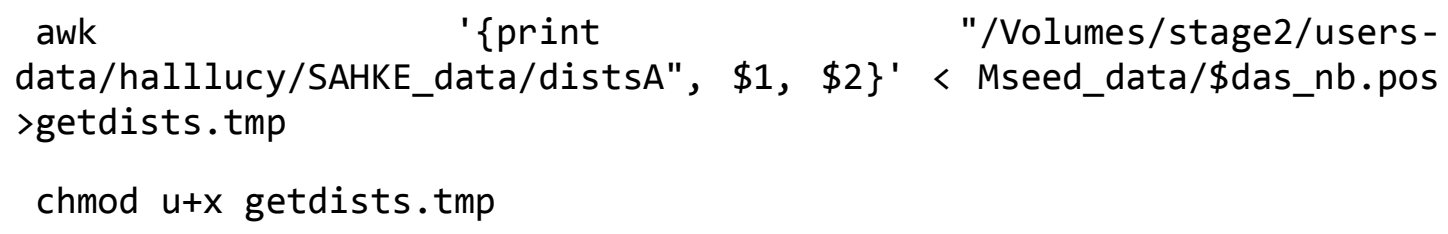

\#input file for dists

\#echo "input for dists (lat lon)" >latlon.txt

echo "event file used: \$events"

awk $-\mathrm{F}, \quad$ ' print $\$ 4, \$ 5\}^{\prime}<\$$ events $>$ latlon.txt

\#run script to get distances

./getdists.tmp

\# merge event file with distance file

tail - $n+2$ dists.out $\mid$ awk ' $\{$ for ( $i=1 ; i<=N F ; i++)$ printf "\%s ", $\$$ i; printf "\n"; \}' |awk '\{print NR, \$1","\$2","\$3\}' >dists.tmp

awk $-\mathrm{F}$, ' $\{$ for $(i=1 ; i<=N F-3 ; i++)$ printf $\% \mathrm{~s} ", \$ i ", "$; printf "\n"; \}' \$events | awk '\{print NR, \$0\}' > events.tmp

join events.tmp dists.tmp | awk '\{for (i=2; $i<=N F$; $i++)$ printf "\%s ", \$i; printf "\n"; \}'> events.\$das_nb.dists

\#sdiff -w 200 \$events dists.tmp | sed -e 's////g;s/ */ /g' |

\#awk ' print $\$ 1, \$ 2, \$ 3, \quad \$ 4, \$ 5, \$ 6, \$ 7, \$ 8, \$ 9, \$ 10, \$ 11$, ", d=, ", \$13, "deg, ",\$14, "km" \}' > events.\$das_nb.dists

\# split files with events and distances into blocks 
awk $-F,-v \quad M 0=\$ M 0 \quad-v \quad M 1=\$ M 1-v \quad d=\$ d 1 \quad \$ 10>=M O \quad \& \& \quad \$ 10<=M 1$ \&\& $\$ 11<=d$ \{print $\$ 0\}$ ' <events.\$das_nb.dists >block1.\$das_nb.events

awk $-F, \quad-v \quad M 1=\$ M 1-v \quad M 2=\$ M 2-v \quad d=\$ d 2 \quad$ $\$ 10>M 1 \quad \& \& \quad \$ 10<=M 2 \quad \& \& \quad \$ 11<=d$ \{print $\$ 0\}^{\prime}$ <events.\$das_nb.dists >block2.\$das_nb.events

awk $-F, \quad-v \quad M 2=\$ M 2-v \quad M 3=\$ M 3 \quad-v \quad d=\$ d 3 \quad \$ 10>M 2 \quad \& \& \quad \$ 10<=M 3 \quad \& \& \quad \$ 11<=d$ \{print $\$ 0\}$ ' <events.\$das_nb.dists >block3.\$das_nb.events

awk $-F, \quad-v \quad M 3=\$ M 3 \quad-v \quad M 4=\$ M 4 \quad-v \quad d=\$ d 4 \quad \$ 10>M 3 \quad \& \& \quad \$ 10<=M 4 \quad \& \& \quad \$ 11<=d$ \{print $\$ 0\}^{\prime}$ <events.\$das_nb.dists >block4. $\$$ das_nb.events

awk $-F, \quad-v \quad M 4=\$ M 4 \quad-v \quad M 5=\$ M 5 \quad-v \quad d=\$ d 5 \quad \$ 10>M 4 \quad \& \& \quad \$ 10<=M 5 \quad \& \& \quad \$ 11<=d$ \{print $\$ 0\}^{\prime}<$ events. $\$$ das_nb.dists >block5. $\$$ das_nb.events

awk $-F, \quad-v \quad M 5=\$ M 5 \quad-v \quad M 9=\$ M 9-v \quad d=\$ d 9 \quad ' \$ 10>M 5 \quad \& \& \quad \$ 10<=M 9$ \&\& $\$ 11<=d$ \{print $\$ 0\}^{\prime}$ <events.\$das_nb.dists >block9.\$das_nb.events

awk $\quad-F, \quad-v \quad M 9=\$ M 9 \quad-v \quad M 10=\$ M 10 \quad-v \quad d=\$ d 10 \quad \$ 10>M 9 \quad \& \& \quad \$ 10<=M 10 \quad \& \&$ $\$ 11<=d$ pprint $\$ 0\}^{\prime}<$ events. $\$$ das_nb.dists >block10.\$das_nb.events

awk $-F, \quad-v \quad M 10=\$ M 10 \quad-v \quad M 11=\$ M 11 \quad-v \quad d=\$ d 11 \quad \$ 10>M 10$ \&\& $\$ 10<=M 11 \quad \& \&$ $\$ 11<=d$ print $\$ 0\}^{\prime}$ <events. $\$$ das_nb.dists >block11.\$das_nb.events

\# delete empty block files

for file in block*.events

do

if [ ! -s \$file ]

then $\mathrm{rm} \$$ file

fi

done

\# get traveltimes

for block in block*.\$das_nb.events

do

echo \$block

\# first trial to get traveltimes using aktimes

\# might be useful at somepoint, but tooo complicated now 
$\#$ lines=`wc - 1 \$block
$\#$ echo \$block

$\# \mathrm{i}=1$

\# while [ \$i -le \$lines ]

\# do

\# nawk $-F,-v$ i=\$i ' $\{\text { if }(N R==i) \text { print } \$ 3, \$ 4, \$ 5\}^{\prime}<\$$ block >events.evt

\# echo "stations.sta" >aktimes.in

\# echo "events.evt" >>aktimes.in

\# echo "aktimes.tim" > >aktimes.in

\# echo "P" >>aktimes.in

\# cp \$HOME/bin/ak135.*.

\# aktimes >err

\# if test -s err

\# then

\# echo "stations.sta" >aktimes.in

\# echo "events.evt" > >aktimes.in

\# echo "aktimes.tim" > >aktimes.in

\# echo "Pdiff" > >aktimes.in

\# aktimes >err

\# $\mathrm{fi}$

\# if test -s err

\# then

\# echo "stations.sta" >aktimes.in

\# echo "events.evt" > >aktimes.in

\# echo "aktimes.tim" >>aktimes.in

\# echo "Pn" > >aktimes.in

\# aktimes

\# $\mathrm{fi}$

$\# \backslash r m$ ak135.* err events.evt

$\# \backslash r m$ aktimes.in 
\# output file of aktimes (aktimes.tim) format: 1 header line, then \# traveltime (s), lat, lon, station name

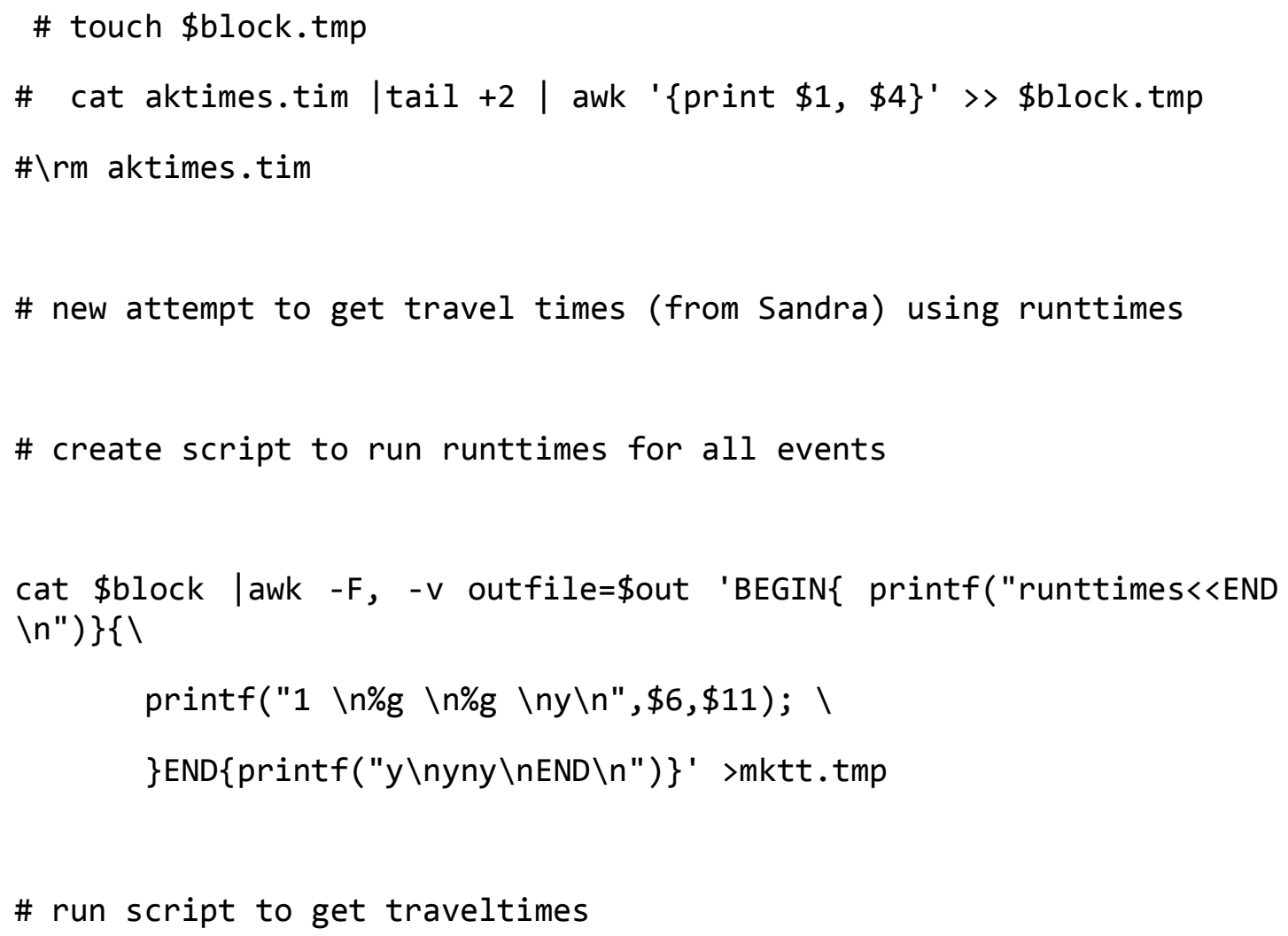




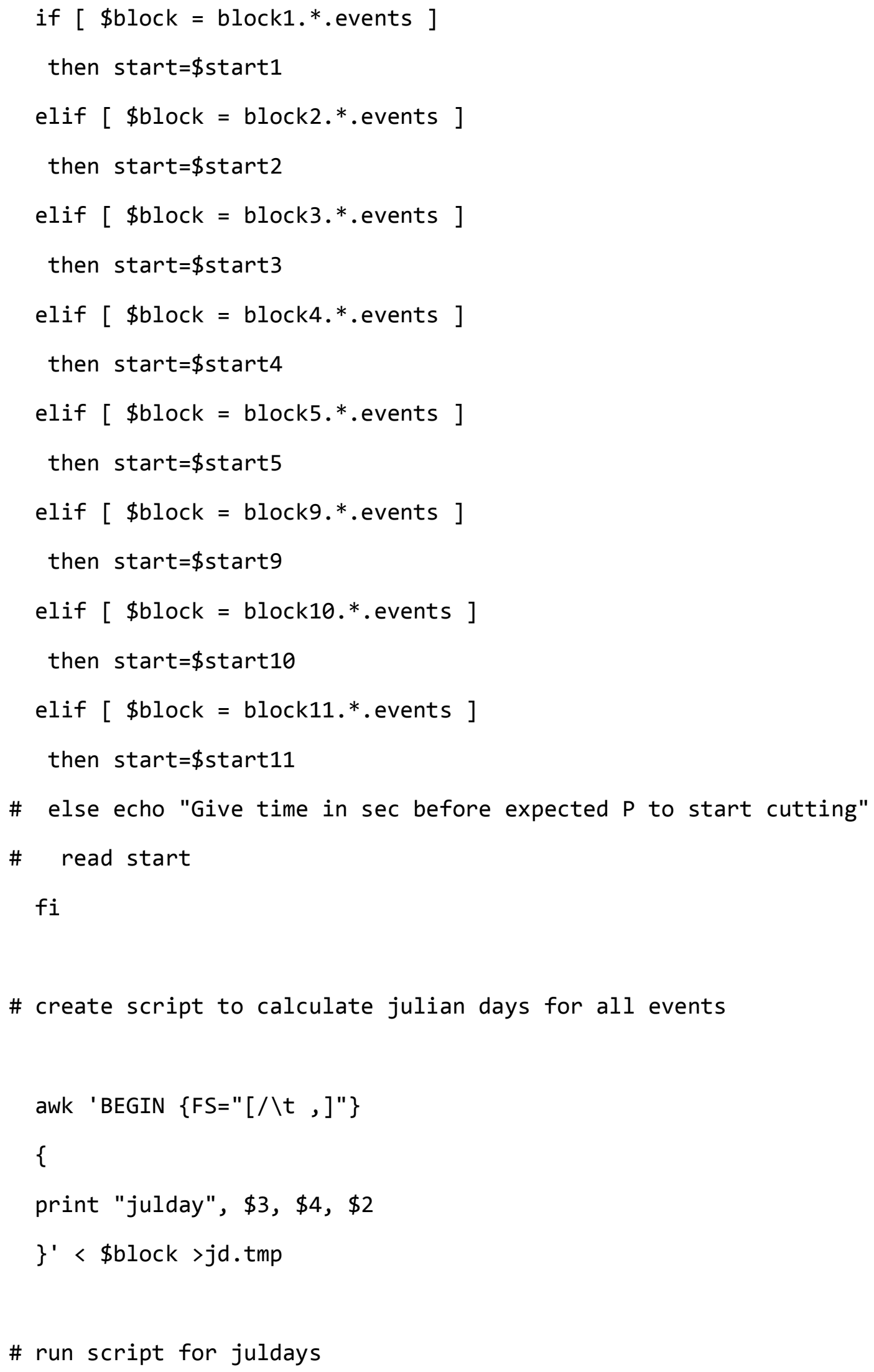


.$/$ jd.tmp >jdout.tmp

\# print all julian days in one file and merge with \#file containing traveltimes

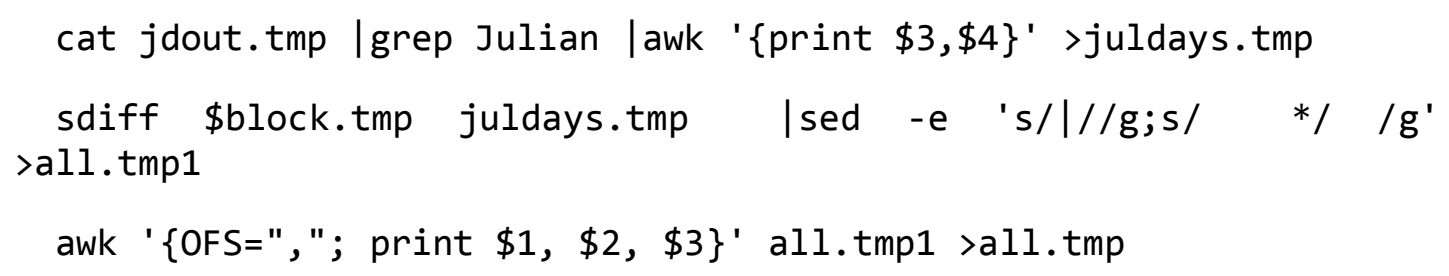

\# create eqcut file with header line echo "\# evtnum evttime lat lon depth size" >
Events/\$\{block\}.eqcut
\# awk to add traveltimes to eventtime and cut "start" seconds
before expected arrival

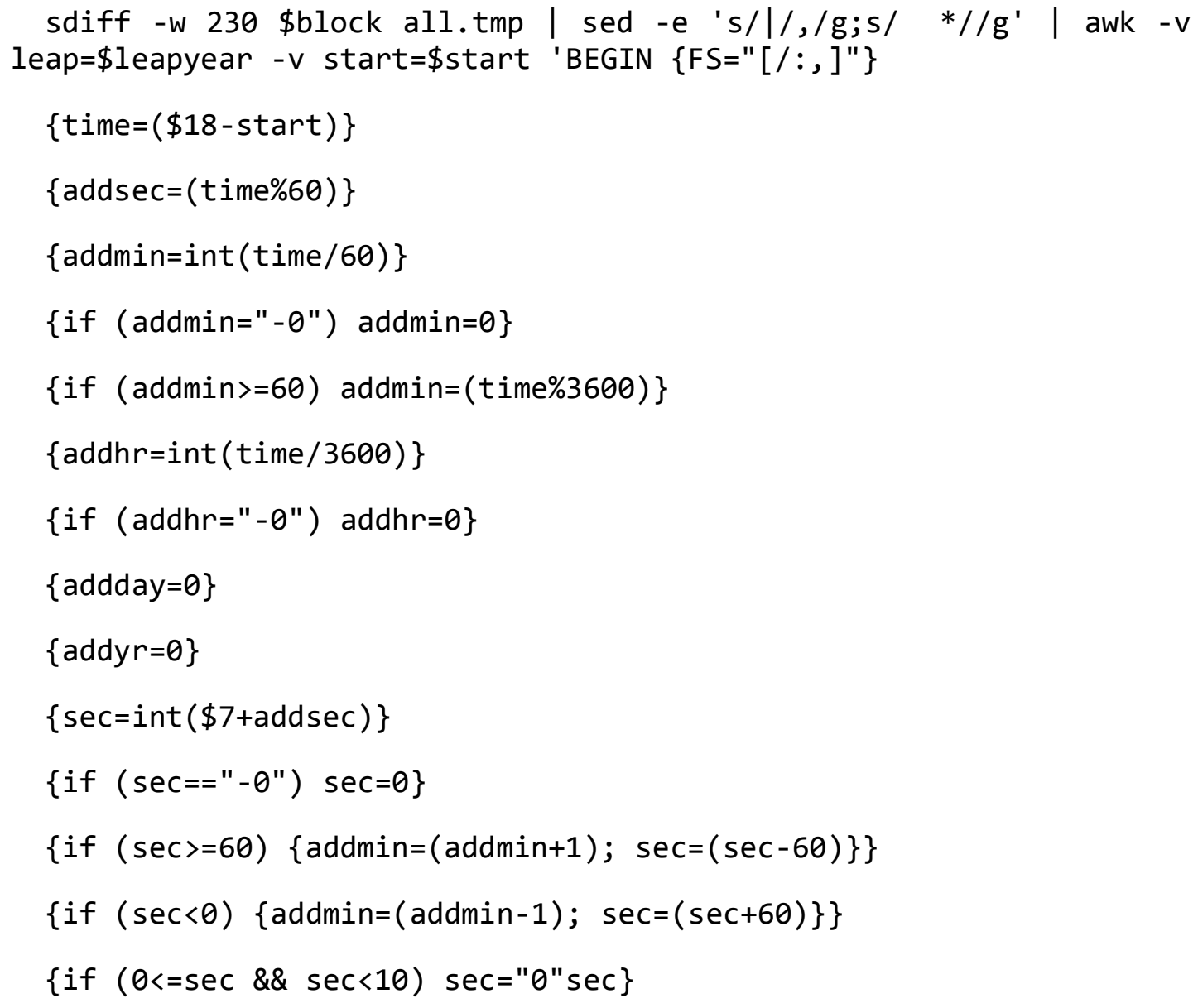




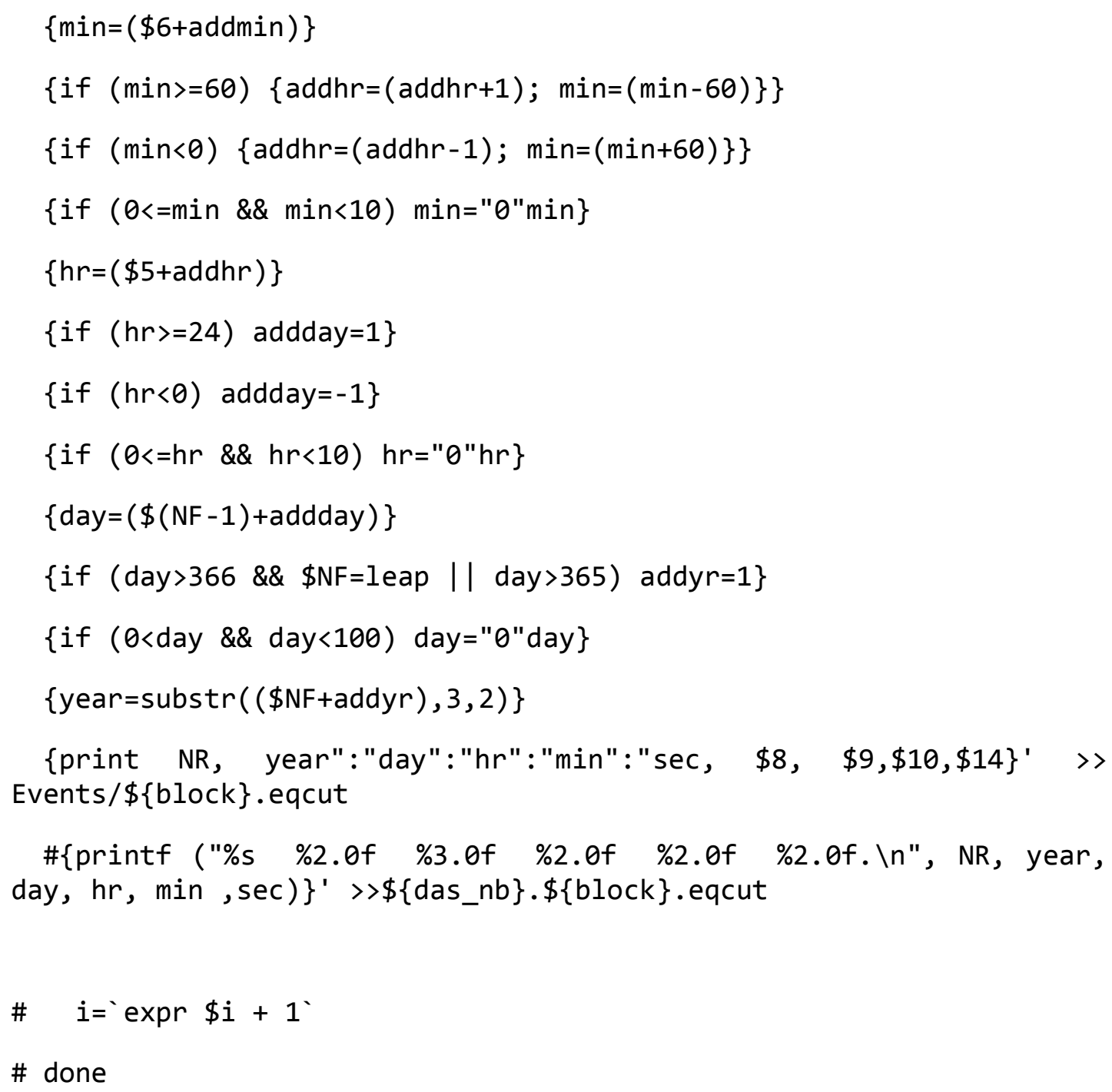

\# CLEAN UP: remove all unnecessary tmp files 
\#rm latlon.txt juldays.tmp jdout.tmp jd.tmp getdists.tmp all.tmp dists.tmp

\#rm station.tmp dists.out block*.tmp mktt.tmp tt.tmp

A3.8CONVERT_RAW.SH

\#!/bin/bash

\#Sapi/Caroline_2011

\#converts cut-events in mini-seed format to SAC

\#process inside the directory (EqCut) with station folders that have cut files

\#put a st_file with columes : stat stlat stlon elev in the same directory(EqCut)

$p t=` p w d `$

echo \$pt

while read stat stlat stlon elev

do

\author{
if $[-d$ stat ] \\ then \\ echo \$stat \\ cd \$stat/EqCut
}

for dir in *

do 


$$
\begin{array}{r}
\text { cd ... } \\
\text { done }
\end{array}
$$

$$
\text { cd } . . / \ldots
$$

fi

done $<\$ p t / s t \_f i l e$

A3.9 ADD_HDR_MODI.SH

\#!/bin/bash

\#The original script is from Jess Johnson2009

\#changed to process Caroline's data 2011

\#path=/Volumes/stage2/users -data/halllucy/SAHKE_cut_events all_hdr_sac/data2011/cut_evts/all_SAC

path=/Volumes/stage2/users-data/halllucy/SAHKE_cut_events all_hdr_sac/data2011/cut_evts

if [ ! -d \$path/all_hdr_sac ]

then

mkdir \$path/all_hdr_sac

fi 


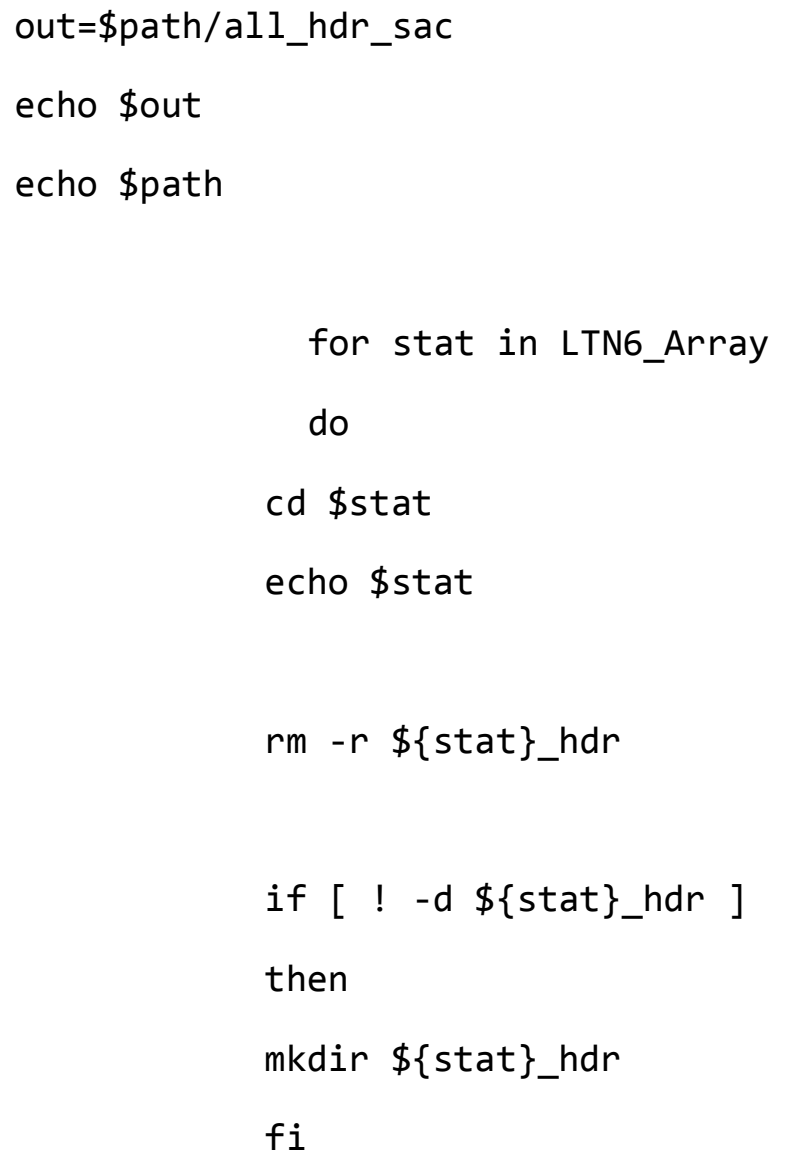


CHNHDR EVDP \$Z

wh over

Ih EVLA EVLO MAG EVDP o

quit

END

cd ..

fi

$$
c p-r \$\{\text { stat\}_hdr \$out }
$$

done < \$path/evtfile

cd ..

done 
A3.10 SAC macro to sort traces and pick $\mathrm{P}$ waves.

**The SAC macro

**From $\quad * *$ http://eqseis.geosc.psu.edu/ cammon/HTML/RftnDocs/pr** e*p01.html

**Modified by Caroline for using on SAHKE data **preparation.

**this SAC macro handles cutting, detrending, **tapering, and separating noisy observations from the

**better signals.

**It is interactive you will be picking the **approximate $\mathrm{P}$ onset from the vertical component **using the PPK command in SAC. When the cursor **appears, place it at the $\mathrm{P}$ onset time and enter ' $t$ ' $* *$ and ' $\theta$ ' (that's zero) to set the t1 header $* *$ value.enter ' $q$ ' to onto the next part of the macro, ${ }^{* *}$ where you decide *whetherto keep the data or move $* *$ them into the noisy *directory. You only need to **decide the time within a fewseconds, don't agonize **over the precision.

**If the data are all noisy just enter ' $q$ ' and then **enter a ' $t$ ' later to move the signal to the trash

$* *$ directory.

**the mean and trend are removed from the **observations and a cosine taper is applied on the **left and right fifth (about 25 seconds if you keep **the time limits in the macro) of the signal.

**You must edit the 'div' line to put in the correct **instrument gains, or just delete that line and

**correct the gains later.

echo on

$* *$ make directories

sc mkdir Trash

sc mkdir GoodOnes

**key on the vertical

qdp off

ygrid on

**synchronize the file start times

do file wild *.z

setbb vert $\$$ file 


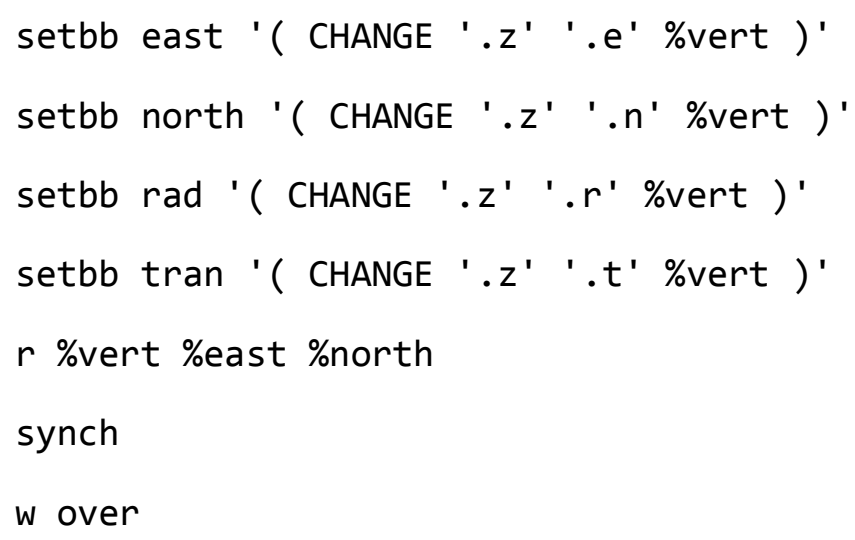


**Move the files into the directory 'Goodones' if they look useable, or 'trash' if they look really bad

p1

setbb resp (REPLY "Enter $t$ to trash the file")

if \%resp eq " $t$ " then

sc mv \%vert Trash

sc mv \%east Trash

sc mv \%north Trash

else

$r$ \%north \%east

rotate to $\mathrm{gcp}$

write \%rad \%tran

sc mv \%vert GoodOnes

sc mv \%east GoodOnes

sc mv \%north GoodOnes

sc mv \%rad GoodOnes

sc mv \%tran GoodOnes

**Turn cut off and do the next one

endif

cut off

enddo 


\section{APPENDIX 4}

A4.1 PYTHON SCRIPT TO CUT EARTHQUAKE EVENTS FROM EARTHDATA STATIONS.

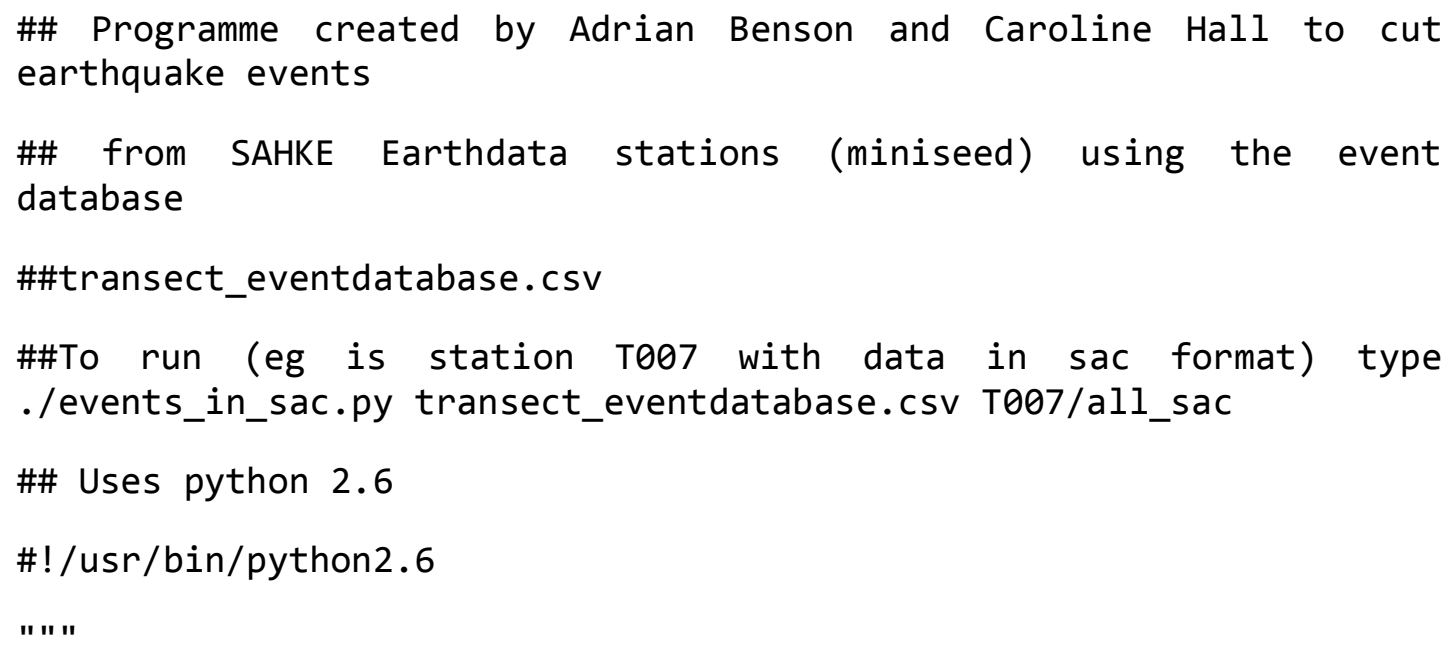


continue

if $\operatorname{len}(\operatorname{arr}[\theta])==4$ and $\operatorname{arr}[0] \cdot \operatorname{startswith}\left({ }^{\prime 20^{\prime}}\right)$ :

$\operatorname{arr}[\theta]=\operatorname{arr}[\theta][2:]$

$\begin{array}{cll}\text { rval.append(\{ 'year': } & \operatorname{int}(\operatorname{arr}[0]), \\ \text { 'month': } & \operatorname{int}(\operatorname{arr}[1]), \\ \text { 'day': } & \operatorname{int}(\operatorname{arr}[2]), \\ \text { 'hour': } & \operatorname{int}(\operatorname{arr}[3][0: 2]), \\ \text { 'mins': } & \operatorname{int~}(\operatorname{arr}[3][2: 4]), \\ \text { 'secs': } & \text { float }(\operatorname{arr}[3][4:]), \\ \text { 'lat': } & \text { float }(\operatorname{arr}[4]), \\ \text { 'lon': } & \text { float }(\operatorname{arr}[5]), \\ \text { 'mag': } & \text { float }(\operatorname{arr}[6]), \\ \text { 'depth': } & \text { float }(\operatorname{arr}[7])\})\end{array}$

return rval

def get_sacfile_list(sacpath):

fname $=$ glob.glob(os.path.join (sacpath, '*.sac') )

rval $=\{\}$

for $f$ in fname:

path, fname = os.path.split $(f)$

basename, component, extn = fname.split('.')

station = basename $[: 4]$

key = basename $[4:]$

if station not in rval:

$\operatorname{rval}[$ station $]=\{\}$

if key not in rval[station]:

$$
\begin{aligned}
& \operatorname{rval}[\text { station }][\text { key }]=\{\} \\
& \operatorname{rval}[\text { station][key]['path'] = path } \\
& \operatorname{rval}[\text { station][key]['basename'] = basename }
\end{aligned}
$$




$$
\begin{aligned}
& \operatorname{rval}[\text { station][key]['year'] = int }(\operatorname{key}[: 2]) \\
& \operatorname{rval}[\text { station][key]['month' ] = int }(\operatorname{key}[2: 4]) \\
& \operatorname{rval}[\text { station][key]['day'] = } \operatorname{int}(\operatorname{key}[4: 6]) \\
& \operatorname{rval}[\text { station] [key]['hour'] = int }(\operatorname{key}[6: 8]) \\
& \operatorname{rval}[\text { station][key]['mins'] = int }(\operatorname{key}[8: 10]) \\
& \operatorname{rval}[\text { station][key]['secs'] = int }(\operatorname{key}[10: 12]) \\
& \operatorname{rval}[\text { station][key]['component'] = [ component } \\
& \text { else : } \\
& \text { rval[station][key]['component' ]. append(component) }
\end{aligned}
$$

return rval

\# MAIN Program

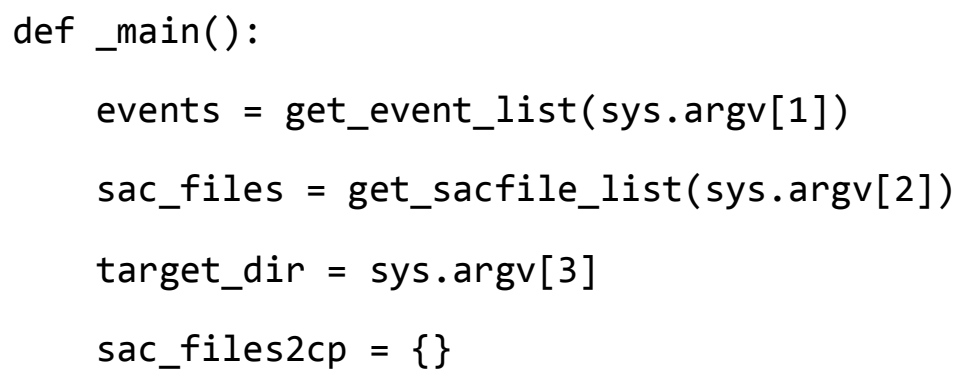

for event in events:

$$
\begin{aligned}
\text { key = "\%02d\%02d\%02d\%02d0000" \% } & \text { (event['year'], } \\
& \text { event ['month'], } \\
& \text { event ['day'], } \\
& \text { event ['hour']) }
\end{aligned}
$$

for station in sac_files: 
if key in sac_files[station]:

for c in sac_files[station][key]['component']:

basename $=" \% s \% s . \% s . s a c " \%$ (station, key, c)

source

os.path.join(sac_files[station][key]['path'], basename)

target $=$ os.path.join(target_dir, basename)

sac_files $2 c p[$ basename $]=[$ source, target $]$

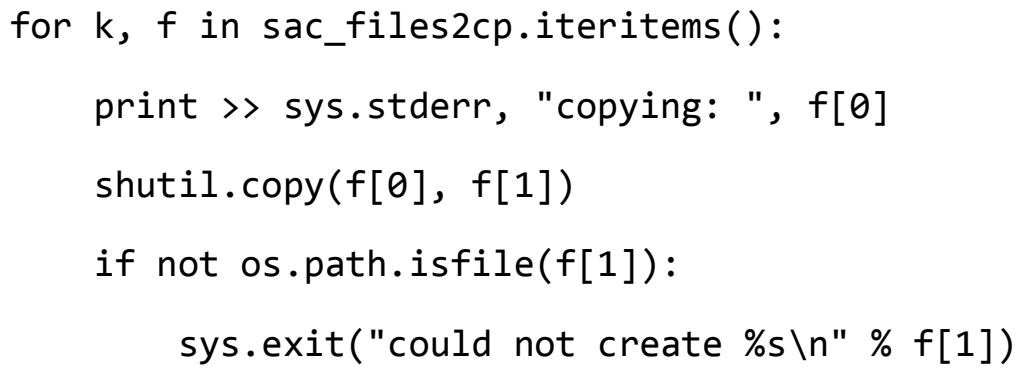




\section{APPENDIX 5}

\section{A5.1 EVENT-DATABASE.CSV}

Teleseisms >M6.0 to cover period of SAHKE seismometer deployments for SAHKE transect. This event database is presented as a comma separated variables (CSV) file. This is the format that is required by the data-processing method described in this Appendix. The data for each event is arranged:

YYYY,MM,DD,HH,mm,SS.ss,lat.xxx,lon.xxx,mag,depth,

YYYY is year; MM is calendar month; DD is day; HH is hour of origin time (using 24 hour clock); mm is minutes; SS is seconds; ss is tenths/hundredths of a second; lat.xxx is latitude of epicentre; lon.xxx is longitude of epicentre; mag is magnitude of event; depth is km to hypocentre.

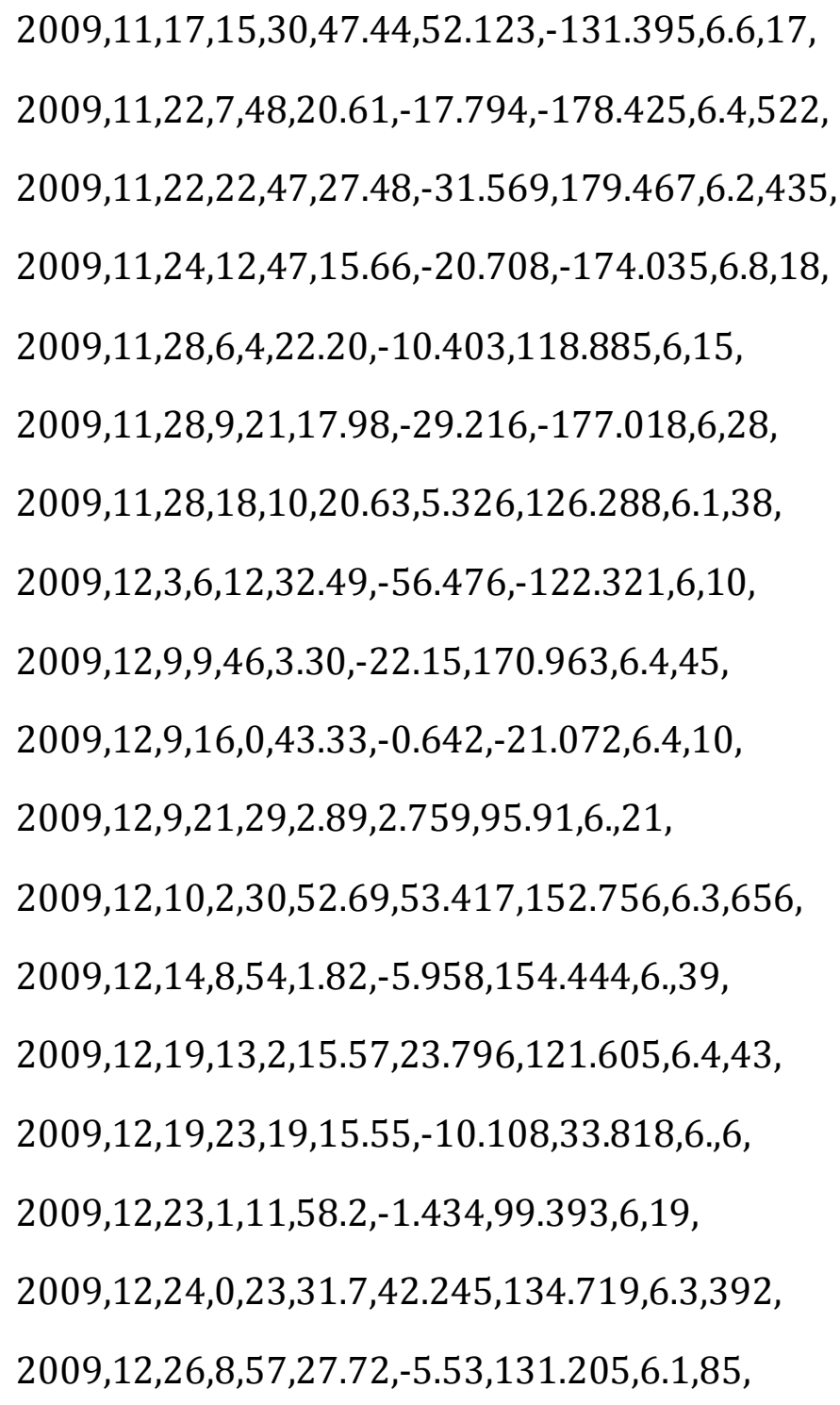




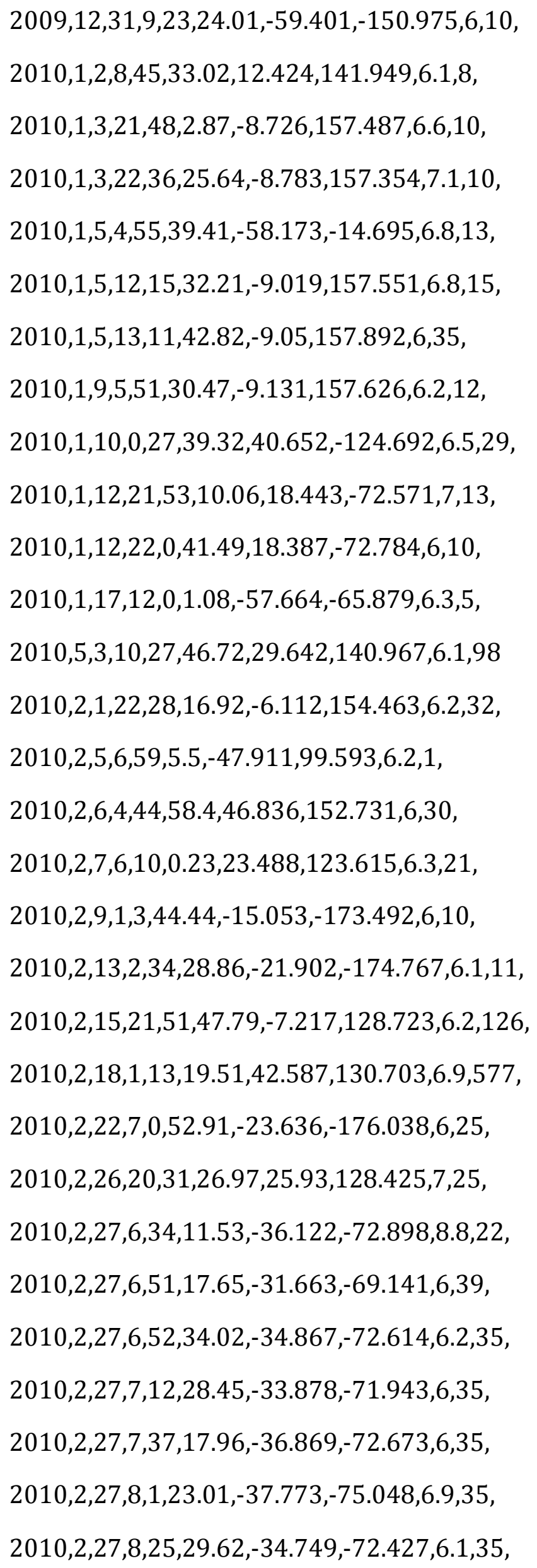


2010,2,27,10,30,36.4,-33.281,-71.955,6,35, 2010,2,27,15,45,37,-24.872,-65.602,6.3,10, 2010,2,27,17,24,30.59,-36.354,-73.208,6.1,19, $2010,2,27,19,0,6.86,-33.422,-71.828,6.3,31$, 2010,2,27,23,12,34.91,-34.7,-71.827,6,35, 2010,2,28,11,25,35.92,-34.903,-71.617,6.2,46, 2010,3,3,17,44,25.04,-36.61,-73.36,6.1,20, 2010,3,4,0,18,51.29,22.918,120.795,6.3,21, 2010,3,4,1,59,48.67,-33.216,-72.125,6,24, 2010,3,4,14,2,27.55,-13.571,167.227,6.5,176, 2010,3,4,22,39,26.53,-22.227,-68.328,6.4,114, 2010,3,5,9,19,36.38,-36.631,-73.223,6.1,29, 2010,3,5,11,47,6.82,-36.665,-73.374,6.6,18, 2010,3,5,16,7,0.68,-3.762,100.991,6.8,26, 2010,3,7,7,5,23.96,-16.24,-115.296,6.3,14, 2010,3,8,2,32,34.71,38.864,39.986,6.1,12, 2010,3,8,9,47,11.6,19.335,144.703,6.1,457, 2010,3,11,14,39,43.95,-34.29,-71.891,6.9,11, 2010,3,11,14,55,27.51,-34.326,-71.799,6.7,18, 2010,3,11,15,6,2.13,-34.47,-72.004,6,31, $2010,3,14,0,57,44.7,-1.692,128.134,6.4,53$, 2010,3,14,8,8,3.96,37.745,141.59,6.5,32, 2010,3,15,11,8,28.96,-35.802,-73.158,6.2,14, 2010,3,16,2,21,57.94,-36.217,-73.257,6.7,18, 2010,3,20,14,0,49.98,-3.361,152.245,6.6,414, 2010,3,25,5,29,24.72,13.827,120.071,6,16, 2010,3,26,14,52,7.23,-27.953,-70.821,6.3,42, 2010,3,28,21,38,28,-35.387,-73.385,6,29, 2010,3,30,16,54,46.73,13.667,92.831,6.7,34, 2010,4,2,22,58,7.56,-36.227,-72.878,6,24, 
2010,4,4,22,40,43.10,32.297,-115.278,7.2,4, 2010,4,5,10,5,46.07,-0.188,125.006,6.2,35, 2010,4,6,22,15,1.58,2.383,97.048,7.8,31, $2010,4,7,14,33,3.49,-3.774,141.927,6,33$, 2010,4,10,16,54,24.25,-20.114,-176.223,6,273, 2010,4,11,9,40,25.6,-10.878,161.116,6.8,21, 2010,4,11,22,8,12.79,36.965,-3.542,6.3,609, 2010,4,13,23,49,38.33,33.165,96.548,6.9,17, 2010,4,14,1,25,15.58,33.195,96.449,6.1,7, 2010,4,17,23,15,22.02,-6.669,147.291,6.2,53, 2010,4,21,17,20,29.11,-15.271,-173.219,6.1,35, 2010,4,23,10,3,6.18,-37.529,-72.969,6,32, 2010,4,24,7,41,0.41,-1.912,128.121,6,27, 2010,4,26,2,59,51,22.18,123.63,6.5,14, $2010,4,30,23,11,43.34,60.473,-177.875,6.5,13$, 2010,4,30,23,16,28.64,60.478,-177.65,6.3,14, 2010,5,3,10,27,46.72,29.642,140.967,6.1,98, 2010,5,3,23,9,44.79,-38.072,-73.454,6.3,19, 2010,5,5,16,29,3.21,-4.054,101.096,6.6,27, 2010,5,6,2,42,47.94,-18.058,-70.547,6.2,37, 2010,5,9,5,59,41.62,3.748,96.018,7.2,38, 2010,5,19,4,15,44.12,-5.074,-77.536,6,140, 2010,5,19,10,30,10.4,-54.8,-135.252,6,10, 2010,5,19,10,51,3.08,-54.843,-135.398,6,10, 2010,5,23,22,46,52.05,-13.928,-74.352,6.1,101, 2010,5,24,16,18,29.09,-8.087,-71.558,6.5,581, 2010,5,25,10,9,5.78,35.336,-35.924,6.3,10, 2010,5,26,8,53,8.03,25.773,129.944,6.5,10, 2010,5,27,17,14,46.57,-13.698,166.643,7.1,31, $2010,5,31,19,51,45.87,11.132,93.471,6.5,112$, 
2010,6,1,3,26,15.76,9.331,-84.206,6,18, 2010,6,9,23,23,17.35,-18.597,169.485,6,12, 2010,6,12,19,26,50.46,7.881,91.936,7.5,35, 2010,6,16,3,6,2.42,-2.386,136.635,6.2,13, 2010,6,16,3,16,27.55,-2.174,136.543,7,18, 2010,6,16,3,58,8.48,-2.329,136.484,6.6,10, $2010,6,17,13,6,46.59,-33.168,179.719,6,170$, 2010,6,18,2,23,5.16,44.449,148.691,6.2,25, 2010,6,24,5,32,27.4,-5.514,151.161,6.1,40, 2010,6,26,5,30,19.49,-10.627,161.447,6.7,35, 2010,6,30,4,31,2.16,-23.307,179.116,6.4,581, $2010,6,30,7,22,27.69,16.396,-97.782,6.3,20$, 2010,7,2,6,4,3.13,-13.643,166.485,6.3,29, 2010,7,4,21,55,51.98,39.697,142.369,6.3,27, $2010,7,10,11,43,32.79,11.143,145.999,6.3,13$, 2010,7,12,0,11,21.25,-22.146,-68.216,6.3,115, 2010,7,14,8,32,21.49,-38.067,-73.31,6.6,22, 2010,7,18,5,56,44.93,52.876,-169.848,6.6,14, 2010,7,18,13,4,9.41,-5.966,150.428,6.9,28, 2010,7,18,13,34,59.36,-5.931,150.59,7.3,35, 2010,7,18,19,48,4.54,52.815,-169.719,6.0,10, 2010,7,20,19,18,21.95,-5.914,150.702,6.3,35, 2010,7,21,9,16,4.42,3.039,128.222,6.1,100, 2010,7,22,5,3,57.09,-15.149,168.168,6.1,10, 2010,7,23,22,8,11.25,6.718,123.409,7.3,607, 2010,7,23,22,51,12.45,6.486,123.467,7.6,585, 2010,7,23,23,15,10.19,6.776,123.259,7.4,640, 2010,7,24,5,35,1.06,6.218,123.519,6.6,553, 2010,7,29,7,31,56.84,6.528,123.247,6.6,627, 2010,7,30,3,56,13.71,52.498,159.843,6.3,23, 


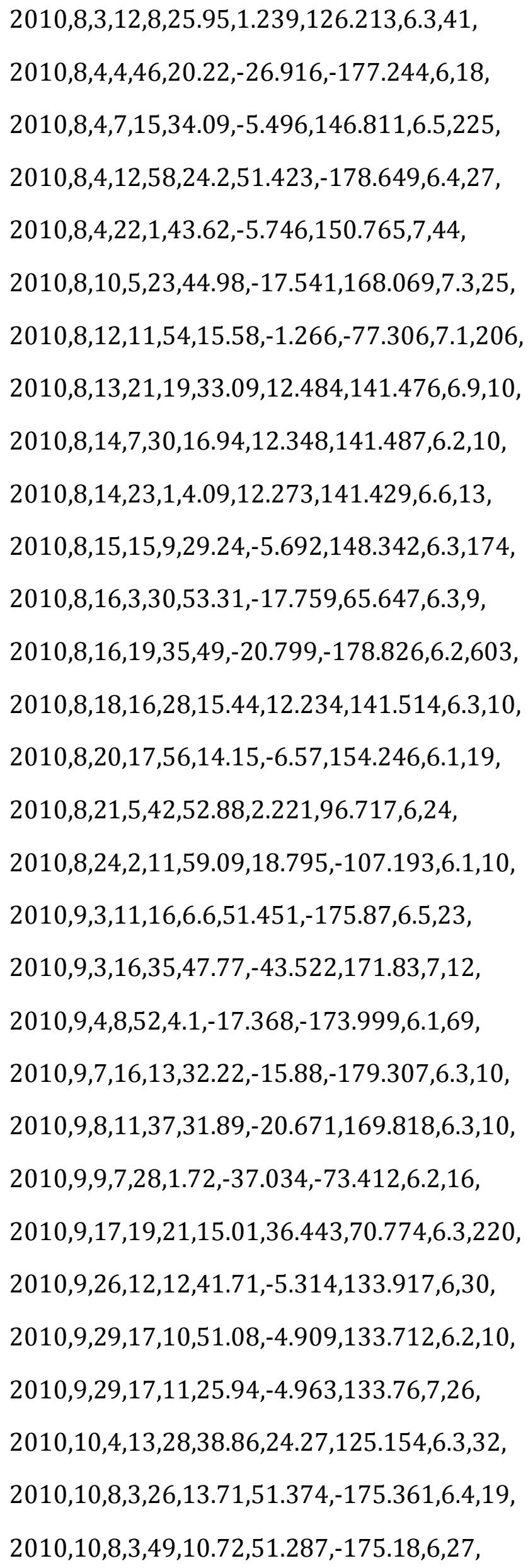


2010,10,8,5,43,7.63,2.833,128.229,6.1,116, 2010,10,21,17,53,13.09,24.69,-109.159,6.7,10, 2010,10,25,14,42,22.46,-3.487,100.082,7.8,20, 2010,10,25,19,37,31.15,-2.958,10.372,6.3,26, 2010,10,30,15,18,33.07,-56.586,-142.292,6.4,10, 2010,11,3,11,18,15.57,-4.617,134.071,6,10, 2010,11,3,23,34,42.68,-20.467,-174.28,6.1,19, 2010,11,10,4,5,24.41,-45.464,96.394,6.5,10, 2010,11,21,4,36,31.44,-54.967,-131.479,6,10, 2010,11,23,9,1,6.86,-5.959,148.966,6.1,68, 2010,11,30,3,24,41.6,28.36,139.154,6.8,486, 2010,12,1,16,1,27.44,-15.888,-178.956,6.1,15, 2010,12,1,16,1,27.44,-15.888,-178.956,6.1,15, 2010,12,2,3,12,9.82,-6.001,149.977,6.6,33, 2010,12,8,5,24,35.26,-56.412,-25.741,6.3,29, 2010,12,13,1,14,42.32,-6.534,155.647,6.2,135, 2010,12,15,11,29,30.84,-7.268,128.785,6,134, $2010,12,20,18,41,59.2,28.412,59.18,6.7,12$, $2010,12,21,17,19,40.66,26.901,143.698,7.4,14$, 2010,12,22,21,49,38.79,26.811,143.601,6.4,10, 2010,12,23,14,0,32.33,53.127,171.161,6.3,18, 2010,12,24,5,48,52.99,-63.592,-167.354,6,4, 2010,12,25,13,16,37,-19.702,167.947,7.3,16, 2010,12,26,2,13,37.68,-19.616,168.284,6,13, 2010,12,28,8,34,17.55,-23.407,-179.802,6.3,551, 2010,12,29,6,54,19.64,-19.661,168.14,6.4,16, 2011,1,1,9,56,58.12,-26.803,-63.136,7,576, 2011,1,2,20,20,17.78,-38.355,-73.326,7.2,24, 2011,1,5,6,46,14.63,-22.26,171.631,6.1,112, 2011,1,9,10,3,44.28,-19.157,168.311,6.5,24, 
2011,1,9,17,21,51.65,-19.201,168.155,6.1,18, 2011,1,12,21,32,55.21,26.978,139.869,6.4,527, 2011,1,13,16,16,41.54,-20.628,168.471,7,9, 2011,1,17,19,20,57.21,-5.03,102.647,6,36, 2011,1,18,20,23,23.48,28.777,63.951,7.2,68, 2011,1,24,2,45,31.52,38.413,72.791,6,110, 2011,1,26,15,42,29.59,2.205,96.829,6.1,23, 2011,1,27,8,38,28.66,28.194,59.013,6.2,12, 2011,1,29,6,55,26.13,70.936,-6.679,6.2,6, 2011,1,31,6,3,27.30,-22.009,-175.622,6,76, 2011,2,4,13,53,46.26,24.618,94.68,6.2,85, 2011,2,7,19,53,44.16,-7.161,155.175,6.4,428, 2011,2,10,14,39,27.71,4.195,122.974,6.5,523, 2011,2,10,14,41,58.82,4.077,123.039,6.6,525, 2011,2,11,20,5,30.79,-36.474,-73.125,6.9,27, 2011,2,12,1,17,1.41,-37.027,-72.954,6.1,16, 2011,2,12,17,57,56.63,-20.886,-175.673,6.1,89, 2011,2,13,10,35,6.74,-36.649,-73.176,6,17, 2011,2,14,3,40,9.92,-35.38,-72.834,6.7,21, 2011,2,15,13,33,53.18,-2.497,121.483,6.1,16, 2011,2,20,21,43,24.15,55.918,162.117,6.1,33, 2011,2,21,10,57,52.41,-26.142,178.394,6.5,558, 2011,2,21,23,51,42.35,-43.583,172.68,6.1,5, 2011,3,1,0,53,46.34,-29.701,-111.981,6,10, 2011,3,6,12,31,59.78,-18.021,-69.362,6.3,118, 2011,3,6,14,32,36.08,-56.422,-27.063,6.5,87, 2011,3,7,0,9,36.45,-10.349,160.766,6.3,22, 2011,3,9,2,45,20.33,38.435,142.842,7.3,32, 2011,3,9,18,16,16.44,38.315,142.434,6,22, 2011,3,9,21,24,1.68,38.296,142.808,6.4,15, 
2011,3,9,21,24,49.76,-5.985,149.777,6.4,29, 2011,3,10,17,8,36.86,-6.873,116.72,6.5,510, 2011,3,11,5,46,24.12,38.297,142.373,9,29, 2011,3,11,5,54,31.94,37.712,141.184,6.3,32, 2011,3,11,5,55,45.48,37.359,143.351,6.4,35, 2011,3,11,5,58,7.49,37.623,142.155,6.3,50, 2011,3,11,6,0,39.30,38.095,142.492,6.2,40, 2011,3,11,6,6,13.17,39.003,142.29,6.3,42, 2011,3,11,6,7,20.88,36.419,141.876,6.4,32, 2011,3,11,6,8,29.66,38.969,143.37,6.7,2, 2011,3,11,6,12,36.36,37.788,144.233,6.2,25, 2011,3,11,6,13,1.04,37.211,141.601,6.2,40, 2011,3,11,6,15,23.12,37.93,143.802,6.3,35, 2011,3,11,6,15,40.28,36.281,141.111,7.9,42, 2011,3,11,6,18,49.51,36.023,142.269,6.6,16, 2011,3,11,6,20,4.11,36.004,142.067,6.5,49, 2011,3,11,6,21,32.70,38.29,142.813,6.2,51, 2011,3,11,6,23,9.48,39.03,142.284,6.2,56, 2011,3,11,6,25,50.30,38.058,144.59,7.7,18, 2011,3,11,6,29,15.99,37.812,144.233,6.1,40, 2011,3,11,6,48,45.59,37.961,142.724,6.2,11， 2011,3,11,6,49,16.61,37.337,144.237,6.1,47, 2011,3,11,6,57,16.51,35.712,140.875,6,47, 2011,3,11,6,59,0.27,37.357,144.725,6.3,35, 2011,3,11,7,14,58.82,36.586,141.823,6.3,24, 2011,3,11,7,25,36.46,37.934,144.529,6.1,39, 2011,3,11,7,28,12.36,36.823,141.824,6.1,28, 2011,3,11,7,29,1.83,39.031,142.349,6.3,45, 2011,3,11,7,30,18.45,37.442,141.195,6,49, 2011,3,11,8,12,7.26,36.569,141.486,6.2,39, 
2011,3,11,8,15,41.85,37.047,144.541,6.1,41, 2011,3,11,8,19,24.38,36.166,141.562,6.5,6, 2011,3,11,8,26,36.93,37.367,143.017,6.1,17, 2011,3,11,8,27,51.60,38.017,142.657,6,42, 2011,3,11,8,31,9.26,37.469,141.176,6,37, 2011,3,11,8,33,0.78,39.14,142.967,6,27, 2011,3,11,10,10,34.22,39.185,142.76,6,26, 2011,3,11,11,36,40.92,39.241,142.463,6.6,25, 2011,3,11,15,13,15.09,35.999,141.805,6.3,23, 2011,3,11,15,20,8.19,36.398,141.864,6,52, 2011,3,11,18,59,16.54,37.014,138.376,6.2,9, 2011,3,11,19,2,59.17,39.342,142.872,6,27, 2011,3,11,19,46,50.88,40.483,139.055,6.2,10, 2011,3,11,20,11,24.06,39.005,142.633,6.1,17, 2011,3,12,1,47,15.40,37.594,142.648,6.5,20, 2011,3,12,13,15,41.65,37.249,141.159,6.1,38, 2011,3,12,23,24,48.78,38.047,141.72,6.1,15, 2011,3,13,1,26,4.25,35.723,141.637,6.1,8, 2011,3,14,6,12,36.06,37.785,142.456,6,14, 2011,3,15,13,27,56.63,37.576,142.237,6,28, 2011,3,15,13,31,46.32,35.272,138.582,6,9, $2011,3,15,15,23,54.13,40.333,143.287,6.1,19$, 2011,3,17,2,48,0.03,-17.275,167.826,6.2,17, 2011,3,17,4,13,56.78,40.136,142.168,6.2,29, 2011,3,20,8,26,10.73,18.999,121.244,6,35, 2011,3,22,7,18,45.38,37.244,144.003,6.4,11, 2011,3,22,9,19,6.23,37.325,141.791,6.1,31, 2011,3,22,9,44,28.42,39.85,143.442,6.4,7, 2011,3,24,13,55,12.01,20.687,99.822,6.9,8, 2011,3,25,11,36,24.49,38.772,141.88,6.2,39, 
2011,3,26,22,49,41.47,-15.851,-179.406,6,10, 2011,3,27,22,23,58.80,38.415,142.011,6.2,19, 2011,3,29,10,54,33.20,37.401,142.29,6.1,15, 2011,3,31,0,11,58.30,-16.541,-177.517,6.3,15, 2011,3,31,7,15,30.19,38.922,141.821,6,42, 2011,4,1,13,29,10.69,35.662,26.56,6.0,59, 2011,4,3,14,7,9.33,-17.642,-178.585,6.4,551, 2011,4,3,20,6,40.39,-9.848,107.693,6.7,14, 2011,4,6,14,1,43.34,1.615,97.097,6,25, 2011,4,7,13,11,22.40,17.208,-94.338,6.6,166, 2011,4,7,14,32,43.29,38.276,141.588,7.1,42, 2011,4,11,8,16,12.73,37.001,140.401,6.6,11, 2011,4,11,23,8,16.87,35.417,140.575,6.2,15, 2011,4,13,19,57,25.42,39.583,143.34,6,22, 2011,4,18,13,3,2.73,-34.336,179.874,6.6,86, 2011,4,21,13,37,3.34,35.579,140.305,6.2,43, 2011,4,23,4,16,54.72,-10.375,161.20,6.8,79, 2011,4,24,23,7,51.49,-4.586,122.771,6.1,8, 2011,4,30,8,19,16.07,6.851,-82.333,6.1,8, 2011,5,5,14,58,18.68,38.17,144.032,6,11, 2011,5,10,8,55,8.93,-20.244,168.226,6.8,11, 2011,5,13,23,35,52.86,37.396,141.341,6.1,35, 2011,5,15,13,8,13.06,0.569,-25.647,6.1,10, 2011,5,15,18,37,10.37,-6.104,154.414,6.4,40, 2011,6,1,12,55,22.38,-37.578,-73.691,6.3,21, 2011,6,3,0,5,0.83,37.285,143.907,6.1,14, 2011,6,5,11,51,12.01,-55.843,146.62,6.4,3, 2011,6,13,14,31,22.99,2.515,126.457,6.3,61, 2011,6,16,0,3,35.79,-5.928,151.04,6.4,16, 2011,6,20,16,36,1.16,-21.701,-68.228,6.4,128, 
2011,6,21,2,4,15.94,-11.479,165.551,6,14, 2011,6,22,21,50,52.35,39.955,142.205,6.7,33, 2011,6,24,3,9,39.47,52.05,-171.836,7.3,52, 2011,6,26,12,16,38.6,-2.384,136.631,6.3,17, 2011,7,6,19,3,18.26,-29.539,-176.34,7.6,17, 2011,7,9,15,2,27.24,-29.337,-177.051,6,14, 2011,7,9,19,35,18.75,-29.436,-177.007,6,15, 2011,7,10,0,57,10.8,38.034,143.264,7,23, 2011,7,11,20,47,4.3,9.509,122.175,6.4,19, 2011,7,15,13,26,2.95,-60.762,-23.523,6.1,10, 2011,7,16,0,26,12.64,-33.819,-71.832,6,20, 2011,7,16,19,59,12.89,54.787,-161.29,6.1,36, 2011,7,19,19,35,43.48,40.081,71.41,6.1,20, 2011,7,20,22,4,59.32,-10.34,162.01,6,21, 2011,7,21,23,1,42.51,-62.496,164.452,6,10, 2011,7,23,4,34,24.18,38.898,141.815,6.3,41, 2011,7,24,18,51,24.52,37.727,141.394,6.3,35, 2011,7,25,0,50,47.59,-3.182,150.611,6.3,10, $2011,7,26,17,44,20.38,25.101,-109.525,6,12$, 2011,7,29,7,42,22.63,-23.784,179.76,6.7,523, 2011,7,30,18,53,49.68,36.943,140.959,6.3,30, 2011,7,31,14,34,47.32,-17.016,171.579,6.1,10, 2011,7,31,23,38,56.61,-3.518,144.828,6.6,10, 2011,8,4,13,51,34.56,48.833,154.769,6.1,36, 2011,8,10,23,45,43.04,-7.04,-12.618,6,10, 2011,8,16,11,3,57.7,-2.331,128.002,6.1,35, 2011,8,17,11,44,8.37,36.765,143.77,6.1,9, 2011,8,19,3,54,26.78,-16.522,-177.004,6.2,407, 2011,8,19,5,36,33.04,37.671,141.652,6.2,47, 2011,8,20,16,55,2.81,-18.365,168.143,7.2,32, 
2011,8,20,17,13,6.38,-18.308,168.156,6.5,35, 2011,8,20,18,19,23.55,-18.311,168.218,7.1,28, 2011,8,22,20,12,20.95,-6.282,104.054,6.1,29, 2011,8,24,17,46,11.65,-7.641,-74.525,7,147, 2011,8,24,23,6,17.09,-18.155,167.727,6.2,13, 2011,8,30,6,57,41.61,-6.362,126.752,6.9,469, 2011,9,1,6,14,38.65,-12.357,166.657,6,39, 2011,9,2,10,55,53.59,52.171,-171.708,6.9,32, 2011,9,2,13,47,9.62,-28.398,-63.029,6.7,578, 2011,9,3,4,48,57.31,-56.451,-26.847,6.4,84, 2011,9,3,22,55,40.92,-20.671,169.716,7,185, 2011,9,5,9,52,1.13,-15.295,-173.621,6.2,37, 2011,9,5,17,55,11.22,2.965,97.893,6.7,91, $2011,9,9,19,41,34.15,49.535,-126.893,6.4,22$, 2011,9,14,18,10,9,53.107,172.984,6,15, 2011,9,15,7,53,18.63,-35.366,-179.039,6.1,10, 2011,9,15,8,0,9.64,36.256,141.338,6.1,28, 2011,9,15,19,31,4.08,-21.611,-179.528,7.3,644, 2011,9,16,19,26,40.97,40.271,142.78,6.7,35, 2011,9,18,12,40,51.83,27.73,88.155,6.9,50, 2011,9,22,23,7,3.57,-15.437,-175.311,6.4,10, 2011,10,7,8,58,28.91,-32.514,-179.038,6.1,36, 2011,10,13,3,16,30.16,-9.35,114.587,6.1,39, 2011,10,14,3,35,14.81,-6.57,147.881,6.5,37, $2011,10,14,6,10,14.6,54.08,123.722,6,12$, 2011,10,18,5,5,6.25,-5.785,151.037,6.1,26, 2011,10,21,8,2,37.95,43.892,142.479,6.1,187, 2011,10,21,17,57,16.1,-28.993,-176.238,7.4,33, 2011,10,23,10,41,22.93,38.722,43.513,7.1,16, $2011,10,27,0,15,24.52,-17.941,-179.531,6,602$, 
$2011,10,28,18,54,34.04,-14.438,-75.966,6.9,24$, 2011,11,1,12,32,0.43,19.831,-109.205,6.3,10, 2011,11,2,14,59,27.94,-55.294,-128.843,6.1,10, 2011,11,7,22,35,25.63,11.56,-85.861,6,177, 2011,11,8,2,59,8.51,27.324,125.621,6.9,224, 2011,11,11,10,41,37.48,-55.981,-124.439,6,10, 2011,11,14,4,5,11.39,-0.949,126.91,6.3,17, 2011,11,17,1,57,5.73,-1.702,-81.546,6,26, $2011,11,22,18,48,16.3,-15.364,-65.089,6.6,549$, 2011,11,23,19,24,31.47,37.365,141.368,6.1,34, $2011,11,24,10,25,34.03,41.898,142.639,6.2,38$, 